\title{
Trace metal variations through the Tartan and Waipawa formations: implications for the environment of deposition.
}

\author{
By: \\ Alexander T. Fuerst
}

\author{
A thesis \\ submitted to the Victoria University of Wellington \\ in partial fulfilment of the requirements for the degree of \\ Master of Science \\ in Petroleum Geoscience
}

Victoria University of Wellington, 2012. 



\section{Abstract}

An inorganic geochemical study of the Late Paleocene organic matter-rich Waipawa and Tartan formations was undertaken in order to investigate the depositional environment. The formation varies in thickness between 2 and 50 metres and is distributed across many of New Zealand's Cenozoic basins, where it forms an important potential hydrocarbon source rock. This study measured major and trace elements which can be loosely grouped into redox sensitive, biologically influenced, terrestrially sourced, and rare earth elements (REE). The study focused on three sections through the Waipawa and Tartan formations: Angora Quarry in the East Coast Basin, and the Great South Basin hydrocarbon exploration wells Kawau-1A and Pakaha-1.

At Angora Quarry, x-ray fluorescence (XRF) was used to measure the major constituents $\mathrm{Na}_{2} \mathrm{O}, \mathrm{MgO}, \mathrm{Al}_{2} \mathrm{O}_{3}, \mathrm{SiO}_{2}, \mathrm{P}_{2} \mathrm{O}_{5}, \mathrm{SO}_{3}, \mathrm{~K}_{2} \mathrm{O}, \mathrm{CaO}, \mathrm{TiO}_{2}, \mathrm{MnO}$ and $\mathrm{Fe}_{2} \mathrm{O}_{3}$. inductively-coupled plasma mass spectrometry (ICP-MS) was used to measure $\mathrm{Li}, \mathrm{Ca}$, Ti, V, Cr, Co, Ni, Cu, Zn, Ga, Ge, As, Rb, Sr, Y, Zr, Nb, Mo, Cd, Sn, Sb, Ba, REE, Hf, $\mathrm{Tl}, \mathrm{Pb}$, Th and $\mathrm{U}$.

For Pakaha-1 and Kawau-1A side wall core samples, ICP-MS was used to measure Ti, V, Cr, Mn, Co, Ni, Cu, As, Se, Rb, Sr, Y, Zr, Nb, Mo, Cd, Sn, Sb, Hf, Ta, W, $\mathrm{Tl}, \mathrm{Pb}, \mathrm{Bi}$, Th and $\mathrm{U}$. Insufficient sample was available for XRF on these samples.

No major changes in oxygen concentration during deposition were recorded by redox-sensitive elements from Angora Quarry and Pakaha-1 sediments; however samples from Kawau-1A and from a section $1 \mathrm{~km}$ upstream from Angora Quarry were deposited under somewhat oxygen-depleted conditions. As the anoxic and suboxic indicators show significantly lower variations than under present day anoxic environments, and in Angora Quarry $\mathrm{CaO}$ and $\mathrm{SO}_{3}$ are significantly depleted with higher aluminosilicates a rapid deposition is required to explain the preservation of the organic matter. In the Great South Basin wells, the clay content correlates directly with increased gamma ray levels measured by well logs.

Increased influx of terrestrial clays has been linked to marine transgressions in many New Zealand sediments and is been taken to mean the same for the Waipawa and Tartan formations. The oxygen depletion indicates that water depths during deposition 
exceeded 50 metres. The depositional model proposed here, therefore, is that of a major marine transgression that flooded and eroded near-shore swamps, re-depositing the terrestrial organic matter offshore. The increased nutrients released by this would have stimulated bioproductivity and locally, where conditions were suitable, depleted the oxygen content of the water column.

This study also suggests ternary diagrams are valuable for calculating the enrichment of elements affected by two processes, such as $\mathrm{Sr}$, which is related to both detrital $\mathrm{Al}$ and related to biological $\mathrm{Ca}$. $\mathrm{Ga}, \mathrm{Ba}$ and $\mathrm{Al}$ content are also related on a ternary diagram indicating the similar terrestrial and biological relationships for $\mathrm{Ba}$ and Ga. W was found to behave in a similar way to Bi. Enrichment factors proved less useful than absolute enrichment for Kawau-1A, where detrital input varied greatly and was found to be significantly different in composition to average shale as defined by Wedephol (1971). 


\section{Acknowledgements}

I would like first thank my supervisors, and acknowledge the input, Marc-Alban Millet for the geochemical aspects and the time and help you provided with the lab work and editing, and John Collen for this project, for your tireless editing, and for the weekly meeting that allowed me to bounce ideas off you regularly.

I am very grateful to OMV New Zealand Limited, both for the scholarship you provided and the employment during my thesis.

I'd like to thank Euen Smith for his help with ternary diagrams, Joel Rayen, for keeping me company during the fieldwork, and Harriette Mangin and Laura Campbell for the accommodation and company in Hastings during my fieldwork.

I am indebted to my family, my parents for their financial assistance and for being there through the many long years of study, and my sister for the countless times she has taken me out for dinner, you have helped keep me sane through these past few years.

To friends, many of whom I feel I've abandoned over the last few months, I apologise. 


\section{Table of contents}

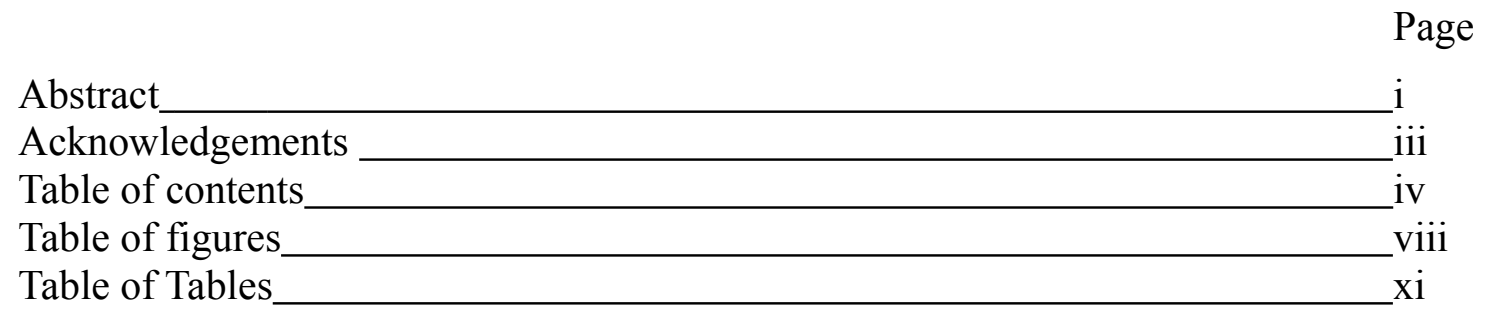

\section{Introduction}

1.0. .Introduction

1.1. Introduction to the Waipawa and Tartan formations___ 2

$\begin{array}{ll}\text { Waipawa Formation } & 2 \\ \text { Tartan Formation_- } & 3 \\ \text { Distribution } & 5 \\ \text { Gamma ray spike } & 5 \\ \text { Nomenclature of the Waipawa Formation } & 6\end{array}$

1.2. Previous work on the Waipawa and Tartan formations___ 6

1.3. Introduction to anoxic environments and trace metal variations ___ 11

1.4. Aim 14

1.5 Thesis outline___ 15

\section{Trace metal variations 16}

2.0. Processes governing trace metal variations in organic-rich sediments

2.1 Different oxygen depleted environments and the representative enrichment processes 18

Closed oxygen depleted systems__ 19

Silled anoxic basins _ 20

Marine upwelling__ 21

2.2 Major and Trace element variations in sediments___ 23

Mainly terrestrially sourced elements___ 24

Indicators of anoxia (major components of sedimentary pyrite)__ 26

Indicators of anoxia (included in sedimentary pyrite)__ 26

Indicators of anoxia (included in sedimentary pyrite); anthropogenic in recent sediments___ 27

Biological component or involved in biocycling__ 27

Biological component or involved in biocycling. Indicators of anoxia (included in sedimentary pyrite) ___ 29

Depleted under suboxic/dysoxic conditions. Indicators of anoxia (included in

Enriched under reducing conditions__ 30

Enriched under reducing conditions, rarely studied___ 31

Rarely studied in sediments___ 32

Rare earth elements (REE)__ 32 
3.0. Regional setting

3.1. The East Coast Basin__ 36

Introduction__ 36

Stratigraphy_ 36

Whangai Formation__ 37

Waipawa Formation_ 37

Wanstead Formation_ 38

3.2. Great South Basin__ 38

Introduction__ 38

Stratigraphy_ 39

Wickliffe Formation__ 39

Tartan Formation__ 40

Laing Formation_ 41

4. Methods and field work

4.0. Introduction__ 42

4.1. East Coast Basin fieldwork and samples___ 42

4.2 Great South Basin__ 47

Pakaha-1_ 47

Kawau-1A_ 48

4.3. Laboratory techniques $\quad 50$

Pre-laboratory sample preparation

Beaker cleaning__ 50

Sample digestion__ 51

4.4 Data Processing __ 51

Absolute concentration__ 51

Error calculations__ 53

Terrestrial background correction__ 56

5. Results

5.0. Angora Quarry _ 63

Overview_ 63

Major sedimentary components__ 64

Aluminium_65 65

Mainly terrestrially-sourced elements___ 65

Loss on ignition (LOI)_ 67

Indicators of anoxia (major components of sedimentary pyrite)___ 67

Indicators of Anoxia (included in sedimentary pyrite)__ 67

Indicators of anoxia (included in sedimentary pyrite); anthropogenic in recent sediments___ 68

Biological component or involved in biocycling___ 68

Biological component or involved in biocycling; indicators of anoxia (included in sedimentary pyrite). 72

Depleted under oxygen-depleted conditions; indicators of anoxia (included in sedimentary pyrite) __ 73

Enriched under reducing conditions _ 73

Enriched under reducing conditions, rarely studied___ 74

Rarely studied in sediments___ 74 
5.0. Kawau-1A__ 77

Overview__ 77

Mainly terrestrially-sourced elements__ 78

Indicators of Anoxia (included in sedimentary pyrite)__ 79

Indicators of anoxia (included in sedimentary pyrite); anthropogenic in recent sediments__ 80

Biological component or involved in biocycling___ 81

Biological component or involved in biocycling; indicators of anoxia (included in sedimentary pyrite) ___ 81

Depleted under oxygen-depleted conditions; indicators of anoxia (included in sedimentary pyrite) _ 82

Enriched under reducing conditions___ 82

Enriched under reducing conditions, rarely studied___ 83

Rarely studied in sediments__ 84

Rare earth elements (REE)_ 84

5.0. Pakaha-1__ 85

Overview__ 85

Mainly terrestrially-sourced elements__ 86

Indicators of Anoxia (included in sedimentary pyrite)___ 87

Indicators of anoxia (included in sedimentary pyrite); anthropogenic in recent sediments___ 87

Biological component or involved in biocycling___ 88

Biological component or involved in biocycling; indicators of anoxia (included in sedimentary pyrite)___ 88

Depleted under oxygen-depleted conditions; indicators of anoxia (included in sedimentary pyrite)__ 89

Enriched under reducing conditions__ 90

Enriched under reducing conditions, rarely studied___ 91

Rarely studied in sediments__ 91

Rare earth elements (REE)__ 92

\section{Discussion}

6.0. Angora Quarry ___ 93

Overview__ 93

Terrestrial indicators__ 96

Anoxic indicators (sedimentary pyrite)__ 97

Oxygen depletion__ 97

Biological components and biocycling___ 98

Rare Earth Elements___ 101

Summary of Angora Quarry___ 101

6.1. Kawau-1A__ 102

Overview_ 102

Terrestrial indicators__ 102

Anoxic indicators (sedimentary pyrite)__ 103

Oxygen depletion__ 104

Biological components and biocycling___ 104

Rarely studied elements__ 105

Rare Earth Elements__ 105

Summary of Kawau-1A__ 105

6.2. Pakaha-1__ 106

Overview 106

Terrestrial indicators__ 106

Anoxic indicators (sedimentary pyrite)__ 107 
Oxygen depletion

Biological components and biocycling

Rarely studied elements

Rare Earth Elements

Summary of Pakaha-1

6.3. Regional depositional environment

East Coast Basin trace element work from Elgar (1997) 109

Summary of results

Possible depositional environments

Comparison of depositional environments

Summary

6.4. Discussion of trace metals

Effects of thermal maturation on trace metals

7. Conclusions

7.0. Angora Quarry Section

7.1. Kawau-1A

7.2. Pakaha-1

7.3. Trace metals in sediments

7.4. Depositional environment

7.5. Future work

References

\section{Appendices}

Appendix A 


\section{List of figures}

Page

Figure 1.1.1. Map showing known locations of the Tartan and Waipawa Formations.__ 4

Figure 1.1.2. Gamma ray log in the Kawau-1A well.

Figure 1.2.1. Sulphur plotted against TOC for the East Coast Basin.___ 8

Figure 1.2.2. Rock Eval data for the East Coast Basin.___ 9

Figure 1.2.3. Rock Eval data for the Great South Basin.__ 10

Figure 2.1.1. Diagram of a closed anoxic basin. 20

Figure 2.1.2. Diagram of a silled anoxic basin.__ 20

Figure 2.1.3. Diagram of upwelling-caused oxygen minimum layer.__ 22

Figure 3.0.1. Maps showing the evolution of the New Zealand continent 65Ma to 40Ma._35

Figure 3.1.1. Generalised stratigraphy of the East Coast Basin.__ 36

Figure 3.2.1. Generalised stratigraphy of the Great South Basin.__ 39

Figure 4.1.1. Maps showing the location of Angora Quarry field area.__ 43

Figure 4.1.2. Simplified stratigraphy columns through the Angora Quarry and stream sections. 44

Figure 4.1.3. Photos of field samples at Angora Quarry.__ 45

Figure 4.1.4. Photos of Terribelina fossils in the samples.___ 45

Figure 4.1.5. Photos sorted by darkness for the Angora Quarry samples. __ 46

Figure 4.1.6. Photos sorted by darkness for the samples $1 \mathrm{~km}$ upstream from Angora Quarry._ 46

Figure 4.2.1. Gamma ray log through Pakaha-1 with highlighted sample locations. __ 47

Figure 4.2.2. Gamma ray log through Kawau-1A with highlighted sample locations.__ 49

Figure 4.4.1. Raw ICP-MS measurements for $\mathrm{Ca}$ in field samples.__ 52

Figure 4.4.2. Raw ICP-MS measurements for Mo in field samples, showing problems caused by the BCR-2 standard. 53

Figure 4.4.3. Graph comparing local background element concentrations with that of average shale define by Wedephol (1971)._ 56

Figure 4.4.4. Depth section for As from Kawau-1A showing the difference between enrichment factor and absolute enrichment calculations.__ 58

Figure 4.4.5. Ternary diagram for $\mathrm{CaO}, \mathrm{Sr}$ and $\mathrm{Al}_{2} \mathrm{O}_{3}$.

Figure 4.4.6. Synthetic perfect data for a $\mathrm{CaO} \mathrm{Sr}$ and $\mathrm{Al}_{2} \mathrm{O}_{3}$ ternary diagram, before and after the detrital correction. 60

Figure 5.0.1. Graph showing the difference between Ca measured by ICP-MS and XRF for Angora Quarry.

Figure 5.0.2. Ternary diagrams showing the major sedimentary components: $\mathrm{Al}_{2} \mathrm{O}_{3}$, $\mathrm{CaO}$ and $\mathrm{SiO}_{2}$ for the East Coast Basin.

Figure 5.0.3. A depth graph for $\mathrm{Al}_{2} \mathrm{O}_{3}$ at the Angora Quarry section. 65

Figure 5.0.4. Depth sections showing: absolute concentration, enrichment factors and absolute enrichments at Angora Quarry for $\mathrm{TiO}_{2}, \mathrm{Nb}, \mathrm{Rb}, \mathrm{K}_{2} \mathrm{O} \mathrm{Th}$, $\mathrm{Zr}$, Hf and Ga.

Figure 5.0.5. Depth sections showing: absolute concentration, enrichment factors and absolute enrichments at Angora Quarry for LOI.

Figure 5.0.6. Depth sections showing: absolute concentration, enrichment factors and absolute enrichments at Angora Quarry for $\mathrm{Fe}_{2} \mathrm{O}_{3}$ and $\mathrm{SO}_{3}$.

Figure 5.0.7. Depth sections showing: absolute concentration, enrichment factors and absolute enrichments at Angora Quarry for Zn and Mo. 68

Figure 5.0.8. Depth sections showing: absolute concentration, enrichment factors and absolute enrichments at Angora Quarry for $\mathrm{Pb}$. 68 
Figure 5.0.9. Depth sections showing: absolute concentration, enrichment factors and absolute enrichments at Angora Quarry for $\mathrm{Ba}, \mathrm{P}_{2} \mathrm{O}_{5}, \mathrm{CaO}, \mathrm{MgO}$, $\mathrm{Sr}, \mathrm{SiO}_{2}$ and Ge.

Figure 5.0.10. Cartesian graph between $\mathrm{Ga}$ and $\mathrm{Ba}$, and a Ternary diagram between $\mathrm{Ga}$, $\mathrm{Ba}$ and $\mathrm{Al}_{2} \mathrm{O}_{3}$. 70

Figure 5.0.11. Diagram showing the steps in calculating absolute enrichments for $\mathrm{Sr}$ _ 70

Figure 5.0.12. Diagram showing issues with calculating absolute enrichments for $\mathrm{Mg}$._ 71

Figure 5.0.13. Plot of $\mathrm{SO}_{3}$ against $\mathrm{CaO}$.

Figure 5.0.14. Depth sections showing: absolute concentration, enrichment factors and absolute enrichments at Angora Quarry for $\mathrm{Tl}, \mathrm{Cu}, \mathrm{Cd}$ and Ni.

Figure 5.0.15. Depth sections showing: absolute concentration, enrichment factors and
absolute enrichments at Angora Quarry for $\mathrm{MnO}$ and Co.

Figure 5.0.15. Depth sections showing: absolute concentration, enrichment
absolute enrichments at Angora Quarry for $\mathrm{MnO}$ and $\mathrm{Co}$. 73

Figure 5.0.16. Depth sections showing: absolute concentration, enrichment factors and absolute enrichments at Angora Quarry for As, U, V and Cr. 74

Figure 5.0.17. Depth sections showing: absolute concentration, enrichment factors and absolute enrichments at Angora Quarry for Sb. 74

Figure 5.0.18. Depth sections showing: absolute concentration, enrichment factors and absolute enrichments at Angora Quarry for $\mathrm{Sn}, \mathrm{Li}$ and $\mathrm{Na}_{2} \mathrm{O}$. 75

Figure 5.0.19. Depth sections showing: absolute concentration, enrichment factors and absolute enrichments at Angora Quarry for the La._ 75

Figure 5.0.20. REE normalised to chondrite. 76

Figure 5.0.21. REE normalised to North American Shale Composite (NASC).__ 77

Figure 5.1.1. Gamma ray log compared to $\mathrm{Ti}$ and $\mathrm{Zr}$ in Kawau-1A._ 78

Figure 5.1.2. Depth sections showing: absolute concentration, enrichment factors and absolute enrichments in Kawau-1A for Ti, Th, Hf, Zr, Rb, Nb and Ta._79

Figure 5.1.3. Depth sections showing: absolute concentration, enrichment factors and absolute enrichments in Kawau-1A for Mo 79

Figure 5.1.4. Depth sections showing: absolute concentration, enrichment factors and absolute enrichments in Kawau- $1 \mathrm{~A}$ for $\mathrm{Pb}$ and $\mathrm{Bi}$. 80

Figure 5.1.5. Depth sections showing: absolute concentration, enrichment factors and absolute enrichments in Kawau-1A for Sr.

Figure 5.1.6. Depth sections showing: absolute concentration, enrichment factors and absolute enrichments in Kawau-1A for $\mathrm{Tl}, \mathrm{Cu}, \mathrm{Cd}$ and $\mathrm{Ni}$. 81

Figure 5.1.7. Depth sections showing: absolute concentration, enrichment factors and absolute enrichments in Kawau-1A for Mn and Co.

Figure 5.1.8. Depth sections showing: absolute concentration, enrichment factors and absolute enrichments in Kawau-1A for As, U, V, and Cr.

Figure 5.1.9. Depth sections showing: absolute concentration, enrichment factors and absolute enrichments in Kawau-1 A for $\mathrm{Sb}$ and, $\mathrm{Se}$.

Figure 5.1.10. Ternary diagrams for $\mathrm{Bi}, \mathrm{Sb}$ and $\mathrm{Zr}$, and $\mathrm{Bi}, \mathrm{Sb}$ and $\mathrm{Ti}$ for Kawau-1A samples.

Figure 5.1.11. Depth sections showing: absolute concentration, enrichment factors and absolute enrichments in Kawau-1A for Sn and W.

Figure 5.1.12. A plot of $W$ against Bi for Kawau-1A samples. 84

Figure 5.1.13. Depth sections showing: absolute concentration, enrichment factors and absolute enrichments in Kawau-1A for Y.

Figure 5.2.1. Gamma ray log compared to $\mathrm{Ti}$ and $\mathrm{Zr}$ in Pakaha-1.

Figure 5.2.2. Depth sections showing: absolute concentration, enrichment factors and absolute enrichments in Pakaha-1 for Ti, Th, Hf, Zr, Rb, Nb and Ta._ 86

Figure 5.2.3. Depth sections showing: absolute concentration, enrichment factors and absolute enrichments in Pakaha-1 for Mo.

Figure 5.2.4. Depth sections showing: absolute concentration, enrichment factors and absolute enrichments in Pakaha-1 for $\mathrm{Pb}$ and $\mathrm{Bi}$ 
Figure 5.2.5. Depth sections showing: absolute concentration, enrichment factors and absolute enrichments in Pakaha-1 for Sr.

Figure 5.2.6. Depth sections showing: absolute concentration, enrichment factors and absolute enrichments in Pakaha-1 for Tl, $\mathrm{Cu}, \mathrm{Cd}$ and $\mathrm{Ni}$.__ 89

Figure 5.2.7. A graph of $\mathrm{Tl}$ against $\mathrm{Rb}$ for Pakaha-1 samples.

Figure 5.2.8. Depth sections showing: absolute concentration, enrichment factors and absolute enrichments in Pakaha-1 for Mn and Co. 90

Figure 5.2.9. Depth sections showing: absolute concentration, enrichment factors and absolute enrichments in Pakaha-1 for As, U, V and Cr. 90

Figure 5.2.10. Depth sections showing: absolute concentration, enrichment factors and absolute enrichments in Pakaha-1 for $\mathrm{Sb}$ and $\mathrm{Se}$. 91

Figure 5.2.11. Depth sections showing: absolute concentration, enrichment factors and absolute enrichments in Pakaha-1 for Sn and W.

Figure 5.2.12. Depth sections showing: absolute concentration, enrichment factors and absolute enrichments in Pakaha-1 for Y.

Figure 6.0.1. Depth sections showing TOC concentrations through Angora Quarry. 93

Figure 6.0.2. $\mathrm{Al}_{2} \mathrm{O}_{3}$ plotted against increasing darkness of sample. ___ 94

Figure 6.0.3. $\mathrm{CaO} / \mathrm{Al}_{2} \mathrm{O}_{3}$ plotted against increasing darkness of sample.__ 95

Figure 6.0.4. $\mathrm{SiO}_{2} / \mathrm{Al}_{2} \mathrm{O}_{3}$ plotted against increasing darkness of sample.__ 95

Figure 6.0.5. Comparisons of $\mathrm{Al}_{2} \mathrm{O}_{3}, \mathrm{Zr}$ and $\mathrm{Hf}$ for Angora Quarry.____ 96

Figure 6.0.6. Depth sections through Angora Quarry for Ce/La and Gd/Eu. __ 98

Figure 6.0.7. Ternary diagram for data from Ross and Bustin (2009) for Ba, Ga and $\mathrm{Al}_{2} \mathrm{O}_{3}$. 99

Figure 6.0.8. S against TOC for the East Coast Basin, including this study.__ 100

Figure 6.1.1. Depth sections showing TOC in Kawau-1A.__ 102

Figure 6.2.1. Depth sections showing TOC in Pakaha-1.___ 106

Figure 6.3.1. Th plotted against $\mathrm{Rb}$ for the previous trace element work done in the East Coast Basin.

Figure 6.3.2. Sea level curve for the Late Paleocene with various age constraints for the Waipawa Formation. 114

Figure 6.4.1. Plot comparing the trace element concentration in oils sourced from the Waipawa Formation to the Waipawa Formation. 


\section{List of tables}

\section{Page}

Table 1.1.1. Depths and thicknesses of the Tartan Formation in the Great South and

Canterbury basins. 4

Table 4.2.1. Descriptions of side wall core samples from Pakaha-1. 48

Table 4.2.2. Descriptions of side wall core samples from Kawau-1A.__ 49

Table 4.4.1. Error calculations for Kawau-1A and Pakaha-1A.___ 54

Table 4.4.2. Error calculations for Angora Quarry.___ 55

Table 5.0.1. Concentration of REE in Chondrite and North American Shale Composition (NASC). 76

Table 6.0.1. Comparison of the correlation between terrestrial indicators at Angora Quarry. 96

Table 6.1.1. Comparison of the correlation between terrestrial indicators at Kawau-1A. 103

Table 6.2.1. Comparison of the correlation between terrestrial indicators at Pakaha-1. 107 


\section{Chapter 1 \\ Introduction}

\subsection{Introduction}

This thesis is a study of the inorganic geochemistry of the Tartan and Waipawa formations. These units are important, their high organic-matter content makes them potential hydrocarbon source rocks, and for the unique yet regionally widespread facies they represent.

Late Paleocene and Early Eocene strata contain the record of some unique and short-lived global climatic events, amongst them the Paleocene carbon isotope maximum (PCIM) representing the increased burial of mainly terrestrial organic-carbon (e.g. Shackleton, 1987; Kurtz et al., 2003). The PCIM began around 59.5 Ma and lasted about 4 million years. It was followed immediately by the Initial Eocene Thermal Maximum (IETM) that lasted approximately 100,000 years. Sediments rich in organic matter were deposited in a number of basins around the world during the IETM (e.g. Gavrilov et al., 1997; Speijer et al., 1997), as a result of a maximum marine transgression, warm temperatures and a high influx of terrestrial organic matter into the oceans from flooding near shore swamps.

Around New Zealand, regionally extensive organic-matter rich sediments were deposited earlier during the PCIM (Hollis et al., 2005a); known as the Waipawa or Tartan formations dependant on locality.

While locally in New Zealand there are changes in lithology during the IETM (e.g. a marl-rich horizon, Nicolo et al., 2007), the Late Paleocene Waipawa and Tartan formations show more profound lithological changes and these occur in most New Zealand Cenozoic sedimentary basins (Killops et al., 2000). A Late Paleocene unconformity is also common above the Tartan and Waipawa formations (McMillan and Wilson, 1997) and in the Late Paleocene in general with the Waipounamu Erosion Surface (LeMasurier and Landis, 1996; Beggs, 2010a).

Around New Zealand many Cenozoic basins underwent significant marine 
deposition during the Late Paleocene, yet most of these basins have minimal exposure onshore. Most of our information comes from the hydrocarbon exploration industry in the form of seismic surveys and exploration wells. The East Coast Basin is the exception, due to the recent activity of the Hikurangi subduction thrust, Early Cretaceous and younger sediments have been exposed from the East Cape in the north to Marlborough in the south (Field et al., 1997).

Organic-matter is mainly degraded through consumption by other life forms; this is enhanced by biological reworking due to the mixing of sediments (Demaison and Moore, 1980). To be preserved on a geological timescale organic-matter rich sediments must be deposited in and environment which is limited in the amount of life it can support during deposition to avoid degradation and recycling of the organic matter. A large influx of organic matter relative to the background detrital matter is also required to produce significant organic-matter enrichment. In marine environments the most common way to get high organic matter incorporated into sediments is under oxygendepleted conditions, where the lack of oxygen limits life forms to sulphate and carbondioxide reducing bacteria (e.g. Demaison and Moore, 1980). Rapid deposition of recycled organic matter from another location may also be possible; however high organic matter influx can also drive anoxia as was shown to be the case in some Early Eocene organic-rich sapropels by Gavrilov et al. (1997) over a large area of southern Russia, adjoining regions of Crimea, to central and southern Asia. The effect of oxygen depletion limits processes such as bioturbation, which mixes the upper few $\mathrm{cm}$ of the sediments (Demaison and Moore, 1980). Under anoxic conditions (no oxygen) bacterial degradation is limited to $\mathrm{CO}_{2}, \mathrm{CH}_{4}$ and sulphate-reducing bacteria. However none of these are as efficient as aerobic (oxygen-reducing) life forms at recycling organic matter (e.g. Demaison and Moore, 1980).

\subsection{Introduction to the Waipawa and Tartan formations}

\section{Waipawa Formation}

The Waipawa Formation is an organic-rich Late Paleocene mudstone to siltstone 
found in most New Zealand Cenozoic basins, excluding the Great South and Canterbury basins. The formation rarely exceeds $50 \mathrm{~m}$ in thickness, but averages $3.6 \%$ total organic carbon (TOC) and has a wide lateral distribution, making it an important potential hydrocarbon source rock (e.g. Katz, 1968; Hollis et al., 2005b). The type locality for the Waipawa Formation is located in the township of Waipawa (Moore et al., 1986).

\section{Tartan Formation}

In the Great South and Canterbury basins (Figure 1.1.1), a formation which is a similar facies to the Waipawa Formation, and the same age has been named 'Tartan Formation'. The inability to show correlation across the Chatham Rise has led to the use of a different name (Cook et al., 1999; Schiøler et al., 2010). Cook et al., 1999 suggested Pakaha-1 as the type section between 2503-2551 m, however Schiøler et al., (2010) defined the Tartan Formation as 2515.2-2587.2 $\mathrm{m}$ in Pakaha-1. Whether this should be taken as the new type section is not yet clear.

\section{Distribution}

In the East Coast Basin the Waipawa Formation is identified throughout most of the basin (e.g. Moore, 1988); however, locally (e.g. Tawanui) a greensand unit in the uppermost Te Uri member of the Whangai Formation is demonstrated to be the time equivalent of the Waipawa (e.g. Rogers et al., 2001). Outside the East Coast, the Waipawa Formation has been identified in the Ariki-1 well in the northern Taranaki (Shell BP Todd Oil Services Ltd., 1984; Killops et al., 1994; King and Thrasher, 1996), in the Northland (Isaac et al., 1994; Conoco Northland Ltd, 1999; Hollis et al., 2006) and Westland (Nathan, 1977) basins. Its equivalent has also been suggested as being present in the Reinga Basin from seismic facies analysis (Stagpoole et al., 2009).

The Tartan Formation is has been identified in both the Great South and Canterbury basins (Killops et al., 1997, 2000; Cook et al., 1999; Schiøler et al., 2010). Figure 1.1.1 shows the known locations of the Waipawa and Tartan formations.

In the Great South and Canterbury basins there is no onshore exposure of the Tartan Formation; however it has been intersected in multiple hydrocarbon exploration 


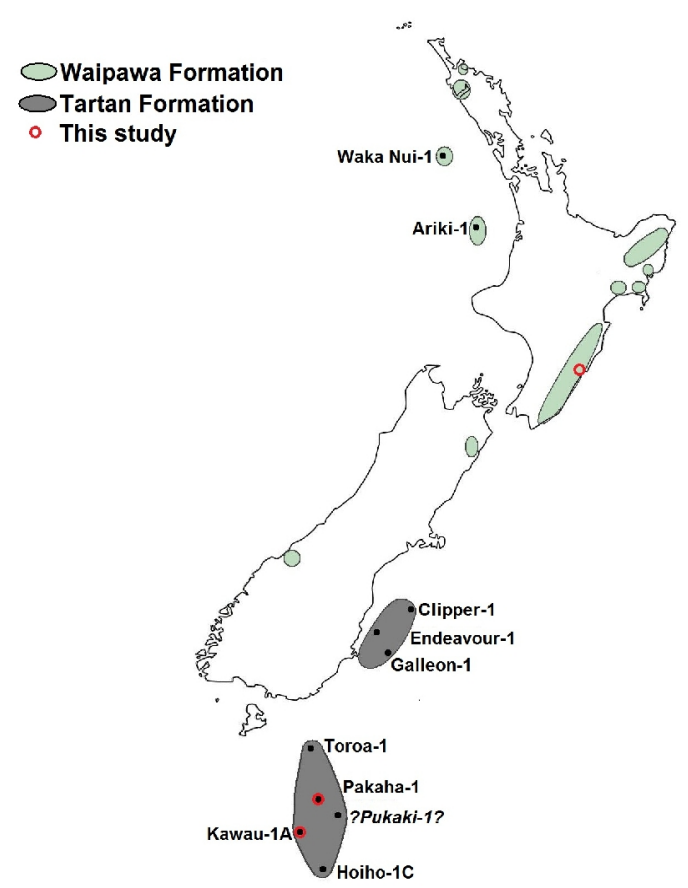

Figure 1.1.1: Known locations of the Waipawa and Tartan Formation formations around New Zealand. Map after Killops et al. (2000)

Pukaki-1 is uncertain, see text.

wells (table 1.1.1; figure 1.1.1). In the Great South Basin, four wells encountered the Tartan Formation (Kawau-1A, Pakaha-1, Hoiho-1C and Toroa-1). In Pukaki-1 an unconformity was recognised near the top of the Late Paleocene and the formation was interpreted to be missing (Cook et al., 1999). Recently the Tartan Formation was

\begin{tabular}{|c|c|c|c|}
\hline Well Name (Great South Basin) & Top $(\mathrm{mbkb})$ & Bottom $(\mathrm{mbkb})$ & Thickness $(\mathrm{mbkb})$ \\
\hline Toroa-1 & 2152.1 & 2187.7 & 35.6 \\
\hline Pakaha-1 & 2515.5 & 2587.2 & 71.7 \\
\hline Kawau-1A & 2233.1 & 2264.2 & 31.8 \\
\hline Pukaki-1 ${ }^{*}$ & 2297.5 & 2327.6 & 30.1 \\
\hline Hoiho-1C & 1568.8 & 1596.4 & 27.6 \\
\hline (Canterbury Basin) & & & \\
\hline Clipper-1 & 2756.1 & 2787.1 & 31.0 \\
\hline Endeavour-1 & 1728.8 & 1757.7 & 28.9 \\
\hline Galleon-1 & 2505.8 & 2522.3 & 16.5 \\
\hline
\end{tabular}

Table 1.1.1: Depths and thickness of the Tartan Formation in the Great South and Canterbury basins wells. Depth is in meters below kelly bushing. Depths from Schiøler et al. (2010).

* Pukaki-1 may not actually contain the Tartan Formation, see text for details. 
suggested as present (Schiøler and Roncaglia, 2008; Schiøler et al., 2010) based on cuttings and the well log signal, but this does not fit with the most recent seismic interpretation of reprocessed seismic data (ExxonMobil, 2010a, 2010b). As this well was not included in the present study, further discussing this issue is beyond the scope of this thesis.

\section{Gamma ray spike}

On well logs, the Tartan Formation coincides with a gamma ray spike which is considered one of the defining characteristics of the formation. The spike may be sourced from U-bearing organic matter, terrestrially derived clays, or both (Schiøler et al., 2010) or U salts precipitated due to oxygen depletion (Killops et al., 2000). An example of the gamma ray spike is shown for Kawau-1A (figure 1.1.2). Trace metals may be able to determine the source of the spike.

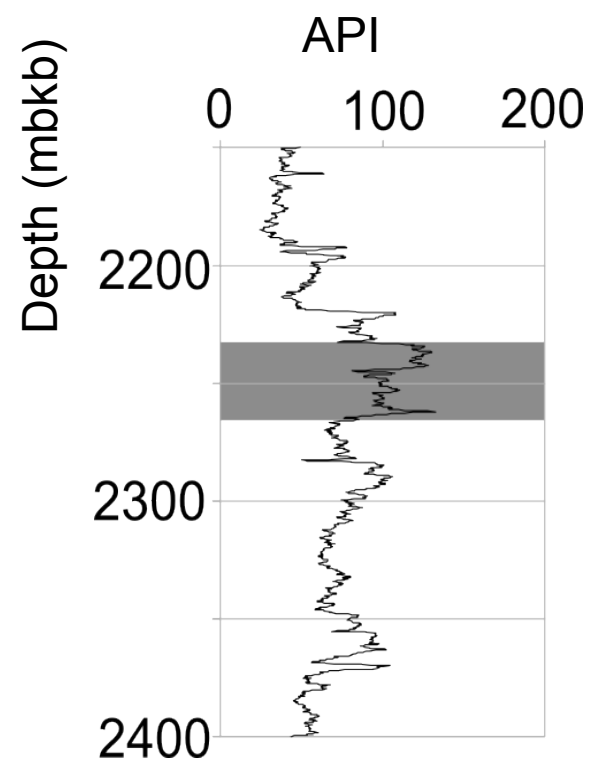

Figure 1.1.2: Gamma ray log response in the Kawau-1A well. The units are in API; 100 API is the response of average shale. The Tartan Formation is highlighted in grey.

Log data from Hunt International (1977).

\section{Nomenclature of the Waipawa Formation}

The name "Waipawa" was first used in the literature by Finlay (1940) while discussing the distribution of Conotrochammina whangaia, a spiral foraminiferan 
present in both the Whangai and the "Waipawa Black Shale". However, the formation was not adequately described prior to Hornibrook and Harrington (1957), and first formally defined by Hornibrook (1959). Prior to 1957, depending on the region, the Waipawa Formation was included in the Whangai Formation, Mangatu Group or Wanstead Formation, or confused with Tapuwaeroa siltstone (Moore, 1988).

The Waipawa Formation was redefined by Moore (1986) as it was recognised as an important stratigraphic marker, and was deemed to be regionally significant. At the same time, the Wheturau Lithofacies from the Rakaurma Peninsula was recognised as a lateral continuation of the Waipawa Formation.

The Waipawa Formation is present in many New Zealand basins; however, the equivalents in the Canterbury and Great South basins have been given the name Tartan Formation by Cook et al. (1999). The reason for the different names is due to an inability to demonstrate that the formations can be correlated across the Chatham Rise.

\section{Nomenclature of the Tartan Formation}

While the Tartan Formation was referred to as the Waipawa Black Shale in several well reports (Kawau-1A, Hunt International, 1977; Pakaha-1, HIPCO, 1977a; Hoiho1C, Hunt International, 1978), the interval was renamed by Cook et al. (1999) because of its wide geographic separation from the original Waipawa Formation and because unequivocal correlation between the basins could not be demonstrated.

\subsection{Previous work on the Waipawa and Tartan formations}

To date most studies of these formations have focused on palaeontology or organic or stable isotope geochemistry. A few studies have mapped the seismic extent (Field and Brown, 1989; Cook et al., 1999, Uruski et al., 2007; Stagpoole et al., 2009), and some major elements have been measured (Moore, 1988). Only one trace element study on the Waipawa Formation has been produced (Elgar, 1997); no such study has been undertaken on the Tartan Formation in the Great South Basin. There have also been several suggested depositional environments.

Hornibrook and Harrington (1957) suggested a shallow marine to estuarine 
environment of deposition based on difficulties in lateral paleontological correlation suggesting a more restricted environment than the open ocean; a shallow marine environment was later supported by Moore (1988) and Cook et al. (1999).

However a shallow marine environment would require a marine regression, which was suggested as unlikely due to the open marine nature of the underlying Whangai and overlying Wanstead formations, and a general marine transgression during the Late Paleocene (Killops et al., 2000). The presence of Glomospira charoides and Rzehakina epigona which are indicators of bathyal to abyssal depths, and the wide lateral extent of the Waipawa Formation and its equivalents make shallow marine environments unlikely (Killops et al., 1996, 2000). Hence a regional upwelling around Late Paleocene New Zealand was proposed by these authors. Oxygen-depleted water upwelling at the edge of the continental slope due to both prevailing westerly winds and changes in deep water circulation was suggested as the likely cause of anoxic conditions affecting the upper slope to shelf environment around New Zealand (Killops et al., 2000).

The presence of unusually abundant 24-n-propylcholestanes (Killops et al., 2000) was thought to be caused by enhanced bioproductivity, in particular of phytoplankton above the oxygen-minimum layer. A high sulphur measurement by Hirner and Robinson (1989) was interpreted as a potential indication of anoxic conditions (Killops et al., 2000). $\mathrm{H}_{2} \mathrm{~S}$ is only present in the water column in strongly anoxic conditions, (e.g. Berner, 1981), and is precipitated into pyrite through sulphate-reducing bacteria. When anoxic conditions occur on the water bottom or shallowest sediments the proximity to mobile water allows more access to nutrients and sulphate-reducing bacteria are able to precipitate more pyrite. If anoxic conditions only occur deep within the sediments, there is limited $\mathrm{H}_{2} \mathrm{~S}$ to be precipitated into pyrite.

Rogers (1995) and Elgar (1997) presented data of both total S and TOC in the Waipawa Formation as well as many other formations in the East Coast Basin (appendix A). TOC plotted against $\mathrm{S}$ allows you to differentiate terrestrial organic and marine organic matter as well as whether the depositional environment was anoxic (Leventhal, 1993). Terrestrial organic matter contains very little sulphur, whereas marine organic matter contains a larger proportion of sulphur, and anoxic environments through the precipitation of pyrite add more sulphur to the sediments. Figure 1.2.1 shows these results for TOC against S; the variation in the Waipawa Formation seen in figure 1.2.1 


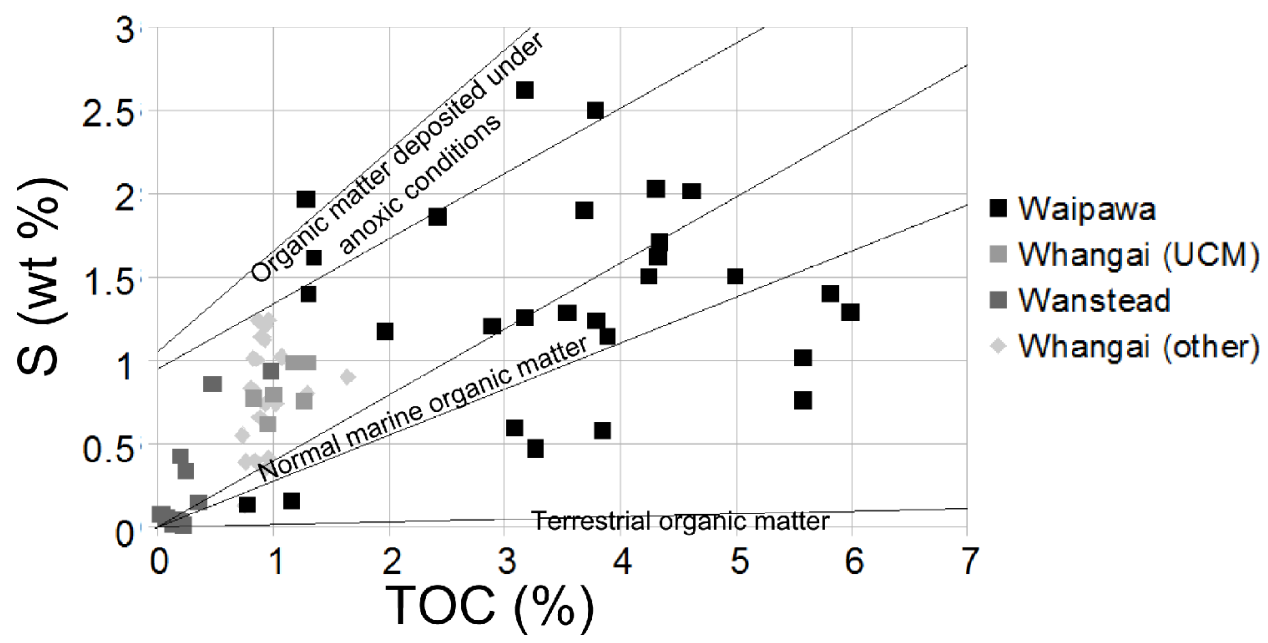

Figure 1.2.1: $S$ vs TOC for multiple formations in the East Coast Basin. The Waipawa Formation shows large variation on this graph including samples which look to be anoxic and ones which look to be a mixture of marine and non marine organic matter. Data sourced from Rogers (1995) and Elgar (1997).

indicates the depositional environment cannot be as easily explained by purely anoxic conditions. A terrestrial component to the organic matter has also been widely recognised as one of the characteristics of the Waipawa and Tartan formations (e.g. Rogers, 1995, Elgar, 1997, Killops et al., 2000; Schiøler et al., 2010).

Schiøler et al. (2010) conducted a detailed palynofacies analysis of sidewall cores from directly above, below and through the Tartan Formation. From this, they identified a high percentage of brown phytoclasts, rare marine algae and amorphous organic matter, suggesting a mixture of marine and terrestrial kerogen, with a significant proportion of the kerogen of terrestrial origin. This was suggested to indicate a marginally marine environment of deposition with bottom waters varying between oxic and anoxic dependant on locality. Low abundances of foraminifera suggested a hyposaline proximal environment, existing during a time of maximum marine regression. The high terrestrial organic matter input was suggested to result from an influx of woody material from onshore, and the characteristic gamma ray spike identifying the Tartan Formation was potentially associated with terrestrial clays. The high influx of terrestrial matter potentially resulted in increased productivity in the water column and at the surface.

Rock Eval Pyrolysis studies performed on the Waipawa and Tartan formations 

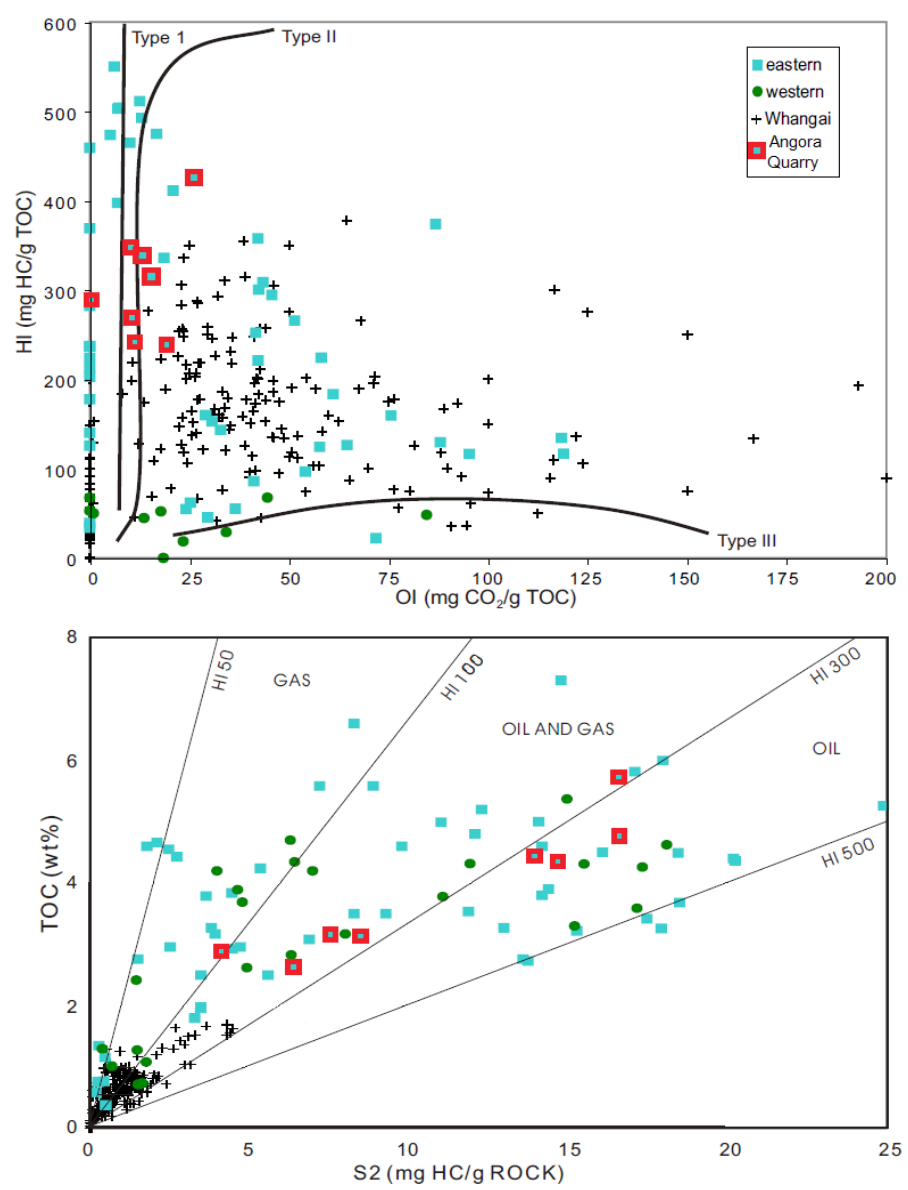

Figure 1.2.2: Compilation of Rock Eval results for Waipawa and Whangai formations. The great variation in organic geochemistry shows the formations have a broad range of organic geochemistry properties. The red squares are from Angora Stream, the same field area as in the present study. Figure based on Hollis et al. (2005b).

measured the source rock properties (figure 1.2.2; 1.2.3), indicating whether they are oil or gas prone amongst other things. The hydrogen index (HI) is an indicator of the amount of hydrogen is available for the production of hydrocarbons - the higher the hydrogen index, the more oil prone a formation is.

In the East Coast Basin (figure 1.2.2) a large variation in all source rock properties is observed. The formation varies between being oil, oil and gas, and gas prone, as does the Whangai Formation.

The Tartan Formation in the Great South Basin (figure 1.2.3) shows less variation in the HI values, but whether this is due to a limited number of samples analysed or a more homogenous unit in the Great South Basin is unknown.

The Schiøler et al. (2010) model is able to explain the distribution and the variation in the organic geochemistry of the Tartan Formation (figure 1.2.3). However, 

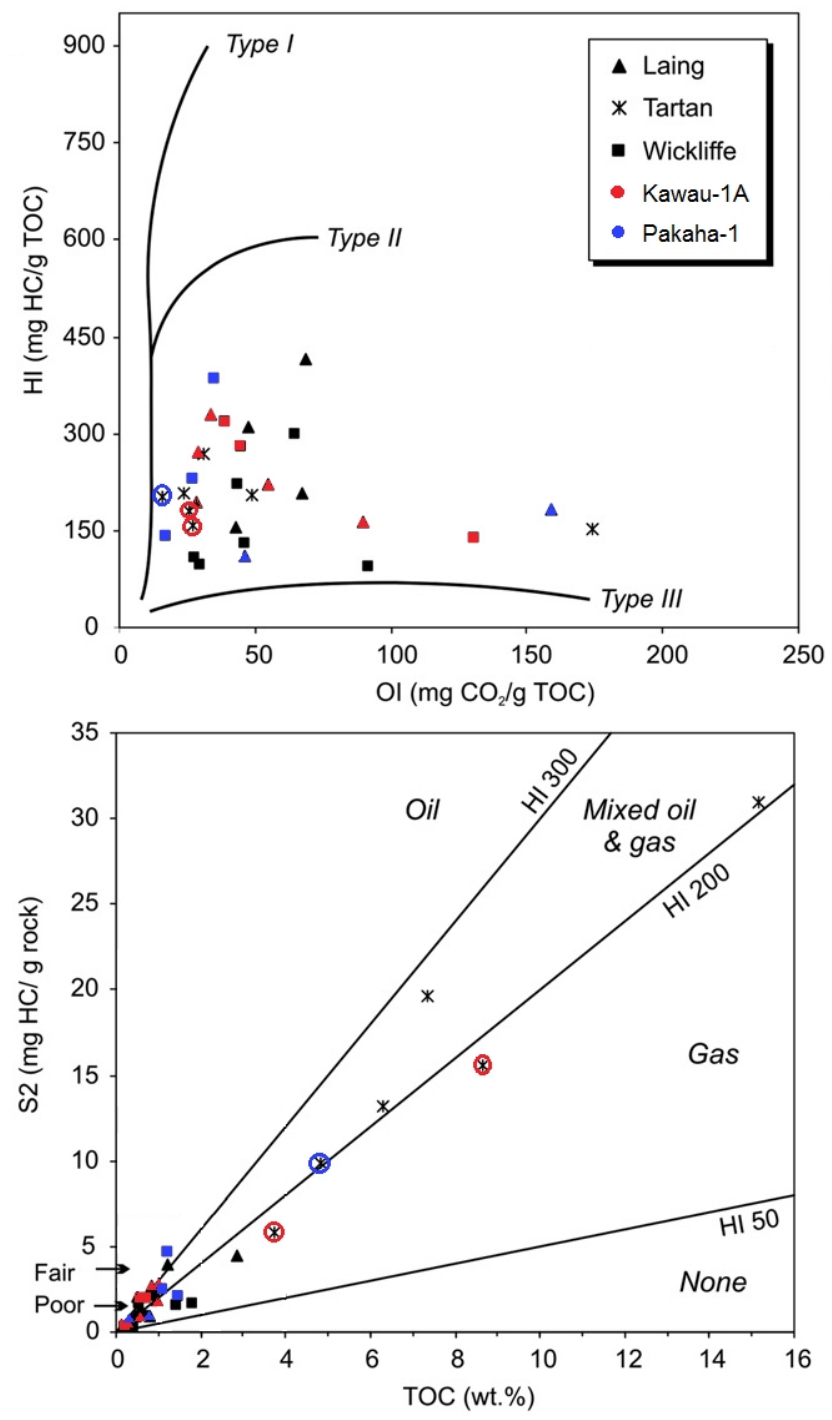

Figure 1.2.3: Rock Eval results from for SWC samples in the Great South Basin. Aside from samples for which no more material is available, the red and blue SWC samples are the same as were used in this study. Figure edited from Schiøler et al. (2010).

the East Coast Basin samples of the Waipawa Formation show a greater variation in kerogen types (figure 1.2.2) and there is evidence from sulphur and TOC that at some locations the Waipawa Formation consists largely of marine organic matter (figure 1.2.1). The Waipawa Formation is also not as thick, averaging $17 \mathrm{~m}$ (Hollis et al., 2005b) whereas the Tartan formation is on average $34 \mathrm{~m}$ thick (Schiøler et al., 2010). Waipawa Formation has also been linked to isotopically light liquid crude oil (Killops et al., 1994; Rogers et al., 1999) that is characteristic of marine, not terrestrial organicmatter. An explanation for fully marine organic-matter in some locations of the Waipawa Formation is not addressed by the Schiøler et al., (2010) model. 
Elgar (1997) conducted the first trace element measurements on the Waipawa Formation in the East Coast Basin. The study, however, was a regional study and no detailed sections were examined through the Waipawa Formation. This study will be addressed later.

\subsection{Introduction to Anoxic Environments and Trace Metal Variations}

Due to differing definitions of the terms 'anoxic,' 'dysoxic,' 'suboxic' and 'oxic' in the literature, it is important to first determine which set of definitions are used to describe the different environments in this and subsequent chapters. Multiple attempts at providing terminology have been made (e.g. Rhoads and Morse, 1971; Berner, 1981; Tyson and Pearson, 1991), while some early authors set their own boundaries for anoxic conditions (e.g. Demaison and Moore, 1980 at 0.5ml/L). Tyson and Pearson (1991) attempted to come up with a universal system in response to the multiple terminologies already in use. However, presently the literature remains confused.

Tyson and Pearson (1991) suggested oxic as 8.0-2.0ml/L $\left(\mathrm{O}_{2}\right)$, dysoxic as 2.0$0.2 \mathrm{ml} / \mathrm{L}$, suboxic as $0.2-0.0 \mathrm{ml} / \mathrm{L}$ and anoxic as $0.0 \mathrm{ml} / \mathrm{L}$, with the latter also characterised by the presence of $\mathrm{H}_{2} \mathrm{~S}$. Corresponding biofacies were defined as: aerobic, dysaerobic, quasi-anaerobic, and anaerobic. This study will use these terminologies and where possible will apply these terms to the interpretation of previous literature. The main issues occur in the exchangeable use of dysoxic and suboxic across the literature, and the definition of anoxic as varying between $0.5 \mathrm{ml} / \mathrm{L}$ and $0.0 \mathrm{ml} / \mathrm{L}$. The presence of $\mathrm{H}_{2} \mathrm{~S}$ is not always treated as the defining factor for anoxic conditions, however, $\mathrm{H}_{2} \mathrm{~S}$ can only exist in the absence of oxygen (Berner, 1981).

An oxygen-depleted environment is important for the preservation of organic carbon, and $80 \%$ of the world's hydrocarbon source-rocks are thought to be deposited under oxygen depleted regimes (Tyson and Pearson, 1991). Increased primary productivity (Pedersen and Calvert, 1990) or increases in rates of deposition (Lee, 1992) 
can also lead to the enhanced preservation of organic matter. Under laboratory conditions the rates of organic matter degradation may show little difference between oxic and anoxic environments (Lee, 1992; Henrichs and Reeburgh, 1987; Westrich and Berner, 1984; Otsuki and Hanya 1972a, b). However, over longer time scales under oxygen-depleted conditions there is a less chemical energy available for life, and hence less organic-matter degradation (Demaison and Moore, 1980; Berner, 1981; Lee, 1992)

Anoxic conditions occur in most sediments during some stage of digenesis (Demason and Moore, 1980; Berner, 1981; Tyson and Pearson, 1991); however when the water column is stratified, anoxic conditions can occur at the sediment-water interface or in the lowermost water column (Tyson and Pearson, 1991). Oxygen depletion in the water column does not need to be stable throughout the year, and seasonal oxygen depletions can occur in situations where the water column is only seasonally stratified.

Trace metal variations in organic-matter rich sediments have been studied for many years with one of the earliest studies being that by Goldschmit (1954). Some earlier studies have noted the relationship between black shales and particular trace metals; for example, McKelvey and Nelson (1950) discussed the enrichment of $U$ and depletion of $\mathrm{Mn}$ in black shales. Since these early studies the understanding of trace metal distributions has increased, as has the precision with which trace metals can be measured. The environments in which organic-rich rocks are deposited are now also better understood. While there are still many gaps in our understanding of trace metals in sediments, many enrichment processes are well known and can be used to help constrain the environments of deposition and the palaeoceanic conditions.

The concentration of trace metals in organic matter-rich sediments varies due to several different processes. The detrital sediment source provides a background amount of trace metals. If there is a variation in sediment source or there is some sediment sorting which increases or decreases particular mineral abundances, then the background detrital input can contain trace metal variations (Dellwig et al., 2000; Brumsack, 2006). Biological processes in the water column can collect particular elements from seawater, and the preservation of the resulting organic matter can give a biological enrichment. At the sediment-water interface biological processes (bioturbation) can disturb the sediments, causing the water to be mixed within the upper 
layer of sediments. This is most common in oxic conditions and helps provide an oxidising environment to the upper sediments (Demaison and Moore, 1980).

Diagenetic processes affect trace elements concentrations. Diagenetic processes start after deposition, and hence include all processes which occur at and below the sediment-water interface. Many of the processes related to oxygen concentration are diagenetic when the correct conditions occur below the sediment-water interface. Diagenetic processes which occur at later stages may affect trace metals, but their influences are poorly understood. These processes include changes in the bulk composition of the sediments, such as cementation and dissolution, that may affect trace metal concentrations if the cement is externally sourced or the dissolved material moves into other formations. With heat and pressure, organic matter-rich rocks expel oil and gas. The extent to which this affects trace metal concentrations is unknown, although Ross and Bustin (2009) measured trace metal in thermally mature shales and noted that trace metals were still enriched. Without comparable studies of otherwise identical immature and mature source rocks, the quantitative effects of hydrocarbon generation on trace metal concentrations and expulsion are unknown.

Trace metals can be enriched under oxygen depleted conditions through either direct precipitation as governed by redox chemistry, or indirectly through inclusions of trace amounts of an element within precipitating minerals such as sulphates and phosphates. Direct precipitation is relatively well understood and there are chemical formulae for the enrichment or depletion of several elements. The indirect precipitation method is more complex and depends on many factors such as the minerals precipitating (most commonly pyrite) and the trace elements present in the water column (e.g. Brumsack, 2006). As these methods affect different elements it is important to separate them.

Frankenberger (1994) measured the trace metal content of oils which were subsequently linked to the Waipawa Formation and underlying Whangai Formation due to biomarker content (Rogers et al., 1999, Killops et al., 1994). Whether or not these oils contain significant concentrations of trace metals in relation to the Waipawa Formation or underlying Whangai Formation will be investigated in this study. 


\subsection{Aim.}

The primary aim of this study is to review the depositional environment of the Tartan and Waipawa Formations using trace metal variations.

- Determine if there is evidence for anoxic, suboxic or oxic conditions during deposition of the Tartan and Waipawa Formations.

- Measure elements related to biological activity in the Tartan and Waipawa Formations and see if any conclusions can be drawn from such elements.

- Use S measurements from this study and TOC (from Leckie (1992) to identify if the organic matter present in the Waipawa Formation is of terrestrial or marine origin.

- Determine whether there are any changes in sediment source evident within the detritally sourced elements.

- Review the literature of the Tartan and Waipawa formations and determine whether our data agrees with the current depositional models.

- Review whether other depositional models can also be reconciled to the same data.

The secondary aim of this thesis is to review the science behind trace element variations in sediments to assess whether this technique is appropriate for answering the primary goals and to help improve the science behind trace element variations.

- Review whether using the average shale standard is appropriate for understanding the trace element variations in this study.

- Review which methods of reducing the trace element data is the most appropriate for our data sets.

- Determine whether other methods of data reduction can be developed for more complex elements e.g. $\mathrm{Sr}, \mathrm{Mg}$.

- Measure a variety of elements which have not been previously measured or have been excluded from previous studies.

- Compare elemental measurements in the Tartan and Waipawa Formation to the TM concentrations previously measured in oils sourced from the 
Waipawa Formation by Frankenberger (1994).

\subsection{Thesis outline}

Chapter two summarises different environments and processes which affect trace element composition, and provides a comprehensive summary of sedimentary geochemistry on different elements.

Chapter three builds on the introduction to the Waipawa and Tartan formations presented in the introduction chapter, describing both the tectonic setting and the units surrounding the formations.

Chapter four is the methods chapter. It discusses the field work, describes the samples, the methods of preparation, the measurement of the samples, the data processing, and the measurement errors.

Chapter five presents the results of the study one field site at a time, and the results are presented in the same order as the trace metals are described in chapter two.

Chapter six discusses the results, and integrates the results into previous work. The first three sections of the discussion deal with the individual field sites, the following two deal with first the depositional environment and then the implications the results have on the science of trace metal accumulation in sediments.

Chapter seven summarises the conclusions of the study, dealing first with the different field sites, then depositional environments, trace element science, and finally future work. 


\section{Chapter 2}

\section{Variations in Trace Metals}

\subsection{Processes governing trace metal variations in organic-rich sediments}

Variations in trace metal concentration in organic-rich sediments have been studied by many authors (e.g. Brumsack; 2006 and references therein), and for some elements the reasons for enrichment or depletion are well known (e.g. Al, Ti, V, Mn, Co and $\mathrm{Mo}$ ). Some elements are often not measured due to various reasons including difficulty in measuring the elements (e.g. W).

Some processes occur in the water column, others occur below the sediment-water interface. Processes which occur below the sediment-water interface are known as diagenetic processes and can be divided into two groups: early and late stage processes. The early stage diagenetic processes occur in the upper few metres of the sediments, while late stage ones which include oil generation and expulsion occur at greater depths of burial. The effects of the processes on bulk rock concentrations occurring below the sediment-water interface are limited by the amounts of trace metals supplied or removed by moving water or fluids. As sediments are increasingly buried, the amount of water which cycles through the system is reduced, limiting the external supply and removal of trace elements, (reduced mass transfer). However enrichment and depletion processes still occur, as mudrocks often act as open systems that allow for exchange of material between adjacent sedimentary units (e.g. Bloch and Hutcheon, 1992; Abanda and Hannigan, 2006).

Variations in the concentration of oxygen in the water column and in the pore spaces during early diagenesis can directly cause the precipitation of elements (e.g. Brumsack, 2006), as oxygen is important in determining the oxidation state of many elements. Oxidation-reduction reactions (redox) are equilibrium reactions in chemistry which are highly dependent on the oxygen content of the water.

Redox reactions have two parts; an oxidation part, which is the loss of an electron 
causing an increase of the oxidation state of the element, and reduction, the gain of an electron giving a decrease in the oxidation state of an element. In marine conditions, water can act as either the oxidant under oxic conditions, or the reductant in oxygendepleted conditions. For many elements, the oxidation state of the element can govern whether the element is more stable in a solid or an aqueous phase. Elements which are enriched in sediments deposited under oxygen-depleted conditions include $\mathrm{V}$ and $\mathrm{Cr}$, while elements such as $\mathrm{Mn}$ and Co are depleted from the sediments under these conditions.

The process of redox enrichment and depletion becomes more complicated when elements are readily included in a mineral which is precipitating due to change in redox conditions but is formed largely from other elements. While many minerals can precipitate under anoxic conditions, those with the greatest effects on other trace metals are sulphides, generally present in the form of sedimentary pyrite. This process occurs only in anoxic conditions, due to the requirement for dissolved $\mathrm{H}_{2} \mathrm{~S}$ to be present in the water column. Under anoxic conditions $\mathrm{H}_{2} \mathrm{~S}$, together with $\mathrm{Fe}$, is precipitated as various forms of sedimentary pyrite. The concentration of sulphur in sediments which are deposited under anoxic conditions is often several orders of magnitude higher than the concentration of many other redox-sensitive trace elements and higher than its concentration in oxic sediments (e.g. Leventhal 1983; 1993; Brumsack, 2006). The processes involved in the precipitation of pyrite often involve traces of other elements and for of the latter elements this may be the dominant enrichment process (Brumsack, 2006).

Many elements are enriched in living organisms; for example, $\mathrm{Cd}$ is involved in plankton growth (Calvert and Pedersen, 1993). Elements which are included in organisms, though, are not always represented to the same extent in the rock. Although enrichments can occur through the burial of dead organic matter, the amount and degree of degradation of the organic matter is important to the direct biological enrichment process. Elements which are included into the tests of the organisms are generally more likely to be preserved (Brumsack 2006). Other forms of biological enrichments occur where the biological processes change an element from an aqueous phase into a solid phase. Under sulphur-rich conditions anaerobic bacteria which respirate $\mathrm{H}_{2} \mathrm{~S}$ often produce metal sulphides such as pyrite (e.g. Vernadsky et al., 1998; Brüchert et al., 
2003).

Late stage diagenetic processes such as mechanical compaction which expel pore water, alteration and dissolution of minerals, precipitation of clays with material sourced from adjacent units, and hydrocarbon expulsion affect the overall composition of the rocks and/or pore fluids, and hence may have a significant affect on the concentration of trace elements. The effects of these are currently not well understood and there have been few studies to quantify the variations due to such diagenetic effects. Sufficient trace elements are preserved in sediments which have undergone late stage diagenesis that the enrichments can be measured (e.g. Abanda and Hannigan, 2006; Ross and Bustin, 2009), but before any studies beyond qualitative trace element work can be undertaken on ancient sediments, these processes need to be better understood and the effects quantified. Abanda and Hannigan (2006) suggested that in particular oil generation may have an effect on black shale composition as large amounts of elements (e.g. S, P, $\mathrm{Tl}, \mathrm{Cd}$, and $\mathrm{Cu}$ ), are associated at least partially with the organic fraction of the rocks.

For most elements, understanding of the main enrichment processes is still at an early stage. Whether and/or how different processes interact with one another and with parameters such as salinity, sedimentation rate, and temperature is uncertain. This makes quantitative studies even of recent sediments difficult. For ancient sediments, additional factors such as unknown concentrations of elements in sea water at the time of deposition and the uncertainty of the processes controlling late stage diagenesis have made the interpretation of trace element enrichments in ancient sediments more qualitative than quantitative.

\subsection{Different oxygen depleted environments and the representative enrichment processes}

There are several different types of oxygen-depleted environments present in nature and preserved in the geological record. The combinations of physical, biological and chemical conditions and processes in these environments can cause variations in 
trace metal abundance. While some anoxic environments persist for geological periods, others occur only briefly. The latter include environments which are seasonally anoxic, such as upwellings caused by changes in prevalent winds causing oxygen depletion and stratification of the water column during part of the year (e.g. Tyson and Pearson, 1991).

The oxidation of sediments which were deposited under oxygen-depleted conditions can reverse many of the processes which caused the elemental enrichments. Such oxidation can occur in seasonally anoxic regions or during sediment resuspension. Morse (1994) showed that anoxic sediments when exposed to oxic conditions for even a day can lose from $20 \%$ to over $90 \%$ of pyrite-bound metals. Other enrichments, as well as the release of pyrite-bound elements, can also be reversed by exposure to oxic conditions.

Different oxygen-depleting environments occur in different geographic locations. Although not all environments can be differentiated by trace metal variations, several major ones can (Brumsack, 2006). Some of the major oxygen-depleting environments are:

\section{Closed oxygen-depleted systems}

Closed, oxygen-depleted systems (figure 2.1.1) are generally lakes which have water flowing into the lake but none leaving. Water is only removed through evaporation. Trace metals are not evaporated into the atmosphere and hence any that are introduced either by inflowing water or leached from sediments will be included into the sediments, within either the oxic or anoxic parts of the lake.

The classic example of an anoxic lake with no outflow is the Dead Sea. This is situated at $410 \mathrm{~m}$ below sea level in the Dead Sea rift valley. The sediments in the Dead Sea were studied by Herut et al. (1997) in respect to trace metal variations. Lateral trace metal variations were detected and related to detrital input. Brumsack (2006) included the Black Sea in an attempt at differentiating different oxygen-depleted environments, using enrichment factors calculated with respect to average shale as defined by Wedepohl (1971). The use of this technique will be discussed in section 4.4.

In closed oxygen-depleted systems, $\mathrm{H}_{2} \mathrm{~S}$ is often present making the closed systems "anoxic" under the Tyson and Pearson (1991) classification system (e.g. 


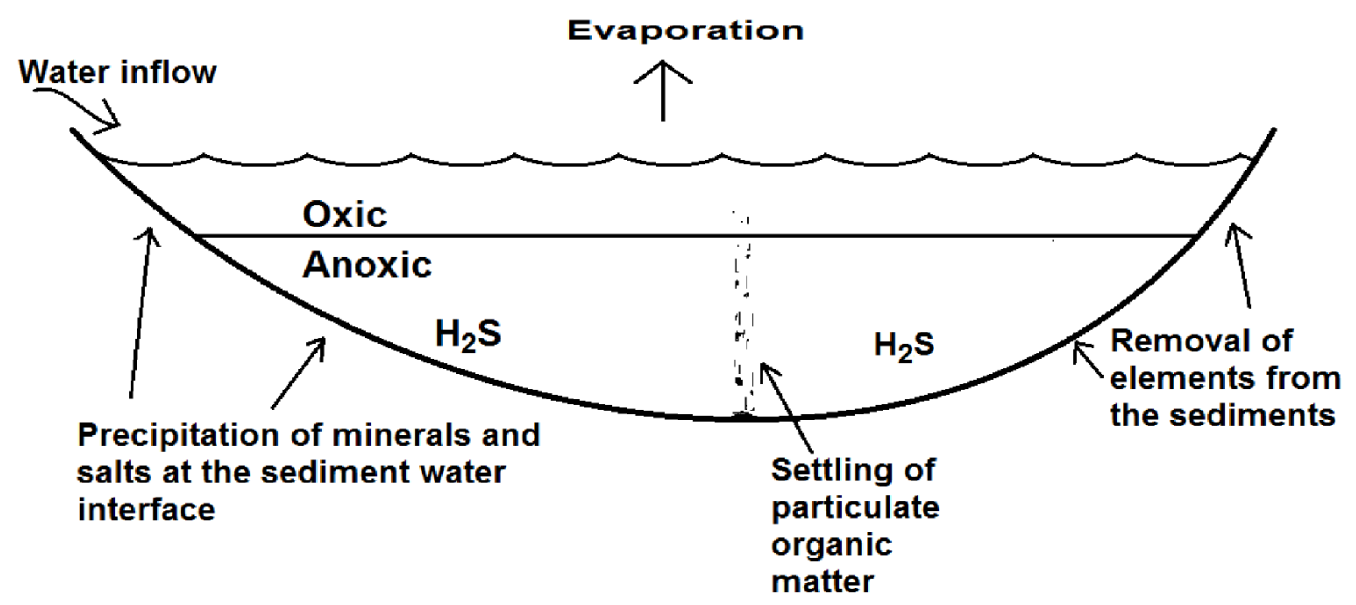

Figure 2.1.1: Diagram of closed anoxic lakes where water flows into the basin but not out. At depth the oxygen is depleted. See text for explanation of the different processes. Figure based on Demaison and Moore (1980) and Brumsack (2006).

Brumsack, 2006). When there is insufficient $\mathrm{Fe}$ in the system pyrite precipitation may not occur or be limited, hence much of the trace metal enrichment which involves the precipitation of pyrite may also be limited below the oxic-anoxic boundary.

\section{Silled anoxic basins}

Silled anoxic basins (figure 2.1.2) differ mainly from closed anoxic basins in that water and trace metals can be cycled through the system as it is not completely isolated.

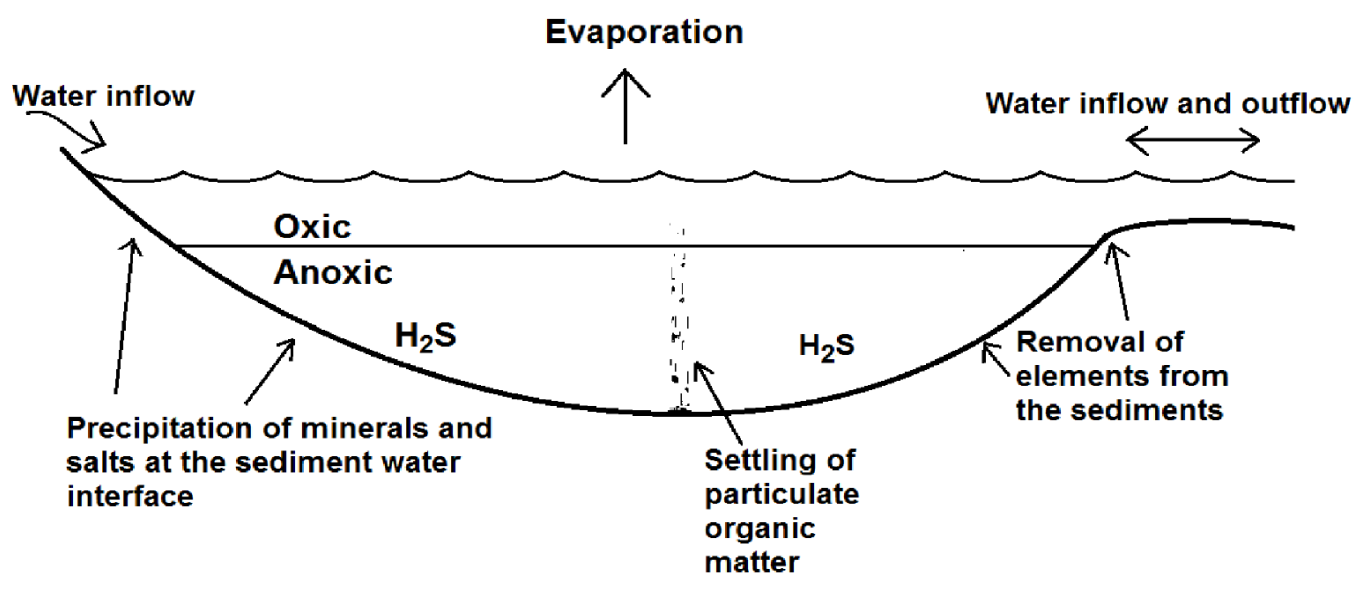

Figure 2.1.2: Diagram of a silled anoxic basin where water flows both in and out of the basin but a physical barrier prevents mixing of the entire water column, and a positive net water balance generates a salinity contrast preventing vertical mixing. See text for explanation of the different processes. Figure based on Demaison and Moore (1980) and Brumsack (2006). 
This ability to cycle water through the system allows trace metals which are more stable in solution under reduced conditions to be removed from the sediments into the water, while those which are more stable in a solid state are enriched to a greater degree than in a closed system.

The redox states of elements along with their residence times in both anoxic and oxic waters are important in silled anoxic basins. The enrichments in the silled anoxic basins are dependent on the net inflow of water, the net outflow, the cycling of water within the basin, the sedimentation rate, and the trace metal concentration in the water.

\section{Marine upwelling}

Another source of oxygen depletion is from upwelling deep sea waters. Upwelling is generally driven either by ocean currents or wind, causing deep nutrient-rich, oxygenpoor bottom waters to rise along the continental slope. While life exists at all levels of the oceans, the main primary productivity occurs in the photosynthetic zone (e.g. Tyson and Pearson, 1991). The nutrient-rich water stimulates life in the photosynthetic zone, recycling dead organic-matter and creating a high demand for oxygen, thus depleting the oxygen and causing the formation of an oxygen-minimum layer (Figure 2.1.3; Demaison and Moore, 1980). At the surface oxygen is again mixed into the water from the atmosphere.

The oxygen-minimum layer must be at sufficient depth that oxygen is not mixed in by wave action, and stratification through changes either in salinity or temperature of the water column is often necessary. The thickness of the oxygen minimum layer can vary greatly, and in some situations can be only the bottom few centimetres of the water-column (Tyson and Pearson, 1991).

For trace metal variations there are two main denominations of upwellings as summarised by Brumsack, (2006) and depicted in figure 2.1.3. A narrow shelf will generally have dysoxic conditions at the sediment-water interface as the water cycles through too quickly for anoxic conditions to build up. There is, however, a vast quantity of water which cycles through and a large amount of primary productivity in upwelling situations, providing both abundant trace metals to be reduced into the sediments and a 


\section{A) Upwelling on a narrow shelf}

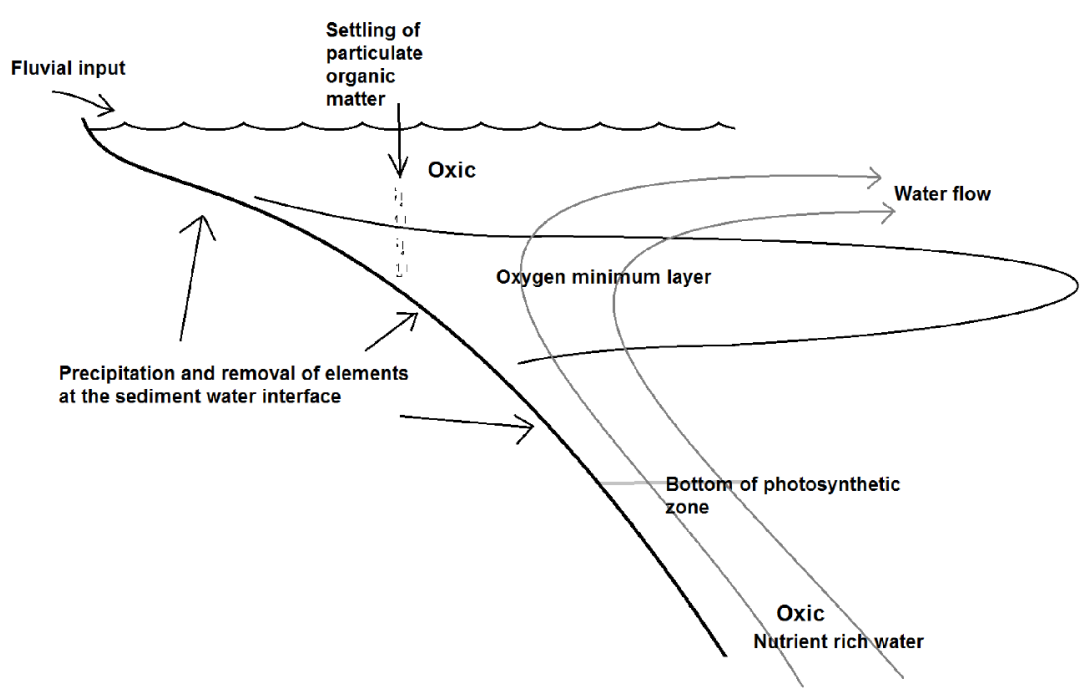

\section{B) Upwelling on an extended shelf}

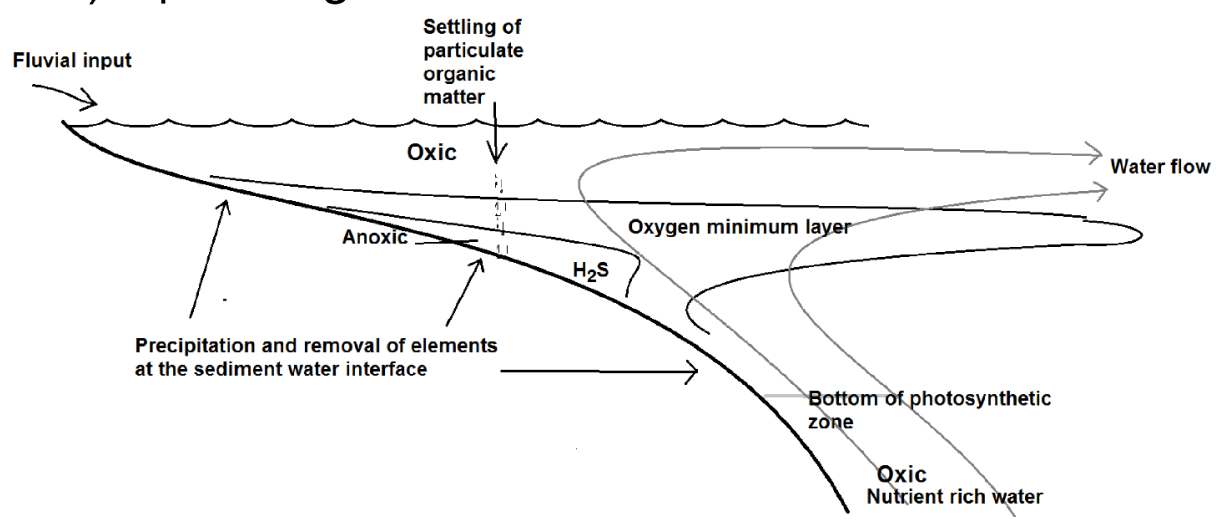

Figure 2.1.3: Diagram of upwelling producing an oxygen-minimum layer on a) a narrow shelf, and b) an extended shelf. Extended shelves can have anoxic conditions while a narrow shelf generally has dysoxic or suboxic conditions. Figure based on Demaison and Moore (1980) and Brumsack (2006).

large influx of organic-matter. On an extended shelf the main difference is that anoxic conditions can occur just above the sediment-water interface and thus pyrite can often be precipitated.

The overall variation in trace elements between different types of upwelling environments is dependent on whether or not $\mathrm{H}_{2} \mathrm{~S}$ is present, the amount of water cycled though, the rate of deposition, the trace metals present in the water column, and the amount and type of productivity above and within the oxygen-depleted layer as well as in the top few cm of sediments. 
Dysoxic and suboxic conditions above the sediment-water interface are indicators that the environment is likely to be that of an upwelling, while anoxic conditions may be present in both basins or upwellings or on extended shelves. Trace element concentrations alone cannot always be used to differentiate between these environments, especially when applied to ancient environments where some elements may be an order of magnitude more or less abundant than that observed in modern environments. This was found to be the case by Brumsack (2006) when applied to Cretaceous black shales, where $\mathrm{Zn}$ and $\mathrm{Ag}$ were found to be an order of magnitude more abundant than in modern environments.

\subsection{Major and Trace element variations in sediments}

The large number of elements examined in the present study have been grouped where possible, by their behaviour in marine conditions, and results are presented in the same order for each of the field sites in both the results and discussion sections, a tabulated summary of trace metal variations is provided in Appendix D. Many elements are affected differently by multiple processes and hence could not always be grouped together.

Many elements in silicate sediments are affected by changes in provenance where different mineral assemblages of the detrital elements have differing concentrations of elements. Variations in other elements such as sulphur are related to organic matter and oceanographic conditions the details of these processes are covered later in this chapter. The bulk composition of marine shales is often characterised by three end members: silica in detrital quartz, aluminium in the clay fraction and calcite in the carbonate content. As these elements are normally measured using XRF, the oxides measured are: $\mathrm{SiO}_{2}, \mathrm{Al}_{2} \mathrm{O}_{3}$ and $\mathrm{CaO}$. Ternary diagrams of these oxides are often produced to show major differences in depositional environments (e.g. Brumsack, 1989). Major changes in depositional and paleoceanographic conditions, especially with respect to sediment source, sorting, rate of deposition and biological input are all likely to have some affect on these three end members and may hence aid in differentiating sediments. 
However, treating sediments as consisting of these three end members alone is a simplification. $\mathrm{SiO}_{2}$ is included in some biological tests (e.g. diatoms, radiolarians, some foraminifera) and in many clay minerals, and $\mathrm{CaO}$ is also included in detrital clays. The overlap of several processes affecting these elements in different sediments are often negligible unless dealing with extreme environments where one or more of these processes is absent or very minor.

\section{Mainly terrestrially-sourced elements}

Aluminium is a structural component of many silicate minerals (e.g. Dean et al., 1997), and generally makes up several weight percent of marine shales. The concentration of $\mathrm{Al}$ in seawater is generally very low (Orians and Bruland, 1986; Brown et al., 1989); however, abundance can vary considerably. For example, while the Pacific Ocean contains between 2.7 and $135 \mathrm{ppt}$ (parts per trillion) of Al, the Mediterranean has values two orders of magnitude higher (Orians and Bruland, 1986). Compared to the concentration in shales (average shale as defined by Wedepohl (1971) contains 16.7\% $\mathrm{Al}_{2} \mathrm{O}_{3}$ ), concentrations in the ocean are very small. Due to the large amount of $\mathrm{Al}$ in detrital clays and the relatively insignificant amounts introduced into shales from other sources, Al is generally used to correct trace element concentrations in shales for their detrial input (e.g. van der Weijden, 2002). At Palmyra Atoll, an isolated carbonate environment where terrestrial clays are insignificant, sediments contain around 4-5 orders of magnitude less $\mathrm{Al}$ in both anoxic and oxic sediments than average shale (Collen J.D. pers. com. 2010), supporting the observation that Al variations are mainly controlled by terrestrial clay content.

Titanium is mainly introduced through detrital minerals. However, the Al/Ti ratio can also be used as an indicator of increased energy within the depositional environment as $\mathrm{Ti}$ is enriched in heavy mineral phases such as rutile, requiring more energy to move relative to other minerals of similar size but lower mass (Dellwig et al., 2000).

Potassium varies little in anoxic sediments; however, variations of $\mathrm{K} / \mathrm{Al}$ or $\mathrm{K} / \mathrm{Si}$ are used as indicators of changes in provenance or sediment sorting, or with $\mathrm{K} / \mathrm{Si}$ can indicate a dilution by biological Si (Wehausen and Brumsack, 2002; Brumsack, 2006). Illite content has been shown to have a major control on the amount of $\mathrm{K}$ in sediments (Yarincik et al., 2000; Ross and Bustin, 2008, 2009), and changes in detrital elements 
such as K-feldspar would have a similar affect. $\mathrm{K}$ also exists in some forms of glauconite, which may be relevant for this study.

Rubidium does not vary significantly in sediments due to oceanographic conditions as it is related to $\mathrm{K}$ in the lithosphere (Plank and Langmuir, 1998) and also generally behaves like other terrestrially sourced elements e.g. Zr, Hf and $\mathrm{Nb}$. Although $\mathrm{Rb}$ is often measured, mechanisms for its enrichment in sediments have not been suggested and it is generally considered an element which can be used as a proxy for detrital input. Ross and Bustin (2009) showed little variation of $\mathrm{Rb}$ in a DevonianMississippian shale sequence in western Canada, with an enrichment factor of close to one.

Thorium is introduced to sediments mainly through detrital components but is often enriched in the presence of Fe-Mn oxyhydroxides, Th is also absorbed into suspended particulate matter, which is at equilibrium with the surrounding water column (Plank and Langmuir, 1998; Bacon and Anderson, 1982). However, Th in the water column is 6 orders of magnitude less abundant than in average shale (Brown et al., 1989; Wedepohl, 1971); hence Th generally behaves as a detrital element and any variation which occurs due to other processes is generally smaller than measurement errors.

Hafnium, $\mathrm{Nb}, \mathrm{Zr}$ and $\mathrm{Ta}$ are elements which have rarely been measured in sedimentary rocks, and no enrichments have been noted. They are also elements which are immobile and not affected by diagenetic, redox or weathering processes (e.g. Ross and Bustin, 2009). The natural sea water concentration of these elements (Brown et al., 1989) varies between 2 (Ta) and $30(\mathrm{Zr})$ ppt, while average shale varies between 2 (Ta) and 160 (Zr) ppm (Wedepohl 1971). Hence, oceanic conditions are largely insignificant in controlling their abundances in sediments with a large detrital fraction.

Gallium is generally considered to behave similarly to other detrital elements, and Staubwasser and Sirocko (2001) used it as an indicator of detrital input. Few studies have included Ga, although that of Ross and Bustin (2009) on a Canadian DevonianMississippian shale sequence showed very little variation in Ga from its abundance in average shale. 


\section{Indicators of anoxia (major components of sedimentary pyrite)}

Iron is present in several forms; it makes up a structural component of many grains, and is also common as an Fe oxide/hydroxide coating on grains. In upwelling environments $\mathrm{Fe}$ can be depleted as it is stable in water in its reduced form. In the presence of $\mathrm{H}_{2} \mathrm{~S}, \mathrm{Fe}$ combines with $\mathrm{S}$ to form pyrite. The amount of $\mathrm{H}_{2} \mathrm{~S}$ which is precipitated into pyrite in anoxic conditions is mainly dependent on the amount of $\mathrm{Fe}$ in the water column (Canfield et al., 1992; Brumsack, 2006).

Sulphur is generally enriched in organic matter-rich sediments (e.g. Brumsack, 2006). Sulphur is enriched in two ways, the first being a directly included into marine organic matter, and the second being the precipitation of pyrite under anoxic conditions (e.g. Leventhal, 1983; Raiswell and Berner, 1985). Pyrite precipitation generally occurs through heterotrophic bacteria (bacteria that respirate sulphur) reducing sulphur from sulphate into metallic sulphide and hydrogen sulphides (e.g. Vernadsky et al., 1998; Brüchert et al., 2003). In the presence of $\mathrm{Fe}$ in the water-column the sulphates are precipitated into pyrites; however, when Fe is not present or only present in insufficient amounts, out-gassing of $\mathrm{H}_{2} \mathrm{~S}$ can occur from the sediments (Chapman and Shannon, 1985; Weeks et al., 2004).

Many elements are included into pyrite precipitates; however, there are several different types of sedimentary pyrites, and it has been suggested that some can form in dysoxic conditions and will hence contain different trace metal concentrations (Tribovillard et al., 2008). Many elements which are included in sedimentary pyrite as traces are also affected by other processes. Associated with biological conditions are S, $\mathrm{Tl}, \mathrm{Cu}, \mathrm{Cd}$ and $\mathrm{Ni}$, depleted under oxygen-depleted conditions are $\mathrm{Mn}, \mathrm{Co}$ and $\mathrm{Bi}$, and complicated by anthropogenic input are $\mathrm{Pb}$ and $\mathrm{Bi}$. These elements have been grouped into different subsections in this chapter to discuss these other processes along with the inclusion into pyrite.

\section{Indicators of anoxia (included in sedimentary pyrite)}

Zinc is enriched in oxygen-depleted environments. Calvert and Pedersen (1993) suggested that it is mainly enriched as part of sulphide precipitation.

Molybdenum is a highly studied trace metal in anoxic sediments. It is found to be 
strongly enriched, and usually included in sulphides (e.g. Elbaz-Poulichet et al., 2005). Mo is enriched in both upwellings (e.g. Böning et al., 2004) and anoxic basins (ElbazPoulichet et al., 2005). $\mathrm{MoO}_{4}{ }^{2-}$ is diffused into sediments forming $\mathrm{MoS}_{4}{ }^{-}$(Erickson and Helz, 2000) and then later forms Mo-Fe-S cuboidal clusters on pyrite, from which it is reduced to Mo(VI) to stabilise the structure (Vorlicek et al., 2004). Crusius et al. (1996) found that enrichment of Mo begins at $\sim 1 \mathrm{~cm}$ below the sediment water interface in anoxic environments, and at $>10 \mathrm{~cm}$ in sub-oxic to oxic environments.

\section{Indicators of anoxia (included in sedimentary pyrite); anthropogenic in recent sediments}

Lead is generally related to sulphur in anoxic sediments (Heinrich et al., 1980) and has a short residence time in the ocean (less than a century) (e.g. Schaule and Patterson, 1981). The residence time is likely to be due to lead being rapidly scavenged by biogenic particles (Brumsack, 1989; Böning et al., 2004). In modern sediments any enrichment due to anoxia is comparably less than the enrichments due to anthropogenic input (Böning et al., 2004).

The concentration of $\mathrm{Bi}$ in upwelling zones is more closely related to sulphur abundance than organic carbon (Heinrich et al., 1980; Bertine et al., 1996), but the exact removal pathways are not yet fully understood (Brumsack, 2006). Understanding of the enrichment of $\mathrm{Bi}$ in recent sediments is hindered by enhanced anthropogenic input from mining (Böning et al., 2004, 2009). Bi is also enriched in ferromanganese phases in marine conditions, and hence is often reduced into an aqueous phase in other oxygen-depleted conditions (Bertine et al., 1996).

\section{Biological component or involved in biocycling}

Barium has been considered a potential proxy for bio-productivity (Schmitz, 1987; Dymond et al., 1992; Prakash Babu et al., 2002). However, it undergoes complex reactions and may be related to water depth (e.g. von Breymann et al., 1992). Ross and Bustin (2009) found little variation in the enrichment factor of $\mathrm{Ba}$ in DevonianMississippian shales in the Western Canadian Sedimentary Basin, suggesting that in their study $\mathrm{Ba}$ it was largely of detrital origin. The Ba content from different terrigenous 
backgrounds is known to vary, and local corrections for detrital Ba were suggested by Klump et al. (2000) in order to avoid using a $\mathrm{Ba} / \mathrm{Al}$ ratio which doesn't reflect local sediments. $\mathrm{Ba}$ is found to be stable only when there is sulphur in the water column (Church and Wolgemuth, 1972). In environments where the sulphur has been reduced into solid form by heterotrophic organisms (pyrite precipitation), $\mathrm{Ba}$ is mobile and hence not included in sediments (Brumsack, 2006; Brumsack and Gieskes, 1983; McManus et al., 1998). There has thus been caution in the use of $\mathrm{Ba}$ as an indicator of either bio-productivity or water depth for sediments which were deposited under anoxic conditions.

Calcium is generally present in marine shales, mostly carbonate shells. Ca from other sources is normally minor in comparison (e.g. Brumsack, 2006). Dissolution of Ca in the water column can occur, although the rates of dissolution are slow (e.g. Peterson, 1966). Calcite dissolution can also occur in the upper sediments. Dissolution is generally more extensive in more highly bioturbidated areas where alkalinity buildup from sulphate reduction has not occurred (e.g. Aller, 1982).

Phosphorus is enriched in organic-matter rich and anoxic sediments. P is a micronutrient, and hence it is more effectively enriched with enhanced organic-matter burial. Redox-dependent cycling in anoxic conditions may aid the release of $\mathrm{P}$, with the reduction of iron oxide phases at the sediment water interface providing a feed-back loop which enhances productivity and hence the degree of anoxia (Ingall and Jahnke, 1996).

Magnesium is related to the kaolinite and dolomite content in many ancient North American black shales (Ross and Bustin, 2008, 2009) and is hence often related to detrital content; trace $\mathrm{Mg}$ is also incorporated in $\mathrm{CaCO}_{3}$ (e.g. Vine and Tourtelot, 1970; Brumsack, 1989, 2006) with a temperature-dependent relationship.

Strontium is incorporated in $\mathrm{CaCO}_{3}$ as it is significantly enriched through the biological precipitation of carbonate tests, which is a temperature-dependent process (Plank and Langmair, 1998).

Silicon is included as a structural component of clastic grains, a major constituent of plankton skeletons (Brumsack, 2006).

Germanium behaves very similarly to $\mathrm{Si}$ in marine conditions, and is taken up by 
siliceous organisms (Froelich and Andreae, 1981). Reducing conditions with which contain $\mathrm{Fe}^{2+}$ in the water column are also considered a potential sink for Ge (Hammond et al., 2000). Very few studies have included Ge in organic-rich sediments.

\section{Biological component or involved in biocycling; indicators of anoxia (included in sedimentary pyrite)}

Sulphur can be biologically sourced (e.g. Leventhal, 1983), it is also major component of sedimentary pyrite and was hence included in that section.

Thallium is a rarely studied trace element in sediments which is not included in many of the older studies. Heinrich et al. (1980) showed that Tl was more closely related to sulphur than to organic carbon. Thallium may also be involved in biocycling as suggested by Böning et al. (2004) with respect to the Peruvian upwelling, but more work is required to confirm this.

Cadmium is enriched in several ways under anoxic conditions. The most important is the inclusion of $\mathrm{Cd}$ into sulphides (e.g. Heinrichs et al., 1980; Kreming, 1983). Heinrichs et al. (1980) showed that Cd was more closely related to sulphur than to organic matter in black shales. It also can accumulate in phosphates (Nathan et al., 1997) which explains some of the differences which are seen in $\mathrm{Cd}$ enrichments relative to other trace elements that are included in sulphates (Turgeon and Brumsack, 2006). Cadmium is also involved in biocycling, and is often associated with plankton growth (Calvert and Pedersen, 1993).

Copper is a micronutrient (e.g. Calvert and Pederson, 1993) and through organic matter is generally enriched in many anoxic environments. Off the coast of Peru biocycling above the oxygen minimum zone is suggested to be the main reason for its enrichment (Böning et al., 2004). Cu can also be included into sulphides (e.g. Morse, 1994). Another factor which can complicate its enrichment is an increase in the concentration of $\mathrm{Cu}$ in sea water with depth due to biological scavenging near the surface (Calvert and Pederson, 1993).

Nickel is considered a micronutrient in the oceans and is important to plankton growth. In anoxic conditions it is also incorporated into sulphides, but requires a solid surface to precipitate onto (Calvert and Pederson, 1993). Ni can also be correlated to 
oxyhydroxides in the water column, which are dissolved in oxygen-depleted pore waters (Calvert and Pederson, 1993).

\section{Depleted under suboxic/dysoxic conditions; indicators of anoxia (included in sedimentary pyrite)}

Bismuth is often also reduced under oxygen depleted conditions Bertine et al. (1996), however is presented in the anthropogenic section.

Manganese is generally depleted in oxygen minimum zones (e.g. Huerta-Diaz and Morse, 1992; Böning et al., 2004; Brumsack, 2006). Mn gets dissolved from the sediments and transported along the oxygen minima layers to more oxygen-rich waters. The processes involved in Mn enrichment or depletion are complex. Enrichment of Mn in sediments usually correlates positively with $\mathrm{Fe}$ and $\mathrm{Co}$ (Roy, 1992). $\mathrm{Mn}^{2+}$ is the reduced form of manganese and is generally soluble in sea water, but easily oxidised to $\mathrm{Mn}^{4+}$ (Huerta-Diaz and Morse, 1992). The latter is more stable as a solid state and often forms manganese nodules. $\mathrm{MnO}_{2}$ is the most common form of solid $\mathrm{Mn}$ in nature, but is not stable in reducing conditions. Thus, Mn depletion is generally observed in upwelling environments. Bacteria utilising solid state sulphate can oxidise Mn into a solid state. With the lack of oxygen in reducing conditions, $\mathrm{Mn}^{4+}$ formed by bacteria is precipitated into calcites or sulphates, with only $\sim 20 \%$ remaining in the water (Aller and Rude, 1988).

Cobalt is included into sulphides, and can thus be enriched in sulphur-rich anoxic conditions (Kreming, 1983). In sulphur-poor anoxic conditions Co behaves similarly to $\mathrm{Mn}$ and $\mathrm{Bi}$, and in upwellings is generally depleted (Böning et al., 2004).

\section{Enriched under reducing conditions}

Arsenic is generally enriched in organic-rich sediments (Brumsack, 2006). Off the coast of Peru it has been suggested As may be enriched through diffusion, and the limited enrichment there was mainly due to sea water availability rather than the saturation of As in the sediments. However, it may also be related to pyrite as it varies similar to Mo (Böning et al., 2004). Huerta-Diaz and Morse (1992) also found that very little As is in the pore fluids in anoxic conditions but that most of it is deposited with pyrite precipitation. Morse (1994) showed that the oxidation of sedimentary pyrite will 
release most of the As in a very short period of time. This type of oxidation occurs naturally during sediment re-suspension or in seasonally anoxic regions. In outcrop, As is considered relatively stable during the weathering of black shales as it has a solid state when oxidised, with leaching tests showing less than $1 \%$ loss upon oxidation (Lavergren et al., 2009).

Chromium is enriched almost purely because of redox sensitivity. It exists in two main forms in the oxic ocean, as $\mathrm{CrO}_{4}{ }^{2-}$ and, to a lesser extent, $\mathrm{Cr}(\mathrm{OH})_{2}{ }^{+}\left(\mathrm{H}_{2} \mathrm{O}\right)_{4}$. However, under reducing conditions, it generally forms $\mathrm{Cr}\left(\mathrm{H}_{2} \mathrm{O}\right)_{4}(\mathrm{OH})_{2}^{+}$(Elderfield, 1970), and is quickly moved into the sediments (Calvert and Pederson, 1993). For Cr to be effectively scavenged into sediments, the pore waters must be completely anoxic (Morse and Luther, 1999).

Vanadium is always enriched in oxygen depleted marine settings. $\mathrm{V}$ has three soluble oxidation states which occur naturally, $\mathrm{HVO}_{4}{ }^{2-} \mathrm{H}_{2} \mathrm{VO}_{4}^{-}$and $\mathrm{VO}(\mathrm{OH})_{3}^{-}$(e.g. Turner et al., 1981). When reduced, however, $\mathrm{V}$ is precipitated as $\mathrm{V}_{2} \mathrm{O}_{3}$ or $\mathrm{V}(\mathrm{OH})_{3}$ (Wanty and Goldhaber, 1992). V has a strong relationship with organic matter yet its concentration is chiefly governed by redox sensitivity (e.g. Shaw et al., 1990). A main limiting factor is often sea water availability, as has been suggested for the Peruvian upwelling (Böning et al., 2004).

Uranium is enriched in reducing sediments in several ways. Uranium enrichments in black shales were noticed very early (e.g. McKelvey and Nelson, 1950), and thus U is one of the better studied elements in anoxic conditions, and has been noted to diffuse directly into the sediments (e.g. Shaw et al., 1990), and to precipitate uranium salts (Disnar and Sureau, 1990). Phosphates contain the best link to U enrichments in most marine sediments, with phosphate-rich black shales considered generally the most enriched (e.g. McKelvey and Nelson, 1950). In anoxic conditions the limiting factor on $\mathrm{U}$ enrichment is generally its availability in sea water.

\section{Enriched under reducing conditions, rarely studied}

Selenium is often enriched in upwelling zones, yet the reason for enrichment is not clear. Se is involved in biocycling (Cutter, 1989) but is also enriched at the bottom of the ocean in the form of $\mathrm{Se}^{6+}$, and thus upwelling intensity may be important in the $\mathrm{Se}$ 
supply in upwelling zones (Crusius and Thompson, 2003). Solid Se is normally related to $\mathrm{Ag}$; in sub-oxic conditions biological influences can produce $\mathrm{AgSe}$ or $\mathrm{Ag}_{2} \mathrm{Se}$ (Crusius and Thompson, 2003).

Antimony is a poorly understood trace element in respect to its behaviour in anoxic conditions (e.g. Filella et al., 2002). Takayanagi and Cossa (1997) suggested that $\mathrm{Sb}$ may be included into manganese and iron oxide particles or sulphides. $\mathrm{Sb}$ is generally enriched in oxygen-depleted environments (e.g. Böning et al., 2004), but the exact process causing the enrichment is unknown.

\section{Rarely studied in sediments}

Tin and $\mathrm{W}$ are very rarely studied metals in oxygen-depleted conditions, having been omitted from most trace element studies on sediments.

Sodium is not considered very well suited to trace element studies in sediments as it would require a salt correction (Brumsack, 2006).

Lithium is a highly reactive element when in solid form. The mechanisms for variation are not well understood, although hydrothermal fluids are thought to be a major cause of Li enrichments (e.g. Chan and Kastner, 2000). It may hence be affected by late stage diagenesis, especially with regards to illite and smectite (e.g. Howard, 1981). Variation in $\mathrm{Li}$ is likely to occur in fluid-sediment processes, as clay ion exchange with ammonium and volcanic ash alteration are known to change the isotopic composition of $\mathrm{Li}$ in the pore waters (Chan and Kastner, 2000).

\section{Rare earth elements (REE)}

Yttrium is occasionally measured in trace metal studies on anoxic sediments (e.g. Ross and Bustin, 2009), but it rarely shows much variation. Y generally behaves in a similar way to the REE (e.g. Haskin and Gehl, 1962), and many techniques have difficulty separating these elements. For this reason $\mathrm{Y}$ is presented with the other REE in this study.

The lanthanides, La, Ce, Pr, Nd, Sm, Eu, Gd, Tb, Dy, Ho, Er, Tm, Yb and Lu are relatively unique in that their abundances are usually addressed relative to one another, 
not in relation to $\mathrm{Al}$. With the exception of $\mathrm{Ce}$, the lanthanides are all trivalent and are fractionated from the neighbouring lanthanides by various chemical processes. The fractionation is caused by having similar chemical properties but with decreasing atomic radii with increasing atomic number (e.g. Bryne and Kim, 1993). The measurement of these elements in sediments is not new, and has been done by many authors; it is normally compared to shale or chondrite standards.

Caesium has been found to behave similar to Mn in sea water (e.g. de Baar et al., 1988; German and Elderfield, 1989; Sholkovitz et al., 1992). Ce is generally depleted from the sediments in anoxic conditions due to redox forcing, and is often found enriched in ferromanganese nodules. Redox depletion starts under suboxic conditions well above the $\mathrm{O}_{2} / \mathrm{H}_{2} \mathrm{~S}$ interface in the Saanich Inlet, British Columbia (German and Elderfield, 1989).

Europium may also be reduced under strong anoxic conditions; however it is generally more stable in its reduced form and hence would be expected to be enriched in anoxic conditions. Eu is, however, difficult to reduce and this is more likely to occur at higher temperatures, such as under hydrothermal and metamorphic conditions (Sverjensky, 1984).

In sea water Gd behaves in the opposite way to $\mathrm{Tb}$, where it is often enriched slightly while $\mathrm{Tb}$ is depleted. This is thought to be due to different behaviours when scavenged by falling particles in the water column (de Baar et al., 1985). This may not always to be reflected in the sediments, however, as what is scavenged from the water column is not always added to the sediments (Brown et al., 1989).

The remaining lanthanides are often thought to be sourced mainly from siliciclastic detritus (Schröder and Grutzinger, 2007); however, they may also be included in the organic fraction, with the organic component having up to an order of magnitude greater lanthanide fraction than the rest of the sample (Abanda and Hannigan, 2006). 
Chapter 3

\section{Stratigraphy and regional setting}

\subsection{Regional setting}

During the Late Paleocene, the New Zealand landmass was entering a passive margin state dominated mainly by thermal subsidence. However, greater subsidence rates than those expected from thermal subsidence alone occurred in the Great South Basin and over much of the Campbell Plateau, suggested to be due to mantle convection (Sutherland et al., 2010). Whether the thermal subsidence or mantle convection related subsidence had begun by the time the Tartan and Waipawa formations were being deposited is uncertain (Schiøler et al., 2010; Beggs 2010a).

Late Cretaceous to Eocene sediments in New Zealand represent a general marine transgression as facies changed from the non calcareous sandstones and mudstones to a calcareous mudstones. In the East Coast Basin this is represented by the transition from the Whangai Formation, a late Cretaceous to Late Palaeocene formation, to the Wanstead Formation (Moore, 1988; Field et al., 1997). A similar change occurs in the Great South Basin where the Wickliffe Formation is replaced by the Laing Formation, then later by an even more distal facies, the Tucker Cove Formation, an EoceneOligocene chalk present in the most distal parts of the basin (e.g. Beggs, 1993; Cook et al., 1999; Schiøler et al., 2010).

The East Coast Basin is characterised by marine sediments through the Paleocene and Eocene, however the sediments suggests a relatively proximal shoreline. In the Great South Basin both terrestrial and marine deposits occur through this time, and a fluctuation paleoshoreline can be traced through time on seismic reflection profiles (Lipski, 2004). Figure 3.0.1 shows the evolution of the New Zealand continent through time, from 65-40 Ma. This figure shows a general marine transgression across the New Zealand landmass and indicates where the Waipawa Formation was deposited in relation to the shoreline location. 
Figure 3.0.1: Maps of New Zealand through time. These maps show the changes which the New Zealand continent went through between 65 and $40 \mathrm{Ma}$.

These maps show the Paleocene rifting, and the subsequent passive margin state.

While a shoreline has been invoked in the East Coast Basin, any terrestrial deposits have long since been eroded away.

Figure from King (2000).

TB = Taranaki Basin, ECB = East Coast Basin, $\mathbf{C B}=$ Canterbury Basin, GSB = Great South Basin, WS = Western Southland Basin, NCB $=$ New Caledonia Basin, EB = Emerald Basin, $\mathbf{C h P}=$ Challenger Plateau, $\mathbf{C P}=$ Campbell Plateau, $\mathbf{C R}=$ Chatham Rise.

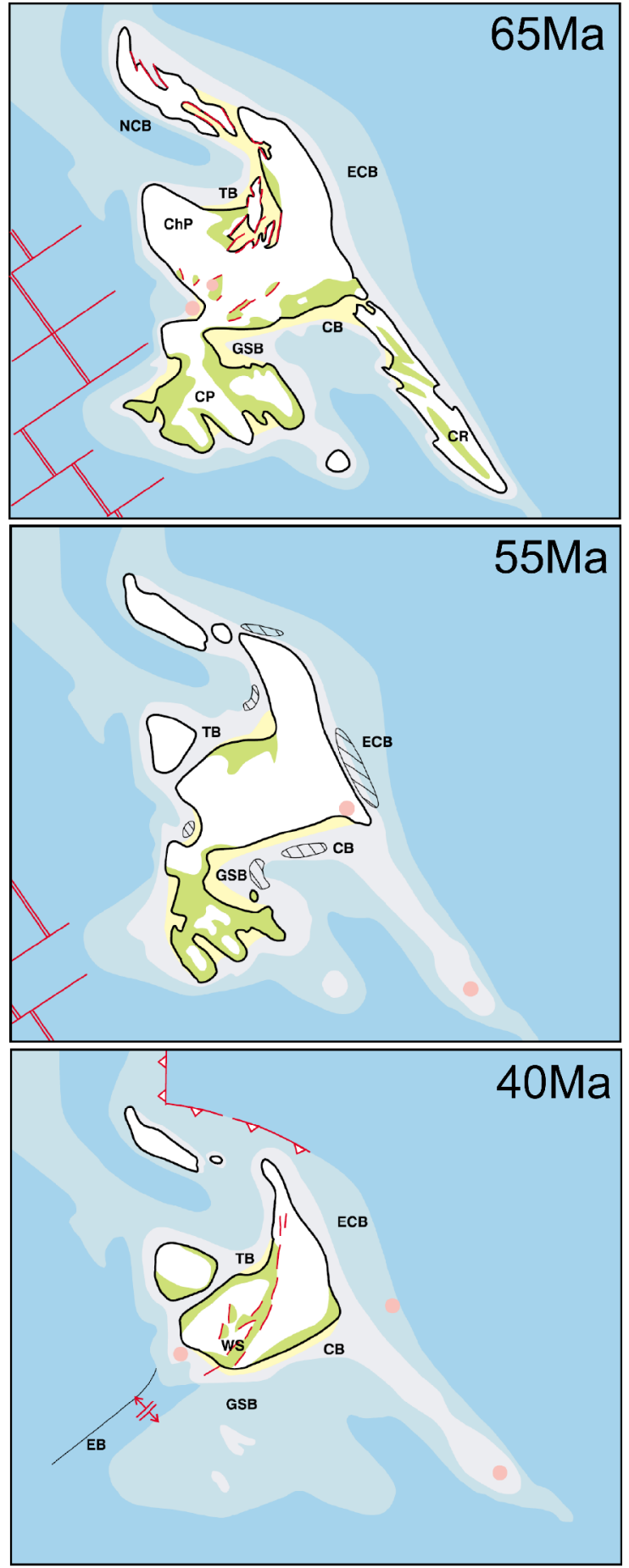

Active volcanism Active faulting Terrestrial depositional Terrestrial non-depositional Marginal marine sand-dominated facies Shelf Slope or sumarine rise Deep ocean

Waipawa or Tartan formation 


\subsection{The East Coast Basin.}

\section{Introduction}

The East Coast Basin is structurally complex due to the initiation of the Hikurangi Subduction Zone. Erosion of Paleogene sediments such that Pliocene sediments directly overlie Mesozoic basement (Beanland et al., 1998) is common in the forearc basin region to the west; the eastern section is dominated by a complex fold thrust belt, which locally exposes Paleogene sediments in the onshore section (Ballance, 1993; Lewis and Pettinga, 1993; Field et al., 1997).

\section{Stratigraphy}

A generalised stratigraphy for the East Coast Basin is provided in figure 3.1.1; most of the basin is dominated by a marine setting during the period of interest (Paleocene and Eocene).

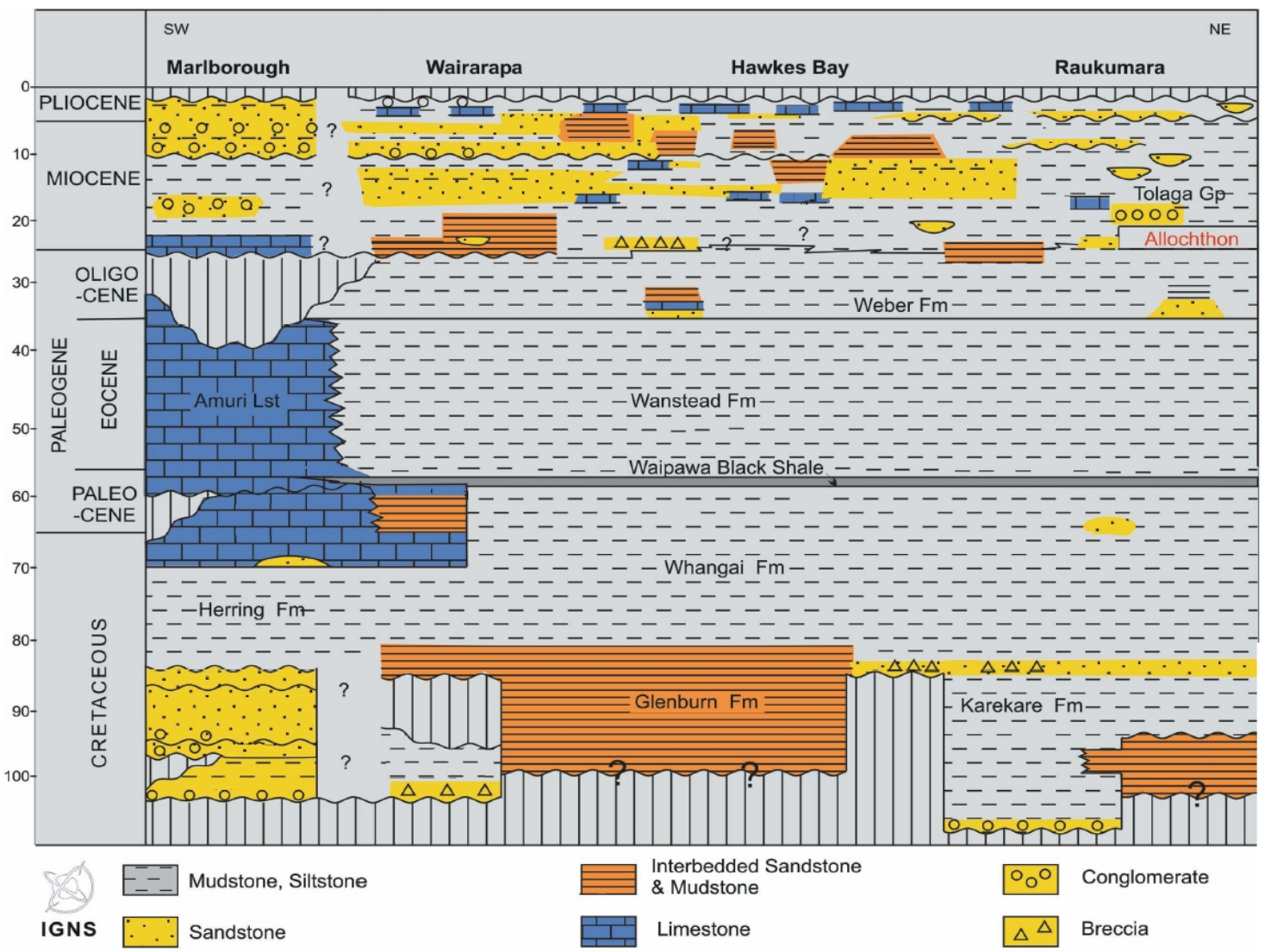

Figure 3.1.1: Generalised stratigraphy of the East Coast Basin, figure from Field et al., (2004). 


\section{Whangai Formation}

The Whangai Formation is a Late Cretaceous to Late Paleocene marine mudstone which consists of several members. Three members are regionally extensive and two only appear only locally (Moore, 1988).

The Rakauroa Member (Moore, 1988) is a hard, poorly-bedded, bioturbated, medium grey, non-calcareous, micaceous mudstone that is rusty when weathered. It contains thin glaconitic sandstone beds, scattered concretions and pyrite nodules, with rare chert and calcareous beds (Moore, 1988).

The Porangahau Member (Moore, 1988) is a hard, well bedded, light to very light grey, highly calcareous mudstone. Glauconitic sandstone beds are common, as are red, brown, and green mudstones and ripple laminated sandstones. Thin light and dark grey alternating mudstone beds within are often referred to as the zebra beds". The mudstone beds within the Porangahau Member are generally moderately to highly bioturbated.

The Upper Calcareous Member is generally a hard (Moore, 1988), poorly bedded, medium-grey micaceous mudstone. This member is slightly calcareous (1-15\%) and generally bioturbated, can contain calcareous concretions, pyrite nodules, glauconitic sandstone beds, and rare brecia. The Upper Calcareous Member is generally a light blue-grey when weathered (Moore, 1988) but a white patchy coating, possibly of gypsum, was noticed on some outcrops during fieldwork.

Kirk's Breccia Member (Moore, 1988) is only present in a few localities and only at the base of the Whangai Formation, and is not important to this study.

The Te Uri Member (Moore, 1988) is only present at some localities, and is not present in the Angora Quarry area. However, Rogers et al. (2001) showed it contains a unit that can be correlated to the Waipawa Formation. It consists of glauconitic sandstone inter-bedded with glauconitic, slightly calcareous, laminated siltstone.

\section{Waipawa Formation}

The Waipawa Formation is dark brown to black, poorly bedded mudstone to siltstone that is occasionally laminated and often glauconitic. The formation generally has a gradational lower contact with a sharp but conformable upper contact. It rarely 
exceeds 50 meters in thickness; however, it is regionally pervasive throughout the East Coast Basin and is common elsewhere around New Zealand.

Many of the geochemical (figure 1.2.1) and lithological properties of the Waipawa Formation vary greatly throughout the East Coast and further afield. The thickness varies from 2 to $60 \mathrm{~m}$ within the East Coast Basin (Hollis et al., 2005b). The colour varies from dark brown to grey black, while the general lithology varies from mudstone to siltstone or occasionally fine sandstone (Moore, 1986).

\section{Wanstead Formation}

'Wanstead Formation' is often used in the East Coast Basin as a generic term referring to fine grained smectite-rich sediments of Paleocene to Eocene age (Moore and Morgans, 1987; Field et al., 1997). The Wanstead Formation is generally poorly bedded and is greenish grey to grey in colour, but can, however, have a bluish tinge locally (Moore and Morgans, 1987). There are occasional glauconitic beds. The formation is generally considered mid-bathyal, and lower bathyal-abyssal in parts (Field et al., 1997).

\subsection{Great South Basin}

\section{Introduction}

The Great South Basin is located south of the South Island of New Zealand. It is a completely offshore basin. While the extent of the basin can be traced using gravity anomalies (e.g. Cook et al., 1999), the bulk of the data on the basin comes from the petroleum industry in the form of eight offshore exploration wells, over $30,000 \mathrm{~km}$ of 2D and $1200 \mathrm{~km}^{2}$ 3D seismic data (Crown Minerals, 2010).

The Tartan Formation was first encountered in the Canterbury Basin, in the Endeavour-1 hydrocarbon exploration well which was drilled in 1971. However it was it was not recognised as the Waipawa equivalent and the interval was tentatively 
correlated to the Otepopo Formation - a Late Paleocene glauconitic sandstone (Wilding and Sweetman, 1971). The Toroa-1 well was the first well in the Great South Basin to penetrate the Tartan Formation in 1976 (HIPCO, 1977b).

\section{Stratigraphy}

Since the rifting of the Great South Basin in the mid Cretaceous (e.g. Cook et al., 1999) it has become progressively dominated by marine sediments. A shrinking terrestrial facies persisted, however, at the north-western basin margin until the Eocene. A generalised stratigraphy for the Great South Basin is presented in figure 3.2.1.

\section{Wickliffe Formation}

The Wickliffe Formation has its type section in Kawau-1A (Cook et al., 1999),

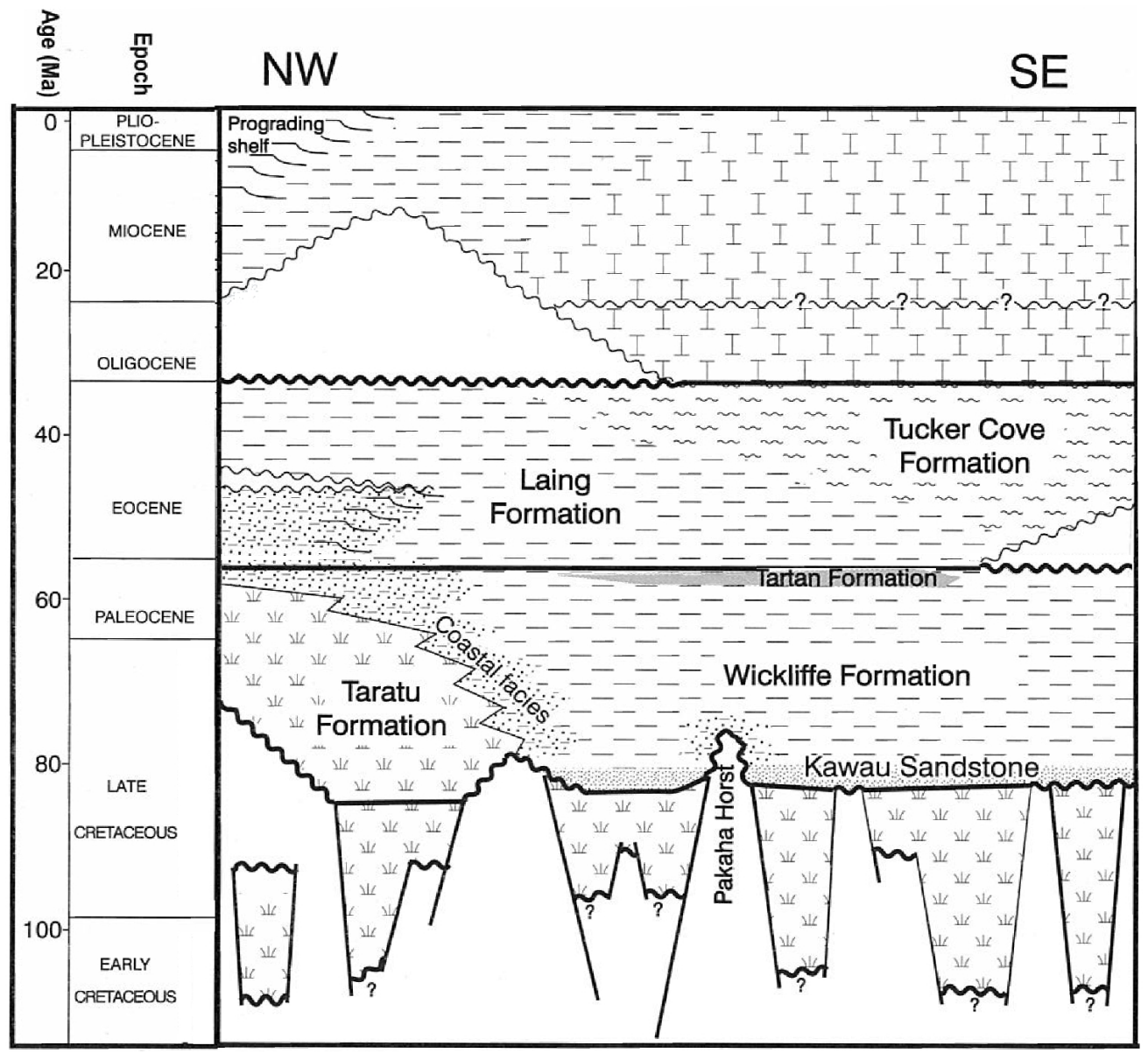

Figure 3.2.1: Generalised stratigraphy for the Great South Basin, figure from Cook et al., (1999), updated with changes from Schiøler et al., (2010) 
where it was first defined as both a $25 \mathrm{~m}$ section above and an $\sim 1000 \mathrm{~m}$ section below the Tartan Formation. This was later revised to include only the interval below the Tartan Formation after a re-examination of cuttings and side wall cores (SWCs) by Schiøler et al. (2010). Both the Wickliffe and Tartan formations are part of the Pakaha Group.

The Wickliffe Formation is described as light grey clay with subordinate darker brown shales. The formation contains muddy sandstone units up to $10 \mathrm{~m}$ thick, which are more prevalent in the western part of the basin. The sandstones are composed of quartz with pyrite, glauconite and mica. Overall, the well logs suggest the formation is composed of a series of fining upwards sequences (Cook et al., 1999). The Wickliffe Formation is also described as similar to the Whangai Formation on the East Coast of the North Island (Beggs, 1993; Cook et al., 1999).

\section{Tartan Formation}

The Tartan Formation is dark brown, carbonaceous and slightly calcareous, very micaceous and slightly glauconitic shale (Cook et al., 1999). The gamma ray logs show a characteristic spike; however, in the more landward wells the spike is more difficult to identify (Schiøler et al., 2010).

Similarly to the East Coast Basin, a greensand formation (the Otepopo Greensand Formation) has been suggested as a possible time equivalent to the Tartan Formation (Wilding and Sweetman, 1971; Meadows, 2009). Study confirming this has yet to be done.

Only limited samples of the Tartan and associated formations are now available from Great South Basin wells. The thickness of the Tartan Formation in the Great South Basin varies between 27.6 and $71.7 \mathrm{~m}$ but is as thin as $16.5 \mathrm{~m}$ in the Canterbury Basin (Schiøler et al., 2010).

Rakiura-1 contained a coarse siltstone to fine sandstone facies that was light brown in colour, very micaceous and only locally carbonaceous. The formation was not originally assigned to the Tartan Formation due to its coarser grain size and lower TOC (Cook et al., 1999). From seismic data and well correlation the Late Paleocene is interpreted at Rakiura-1 as consisting mainly of a regressive package of off-lapping 
sands with the Tartan Formation beginning further to the south-east and representing sediment possibly deposited during maximum sea level regression (Beggs, 2010b).

\section{Laing Formation}

Overlying the Tartan Formation is the Laing Formation, the oldest member of the Rakiura Group. The Laing Formation varies laterally, and at the more proximal wells Rakiura-1, Tora-1 and Tara-1 consists of 30 to $50 \mathrm{~m}$ thickness of sandstone with siltstone interbeds. The fine-grained beds are light grey to buff in colour, moderately calcareous and contain glauconite and traces of pyrite (Cook et al., 1999). The sandstones are generally fine to medium grained, subangular, quartzose, and moderately sorted. The same interval in the more distal Hoiho-1C, Kawau-1A, Pakaha-1 and Pukaki-1 wells consists of calcareous claystones and shales, with some hard crystalline dolomite beds. 
Chapter 4

\section{Methods and field work}

\subsection{Introduction}

This study utilised field samples from the East Coast Basin and side wall core (SWC) samples from the Pakaha-1 and Kawau-1A exploration wells in the Great South Basin. Measurement of trace elements was undertaken using inductively-coupled plasma mass spectrometry (ICP-MS) on an Agilent 7500CS ICPMS of the geochemistry labratory at Victoria University of Wellington, while major elements and sulphur were measured commercially by SpectraChem Analytical, part of CRL Energy Ltd using Xray fluorescence (XRF) on a Siemens SRS3000 wavelength dispersive XRF spectrometer.

Total organic carbon (TOC) has previously been measured for the Great South Basin samples by Meadows (2008), and for Angora Quarry samples by Leckie et al. (1992). However, as the samples collected during the present study from Angora Quarry are not identical to those of Leckie et al. (1992), their TOC values can only be regarded as indicative.

\subsection{East Coast Basin fieldwork and samples}

Angora Quarry is an abandoned quarry located on Angora Road in the southern Hawkes Bay region of the East Coast (figure 4.1.1). The quarry is located in a streamcut valley, and several faults affect this region (Leckie et al., 1992). The main section, including the quarry and the stream below, does not show the contact between the Waipawa and Wanstead formations; further upstream both the Waipawa and Wanstead formations are exposed, although the actual contact here is also obscured.

Field work was conducted during May, 2010. Sampling began $44 \mathrm{~m}$ below the 

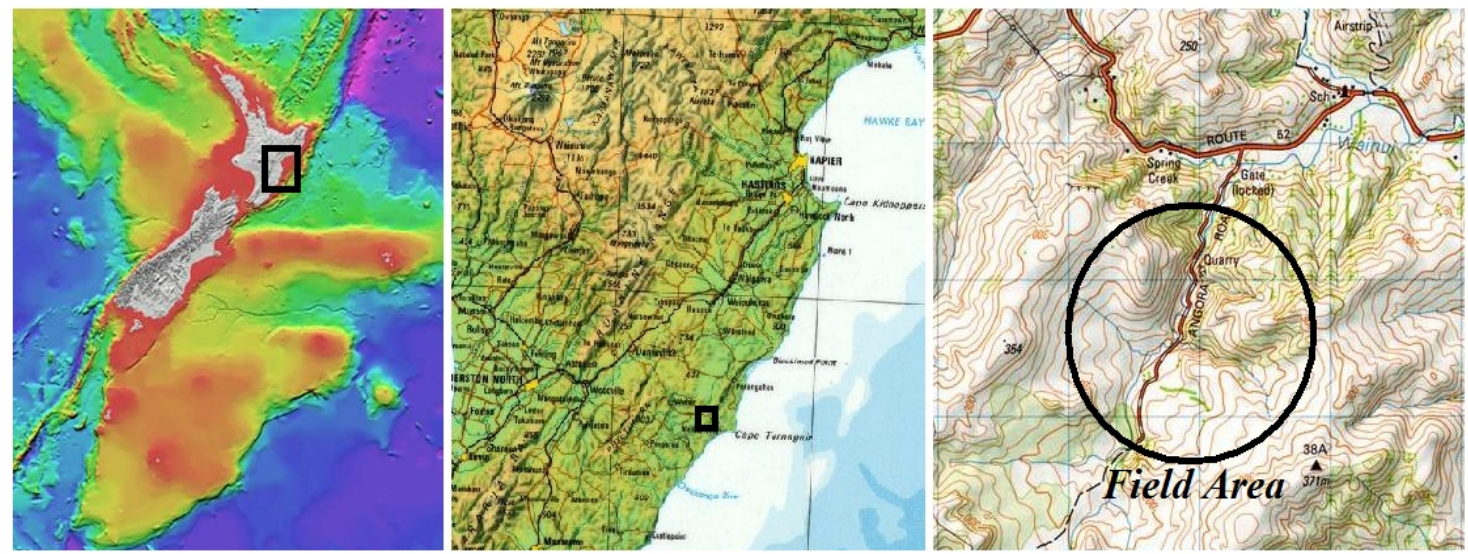

Figure 4.1.1: Location of the Angora Quarry field area.

Waipawa Formation, within the Upper Calcareous Member of the Whangai Formation. Thirteen samples were collected at the quarry and in the stream directly below, eight of which were within the Upper Calcareous Member and five within the Waipawa Formation. Approximately $1 \mathrm{~km}$ upstream another 2 samples were collected, one within the Waipawa Formation and one within the Wanstead Formation. At this location both formations were very weathered and fresh samples required considerable excavation. Separate stratigraphic columns were measured for both sites (Figure 4.1.2). Samples labelled "A-A" are from within or directly below Angora Quarry, while samples labelled "A-C" are from the field site further upstream. Photos of the samples are included as figure 4.4.3.

The Upper Calcareous Member varied significantly in colour through the eight samples collected. The first five samples (A-A-1 to A-A-5) were relatively uniform, blue-grey mudstones when weathered, medium grey when fresh and dry, and light grey when powdered. The thickness of bedding varied from tens of $\mathrm{cm}$ to massive.

The A-A-6 sample (at $20.5 \mathrm{~m}$ ) was dark grey when weathered but light brown when fresh or powdered. The change occurred from the typical Upper Calcareous Member over a distance of about $50 \mathrm{~cm}$ and was gradational. The thickness of this layer is uncertain as the next $10 \mathrm{~m}$ were obscured.

A-A-7 was again light grey when weathered and medium grey when fresh or dry, although slightly darker than the samples 1-5. It showed white spotty weathering (probably gypsum). 


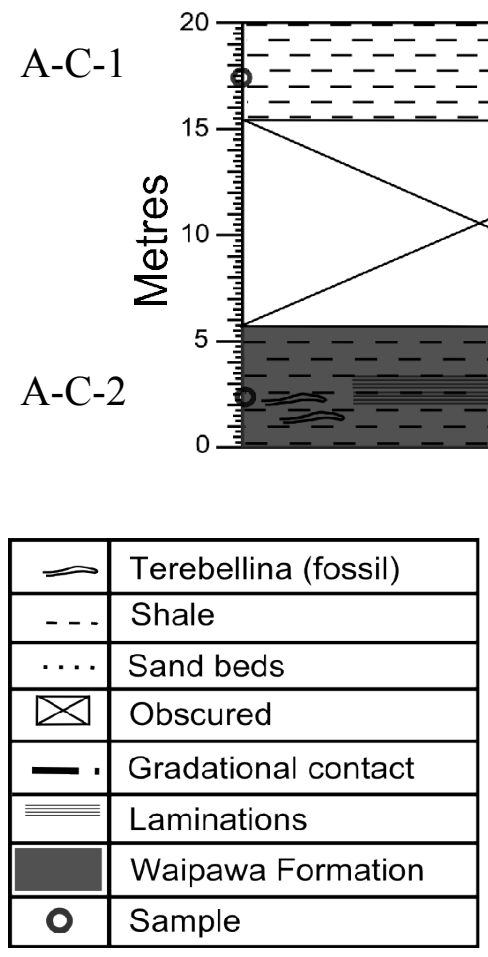

Figure 4.1.2: Simplified stratigraphic columns of the Angora Quarry site. Sample locations are shown as well as major changes throughout the section. Increases in lamination and in Terebellina abundance are indicated by additional symbols.

Laminations and Terebellina fossils are only marked at the sample locations as often these were only visible under closer examination or once dry.
Upstream from Angora Quarry.

Angora Quarry and stream directly below quarry.

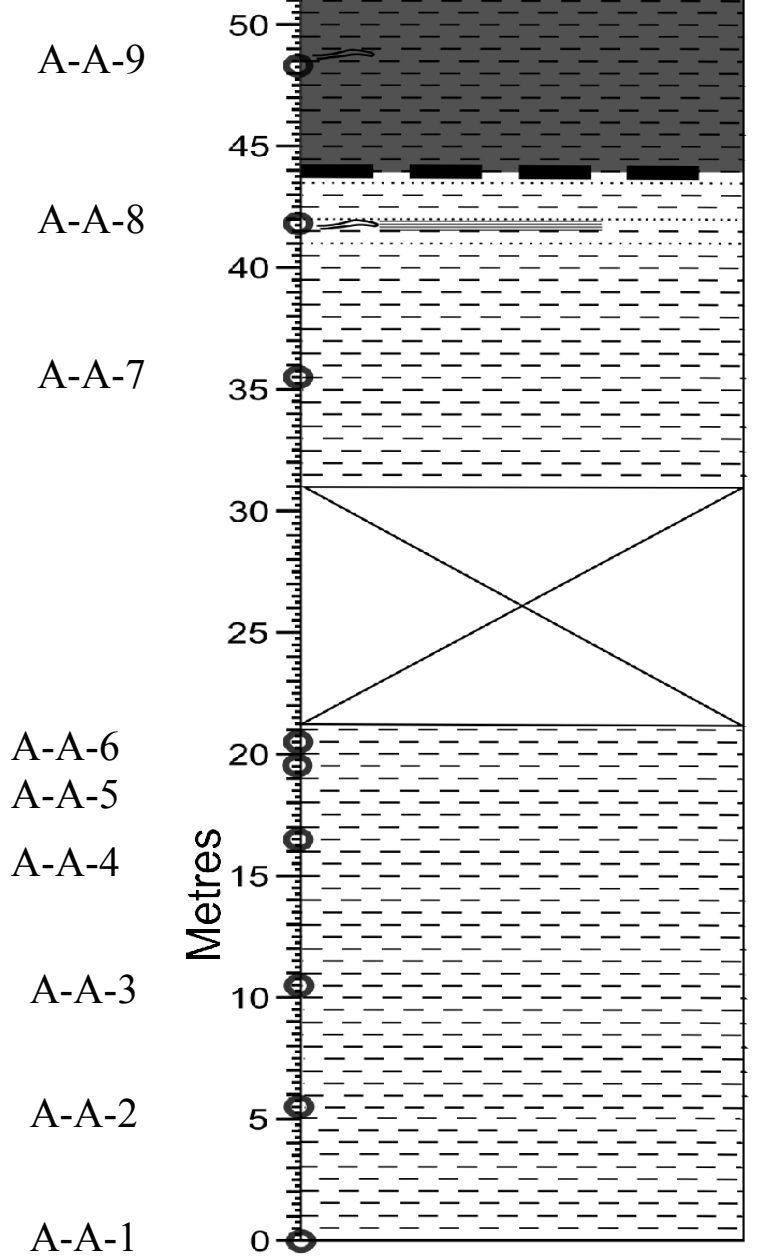



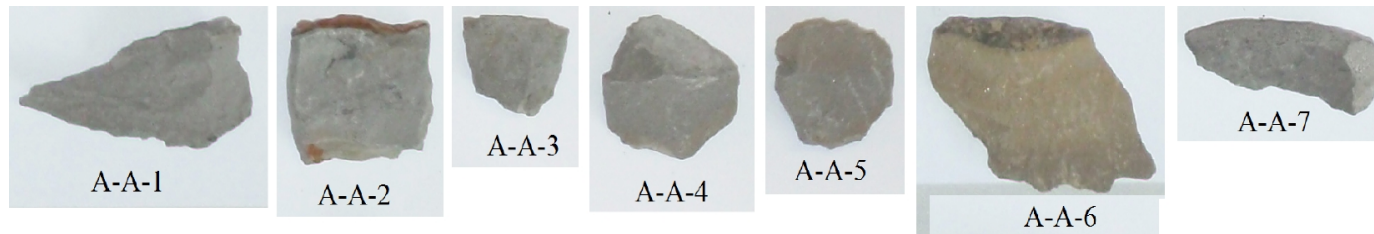

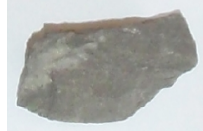

A-A-8

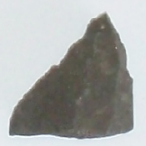

A-A-9
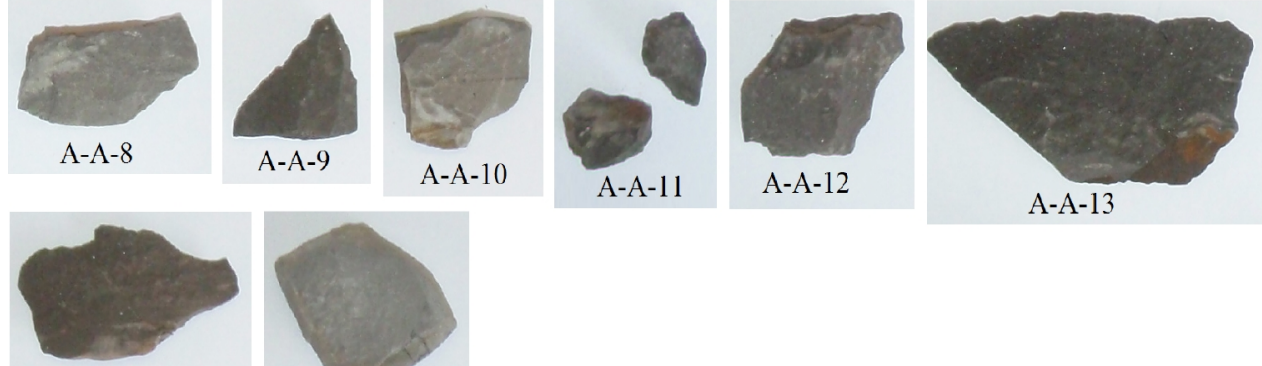

$\mathrm{A}-\mathrm{C}-2$

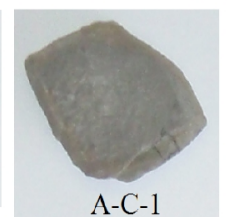

$\mathrm{A}-\mathrm{A}-7$

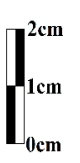

Figure 4.1.3: Images of samples from Angora Quarry on white paper background to show colour variation.

A-A-8 was darker than the rest of the Upper Calcareous Member. It was slightly laminated and contained thin greensand beds between 3-10mm in thickness.

The aggregated tubular foraminiferan Terebellina is common throughout the Waipawa Formation (e.g. Moore 1987, 1988). At Angora Quarry most were fragmented to various degrees. Figure 4.1.4 compares a possible fragment from sample A-A-7, and one of the best preserved fossils images from sample A-A-12. Whether or not sample AA-7 contains Terebellina is uncertain and not important to the conclusions of this study.

The Waipawa Formation conformably overlies the upper calcareous member, with a half metre gradational contact. The Waipawa Formation in this location is dark brown to dark grey in colour, often stained with a red-brown or yellow mineral which precipitates on the outer surface. The red-brown and yellow has been interpreted as jarosite (Moore, 1988), and as gypsum (Hornibrook, 1959). This staining, however, is

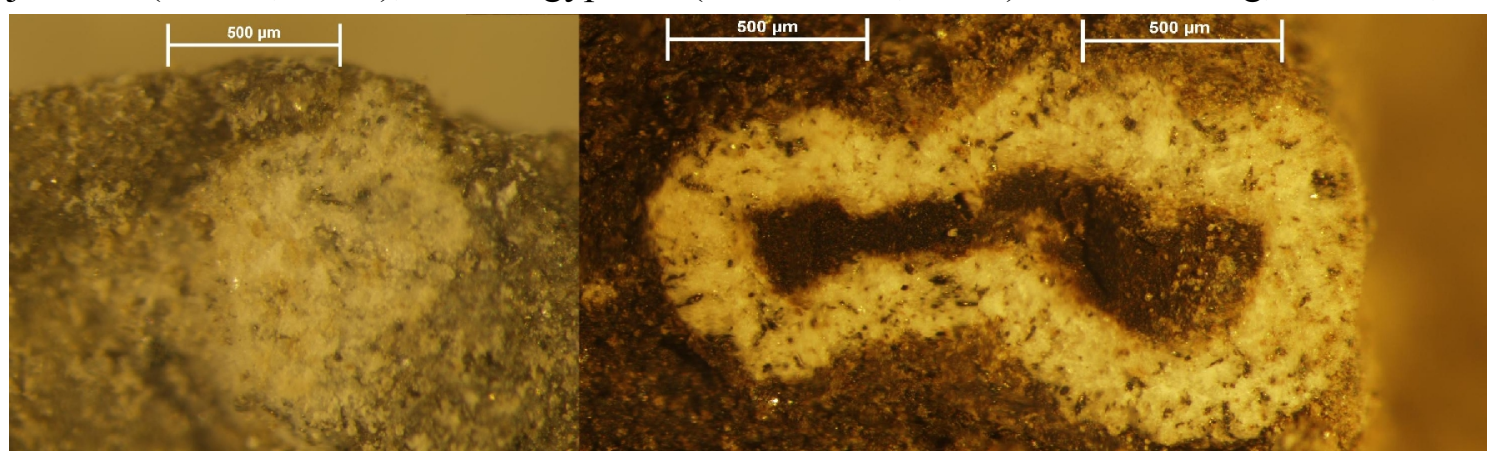

Figure 4.1.4: A comparison between a white speck which may potentially be part of a Terribellina fossil in sample A-A-7 left, and one of the best preserved samples right (sample AA-12). The image to the right is a compilation of 11 images in order to get everything in focus. 
only on the weathered sections and not on the fresh samples collected, determining the exact nature of the mineral is beyond the scope of this study.

Samples A-A-9 to A-A-13 were samples of the Waipawa Formation from within Angora Quarry. All but sample A-A-10 contained Terebellina fragments. The colour varied significantly through these samples with sample A-A-10 the lightest and sample A-A-13 the darkest. The samples ordered in colour are shown in figure 4.1.5, the photos are in black and white in order to easier see differences in how dark the samples are.

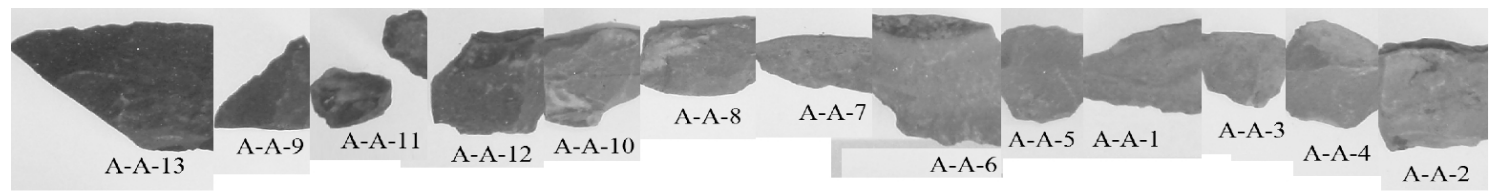

Figure 4.1.5: Samples from Angora Quarry ordered by colour. Images are in black and white in order to highlight the differences. The same images as in figure 4.1 .3 have been used.

The contact between the Waipawa and Wanstead formations was obscured and/or faulted and Wanstead Formation did not outcrop in this area, so samples from the uppermost Waipawa Formation and the overlying Wanstead Formation were taken from $\sim 1 \mathrm{~km}$ upstream. The contact was once again covered although only $9.5 \mathrm{~m}$ of rock was could not be observed. Pictures of the samples are shown in figure 4.1.3. A black and white image of these samples is shown in figure 4.1.6.

In overview, 15 samples were collected during fieldwork, eight samples of which were from the Upper Calcareous Member of the Whangai Formation, six were from the Waipawa Formation, and one was from the Wanstead Formation.

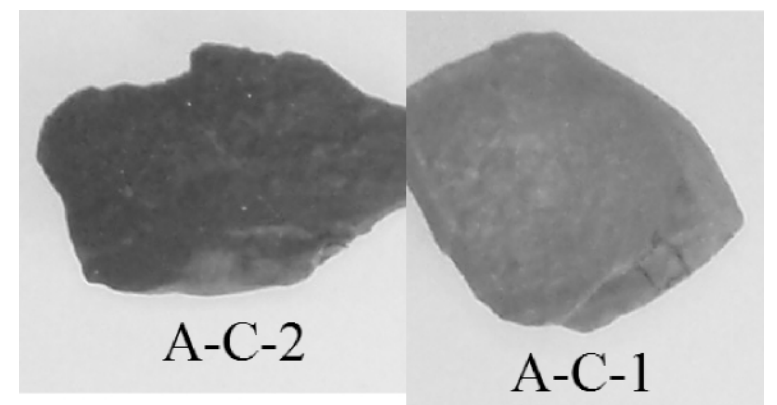

Figure 4.1.6: Greyscale images of samples from field site $\sim 1 \mathrm{~km}$ upstream from Angora Quarry. The same images as in Figure 4.1.3 were used. 


\subsection{Great South Basin}

\section{Pakaha-1}

Pakaha-1 had a total of 30 side wall core (SWC) samples attempted between 3376 and $1935 \mathrm{~m}$ below rotary kelly bushing (mbkb); however, two of the side wall gun bullets failed and three returned empty. The Tartan Formation was encountered in SWC samples 17 and 18. The present study used the six samples between SWC 13 through 24 for which there was still side wall core material remaining after many years of use for other research.

Descriptions of the fresh SWC samples were taken from the well completion report (HIPCO, 1977) and are presented in table 4.2.1. These descriptions are brief, however, and not enough sample remains to do a more detailed description. The shaded samples are those used in this study, as there was insufficient material remaining of the others. The locations of the SWC samples in relation to the gamma ray log are shown in figure 4.2.1.

GR (api)

Figure 4.2.1: Gamma ray wireline log from Pakaha-1 (HIPCO, 1977) plotted alongside the SWC locations. The grey section represents the Tartan Formation, the closed circles represent samples included in this study, and the open circles represent SWC samples which were used up in previous studies. 100 api is an approximate gamma ray value for average shale.

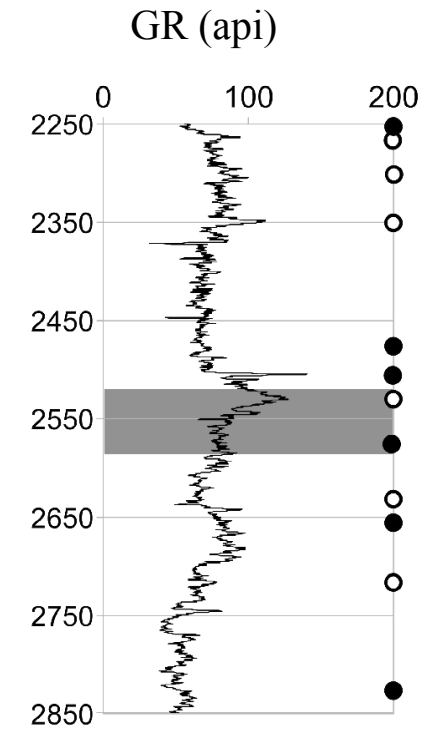




\begin{tabular}{|c|c|c|l|}
\hline SWC & $\begin{array}{c}\text { Depth } \\
\text { feet bkb }\end{array}$ & $\begin{array}{c}\text { Depth } \\
\text { mbkb }\end{array}$ & \multicolumn{1}{c|}{ Description } \\
\hline 24 & 7390 & 2252.47 & $\begin{array}{l}\text { Medium soft moderately soft silt rich calcareous claystone } \\
\text { (nannofossil marl) with minor mica and pyrite. }\end{array}$ \\
\hline 23 & 7425 & 2263.14 & $\begin{array}{l}\text { Medium grey soft silt-rich calcareous claystone (marl) with pyrite plus } \\
\text { minor mica and carbonaceous debris. }\end{array}$ \\
\hline 22 & 7570 & 2307.34 & $\begin{array}{l}\text { Medium grey soft silt-rich claystone with pyrite, plus minor mica, } \\
\text { carbonaceous debris and "glauconite" }\end{array}$ \\
\hline 21 & 7710 & 2350.01 & $\begin{array}{l}\text { Medium brown-grey soft clay-rich siltstone with pyrite, carbonaceous } \\
\text { debris and "glauconite" plus minor mica. }\end{array}$ \\
\hline 20 & 8115 & 2473.45 & $\begin{array}{l}\text { Medium grey moderately soft silt-rich claystone with occasional white } \\
\text { silty lamina, pyrite and calcite plus minor mica, "glauconite" and } \\
\text { carbonaceous debris. }\end{array}$ \\
\hline 19 & 8218 & 2504.85 & $\begin{array}{l}\text { Dark grey soft silt-rich claystone with carbonaceous debris and pyrite } \\
\text { plus minor mica. }\end{array}$ \\
\hline 18 & 8300 & 2529.84 & $\begin{array}{l}\text { Dark brown moderately soft clay-rich carbonaceous claystone with } \\
\text { pyrite plus minor mica }\end{array}$ \\
\hline 17 & 8450 & 2575.56 & $\begin{array}{l}\text { Dark brown moderately soft clay-rich carbonaceous siltstone with } \\
\text { pyrite plus minor calcite and mica }\end{array}$ \\
\hline 16 & 8655 & 2638.04 & $\begin{array}{l}\text { Dark grey moderately hard clay-rich siltstone with calcite, } \\
\text { carbonaceous debris and pyrite plus minor mica. }\end{array}$ \\
\hline 15 & 8720 & 2657.86 & $\begin{array}{l}\text { Dark grey moderately hard silt-rich carbonaceous siltstone with mica } \\
\text { and pyrite plus minor calcite. }\end{array}$ \\
\hline 14 & 8920 & 2718.82 & $\begin{array}{l}\text { Dark grey moderately soft clay-rich carbonaceous siltstone with mica } \\
\text { and pyrite plus minor calcite }\end{array}$ \\
\hline & 9310 & 2837.69 & $\begin{array}{l}\text { Medium grey, moderately hard (fissile) silt-rich claystone with pyrite } \\
\text { and carbonaceous debris plus minor calcite }\end{array}$ \\
\hline
\end{tabular}

Table 4.2.1: SWC descriptions from the Pakaha-1 well report (HIPCO, 1977), although the "as above" descriptions in the report have been elaborated for this table. Shaded rows represent the SWC samples for which there is still material remaining, and hence which were included in this study.

\section{Kawau-1A}

Kawau-1A was included in a preliminary study (Fuerst, 2009) that is included here in appendix B; however these results have been reinterpreted in more detail and in a regional context in this thesis.

Kawau-1A had four sets of SWCs taken, and the Tartan Formation was sampled during the fourth run. Thirty sidewall cores were attempted in the latter, with 29 being recovered. The Tartan Formation was encountered in samples 19/4 and 20/4 (Hunt International, 1977). In order to use a standard naming convention which fits with other studies the ' $/ 4$ ' is added consistently to all Kawau-1A samples to represent the $4^{\text {th }} \mathrm{SWC}$ run. 
As with Pakaha-1, a gamma ray log is presented with the sample locations (figure 4.2.2), and the sample descriptions in table 4.2.2. Both Tartan Formation samples were shot on gamma ray peaks, thus the character of the interval in-between is less certain.

Figure 4.2.2: Gamma ray wireline log from Kawau-1A (Hunt International, 1977) plotted alongside the SWC locations. The grey section represents the Tartan Formation, the closed circles represent samples included in this study, and the open circles represent SWC shots where the samples have been used up in previous studies. 100 api is an approximate value for average shale.

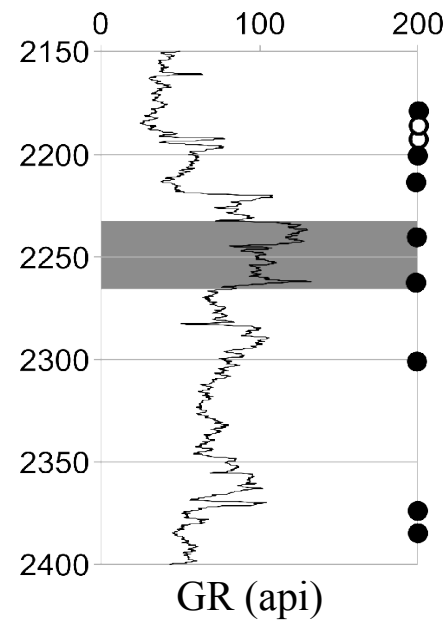

\begin{tabular}{|c|c|c|l|}
\hline SWC & $\begin{array}{c}\text { Depth } \\
\text { feet } \\
\text { bkb }\end{array}$ & $\begin{array}{c}\text { Depth } \\
\text { mbkb }\end{array}$ & \\
\hline $25 / 4$ & 7153 & 2180.23 & $\begin{array}{l}\text { Shale very light grey, very soft, thin laminations, black carbonaceous } \\
\text { partings. }\end{array}$ \\
\hline $24 / 4$ & 7176 & 2187.24 & $\begin{array}{l}\text { Shale, very light grey-buff, soft, semi-waxy, very thin laminations } \\
\text { sub-fissle, very slight trace carbonaceous inclusions. Trace mica, } \\
\text { pyrite }\end{array}$ \\
\hline $23 / 4$ & 7195 & 2193.04 & $\begin{array}{l}\text { Shale light grey-tan, becoming predominantly soft. Very thin } \\
\text { laminations }\end{array}$ \\
\hline $22 / 4$ & 7220 & 2200.66 & $\begin{array}{l}\text { Shale light grey-tan, becoming predominantly soft. Very thin } \\
\text { laminations }\end{array}$ \\
\hline $21 / 4$ & 7276 & 2217.72 & $\begin{array}{l}\text { Shale, very light grey, firm, soft, semi-waxy, think laminations, sub } \\
\text { fissile. Rare carbonaceous inclusion. Trace pyrite. Non calcareous. }\end{array}$ \\
\hline $20 / 4$ & 7350 & 2240.28 & $\begin{array}{l}\text { Shale, chocolate brown, some laminations of dark grey-brown very } \\
\text { micaeous shale. Slight gas odour. }\end{array}$ \\
\hline $19 / 4$ & 7424 & 2262.84 & $\begin{array}{l}\text { Shale, chocolate brown, firm, sub fissil-blocky, non calcareous, } \\
\text { carbonaceous, micaceous, rare trace glauconite. Slight gas odour. }\end{array}$ \\
\hline $18 / 4$ & 7550 & 2301.24 & $\begin{array}{l}\text { Shale, light-medium, firm, blocky, trace mica, pyrite, glauconite. Non } \\
\text { calcareous, no carbonaceous partings. }\end{array}$ \\
\hline $17 / 4$ & 7794 & 2375.61 & $\begin{array}{l}\text { Shale light grey-tan, firm, blocky, slightly calcareous, trace mica, } \\
\text { pyrite, glauconite. Few carbonaceous partings }\end{array}$ \\
\hline & 7830 & 2386.58 & $\begin{array}{l}\text { Shale, light grey-tan, firm, blocky, slightly calcareous, trace mica, } \\
\text { pyrite, glauconite. Few carbonaceous partings }\end{array}$ \\
\hline
\end{tabular}

Table 4.2.2: SWC descriptions from Kawau-1A (Hunt International, 1977), grey rows represent samples included in this study, and white rows are samples which were used up in previous studies. 


\subsection{Laboratory Techniques}

\section{Pre-laboratory sample preparation}

Field samples were crushed and approximately $15 \mathrm{~g}$ of fresh sample was powdered using a tungsten carbide mill. The sample was then mixed and split, and approximately $5 \mathrm{~g}$ of sample was sent to SpectraChem Analytical, Lower Hutt, for XRF analysis of major oxides. Loss on ignition and bulk sulphur were also included in the XRF results. Standard XRF procedures are used and the laboratory is ISO 17025 accredited assuring quality and reproducibility of the results.

Samples from Pakaha-1 and Kawau-1A were not as cemented as the field samples, and hence did not require crushing or powdering. Unfortunately there was insufficient SWC material available for XRF analysis, and thus major oxide information is not available for these samples, ICP-MS was done on the well and field samples.

For Pakaha-1 and Kawau-1A, the primary standard used was USGS BHVO-1 (for calibration), BHVO-2 was used as the secondary standard to check accuracy and reproducibility. For the field samples from Angora Quarry the USGS BHVO-2, was used as the primary standard and BCR-2 as the secondary standard. Different standards where used due to the limited amounts of BHVO-1 being available.

\section{Beaker cleaning}

Beakers were first rinsed then soaked in $\sim 7 \mathrm{M}$ Analytical Reagents grade (AR) $\mathrm{HNO}_{3}$ and placed on a hotplate for 24 hours. They were then rinsed three times in Milli$\mathrm{Q}$ water and soaked in $6 \mathrm{M} \mathrm{AR} \mathrm{HCl}$ for 24 hours, and again rinsed three times with Milli-Q.

The beakers were then individually cleaned; $2 \mathrm{ml}$ of 6-7 $\mathrm{M} \mathrm{HCl}$ sub-boiled (sb) was poured into the beakers and they are left on the hotplate for 1-2 days. This acid was then disposed of and the beakers rinsed three times with Milli-Q water. The process was repeated with $2 \mathrm{ml}$ of 6-7 $\mathrm{M} \mathrm{HNO}_{3}(\mathrm{sb})$. A final clean was conducted using $2 \mathrm{ml}$ of $7 \mathrm{M}$ $\mathrm{HNO}_{3} \mathrm{SEASTAR}^{\mathrm{TM}}$ (ss) with 3-4 drops of HF (ss).

From impurities listed on the containers, AR grade $\mathrm{HNO}_{3}$ contains $0.011 \mathrm{ppm} \mathrm{Fe}$ 
as the highest concentrated impurity; $\mathrm{HCl}$ contains $0.13 \mathrm{ppm} \mathrm{Al}$ as the greatest impurity. The sb grade acids are distilled in the Victoria University geochemical laboratory using quartz and Teflon stills, exact concentrations of impurities are unknown, however likely a few orders of magnitude higher than the 1-5 ppt impurities in the SEASTAR ${ }^{\mathrm{TM}}$ acids.

\section{Sample digestion}

Sample digestion was performed according to Heinrichs and Herrmann (1990). $\sim 50 \mathrm{mg}$ of sample were placed in each beaker; weights were recorded to an accuracy of $0.05 \mathrm{mg}$. 45 drops of $7 \mathrm{M} \mathrm{HF}$ (ss) and 8 drops of $7 \mathrm{M} \mathrm{HNO}_{3}$ (ss) and were left on the hotplate for four days. The samples were then opened dried overnight.

45 drops of $\mathrm{HNO}_{3}$ was added and left open on the hotplate overnight to dry.

$6 \mathrm{ml}$ of $6 \mathrm{M} \mathrm{HCl} \mathrm{(sb)} \mathrm{was} \mathrm{added} \mathrm{and} \mathrm{left} \mathrm{on} \mathrm{the} \mathrm{hotplate} \mathrm{for} \mathrm{two} \mathrm{days.} \mathrm{Beakers}$ were then opened left overnight to dry.

45 drops of $\mathrm{HNO}_{3}$ (ss) was added and left open on the hotplate to dry..

$9 \mathrm{ml}$ of $1 \mathrm{M} \mathrm{HNO}_{3}$ was added and left on the hotplate for two days. The samples were then centrifuged.

The sample was weighed and $0.09 \mathrm{ml}$ was taken and diluted with $9 \mathrm{ml} 1 \mathrm{wt} \%$ $\mathrm{HNO}_{3}$ for analysis using the methodology discussed by Schnetger (1997). The blank was not diluted.

\subsection{Data Processing}

\section{Absolute Concentrations}

The raw ICP-MS data came in the form of counts per second and time, with a value for each element approximately every second. Figure 4.4.1 shows the raw ICPMS data for Ca at Angora Quarry. Each peak represents either a sample or a standard, while the troughs represent the cleaning fluids and the local background. 
The first step in calculating concentrations is to take the average background from $1 \% \mathrm{HNO}_{3}$ from the average from the average within the sample, the parts highlighted in red in figure 4.4.1. This is done for all samples and standards for all elements.

Concentrations are then calculated from the BHVO-2 standard (the concentrations of all standards were taken from the GeoReM database), which was measured five times throughout the process, each correction was to the nearest BHVO-2 measurement. The formula used was:

$\mathrm{E}_{\text {Sample }}=\mathrm{CPS}_{\text {Sample }} / \mathrm{CPS}_{\mathrm{BHVO}-2} * \mathrm{E}_{\mathrm{BHVO}-2}$

where $\mathbf{E}$ is the element concentration and CPS is the counts per second. For Pakaha-1 and Kawau-1A BHVO-1 was used instead of BHVO-2.

In the Angora Quarry samples, the measurement of BCR-2 occurred between the middle of the measurements of other samples. BCR-2 standard contains approximately two orders of magnitude more Mo then the samples. Mo readings dropped slowly after

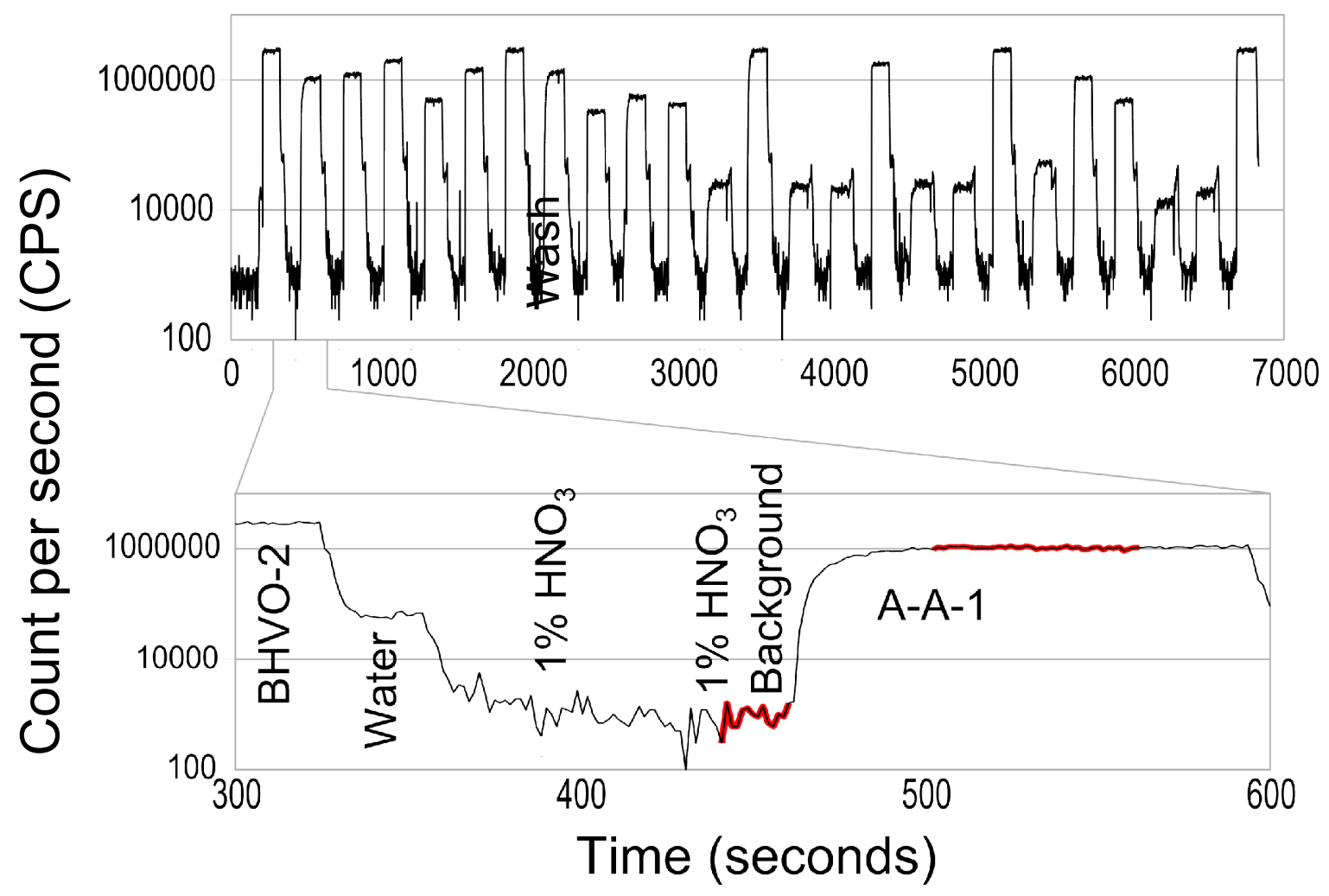

Figure 4.4.1: Raw ICP-MS measurements for Calcite at Angora Quarry. The $Y$ axis gives the CPS, the $X$ time through the measurements. Highlighted in red are the sections of the measurement used for calculating the concentration in A-A-1. The horizontal lines represent two orders of magnitude. 
switching from measuring BCR-2 to the cleaning fluids. The readings were not always down to the background values by the time the cleaning liquid cycle was completed. Thus, several samples were affected by a significantly higher than background level of Mo. Molybdenum is an important element used to determine if an environment is anoxic, a different background curve for Mo was defined for affected samples.

Molybdenum values for A-A-3, 4, 11, and 12 should be treated with caution, as errors may be larger than shown. Figure 4.4.2 shows the raw data for Mo along with the newly defined background curves in red. The samples which had new background values defined are highlighted in red later in this study.

For the Angora Quarry samples, absolute concentrations from the ICP-MS data underwent a final correction step in which data was adjusted to the Ti concentration as measured by XRF. This is simply to correct for any systematic errors for a single sample which can be caused by inaccuracies in measuring and dilution. All results are included as tables in appendix $\mathrm{C}$.

\section{Error calculations}

For Pakaha-1 and Kawau-1A, errors were calculated on BHVO-2, the concentration of BHVO-2 was calculated using BHVO-1 in the same way sample concentrations where calculated, the errors being represented by the difference between

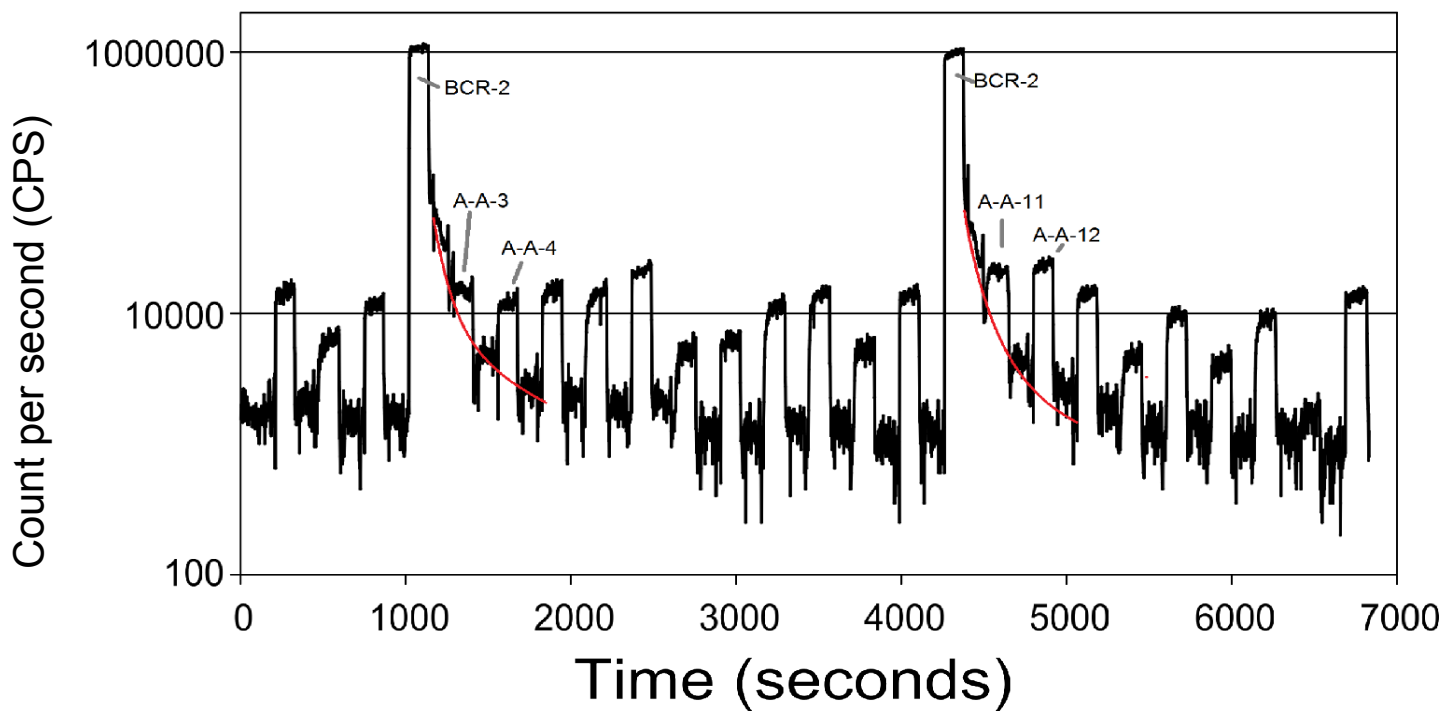

Figure 4.4.2. Raw data for Mo measurements in the Angora Quarry samples. The red line indicates the newly defined background curve for A-A-3, 4, 11 and 12. The graph has a log scale on the $Y$ axis. Only every second order of magnitude is labelled. See text for discussion. 
the measured and the actual measured values. As Pakaha-1 and Kawau-1A were measured in the same run, the errors apply to both of these. The errors are displayed in table 4.4.1 for the Great South Basin samples.

The "range \%" in the errors table (table 4.4.1, 4.4.2) indicates the relative error between elements across different samples. The "offset from ref value" indicates the absolute error which effects all measurements of the same elements identically. The low concentration of $\mathrm{Sb}$ and $\mathrm{Cd}$ in BHVO-2 may also explain the high errors in these, whereas the remaining elements with "offset from ref value" above $10 \%$ have the * symbol, indicating they were published values rather than preferred values, and hence may not have been measured to the same accuracy.

Errors for Angora Quarry were measured using BCR-2 otherwise the errors are the same. Table 4.4.2 shows the calculated errors using BCR-2. When a "*" or a "**" is

\begin{tabular}{|c|c|c|c|c|c|c|c|c|c|}
\hline & \multicolumn{2}{|c|}{$\begin{array}{c}\text { First BHVO-2 measure- } \\
\text { ment }\end{array}$} & \multicolumn{2}{|c|}{$\begin{array}{c}\text { Second BHVO-2 } \\
\text { measurement }\end{array}$} & \multirow[b]{2}{*}{ average } & \multirow[b]{2}{*}{ range } & \multirow[b]{2}{*}{ range $\%$} & \multirow{2}{*}{$\begin{array}{c}\text { ref } \\
\text { value }\end{array}$} & \multirow{2}{*}{$\begin{array}{l}\text { offset from } \\
\text { ref value }\end{array}$} \\
\hline & below & above & below & above & & & & & \\
\hline$\overline{\mathrm{Ti}(\%)}$ & 2.60 & 2.59 & 2.59 & 2.64 & 2.61 & \pm 0.0335 & $1.3 \%$ & 2.73 & $4.5 \%$ \\
\hline V & 303 & 301 & 305 & 308 & 304 & \pm 3.49 & $1.1 \%$ & 317 & $4 \%$ \\
\hline $\mathrm{Cr}$ & 277 & 276 & 275 & 280 & 277 & \pm 3.06 & $1.1 \%$ & 280 & $1.1 \%$ \\
\hline $\mathrm{Mn}$ & 0.161 & 0.160 & 0.160 & 0.162 & 0.161 & \pm 0.00157 & $1 \%$ & 0.17 & $5.4 \%$ \\
\hline Co & 42.5 & 42.4 & 42.9 & 43.9 & 42.9 & \pm 0.999 & $2.3 \%$ & 45 & $4.6 \%$ \\
\hline $\mathrm{Ni}$ & 111 & 111 & 113 & 116 & 113 & \pm 3.04 & $2.7 \%$ & 119 & $5.3 \%$ \\
\hline $\mathrm{Cu}$ & 122 & 122 & 123 & 127 & 124 & \pm 3.73 & $3 \%$ & 127 & $2.6 \%$ \\
\hline As & 0.516 & 0.521 & 0.545 & 0.534 & 0.529 & \pm 0.016 & $3 \%$ & $0.77^{*}$ & $31 \%$ \\
\hline $\mathrm{Se}$ & 0.110 & 0.112 & 0.111 & 0.091 & 0.106 & \pm 0.0148 & $13.9 \%$ & $0.1^{*}$ & $6.1 \%$ \\
\hline $\mathrm{Rb}$ & 8.24 & 8.03 & 8.42 & 8.81 & 8.38 & \pm 0.431 & $5.1 \%$ & 9.11 & $8.1 \%$ \\
\hline $\mathrm{Sr}$ & 372 & 365 & 369 & 379 & 371 & \pm 7.88 & $2.1 \%$ & 396 & $6.2 \%$ \\
\hline $\bar{Y}$ & 24.4 & 23.6 & 24.0 & 25.4 & 24.4 & \pm 1.02 & $4.2 \%$ & 26 & $6.3 \%$ \\
\hline${ }^{90} \mathrm{Zr}$ & 161 & 157 & 159 & 167 & 161 & \pm 6.14 & $3.8 \%$ & 172 & $6.5 \%$ \\
\hline${ }^{91} \mathrm{Zr}$ & 160 & 158 & 159 & 166 & 161 & \pm 5.02 & $3.1 \%$ & 172 & $6.6 \%$ \\
\hline $\mathrm{Nb}$ & 17.2 & 16.9 & 17.0 & 17.6 & 17.2 & \pm 0.414 & $2.4 \%$ & 18.1 & $5.1 \%$ \\
\hline Mo & 3.74 & 3.63 & 3.67 & 3.77 & 3.70 & \pm 0.0693 & $1.9 \%$ & 4 & $7.4 \%$ \\
\hline $\mathrm{Cd}$ & 0.0807 & 0.0835 & 0.0884 & 0.0859 & 0.0846 & \pm 0.00395 & $4.7 \%$ & 0.06 & $41 \%$ \\
\hline Sn & 1.41 & 1.40 & 1.59 & 1.86 & 1.56 & \pm 0.292 & $18.6 \%$ & 1.7 & $8 \%$ \\
\hline $\mathrm{Sb}$ & 0.0833 & 0.0786 & 0.0844 & 0.0911 & 0.0844 & \pm 0.00675 & $8 \%$ & 0.13 & $35 \%$ \\
\hline $\mathrm{Hf}$ & 4.01 & 3.92 & 4.20 & 4.37 & 4.12 & \pm 0.250 & $6.1 \%$ & 4.36 & $5.5 \%$ \\
\hline $\mathrm{Ta}$ & 1.08 & 1.09 & 1.15 & 1.19 & 1.12 & \pm 0.0603 & $5.4 \%$ & 1.14 & $1.8 \%$ \\
\hline $\mathrm{W}$ & 0.152 & 0.137 & 0.178 & 0.195 & 0.166 & \pm 0.0293 & $17.7 \%$ & $0.21^{*}$ & $21 \%$ \\
\hline $\mathrm{TI}$ & 0.0185 & 0.0194 & 0.0241 & 0.0246 & 0.0216 & \pm 0.00315 & $14.6 \%$ & $0.03^{*}$ & $28 \%$ \\
\hline $\mathrm{Pb}$ & 1.53 & 1.46 & 1.60 & 1.67 & 1.57 & \pm 0.105 & $6.7 \%$ & 1.6 & $2.1 \%$ \\
\hline $\mathrm{Bi}$ & 0.00662 & 0.00652 & 0.0108 & 0.0124 & 0.00907 & \pm 0.00331 & $36.5 \%$ & $0.15^{*}$ & $94 \%$ \\
\hline Th & 1.08 & 1.08 & 1.13 & 1.21 & 1.12 & \pm 0.0879 & $7.8 \%$ & 1.22 & $7.8 \%$ \\
\hline$U$ & 0.360 & 0.350 & 0.402 & 0.431 & 0.386 & \pm 0.0452 & $11.7 \%$ & 0.4 & $4.3 \%$ \\
\hline
\end{tabular}

Table 4.4.1: Error calculations for Kawau-1A and Pakaha-1. The * in the reference value column represents where published values were used instead of preferred values from GeoReM as preferred values were not available. See text for discussion. 


\begin{tabular}{|c|c|c|c|c|c|c|c|c|c|}
\hline BCR-2 & $\begin{array}{l}\text { First } \\
\mathrm{m} \\
\text { below }\end{array}$ & $\begin{array}{l}\text { asure- } \\
\text { tt } \\
\text { above }\end{array}$ & $\begin{array}{c}\text { Second } \\
m \\
\text { below }\end{array}$ & $\begin{array}{l}\text { leasure- } \\
\text { nt } \\
\text { above }\end{array}$ & average & range & range $\%$ & $\begin{array}{c}\text { ref } \\
\text { value }\end{array}$ & $\begin{array}{l}\text { offset from } \\
\text { ref value }\end{array}$ \\
\hline$\overline{\mathrm{Li}}$ & 10.3 & 11.1 & 10.0 & 10.1 & 10.4 & \pm 0.693 & $6.7 \%$ & 9 & $15.3 \%$ \\
\hline $\mathrm{Ca}(\%)$ & 7.59 & 7.76 & 6.85 & 6.93 & 7.28 & \pm 0.476 & $6.5 \%$ & 7.12 & $2.3 \%$ \\
\hline $\mathrm{Ti}(\%)$ & 2.45 & 2.48 & 2.19 & 2.19 & 2.33 & \pm 0.156 & $6.7 \%$ & 2.26 & $3.1 \%$ \\
\hline $\mathrm{V}$ & 439 & 437 & 405 & 400 & 420 & \pm 20.0 & $4.8 \%$ & 416 & $0.96 \%$ \\
\hline $\mathrm{Cr}$ & 16.9 & 17.2 & 14.8 & 14.7 & 15.9 & \pm 1.30 & $8.2 \%$ & $13^{* *}$ & $18.4 \%$ \\
\hline Co & 41.0 & 41.2 & 36.2 & 36.4 & 38.7 & \pm 2.52 & $6.5 \%$ & 37 & $4.6 \%$ \\
\hline $\mathrm{Ni}$ & 14.1 & 14.0 & 12.6 & 12.3 & 13.3 & \pm 0.944 & $7.1 \%$ & $12^{\star *}$ & $9.5 \%$ \\
\hline $\mathrm{Cu}$ & 22.3 & 22.6 & 19.9 & 20.0 & 21.2 & \pm 1.36 & $6.4 \%$ & 21 & $0.9 \%$ \\
\hline $\mathrm{Zn}$ & 143 & 152 & 128 & 126 & 137 & \pm 14.7 & $10.7 \%$ & 127 & $8 \%$ \\
\hline $\mathrm{Ga}$ & 59.7 & 60.6 & 53.5 & 54.4 & 57.0 & \pm 3.57 & $6.3 \%$ & 23 & $148 \%$ \\
\hline $\mathrm{Ge}$ & 2.04 & 1.96 & 1.68 & 1.65 & 1.83 & \pm 0.207 & $11.3 \%$ & $1.49^{*}$ & $22.8 \%$ \\
\hline As & 1.17 & 1.19 & 1.15 & 1.16 & 1.17 & \pm 0.0206 & $1.8 \%$ & $0.88^{*}$ & $32 \%$ \\
\hline $\mathrm{Se}$ & 0.320 & 0.121 & 0.030 & 0.024 & 0.124 & \pm 0.196 & $158.4 \%$ & $0.08^{*}$ & $50.9 \%$ \\
\hline $\mathrm{Rb}$ & 50.1 & 49.6 & 46.0 & 45.4 & 47.8 & \pm 2.34 & $4.9 \%$ & 46.9 & $1.8 \%$ \\
\hline $\mathrm{Sr}$ & 368 & 377 & 332 & 332 & 352 & \pm 24.9 & $7.1 \%$ & 340 & $3.6 \%$ \\
\hline $\mathrm{Y}$ & 38.4 & 38.1 & 34.9 & 34.6 & 36.5 & \pm 1.88 & $5.2 \%$ & 37 & $1.4 \%$ \\
\hline${ }^{90} \mathrm{Zr}$ & 200 & 202 & 184 & 183 & 192 & \pm 9.62 & $5 \%$ & 184 & $4.5 \%$ \\
\hline${ }^{91} \mathrm{Zr}$ & 206 & 207 & 182 & 181 & 194 & \pm 13.1 & $6.7 \%$ & 184 & $5.5 \%$ \\
\hline $\mathrm{Nb}$ & 13.3 & 13.2 & 12.2 & 11.9 & 12.6 & \pm 0.736 & $5.8 \%$ & 12.6 & $0.3 \%$ \\
\hline Mo & 328 & 343 & 325 & 300 & 324 & \pm 23.7 & $7.3 \%$ & 250 & $29.6 \%$ \\
\hline $\mathrm{Cd}$ & 0.156 & 0.167 & 0.157 & 0.154 & 0.158 & \pm 0.00859 & $5.4 \%$ & $0.75^{\star}$ & $78.9 \%$ \\
\hline Sn & 1.77 & 1.76 & 1.57 & 1.54 & 1.66 & \pm 0.119 & $7.2 \%$ & $2.3^{*}$ & $27.9 \%$ \\
\hline $\mathrm{Sb}$ & 4.84 & 4.37 & 3.87 & 3.90 & 4.25 & \pm 0.594 & $14 \%$ & $3.5^{\star}$ & $21.3 \%$ \\
\hline $\mathrm{Ba}$ & 740 & 725 & 652 & 657 & 693 & \pm 46.6 & $6.7 \%$ & 677 & $2.4 \%$ \\
\hline $\mathrm{La}$ & 27.4 & 27.5 & 24.2 & 24.2 & 25.8 & \pm 1.66 & $6.4 \%$ & 24.9 & $3.6 \%$ \\
\hline $\mathrm{Ce}$ & 55.6 & 55.0 & 49.8 & 49.7 & 52.5 & \pm 3.09 & $5.9 \%$ & 52.9 & $0.71 \%$ \\
\hline $\mathrm{Pr}$ & 7.49 & 7.36 & 6.69 & 6.64 & 7.04 & \pm 0.450 & $6.4 \%$ & 6.7 & $5.1 \%$ \\
\hline $\mathrm{Nd}$ & 31.5 & 31.2 & 28.5 & 28.0 & 29.8 & \pm 1.81 & $6.1 \%$ & 28.7 & $3.8 \%$ \\
\hline $\mathrm{Sm}$ & 7.15 & 7.10 & 6.49 & 6.41 & 6.79 & \pm 0.378 & $5.6 \%$ & 6.58 & $3.1 \%$ \\
\hline${ }^{151} \mathrm{Eu}$ & 2.22 & 2.20 & 2.01 & 1.98 & 2.10 & \pm 0.123 & $5.9 \%$ & 1.96 & $7.1 \%$ \\
\hline${ }^{{ }^{153} \mathrm{Eu}}$ & 2.28 & 2.22 & 2.06 & 2.01 & 2.14 & \pm 0.138 & $6.4 \%$ & 1.96 & $9.3 \%$ \\
\hline $\mathrm{Gd}$ & 7.57 & 7.37 & 6.86 & 6.61 & 7.10 & \pm 0.489 & $6.9 \%$ & 6.75 & $5.2 \%$ \\
\hline $\mathrm{Tb}$ & 1.16 & 1.12 & 1.04 & 1.01 & 1.08 & \pm 0.0796 & $7.4 \%$ & 1.07 & $1.1 \%$ \\
\hline Dy & 7.02 & 6.83 & 6.42 & 6.29 & 6.64 & \pm 0.379 & $5.7 \%$ & 6.41 & $3.7 \%$ \\
\hline $\mathrm{Ho}$ & 1.41 & 1.39 & 1.30 & 1.27 & 1.34 & \pm 0.0716 & $5.3 \%$ & 1.28 & $4.9 \%$ \\
\hline $\mathrm{Er}$ & 4.07 & 4.00 & 3.65 & 3.58 & 3.82 & \pm 0.250 & $6.5 \%$ & 3.66 & $4.4 \%$ \\
\hline $\mathrm{Tm}$ & 0.573 & 0.565 & 0.517 & 0.508 & 0.540 & \pm 0.0327 & $6 \%$ & 0.54 & $0.09 \%$ \\
\hline $\mathrm{Yb}$ & 3.68 & 3.62 & 3.37 & 3.31 & 3.50 & \pm 0.184 & $5.3 \%$ & 3.38 & $3.5 \%$ \\
\hline $\mathrm{Lu}$ & 0.537 & 0.517 & 0.490 & 0.474 & 0.505 & \pm 0.0326 & $6.5 \%$ & 0.5 & $0.91 \%$ \\
\hline $\mathrm{Hf}$ & 5.33 & 5.26 & 4.92 & 4.72 & 5.06 & \pm 0.332 & $6.6 \%$ & 4.9 & $3.2 \%$ \\
\hline $\mathrm{TI}$ & 0.468 & 0.435 & 0.418 & 0.421 & 0.436 & \pm 0.032 & $7.3 \%$ & $0.3^{*}$ & $45.3 \%$ \\
\hline $\mathrm{Pb}$ & 11.8 & 11.7 & 10.9 & 10.6 & 11.2 & \pm 0.635 & $5.7 \%$ & 11 & $2.2 \%$ \\
\hline Th & 6.52 & 6.42 & 5.74 & 5.63 & 6.07 & \pm 0.448 & $7.4 \%$ & 5.7 & $6.6 \%$ \\
\hline $\mathrm{U}$ & 1.78 & 1.77 & 1.65 & 1.58 & 1.70 & \pm 0.117 & $6.9 \%$ & 1.69 & $0.43 \%$ \\
\hline
\end{tabular}

Table 4.4.2: Errors calculated form BCR-2 for Angora Quarry. The * in the reference value column represents the use of the published value due to the lack of a preferred value in GeoReM. The ** represents where the value for BCR-1 was used instead.

next to the reference value, the reference value is less certain, either because values have not been measured accurately or have not been measured at all and a value from BCR-1 has been taken instead. 


\section{Terrestrial background corrections}

The terrestrial component of sediments generally consists largely of aluminosilicate clays, exact mineralogy varies with the sediment source. There are two different terrestrial corrections which remove this component, both of which require estimates of the concentration of terrestrial component, and both of which generally take $\mathrm{Al}$ as an indicator for the amount of detrital clays.

Most commonly detrital corrections use the chemical composition of average shale, a compilation of shales by Wedephol (1971). A comparison between this derived local background from this study and average shale is shown in figure 4.4.3.

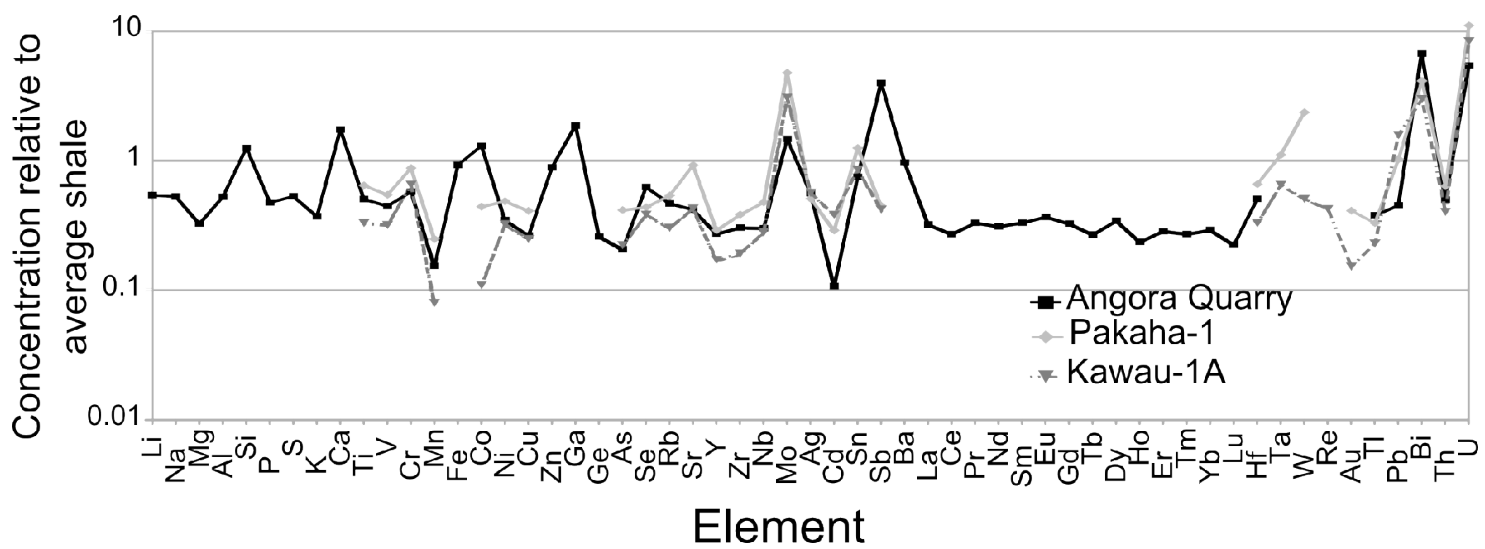

Figure 4.4.3: A graph comparing the average concentration of the Whangai and Wanstead formations at Angora Quarry, and the Laing and Wickliffe formations at Pakaha-1 and Kawau1 A with average shale from Wedephol (1971), which plots at 1 . See text for discussion.

Variations in the local background relative to average shale cover around two orders of magnitude (figure 4.4.3), this variation indicates that average shale is not an ideal standard to use for this study, therefore a locally defined background will be used instead. In this case, the locally defined background is the samples outside the Waipawa or Tartan formations which were measured in the same section. Each section will hence use its own local background.

Enrichment factor:

The first method for calculating a detrital correction is the standard enrichment factor that has become the sole method for calculating enrichment in many recent studies (e.g. Brumsack, 2006; Ross and Bustin, 2009). This method normalises values to 
$\mathrm{Al}$ and then calculates a factor of enrichment relative a set standard. The formula is:

$$
\mathrm{EF}=\left(\mathrm{E}_{\mathrm{S}} / \mathrm{Al}_{\mathrm{S}}\right) /\left(\mathrm{E}_{\mathrm{B}} / \mathrm{Al}_{\mathrm{B}}\right)
$$

where $\mathbf{E F}$ is the enrichment factor, $\mathbf{E}$ is the element being analysed, $\mathbf{A l}$ is aluminium, $\mathbf{s}$ is the sample, and $\mathbf{B}$ is the standard or local background.

The enrichment factor calculation has limitations in regions where Al values are low (Brumsack, 2006), or in situations where the terrestrial content varies significantly throughout the section (this study).

\section{Absolute Enrichment:}

The second method of calculating enrichment is the absolute enrichment method, and is not often used. A formula for calculating it was suggested by Brumsack (2006):

$$
\mathrm{AE}=\mathrm{E}_{\mathrm{S}}-\mathrm{Al}_{\mathrm{S}} *\left(\mathrm{E}_{\mathrm{B}} / \mathrm{Al}_{\mathrm{B}}\right)
$$

where is $\mathbf{A E}$ is the absolute enrichment, $\mathbf{E}$ is the element measured, $\mathbf{A l}$ is aluminium, $\mathbf{s}$ is the sample, and в is the standard used. Brumsack (2006) suggested using average shale for the calculation; however.

The difference between $\mathrm{AE}$ and $\mathrm{EF}$ comes when there is a significant difference in the terrestrial component through a section. In Kawau-1A the uppermost sample contains $20 \%$ of the detrital component as the Tartan Formation. While the AE will show any enrichment above local background as absolute values, the EF will show five times the enrichment due to the low detritial component. Figure 4.4.4 shows the difference between the enrichment factor and absolute enrichment for As in Kawau-1A.

Arsenic was enriched by around 3ppm in the Tartan Formation, and by around $1.5 \mathrm{ppm}$ in the uppermost sample, in the AE graph the enrichment comes across as such, however, the EF is a ratio of As relative to the amount of detrital indicators, hence it is higher in samples which have lower detritial input.

Enrichment factors may be a better method when dealing with elements such as Mn which are depleted under anoxic conditions. Assuming the depletion is leaching the element directly from the detrital content of the sediments, an enrichment factor should be a more appropriate method to express this as it would then represent the fraction of the $\mathrm{Mn}$ dissolved, the AE formula would in this case vary with detrital content. 


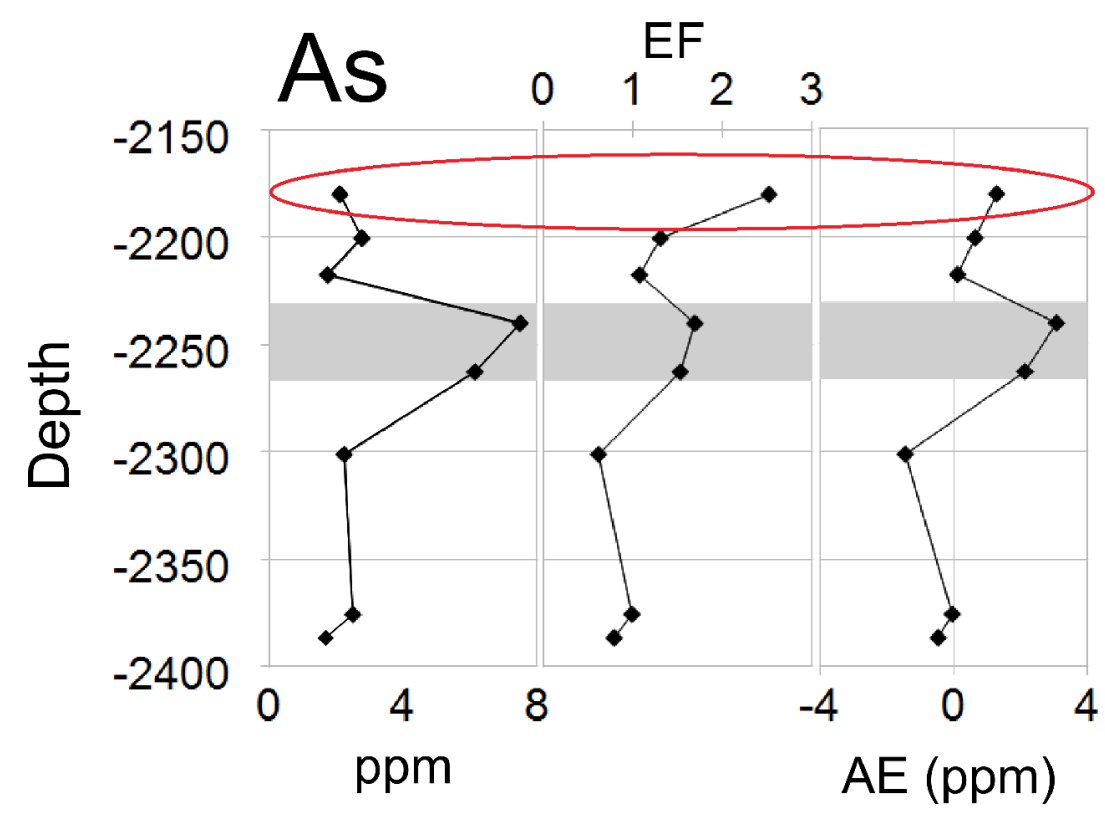

Figure 4.4.4: A comparison of $E F$ and $A E$ for Arsenic. The sample most effected is circled in red. See text for discussion.

$\mathrm{Sr}$ and $\mathrm{Mg}$ have been difficult to deal with, as most marine sediments contain some biological carbonate. The inclusion of $\mathrm{Ca}, \mathrm{Sr}$ and $\mathrm{Mg}$ in biological carbonate as well as being minor components in the terrestrial minerals has made extracting enrichment data difficult. While often measured, these elements generally are not interpreted any further (e.g. Brumsack, 2006; Ross and Bustin, 2009).

The present study suggests a technique for dealing with these elements using ternary plots. However, to produce meaningful results, this technique should only be used in areas where the local background has been defined. This technique will aid in making corrections where two mechanisms of enrichment are prevalent, in this case biological calcite and detrital component. $\mathrm{Sr}$ and $\mathrm{Mg}$ are both used in conjunction with Ca in palaeothermometry (e.g. Dodd 1967), but if any other environmental conditions have an effect on these elements differences may be difficult to detect.

Figure 4.4.5 shows a ternary plot for $\mathrm{Ca}, \mathrm{Sr}$ and $\mathrm{Al}$ for the samples from Angora Stream, along with values for average shale from Wedepohl (1971). Average shale has a very different concentration to the measured samples at Angora Stream and hence would not be suitable for making corrections. The intersection point between the trend line and the edge of the ternary plot occurs where $\mathrm{Sr} * 500$ is equal to $22.9 \%$ of the $\mathrm{Sr} *$ $500+\mathrm{Al}_{2} \mathrm{O}_{3}$ value. 


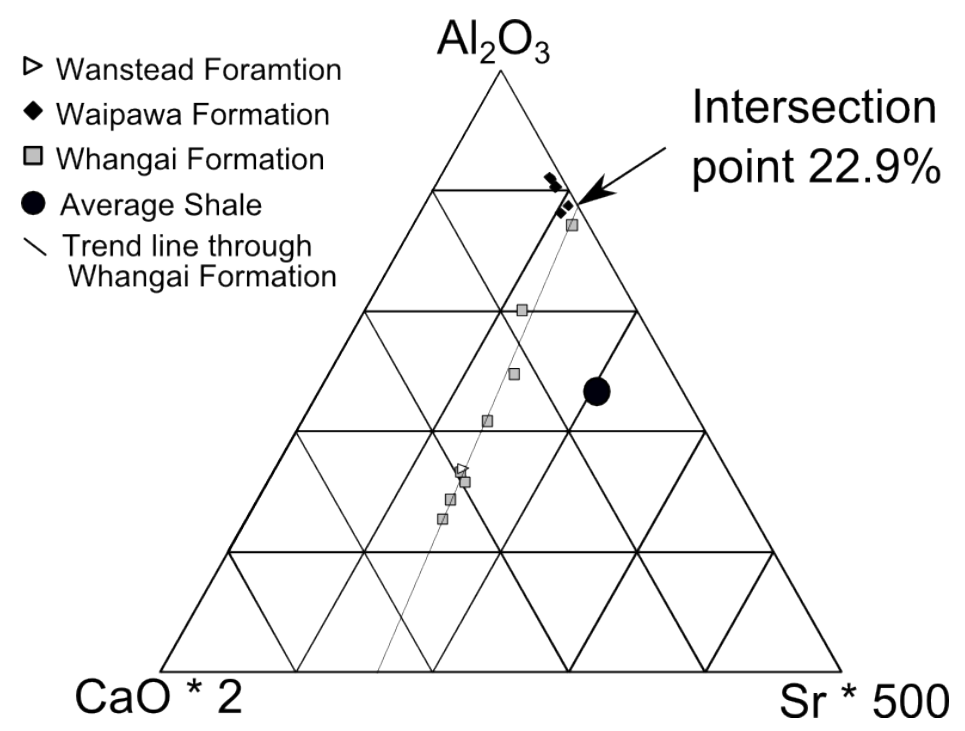

Figure 4.4.5: Ternary plot used to correct $\mathrm{Sr}$ for both local background and carbonate inclusion. Average shale as defined by Wedepohl (1971) is significantly different to values for all the East Coast Basin formations included in this study.

In an ideal situation where all $\mathrm{Ca}$ and $\mathrm{Sr}$ is purely biological and none is introduced from a detrital origin or included in another mineral phase (e.g. gypsum), the line would plot directly through $\mathrm{Al}_{2} \mathrm{O}_{3}$, indicating that $\mathrm{Sr} / \mathrm{Ca}$ varies independently from the detrital content. However, this ideal situation is unlikely so another method must be used to correct for both the biological and the detrital sources of $\mathrm{Sr}$ and $\mathrm{Ca}$.

An assumption must be made for this form of correction that the element varies in the background samples purely due to two sources, in this case detrital content and calcareous input. This can be expressed as:

$$
\mathrm{E}_{\mathrm{S}}=(E / C a)_{\text {DETRITAL }} * \mathrm{Al}+(E / C a)_{\text {BIOLOGICAL }} * \mathrm{Ca}_{\mathrm{BIO}}
$$

where $E_{\mathrm{S}}$ is the amount of element in the sample, $(\mathrm{E} / \mathrm{Ca})$ is the element ratio in either the detrital, or biological calcite fraction, Al is the amount of aluminium, taken to represent the detrital input, and $\mathrm{Ca}_{\mathrm{BIO}}$ is the biological calcite.

The intersection point on the ternary diagram represents only the difference between the $\mathrm{Sr} / \mathrm{Ca}$ ratio in the detrital component and in the calcite. Applying a correction to the $\mathrm{Sr}$ values relative to Al will cause the line to plot directly through the $100 \% \mathrm{Al}_{2} \mathrm{O}_{3}$ point. As the intersection point is at $22.9 \% \mathrm{Sr} * 500$ or $87.1 \% \mathrm{Al}_{2} \mathrm{O}_{3}$, the correction needs to be:

$$
\mathrm{Sr} * 500_{\mathrm{s}}-(22.9 / 87.1) * \mathrm{Al}_{2} \mathrm{O}_{3 \mathrm{~S}}
$$


where $\mathrm{s}$ represents sample.

This correction does not remove the entire background Sr, nor does it remove the $\mathrm{CaO}$ background input. The effect of this correction is purely to apply a correction to the detrital fraction of element E such that

$\left(\mathrm{E}_{\text {Corrected }} / \mathrm{Ca}\right)_{\text {Detrital }}=(\mathrm{E} / \mathrm{Ca})_{\text {Biological }}$

This correction was applied to a synthetic data set where the amount of detrital Al and biological $\mathrm{Ca}$ were calculated using random number generators. $1 \%$ of the detrital $\mathrm{Al}$ value was taken to represent detrital $\mathrm{Ca}, 0.1 \%$ of biological $\mathrm{Ca}$ value biological $\mathrm{Sr}$, and $0.03 \%$ of the detrital Al value detrital Sr. Sr was then multiplied by 500. Figure 4.4.6 shows the impact of this correction on a synthetic data set without random measurement errors and assuming a constant $\mathrm{Sr} / \mathrm{Ca}_{\mathrm{BIOLOGICAL}}$ (no temperature effects).

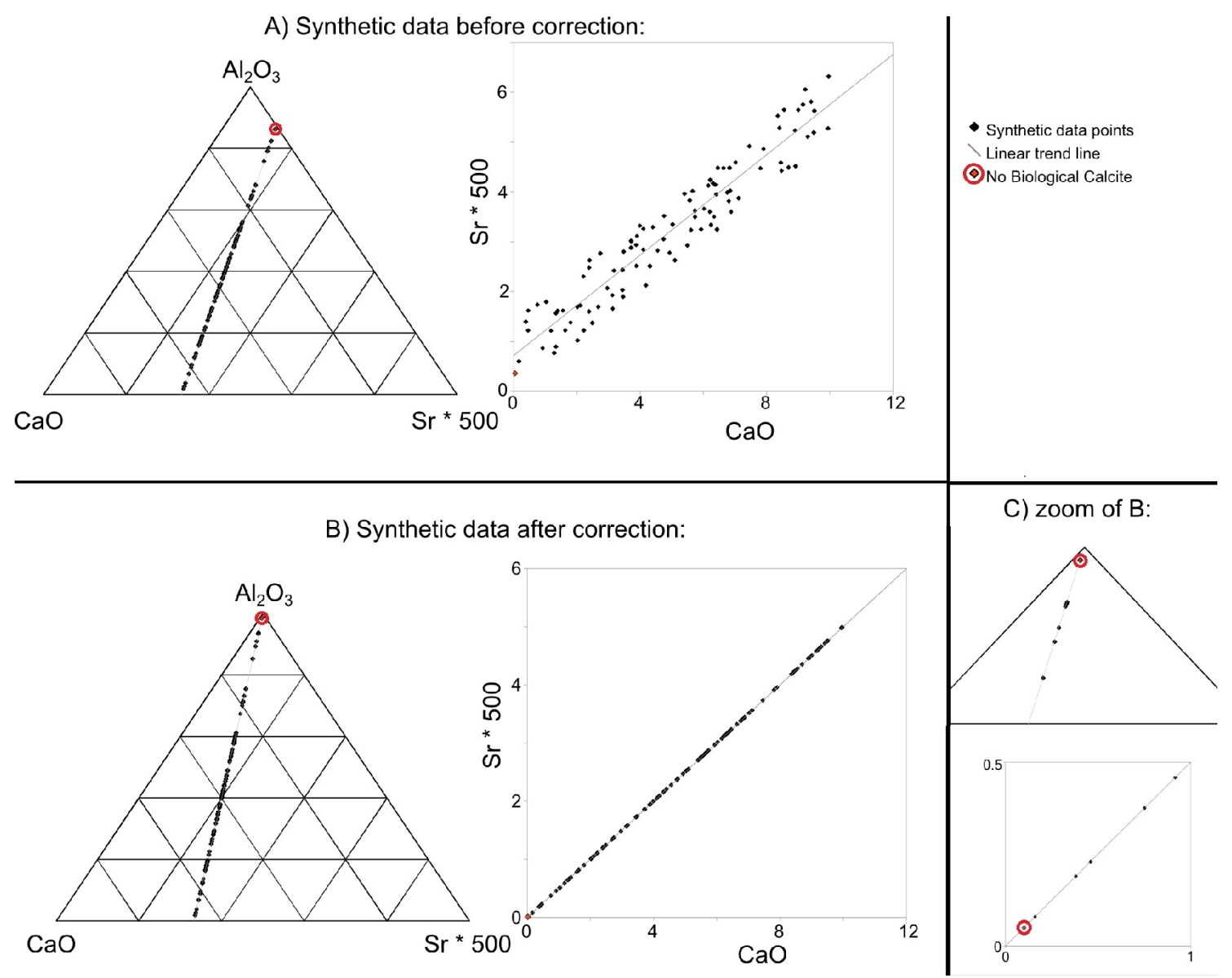

Figure 4.4.6: The first step of the correction method for elements which have two background inputs. The points are synthetic data points representing a set of background samples in which purely biological calcite and background detrital content are important. See text for details. 
As can be seen from the graphs (figure 4.4.6), a trend with a large amount of variation is visible in the Cartesian graph prior to the correction but this variation is removed completely after the correction in $\mathrm{B}$. The amount of variation before the correction is purely due to the variations in both detrital content and calcite content. The correction is not perfect, as can be seen from the red diamond representing purely detrital calcite in $\mathrm{C}$. However, the detrital value has been moved onto the trend line indicating that the remaining detrital calcite has the same ratio of $\mathrm{Sr} / \mathrm{Ca}$ as the biological calcite.

While the synthetic data does not have random errors and we can make assumptions that $\mathrm{Ca} / \mathrm{Sr}$ is constant, real data cannot and this correction may under some circumstances needs to be adjusted. The value on the ternary diagram is an indication of an approximate value; the effect of converting the data to fit in a ternary diagram and applying a correction relative to $\mathrm{Al}$ are both non-linear corrections relative to the $\mathrm{Ca}$ values. This limitation causes the trend line calculation to give slightly different results after the correction to what might otherwise be expected. The detrital correction may hence need to be adjusted using a standard Cartesian graph with $\mathrm{Sr}_{\mathrm{CORRECTED}} / \mathrm{Ca}$. A trendline forced through 0,0 should be applied to the data, and the adjustment value altered to produce the best possible $\mathrm{R}^{2}$ value.

Data points at each end of the Cartesian graph can alter the slope of the graph significantly and hence the intercept. By forcing the intercept through zero and adjusting towards the best $\mathrm{R}^{2}$ value, dependent on the errors and the spread of the data the difference in the value from that extracted from the ternary diagram may or may not be significant; in this study the difference was trivial.

The final step of the correction method is to remove the pseudo-biological input; as part of this is still the detrital content which has the same $\mathrm{Ca} / \mathrm{Sr}$ ratio, this will also be removed. A gradient must be extracted from the Cartesian $\mathrm{Ca} / \mathrm{Sr}$ graph, then a simple correction removes an absolute amount of $\mathrm{Sr}$ dependent on the amount of $\mathrm{Ca}$ in the sample. This is similar to the absolute correction formula but with $\mathrm{Ca}$ instead of $\mathrm{Al}$.

Several assumptions are made in this correction method. The most important is that the section defined as background is only affected by two influences. In the case of $\mathrm{Sr}$ the assumption is made that it is related purely to $\mathrm{Ca}$ and $\mathrm{Al}$. An assumption is also made that there are minimal changes in concentration of the element to the background 
ratio in both the biological sources. In the example used above, it is assumed that the temperature effects on the $\mathrm{Ca} / \mathrm{Sr}$ ratio are minimal and that there is no variation in the $\mathrm{Sr} / \mathrm{Al}$ or $\mathrm{Ca} / \mathrm{Al}$ ratio of the detrital background.

This method may be applicable for other sediment types and processes; however, the same assumptions of constant detrital ratio and a maximum of two sources for the element must also be applicable. If two elements vary identically due to the same environmental conditions a similar straight line will be observed. Ternary graphs can be used in this way to help identify which elements are related under different environmental influences.

The technique of calculating enrichments using ternary diagrams as described above gives absolute encihments; results for elements such as $\mathrm{Sr}$ should hence be comparable to elements which are affected by a single background corrected using the absolute enrichment formula. 


\section{$\underline{\text { Results }}$}

\subsection{Angora Quarry}

\section{Overview}

51 elements were measured for the Angora Quarry samples using XRF or ICPMS. Ti and Ca were measured using both techniques; Ti was used to provide a bulk correction to ICP-MS data accounting for any sample loss during digestion. $\mathrm{Ca}$, which showed great variation across the samples, was used to ascertain whether the two instruments produced compatible data and hence if it would be reasonable to combine the two studies into the same data set. Figure 5.0.1 shows a plot of $\mathrm{Ca}$ measured by the two instruments ( $\mathrm{Ca}_{\mathrm{XRF}}$ Vs. $\left.\mathrm{Ca}_{\mathrm{ICP}-\mathrm{MS}}\right)$. Results are presented in tables in appendix $\mathrm{C}$.

Both ICP-MS and XRF gave very similar results, with the trend line only

\section{XRF vs corrected ICP-MS}

Ca Corrected using XRF Ti Values

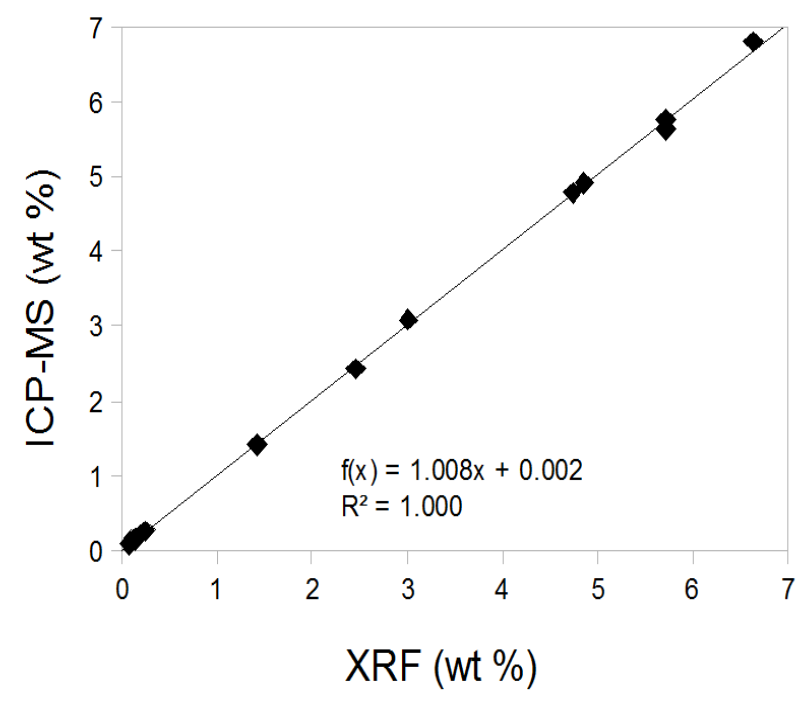

Figure 5.0.1: Graph of $\mathrm{Ca}_{\mathrm{XRF}} \mathrm{Vs}$. $\mathrm{Ca}_{\mathrm{ICP}-\mathrm{MS}}$ to ascertain whether these two techniques are comparable for this particular study. See text for discussion 
deviating slightly from the 1:1 ratio; such variation is well within the error limits of the analyses. The graph (figure 5.0.1) indicates that these two data sets can confidently be used conjointly.

Elements are presented in the same groups for all the locations and in the same order as in chapter 2.4. Where possible, the processes discussed in chapter 2 will be linked to results in the discussion chapter, although not all of the processes are observed.

\section{Major sedimentary components}

Ternary plots of $\mathrm{CaO}, \mathrm{Al}_{2} \mathrm{O}_{3}$, and $\mathrm{SiO}_{2}$ can be used to infer sediment composition, (Brumsack, 1989; section 2.2), as these three major oxides are the main inorganic compounds in most sediments. Moore (1988) measured oxides in many East Coast formations and figure 5.0.2 shows data from both his and the present study.

Values for $\mathrm{CaO}$ and $\mathrm{Al}_{2} \mathrm{O}_{3}$ are multiplied by constants ( 2 and 5 respectively) making them comparable to $\mathrm{SiO}_{2}$ and consistent with existing literature which uses the same values (e.g. Brumsack, 1989). A value for average shale (from Wedepohl, 1971) has also been plotted on these ternary diagrams; however, none of the samples analysed here nor any other samples analysed from the East Coast Basin have the same concentration as average shale.

A) This study:

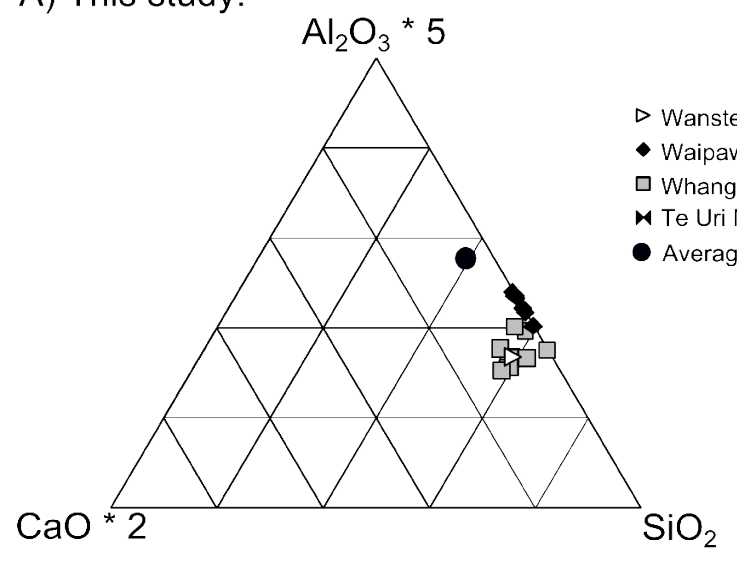

B) This study + Moore (1988): . 
This diagram already separates most Waipawa Formation samples from the Whangai Formation due to the decrease in calcite. The Te Uri Member of the Whangai Formation plots amongst the other Whangai Formation samples.

\section{Aluminium}

The graph for $\mathrm{Al}_{2} \mathrm{O}_{3}$ (figure 5.0.3) shows considerable variation with depth, from 7.5 to $12.8 \mathrm{wt} \%$. From sample A-A-1 to A-A-13 $\mathrm{Al}_{2} \mathrm{O}_{3}$ concentration can be viewed as either a near linear increase or a stepped increase with a middle step between 20 and $40 \mathrm{~m}$.

For the Angora Quarry samples, $\mathrm{Al}_{2} \mathrm{O}_{3}$ is used to correct the rest of the data for the terrestrial component and hence no enrichment factor or absolute enrichment graphs are plotted. For this and subsequent images, the grey band represents the Waipawa Formation, the black line represents field site A-A at the Quarry, and the grey line represents the section field site A-C, $\sim 1 \mathrm{~km}$ upstream. The "average shale" value for $\mathrm{Al}_{2} \mathrm{O}_{3}$ (Wedepohl, 1971) is $16.7 \mathrm{wt} \%$. Where possible this will be denoted with a

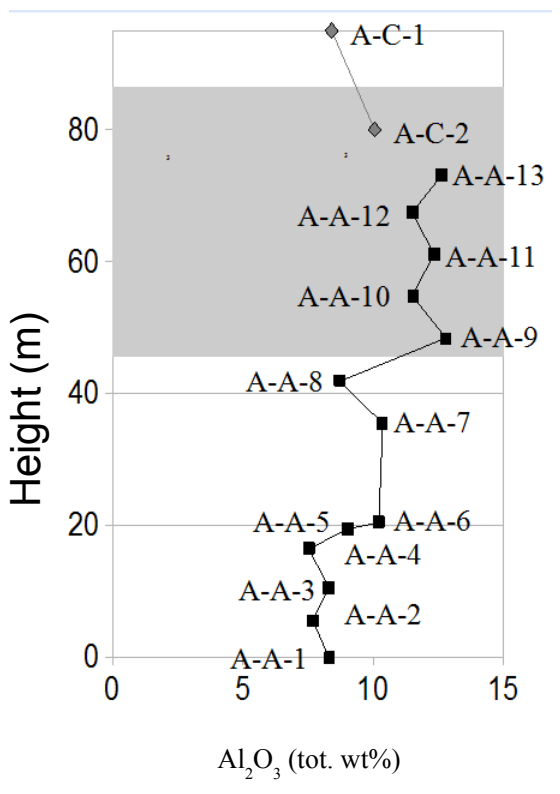

Figure 5.0.3 Variation of $\mathrm{Al}_{2} \mathrm{O}_{3}$ with depth. vertical line on the absolute variation sections; however, where this would require a change in scale that would obscure other variations within the formation, average shale is not plotted. Although samples have been labelled in figure 5.0.3, the samples are not labelled in the other graphs in this section as the graphs are smaller. Hence this graph should be used for sample reference.

\section{Mainly terrestrially-sourced elements}

Figure 5.0.4 shows the graphs for the other elements for which the variation is assumed to be largely due to detrital contribution to the sediments. Most of the elements show a similar trend to $\mathrm{Al}_{2} \mathrm{O}_{3}$, and have an enrichment factor of about 1 and an absolute enrichment close to 0 . The single exception is Ga which does not vary along with the 

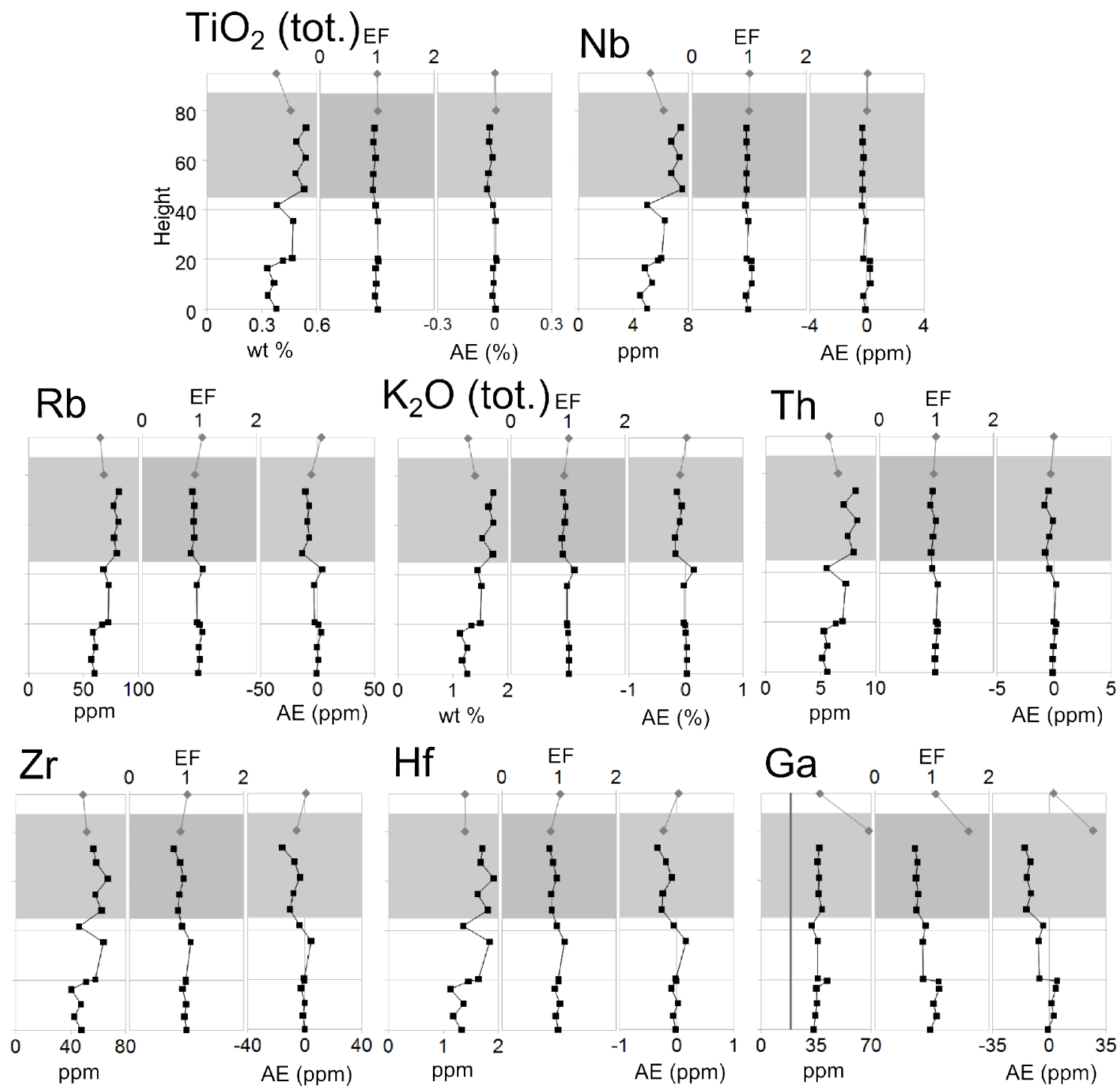

Figure 5.0.4: Depth vs. Elements thought to be detrital indicators (as discussed in section 2.2) for Angora Quarry. EF is for enrichment factor, $\mathbf{A E}$ is for absolute enrichment.

other largely terrestrially-sourced elements.

As a cautionary note, care should be taken when viewing multiple enrichment factor graphs. The enrichment factor formula introduces the variation seen in $\mathrm{Al}$ into $\mathrm{EF}$ and $\mathrm{AE}$ graphs, and hence can increase the apparent correlation between unrelated elements (van der Weijden, 2002). For detrital elements this is not an issue, but for elements which are largely independent of Al it can falsely lead to an appearance of correlation. 


\section{Loss on ignition (LOI)}

LOI is the loss of mass when heated in a furnace to $1000^{\circ} \mathrm{C}$ and mainly indicates volatile mater. LOI (figure 5.0.5) increases through the Waipawa Formation, which may be due to the increase in organic matter, which reaches $6 \%$ in Angora Quarry (Lecike et al., 1992).

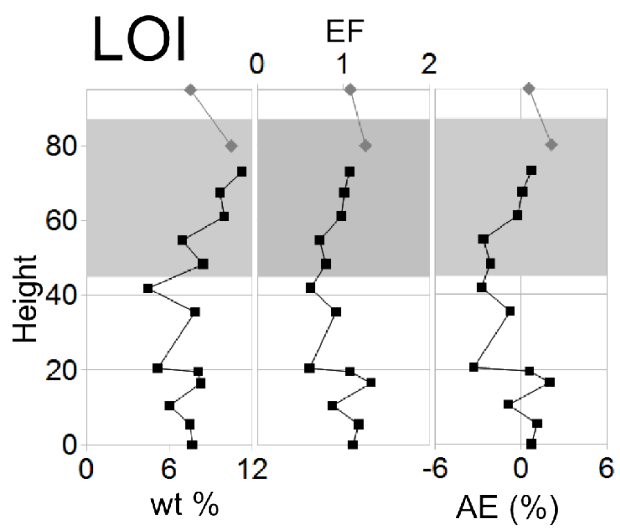

Figure 5.0.5: LOI through the Angora Quarry section.

\section{Indicators of anoxia (major components of sedimentary pyrite)}

Fe and $\mathrm{S}$ are plotted against depth in figure 5.0.6. Fe shows an increase at $20 \mathrm{~m}$, significantly below the Waipawa Formation in samples, but otherwise remains relatively uniform once corrected for terrestrial input. Sulphur shows depletion through the section; samples at 20.5, 41.9, 48.3, 54.7, 67.5 and 80 metres all had $\mathrm{SO}_{3}$ contents below the detection limit of $0.01 \mathrm{wt} \%$ for XRF. Further study to determine the exact concentration was not followed up here.

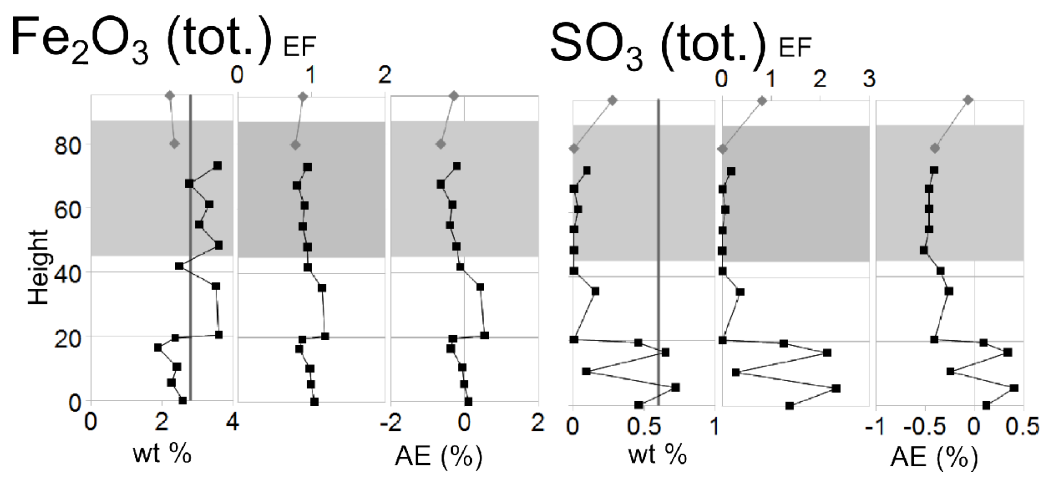

Figure 5.0.6: Graphs of Fe and S, which are the major components of pyrite.

\section{Indicators of anoxia (included in sedimentary pyrite)}

The abundance of $\mathrm{Zn}$ with depth (figure 5.0.7) varies significantly between 54 and 213 ppm, but only the sample at $41.9 \mathrm{~m}$ shows strong enrichment. Difficulties in measuring Mo were discussed earlier in this chapter, and the samples affected are highlighted in red. Concentrations of Mo fluctuate between 1.4 and 8 ppm throughout 


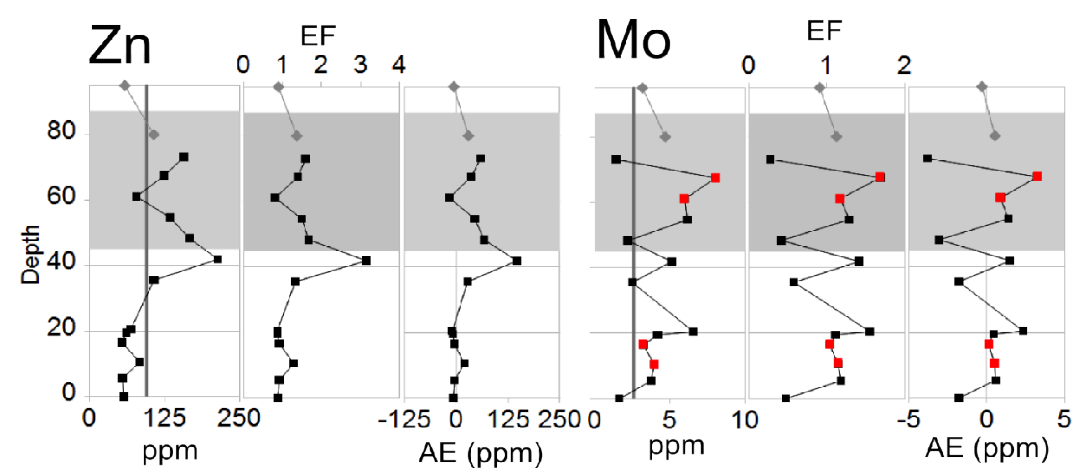

Figure 5.0.7: $\mathrm{Zn}$ and Mo at Angora Quarry. Highlighted in red are the samples which required the correction method described in figure 4.4.2 and associated text.

the section.

Indicators of anoxia (included in sedimentary pyrite); anthropogenic in recent sediments

$\mathrm{Pb}$ (figure 5.0.8) varies in a similar way to detrital content (figure 5.0.4), once detrital content has been corrected for using EF and AE formula, $\mathrm{Pb}$ shows considerably less variation however shows $2.7 \mathrm{ppm} \mathrm{AE}$ in one sample at $54.7 \mathrm{~m}$, during the deposition of the Waipawa Formation.

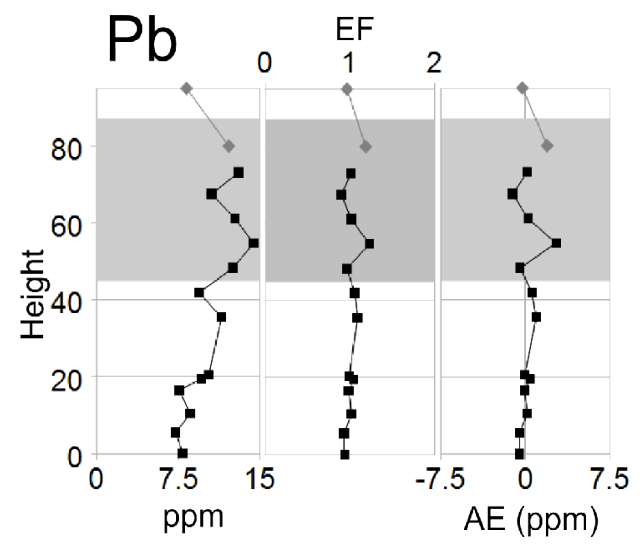

Figure 5.0.8: Depth graphs for $\mathrm{Pb}$ at Angora Quarry. There is considerably less variation in the $E F$ and $A E$ than that shown by the absolute concentrations.

\section{Biological component or involved in biocycling}

The elements which have a major biological component to them or which are important for biocycling are plotted in figure 5.0.9. 

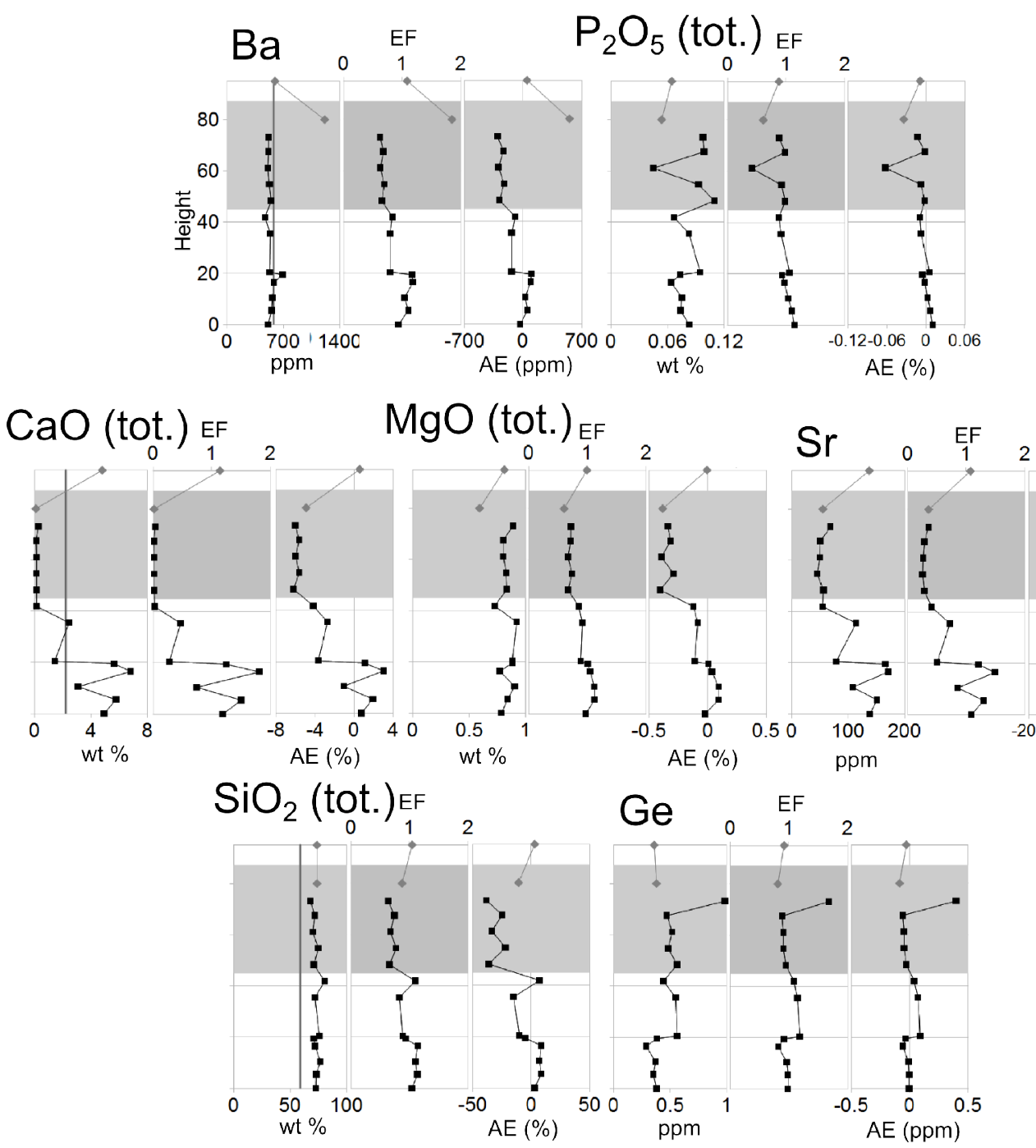

Figure 5.0.9: Depth plots of elements which have a major biological component or are involved in biocycling. The similarities between $\mathrm{Ca}$, and $\mathrm{Sr}$ are quite pronounced. There also appear to be to be similarities between $\mathrm{Ga}$ (figure 5.0.4) and $\mathrm{Ba}$.

$\mathrm{Ba}$ appears to have a similar trend to $\mathrm{Ga}$ (figure 5.0.4); however, a plot of $\mathrm{Ba} / \mathrm{Ga}$ with the A-C-2 $(80 \mathrm{~m})$ sample removed because it is significantly different only shows an $\mathrm{R}^{2}$ correlation of 0.55 (as opposed to 0.96 if A-C-2 is left in). Figure 5.0.10 shows $\mathrm{Ba} / \mathrm{Ga}$, and $\mathrm{a} \mathrm{Ba} / \mathrm{Al} / \mathrm{Ga}$ ternary diagram. Correlation in the ternary diagram is improved, with an $\mathrm{R}^{2}$ value of 0.94 without sample A-C-2. A better fit is attained by including $\mathrm{Al}_{2} \mathrm{O}_{3}$, indicating a these elements share the same detrital and non detrital component.

The similarities between $\mathrm{Ca}$ and $\mathrm{Sr}$ are clearly visible in figure 5.0.9. The normalisation technique described in section 4 was applied to $\mathrm{Sr}$ to create a version of AE which took into account both biological and detrital components (figure 5.0.11). The 


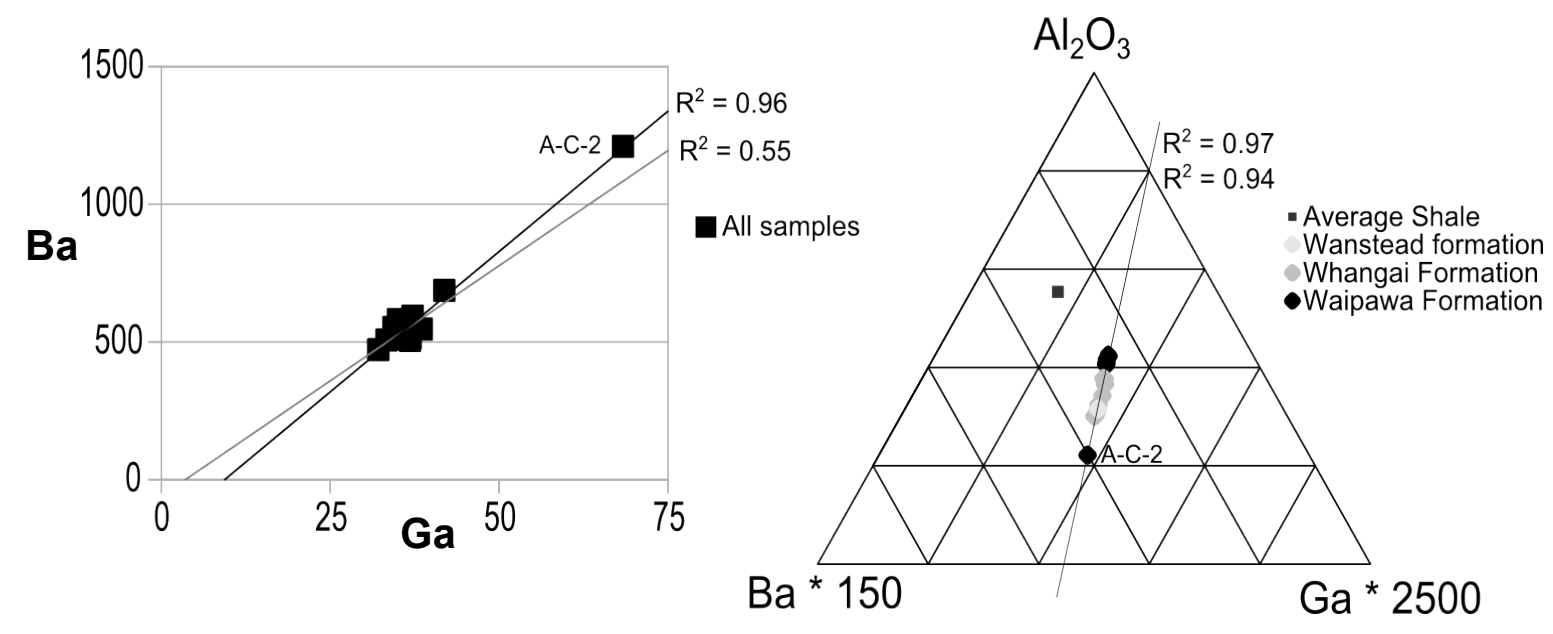

Figure 5.0.10: The relationship between $\mathrm{Ga}$ and $\mathrm{Ba}$ for the Angora Quarry samples. A direct relationship between $\mathrm{Ba}$ and $\mathrm{Ga}$ is not be indicated on the Cartesian graph; however, if the ratio differed in the terrigenous background to the biological process involved, the relationship would produce a better fit on the ternary diagram. In both cases, the upper $R^{2}$ value is with $A-C-2$ included and the lower value is without $A-C-2$.
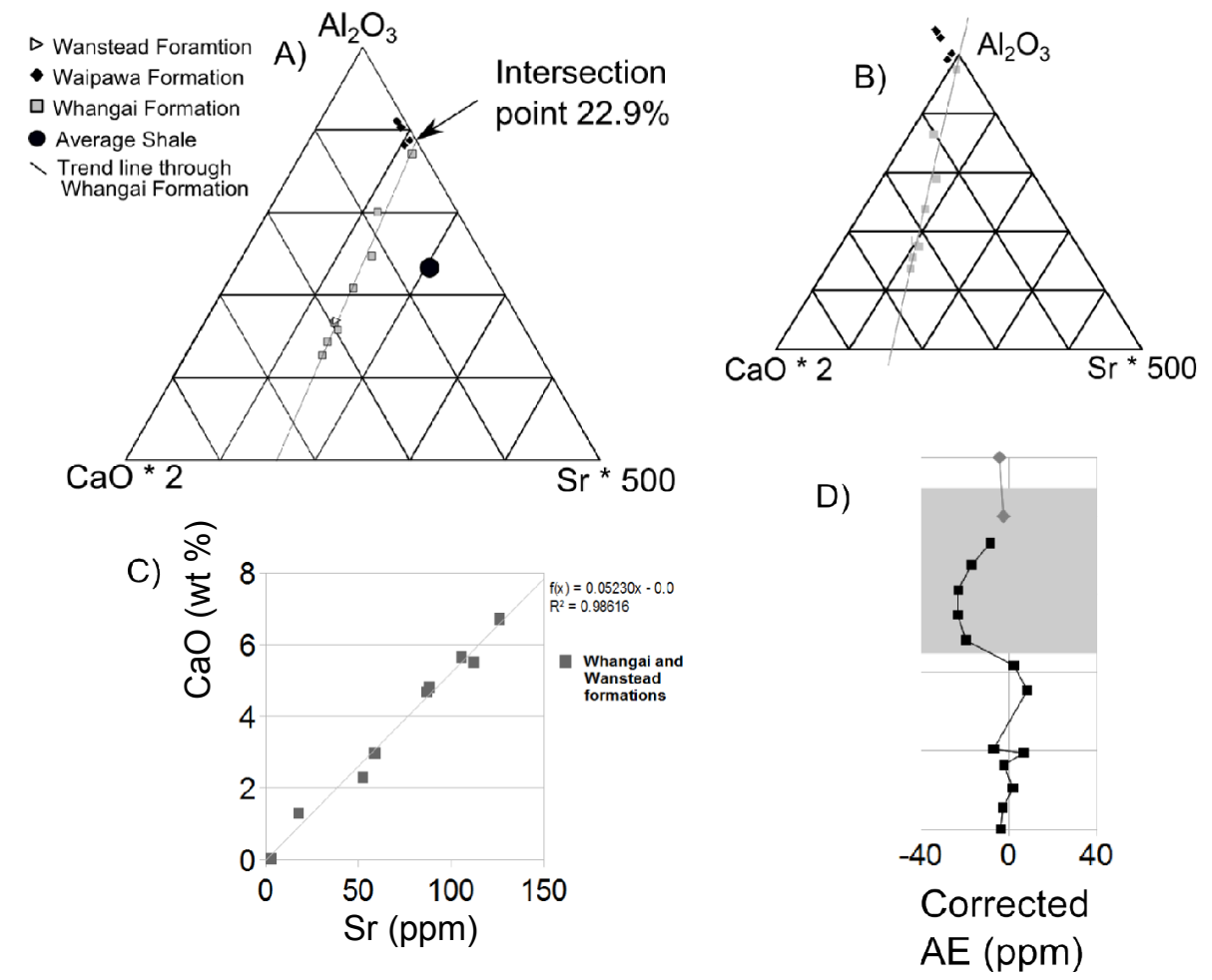

Figure 5.0.11: The correction of $\mathrm{Sr}$ for both $\mathrm{Al}$ and $\mathrm{Ca}$. A contains the raw data, $\mathbf{B}$ after the detrital correction, $\mathbf{C}$ after adjusting the correction, and $\mathbf{D}$ after applying the biological correction. 
depletion of $\mathrm{Sr}$ in the Waipawa Formation (D) is real depletion, as can be seen in figure 5.0.11 A where the Waipawa Formation samples plot further from Sr on the ternary diagram.
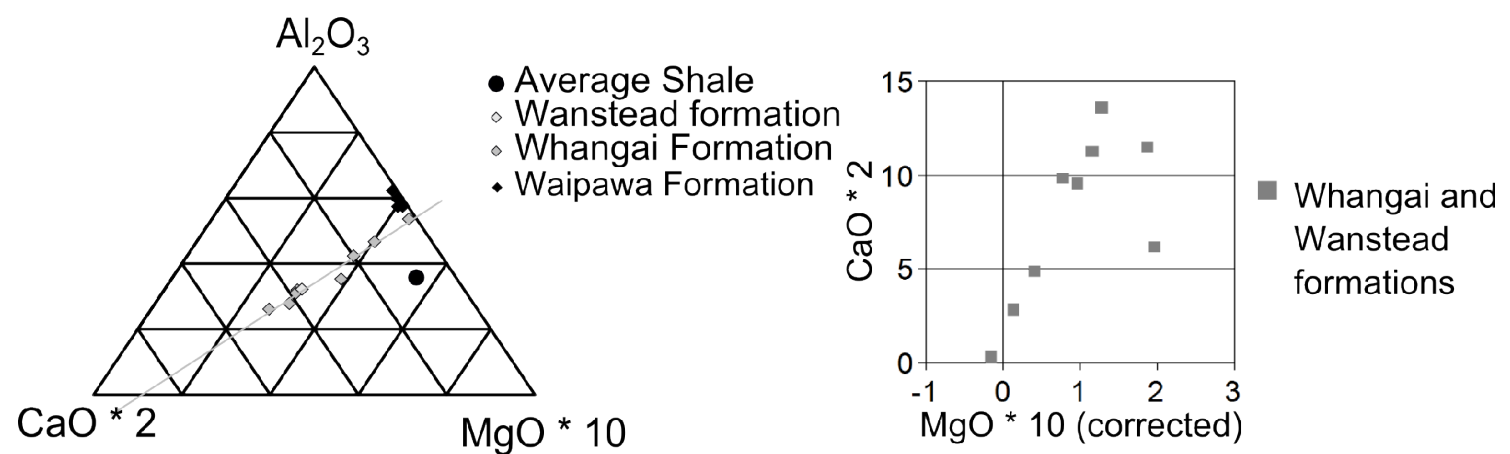

Figure 5.0.12: A ternary diagram for $\mathrm{Ca}, \mathrm{Mg}$, and $\mathrm{Al}$ (left), and a Cartesian graph (right) showing the corrected $\mathrm{Mg}$ data after the $\mathrm{Al} / \mathrm{Mg}$ ratio has been corrected.

An attempt was made to correct $\mathrm{Mg}$ in the same way as for Sr. However, on a ternary diagram (figure 5.0.12), $\mathrm{Mg}$ crosses very close to $\mathrm{Ca}$, showing that the variation is only slightly influenced by $\mathrm{Ca}$. In this study it appears that biological $\mathrm{CaCo}_{3}$ contributes only a minor amount towards the overall $\mathrm{Mg}$ content, and some other process is significant enough to impact on this correction. Therefore $\mathrm{Mg}$ could not be corrected in the same way as Sr but, in sediments with higher Ca contents and lower detrital contributions, it may be possible to correct for both biological and terregionous Mg content

The $\mathrm{CaO}$ depth graph (figure 5.0.9) has a similar shape to the $\mathrm{SO}_{3}$ depth graph (figure 5.0.6). Figure 5.0.13 shows the relationship between $\mathrm{SO}_{3}$ and $\mathrm{CaO}$. There is a definite similarity between $\mathrm{CaO}$ concentration and $\mathrm{SO}_{3}$, but the relationship is not linear and hence a direct linear relationship cannot be inferred.

No correlations were found between the other elements of biological origin. A change in element concentrations between samples 19.5 and $20.5 \mathrm{~m}$ (figure 5.0.9) is noticeable in all the biologically influenced elements, and appears far more prominent than the change in element concentration between the Whangai and Waipawa formations. 


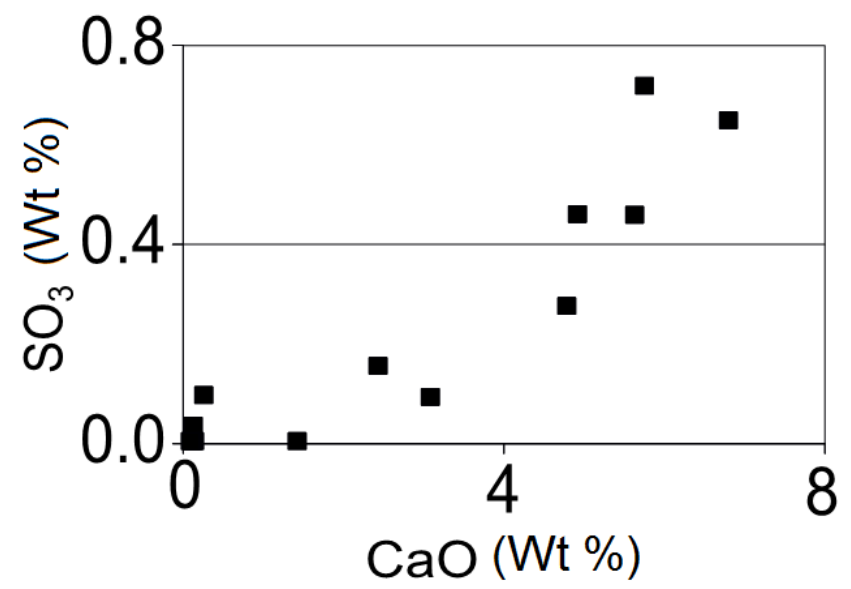

Figure 5.0.13: A plot of $\mathrm{CaO}$ vs. $\mathrm{SO}_{3}$ at Angora Stream. See text for discussion.

\section{Biological component or involved in biocycling; indicators of anoxia (included in} sedimentary pyrite)

No direct relationship could be found between $\mathrm{Cu}, \mathrm{Tl}, \mathrm{Cd}$ and $\mathrm{Ni}$ (figure 5.0.14) and any of the other biological indicators or indicators of anoxia. The two samples enriched in $\mathrm{Cu}(61.1$ and $80 \mathrm{~m})$ are also the two samples with lowest $\mathrm{P}$ content, but no other samples indicate a relationship between $\mathrm{Cu}$ and $\mathrm{P}$. Both the $\mathrm{AE}$ and the $\mathrm{EF}$
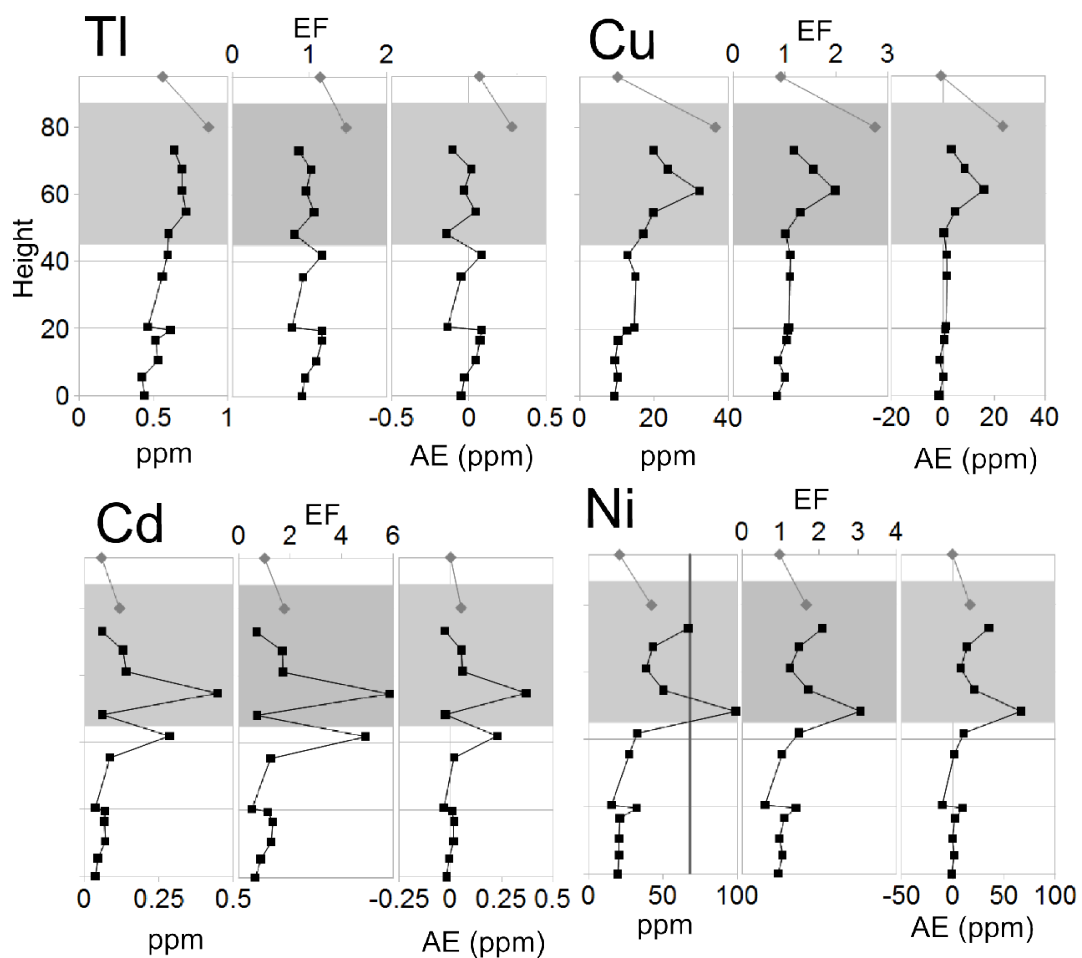

Figure 5.0.14: Depth graph for elements affected by both sedimentary pyrite and biological processes. 
methods introduce high frequency variation (larger variation in nearby samples) into the Tl graph. Both Cd and Ni show peaks near the base of the Waipawa Formation; both are involved in biocycling and are important for plankton growth. The peaks for these enrichments are in different samples therefore the reason for these abundances is not clear.

\section{Depleted under reducing conditions; indicators of anoxia (included in sedimentary pyrite)}

There is no correlation between $\mathrm{Mn}$ and Co (figure 5.0.15). Mn was measured using XRF, and could only be measured to $0.01 \mathrm{wt} \%$; hence the results should be treated with care. Co shows an increase in concentration through the Waipawa Formation. In average shale, $\mathrm{Mn}$ is present at $0.085 \mathrm{wt} \%$ (Wedepohl, 1971), which is considerably higher than the values measured for Angora Quarry.

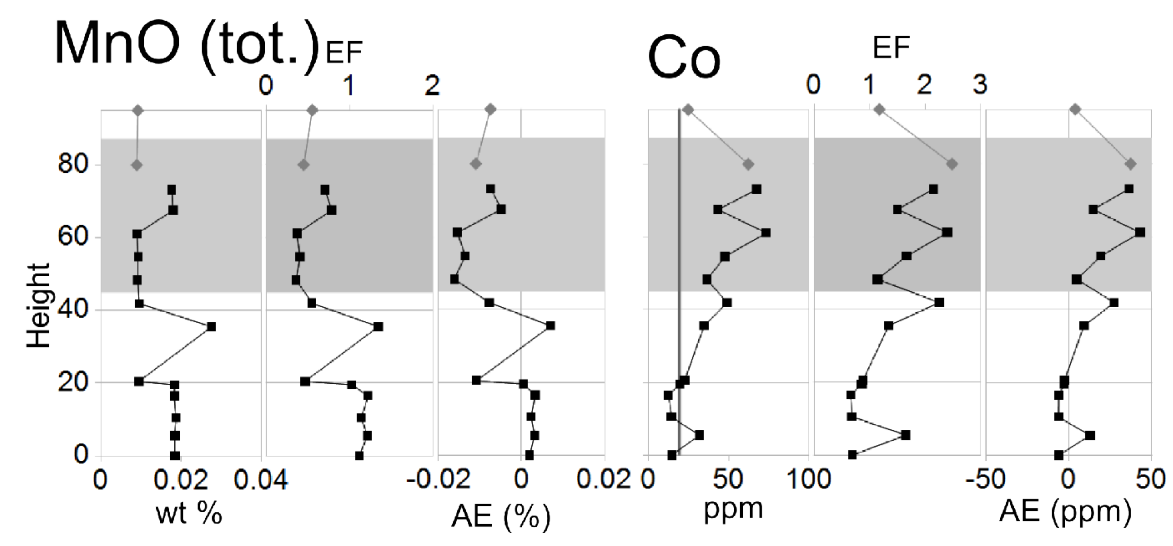

Figure 5.0.15: $\mathrm{Mn}$ and Co variations with depth. XRF results are measured to an accuracy of 0.01 wt \%.

\section{Enriched under reducing conditions}

$\mathrm{U}$, As and $\mathrm{Cr}$ all show a slight increase in concentration (figure 5.0.16), even after normalisation in the Waipawa Formation and, in the case of As, also in sample $20.5 \mathrm{~m}$. $\mathrm{V}$ is enriched in some of the Waipawa Formation samples but not to any significant degree. $U$ is significantly more abundant than in average shale through the entire section, whereas As and $\mathrm{V}$ are considerably less abundant than the average shale 
concentrations of 10 and $130 \mathrm{ppm}$ respectively.
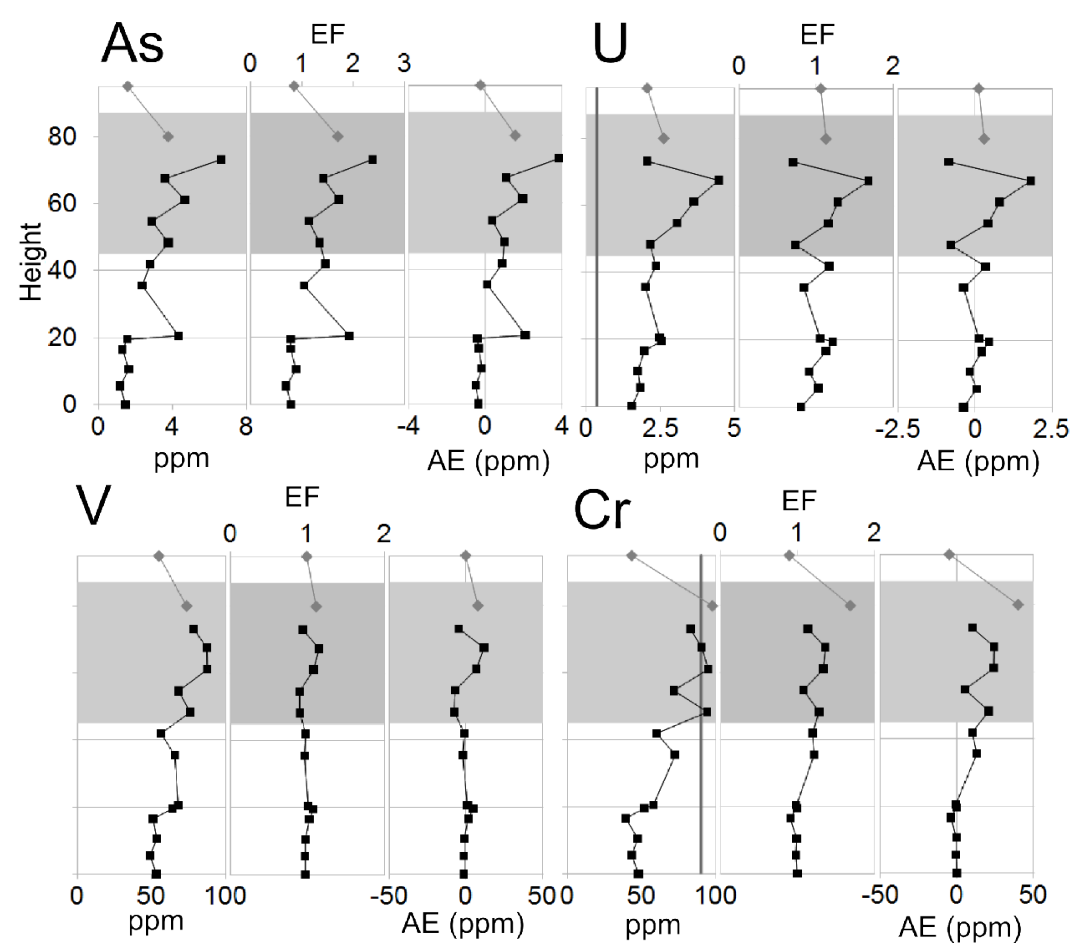

Figure 5.0.16: Elements which are generally enriched under oxygen depleted conditions.

\section{Enriched under reducing conditions, rarely studied}

$\mathrm{Sb}$ (figure 5.0.17) shows no distinct trend through the section, with great variations in concentration $(5-8 \mathrm{ppm})$ in the Whangai Formation samples. After correcting for detrital input $\mathrm{Sb}$ shows depletion in many of the Waipawa Formation samples.

\section{Rarely studied in sediments}

Sn shows little variation prior to detrital corrections (figure 5.0.18), and the correction introduces more variation. Aside from a peak in abundance in Li at $48.3 \mathrm{~m}$

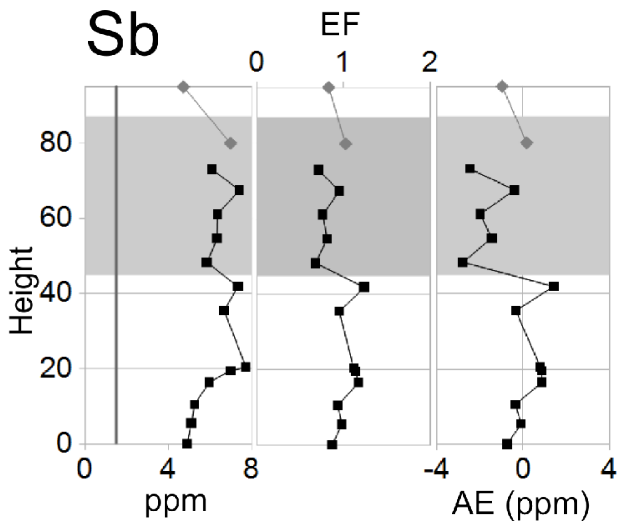

Figure 5.0.17: Antinomy is rarely studied but generally enriched under oxygen-depleted conditions. 
the concentration is relatively constant, especially in the AE and EF graphs. Na peaks in concentration at $41.9 \mathrm{~m}$, there are other minor fluctuations in the $\mathrm{AE}$ and $\mathrm{EF}$ sections for $\mathrm{Na}$.

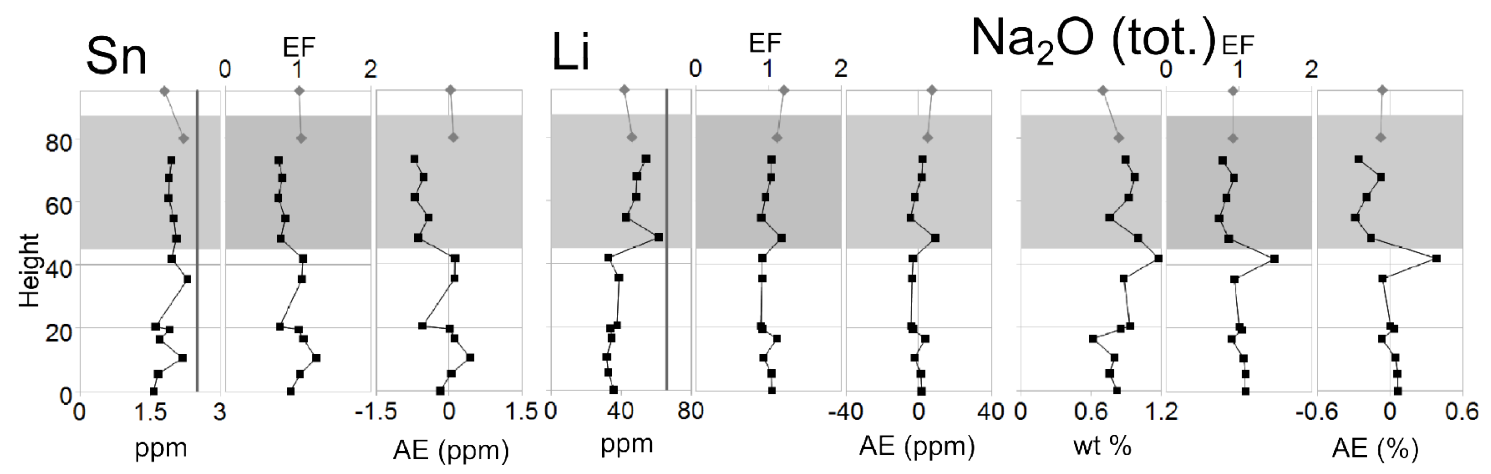

Figure 5.0.18: Element-depth graphs for elements which are rarely studied in sediments or which are generally not considered suitable for sediment studies.

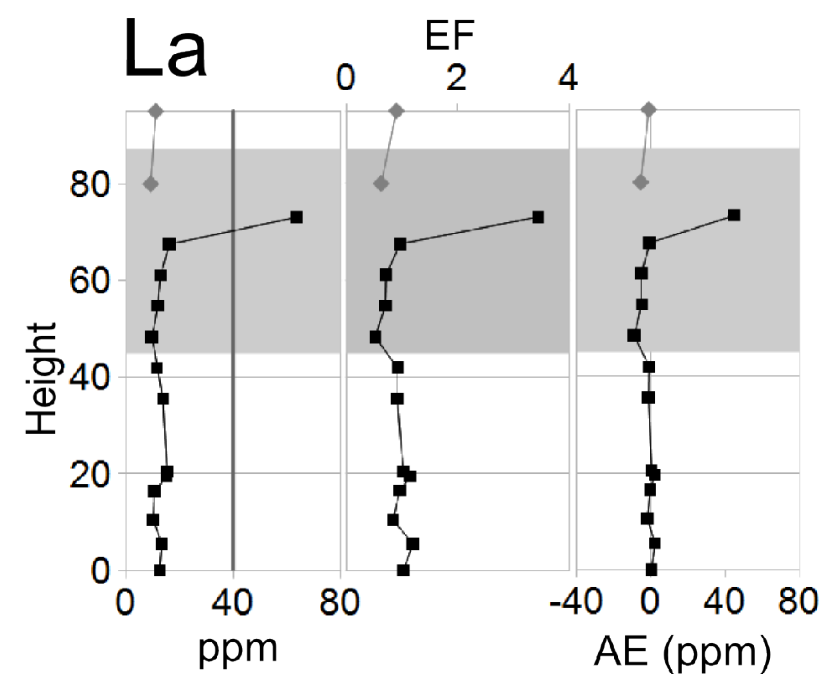

Figure 5.0.19: Depth section for La, all other REE and $Y$ which behaves like REE follow the same trend and have the same shape, so they were not plotted separetly.

\section{Rare Earth Elements (REE)}

Rare earth elements all show identical trends through the section, so only La was plotted (figure 5.0.19), the most prominent feature being the increase in abundance in sample A-A-13. A comparison between the different rare earth elements can be done by normalising them to different standards. The two standards used were average chondrite 


\begin{tabular}{|c|c|c|c|c|c|c|c|c|}
\hline & Chondrite & NASC & & Chondrite & NASC & & Chondrite & NASC \\
\hline $\mathrm{La}$ & 0.367 & 32 & $\mathrm{Eu}$ & 0.087 & 1.24 & $\mathrm{Er}$ & 0.249 & 3.40 \\
\hline $\mathrm{Ce}$ & 0.957 & 73 & $\mathrm{Gd}$ & 0.306 & 5.20 & $\mathrm{Tm}$ & 0.036 & 0.50 \\
\hline $\mathrm{Pr}$ & 0.137 & 7.9 & $\mathrm{~Tb}$ & 0.058 & 0.85 & $\mathrm{Yb}$ & 0.248 & 3.10 \\
\hline $\mathrm{Nd}$ & 0.711 & 33 & $\mathrm{Dy}$ & 0.381 & 5.80 & $\mathrm{Lu}$ & 0.038 & 0.48 \\
\hline $\mathrm{Sm}$ & 0.231 & 5.7 & $\mathrm{Ho}$ & 0.085 & 1.04 & $\mathrm{Y}$ & 2.250 & 27 \\
\hline
\end{tabular}

Table 5.0.1: Values for average chondrite and NASC from Taylor and McLennan (1985). These values represent 1 in figures 5.1.19 and 5.1.20.

and NASC (North American Shale Composite) from Taylor and McLennan, (1985).

Comparison of Angora Quarry rare earth concentrations to those of average chondrite shows that all of the former samples are enriched in the light REEs (La-Sm) (figure 5.0.20). There is little variation between the different samples, excluding sample A-A-13 which appears to be particularly enriched in the mid REEs (Pr- Er). A standard which appears to be more appropriate is the NASC standard, as this standard is also

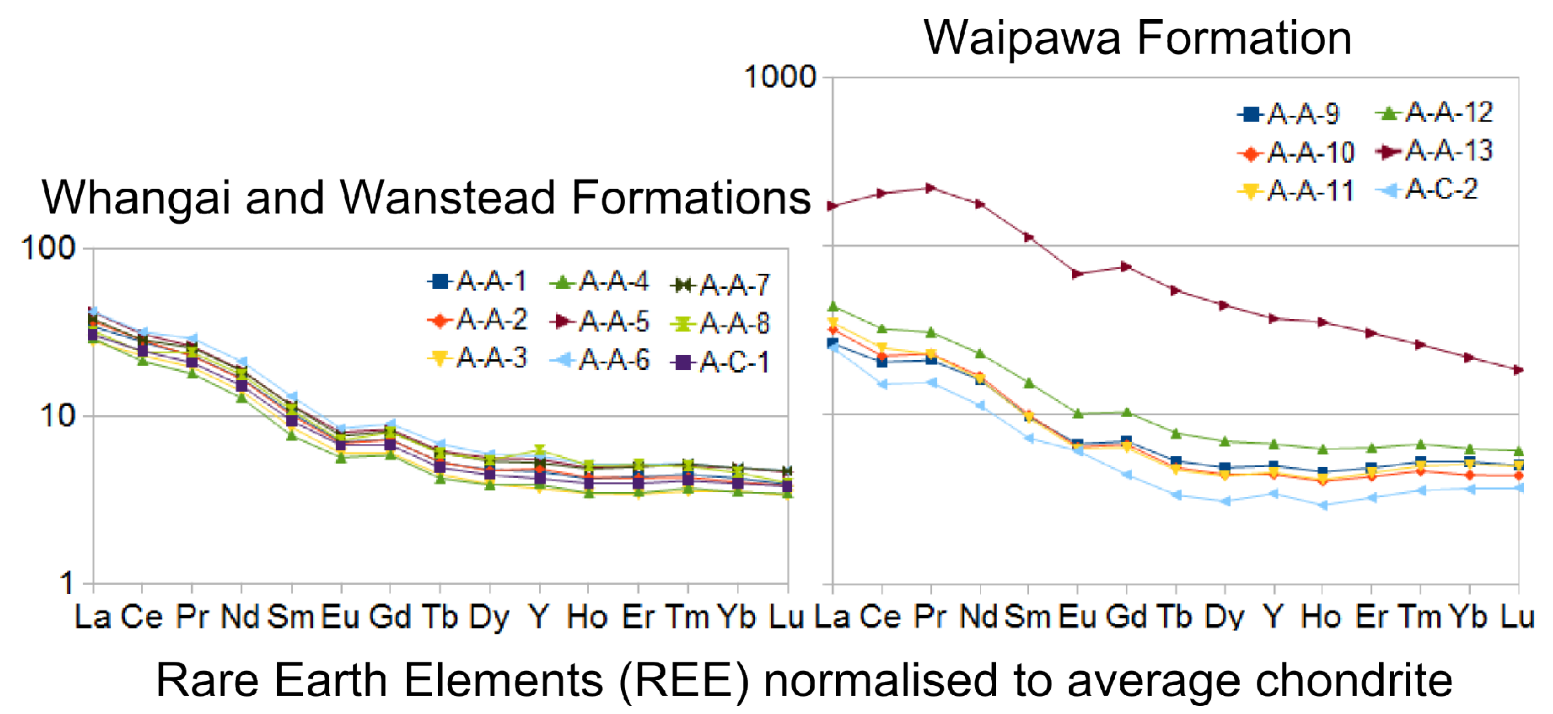

Figure 5.0.20: Rare earth elements from the section at Angora Quarry normalised to chondrite.

The Waipawa Formation samples are plotted separately from the Whangai and Wanstead formations.

enriched in light REEs (figure 5.1.21).

When normalised to NASC it is apparent that for the Whangai and Wanstead formations the trend is relatively uniform and flat, aside from A-A-8 which has less La and Ce than other Whangai Formation samples. The Waipawa Formation samples show more variation. Enrichment in the mid REEs is a lot more apparent in A-A-13, while A$\mathrm{C}-2$ shows more variation. In particular the latter is higher in $\mathrm{Eu}$ and more strongly 


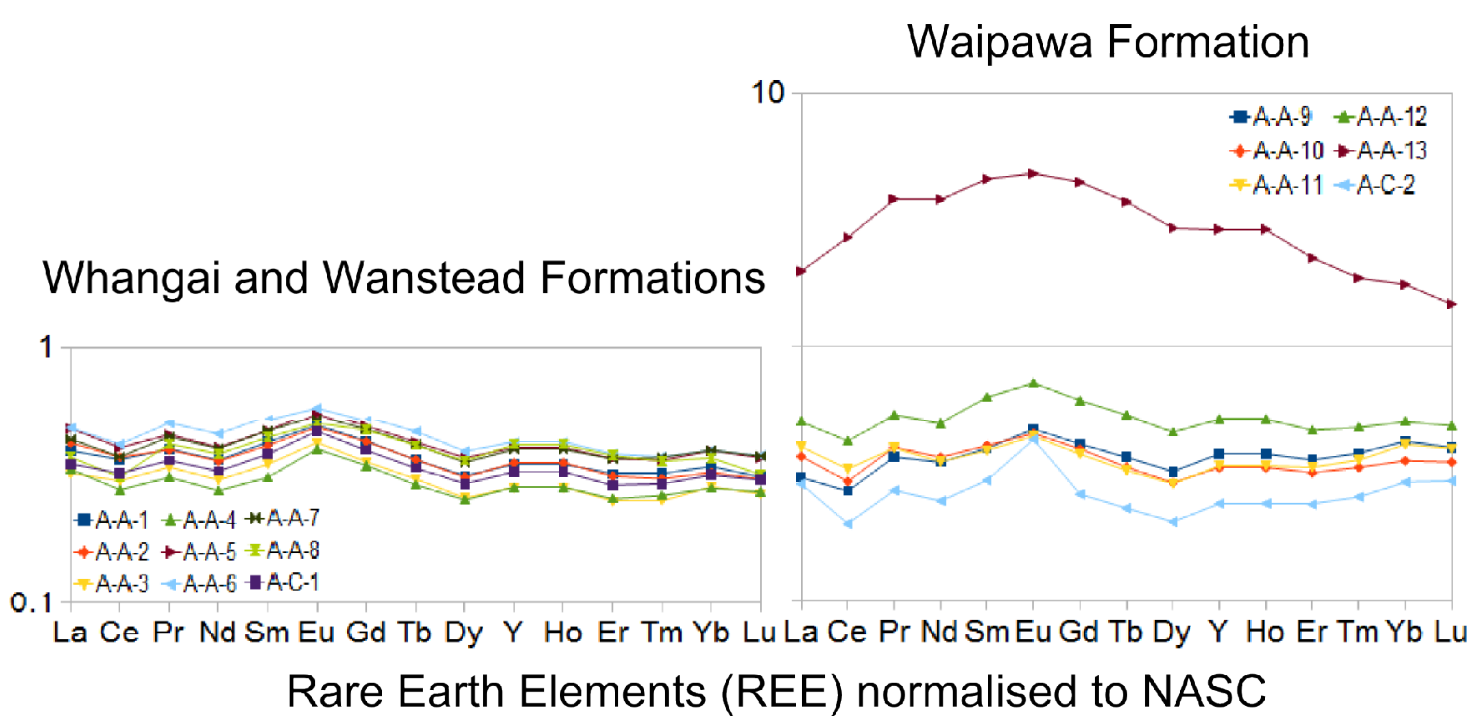

Figure 5.0.21: REE from Angora Quarry normalised to NASC. The Waipawa Formation samples are plotted separately from the Whangai and Wanstead formations.

depleted in Ce.

\subsection{Kawau-1A}

\section{Overview}

26 elements were measured for Kawau-1A. XRF was not conducted on the SWC samples from Kawau-1A as there was insufficient sample material. Al could not be measured due to the concentration being too high, therefore for EF and AE calculation purposes variations in $\mathrm{Hf}, \mathrm{Zr}, \mathrm{Nb}$ and $\mathrm{Ta}$ were averaged in this study. These elements were chosen as they are elements which are known not to vary fractionate significantly in nature (e.g. Ross and Bustin, 2009). Ti was not used as it can vary due to sedimentary sorting (Dellwig et al., 2000).

As no absolute concentrations were available to correct the data for potential sample loss, some samples may have lower concentrations across elements. The EF calculation is based on fractions within the sample and not on absolute concentrations, and thus the EF is unaffected; however the absolute concentrations and the AE may be affected. 
A comparison of two of the terrestrial indicators, $\mathrm{Ti}$ and $\mathrm{Zr}$, to the gamma ray $\log$ (figure 5.1.1) shows that the terrestrial background varies similarly to the gamma ray log. While the absolute concentrations may still vary slightly, the above indicates that it is likely to be approximately correct. However, the gamma ray log may be influenced by other factors as well as the terrestrial background and, whereas the side wall core represents only a few cm of sample, gamma ray log readings are averaged over several metres.

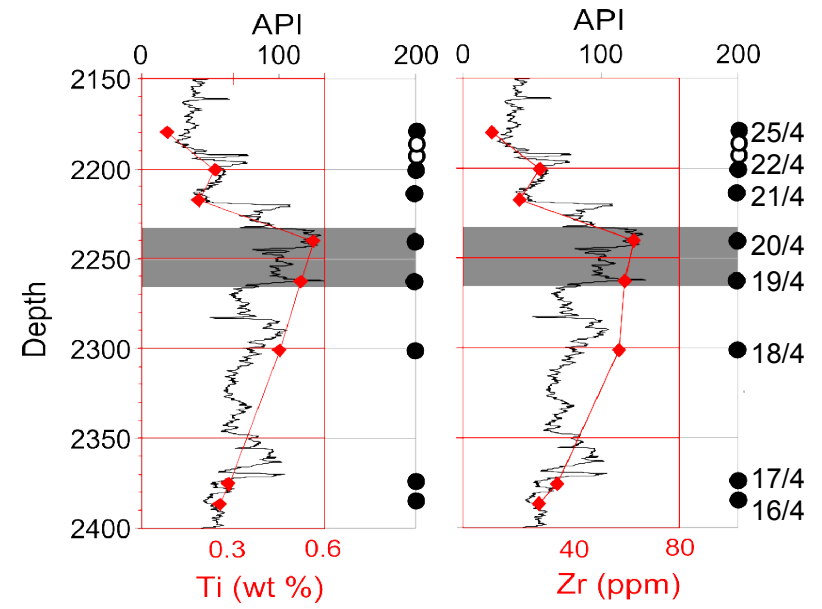

Figure 5.1.1: A comparison between two mainly terrestrially sourced elements $\mathrm{Ti}$ and $\mathrm{Zr}$, and the gamma ray log in Kawau-1A. The Gamma ray log has a maximum resolution of several metres while the SWC samples is a point sample representing only a few $\mathrm{cm}$. Sample numbers are shown to the right.

\section{Mainly terrestrially-sourced elements}

Variation in the terrestrial component within Kawau-1A is significant (figure 5.1.2). The stratigraphically highest sample $2180 \mathrm{~m}$ contains a fifth of the concentration compared to the top sample in the Tartan Formation $(2240 \mathrm{~m})$. This large variation makes a large difference in the EF; when these samples contain the same $\mathrm{AE}$, the $\mathrm{EF}$ is five times higher at $2180 \mathrm{~m}$. 

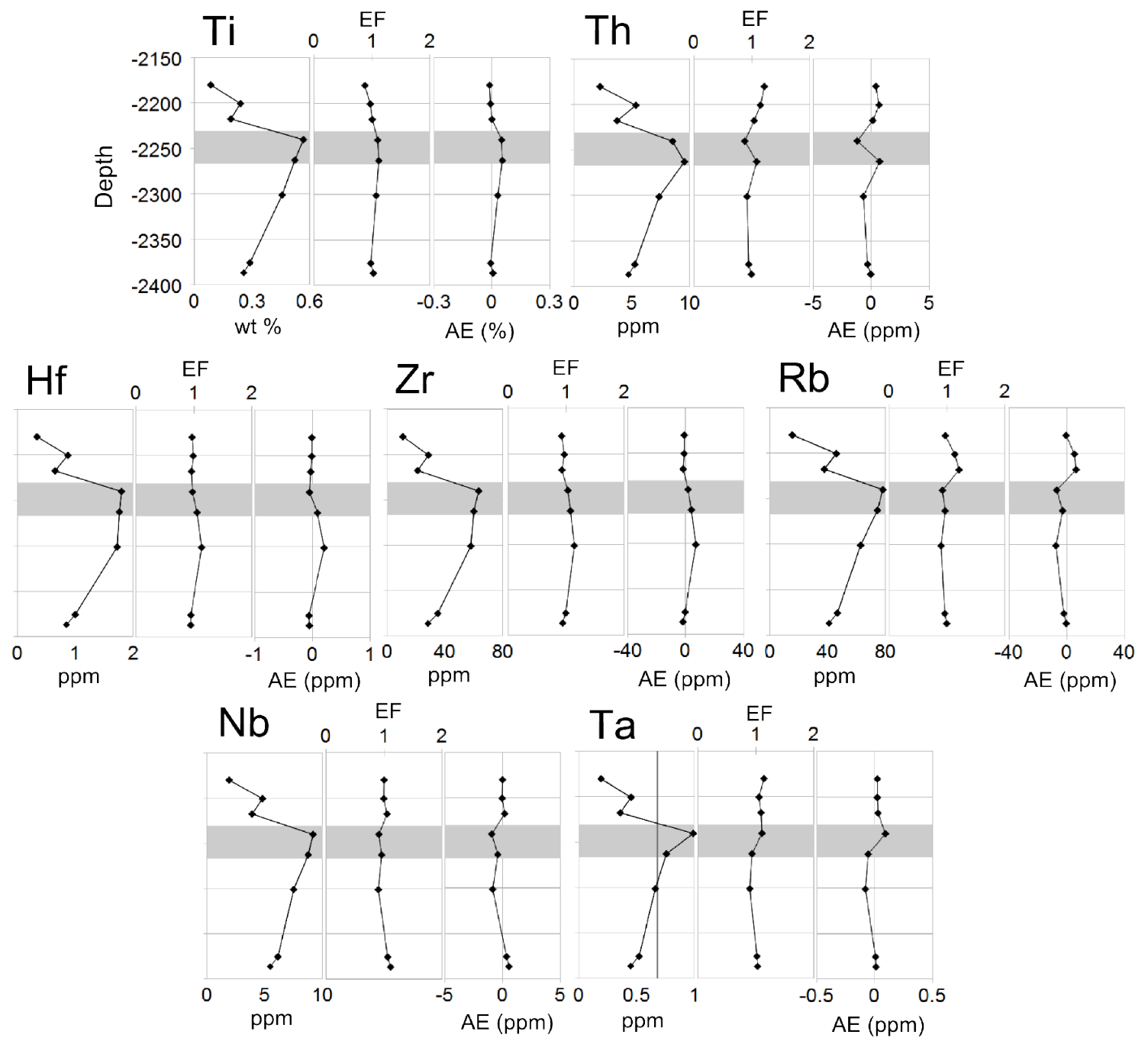

Figure 5.1.2: Terrestrial indicators in the Kawau-1A well plotted in their depth location in the well. See text for discussion.

\section{Indicators of anoxia (included in sedimentary pyrite)}

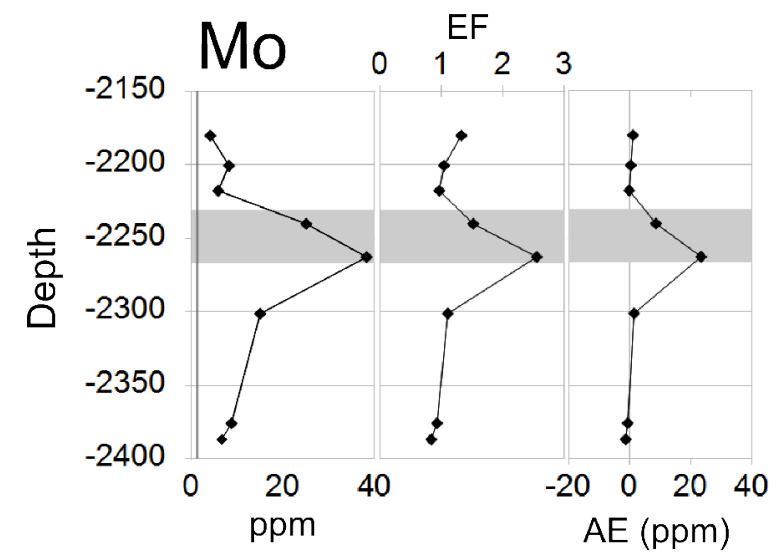

Figure 5.1.3: Mo in Kawau- $1 A$ well, both $A E$ and $E F$ show enrichment of Mo in the Tartan Formation, particularly in the lowermost sample. 
Mo shows significant enrichment through the Tartan Formation (figure 5.1.3), but otherwise there is minimal variation from the local background. For all samples the Mo content is greater than the $2.6 \mathrm{ppm}$ in average shale.

\section{Indicators of anoxia (included in sedimentary pyrite); anthropogenic in recent sediments}

$\mathrm{Pb}$ and $\mathrm{Bi}$ both show variation through the section (figure 5.1.4). $\mathrm{Pb}$ is depleted in the middle three samples $(2220-2305 \mathrm{~m})$ especially in the AE and EF figures. Bi also shows some depletion, although to a lesser degree.

The difference between EF and AE normalisation is evident especially in the top

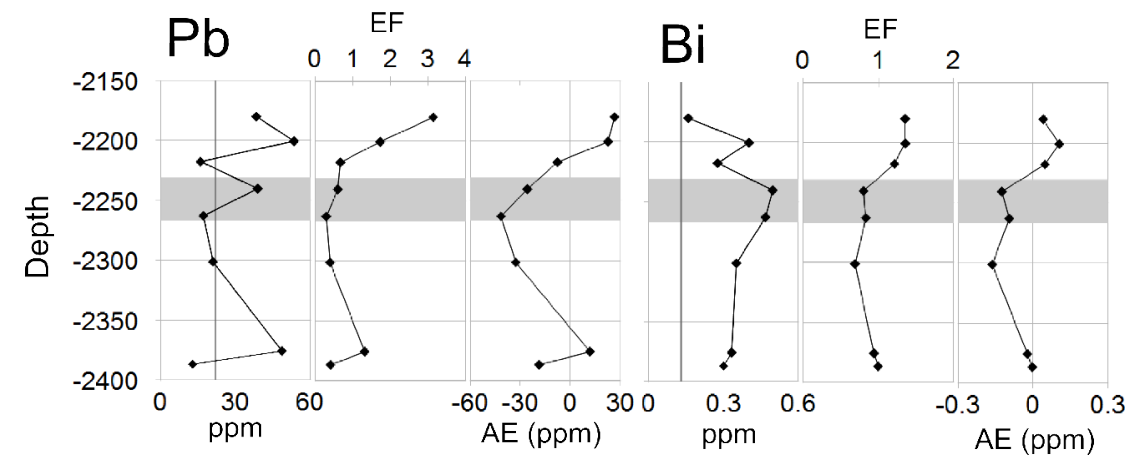

Figure 5.1.4: Depth graphs of $\mathrm{Pb}$ and $\mathrm{Bi}$ in Kawau-1A.

$\mathrm{Pb}$ sample. The AE is similar for the top samples $(2180$ and $2200 \mathrm{~m})$ but at $2180 \mathrm{~m}$ the SWC has a significantly higher EF as a result of having a detrital input some 2.5 times lower.

\section{Biological component or involved in biocycling}

Sr (figure 5.1.5) varies between 47 and 254 ppm through the Kawau-1A well;

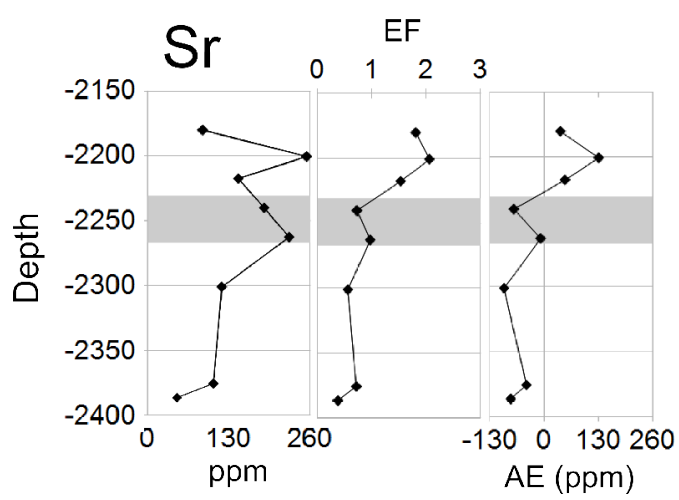

Figure 5.1.5: $\mathrm{Sr}$ variations through the Tartan Formation in the Kawau-1A well. 
however, all samples within the Laing Formation (above the Waipawa Formation) are the only elements which are enriched above the average background in both the AE and EF.

As the $\mathrm{Ca}$ concentration is unknown, using a ternary diagram as for Angora Quarry is not possible. $\mathrm{Ba}$ and $\mathrm{Ga}$ were also not measured, so a ternary diagram showing these is similarly not possible.

\section{Biological component or involved in biocycling; indicators of anoxia (included in sedimentary pyrite)}

$\mathrm{Tl}, \mathrm{Ni}$, and especially $\mathrm{Cd}$ are enriched in the uppermost sample (figure 5.1.6) from the Laing Formation. In the Tartan Formation $\mathrm{Cd}$ is relatively constant after the detrital correction, and $\mathrm{Tl}$ shows only minor changes. $\mathrm{Cu}$ and $\mathrm{Ni}$ both show increases within the
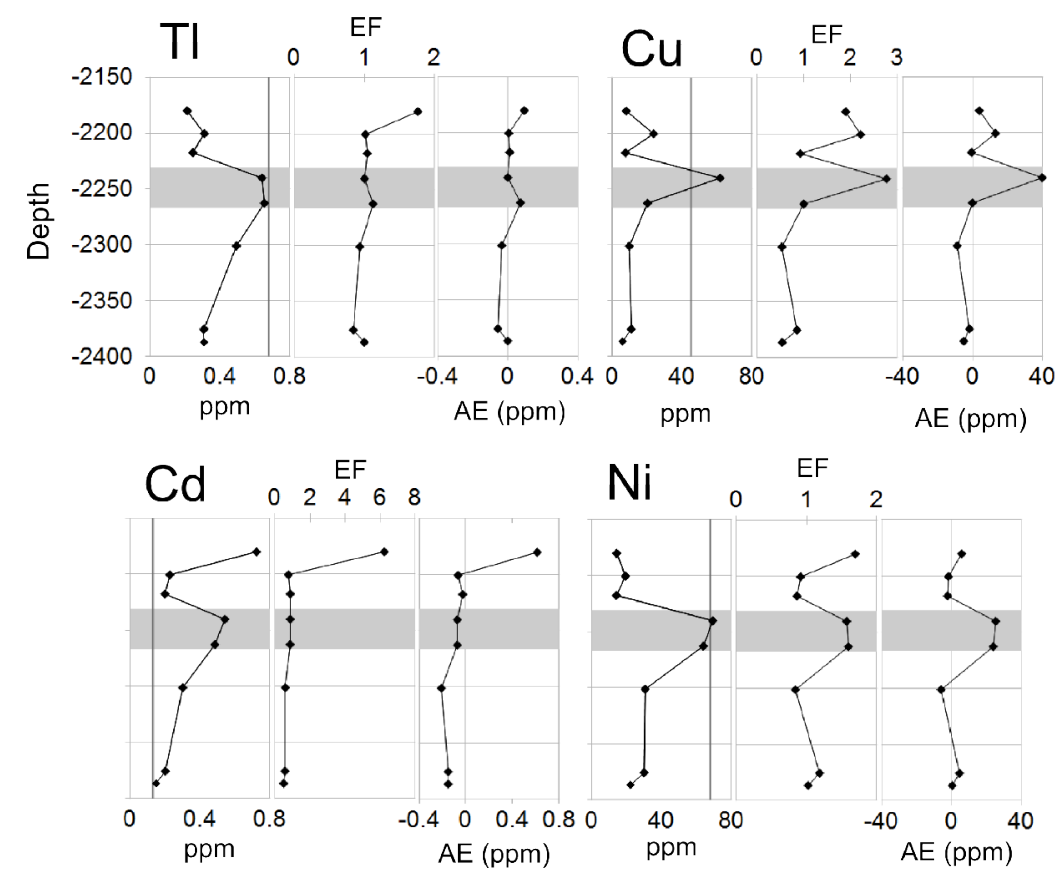

Figure 5.1.6: Elements which are enriched both by inclusion in sedimentary pyrite and through biocycling plotted against depth.

Tartan Formation, $\mathrm{Cu}$ only in the uppermost sample and $\mathrm{Ni}$ in both.

$\mathrm{Ni}$ and $\mathrm{Tl}$ are both examples of $\mathrm{AE}$ normalisation giving results which are more suitable than EFs for the largely varying background composition seen in Kawau-1A. 


\section{Depleted under oxygen-depleted conditions; indicators of anoxia (included in}

sedimentary pyrite)

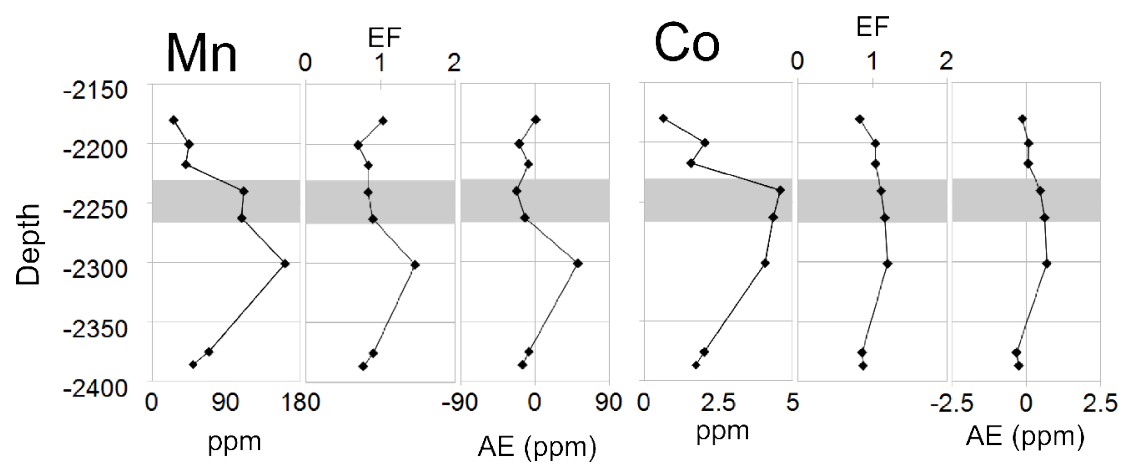

Figure 5.1.7: $\mathrm{Mn}$ and $\mathrm{Co}$ in the Kawau-1A well. See text for discussion

The Mn content is relatively constant (figure 5.1.7) except for $2300 \mathrm{~m}$, where there is $50 \mathrm{ppm}$ more $\mathrm{Mn}$ than expected. Co follows a trend very similar to the terrestrial indicators, and its EF is close to 1.

\section{Enriched under reducing conditions}
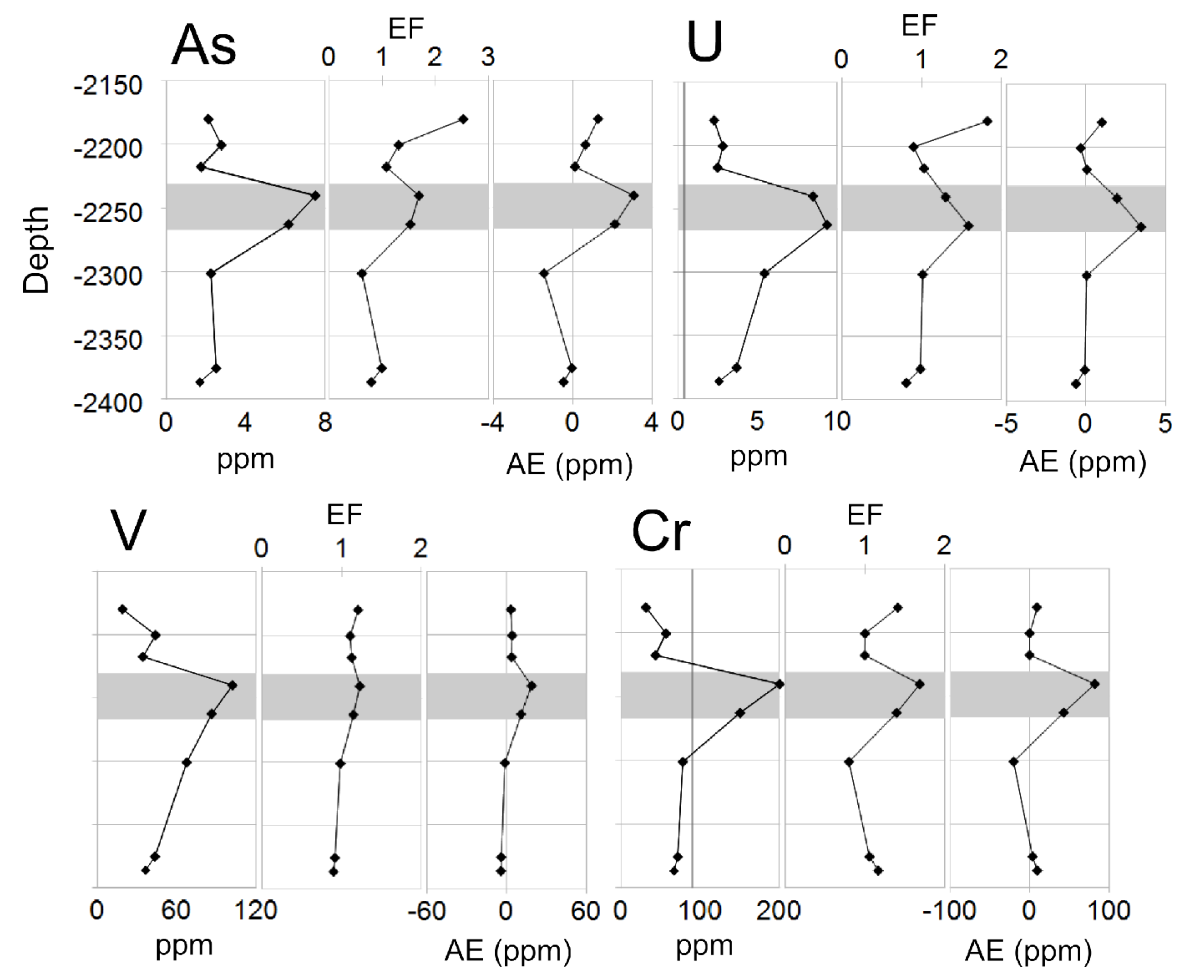

Figure 5.1.8: Elements which are generally enriched under oxygen-depleted conditions. 
Chromium, As, and $\mathrm{U}$ all show some enrichment through the Tartan Formation (figure 5.1.8). V shows only slight, insignificant enrichment.

\section{Enriched under reducing conditions, rarely studied}

Se is enriched through the Tartan Formation and in the uppermost sample from the overlying Laing Formation (figure 5.1.9). Sb shows no enrichment through the Tartan Formation, although it does resemble the trend seen for Bi. Ternary diagrams with Bi, $\mathrm{Sb}$ and $\mathrm{Zr}$ or Ti (figure 5.1.10) do support a possible similarity, suggesting a possible relationship between $\mathrm{Sb}$ and $\mathrm{Bi}$, and a terrestrial component to both of these. However, there is sufficient variation from this trend to indicate that the relationship is more complicated. Ti gives a higher $\mathrm{R}^{2}$ value than $\mathrm{Zr}$ for ternary diagrams indicating that the detrital $\mathrm{Bi}$ and $\mathrm{Sb}$ is closer to Ti values than $\mathrm{Zr}$.

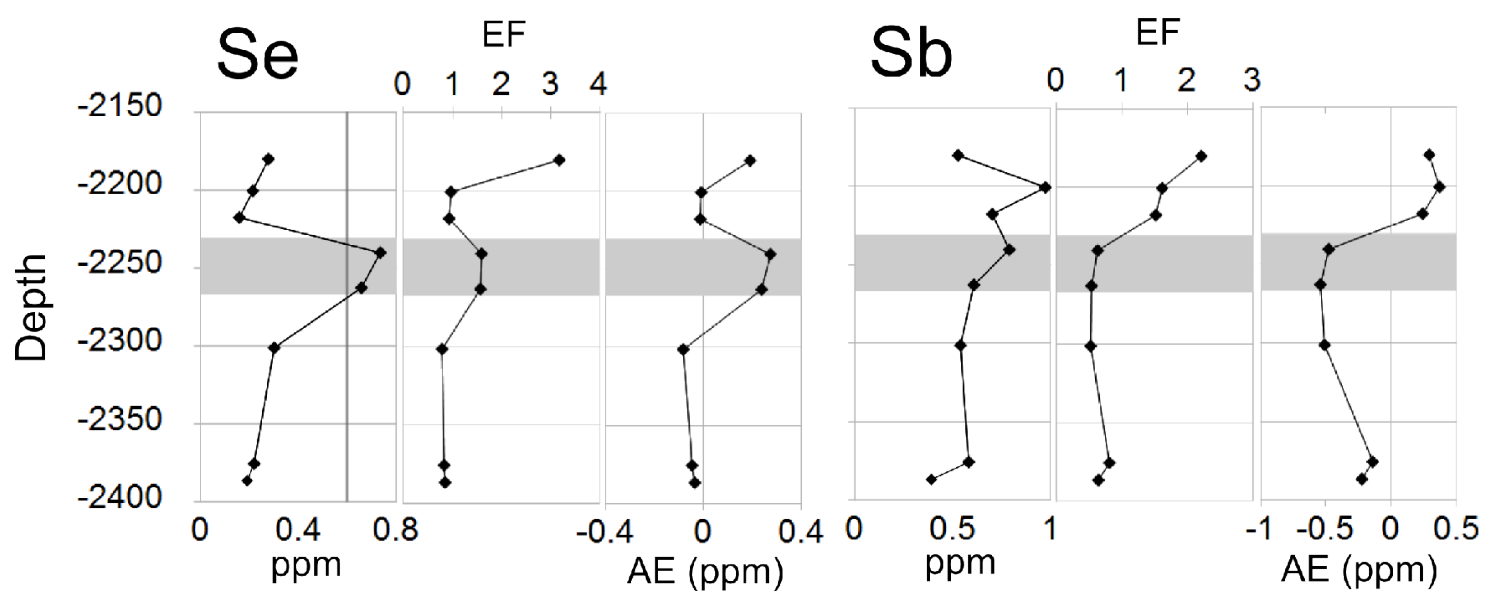

Figure 5.1.9: Elements which are rarely studied but usually enriched under oxygen-depleted conditions.
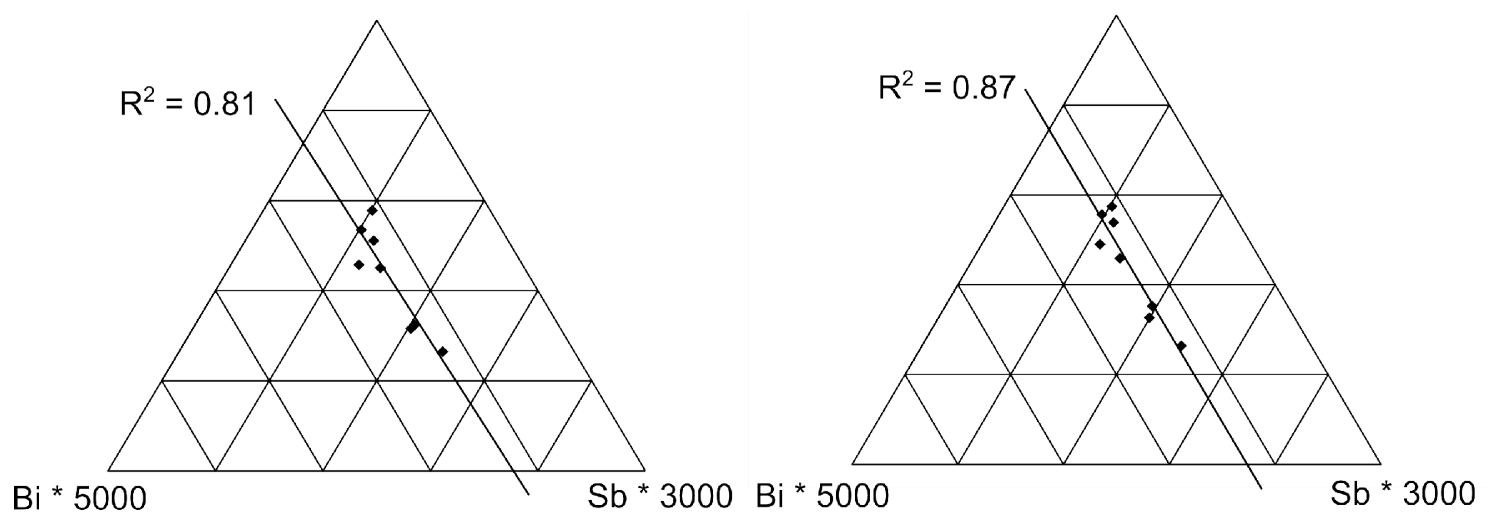

Figure 5.1.10: Ternary diagrams showing a relationship between the local background, $\mathrm{Bi}$ and $\mathrm{Sb}$. 


\section{Rarely studied in sediments}

Sn and $\mathrm{W}$ are rarely measured in sediment geochemistry. W (figure 5.2.11) appears to behave in a similar way to $\mathrm{Bi}$ and, when plotted against each other, an $\mathrm{R}^{2}$ value of 0.93 is obtained (figure 5.1.12). Sn behaves in a unique way in Kawau-1A and could not be correlated to any other element.

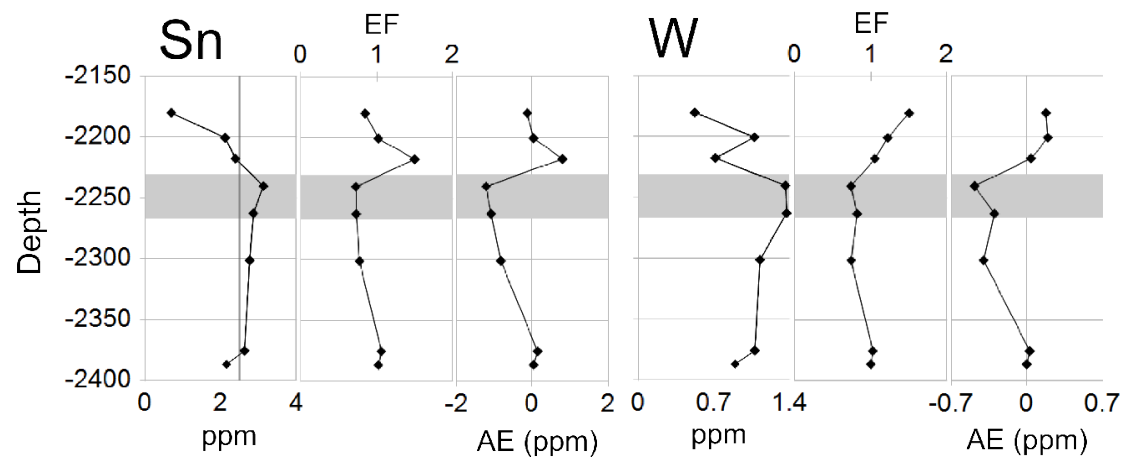

Figure 5.1.11: Rarely measured elements, $\mathrm{Sn}$ and $\mathrm{W}$ in Kawau-1A.

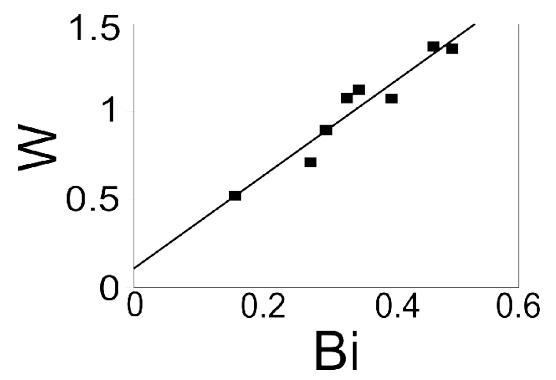

Figure 5.1.12: A plot of $W$ vs. Bi from Kawau-1A. A strong correlation $\left(R^{2}\right.$ of 0.93 ) between $\mathrm{Bi}$ and $\mathrm{W}$ indicates there may be a relationship.

\section{Rare Earth Elements (REE)}

No REE where measured, however, $\mathrm{Y}$ behaves like a rare earth element (e.g. Haskin and Gehl, 1962). Y is enriched in the Tartan Formation. Y concentrations are

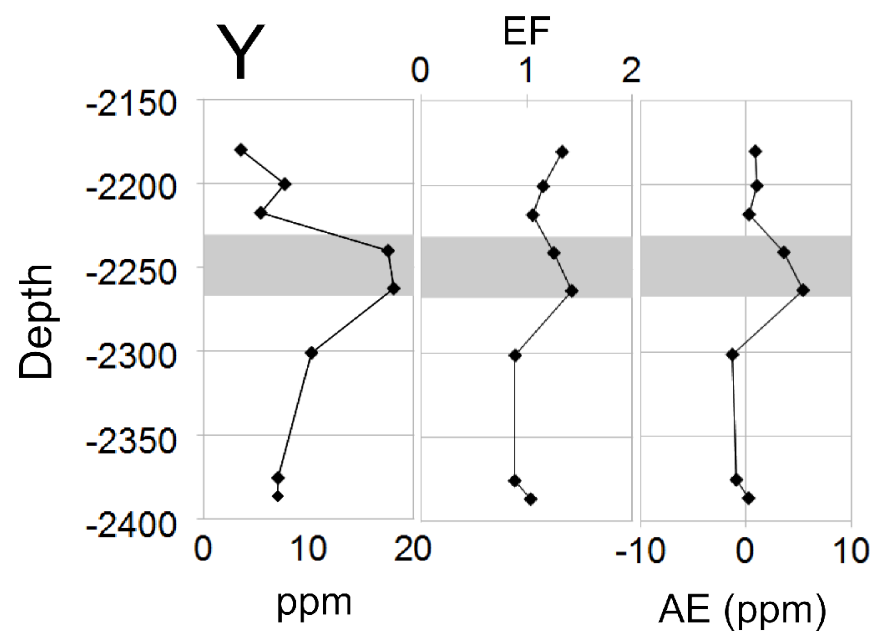

Figure 5.1.13: Depth section for $Y$ in Kawau-1A. $Y$ is enriched through the Tartan Formation. 
similar to concentrations at Angora Quarry where, excluding the erroneously high value, concentrations ranged from 7.7 to $15.3 \mathrm{ppm}$.

\subsection{Pakaha-1}

\section{Overview}

The concentration of 26 elements were measured in Pakaha-1. Samples were reduced and normalised in the same way as for Kawau-1A. The gamma ray log is shown with $\mathrm{Zr}$ and Ti overlaid (figure 5.2.1). Only the SWC sample at $2480 \mathrm{~m}$ (sample 20) varies greatly from the gamma ray trend. Whether this indicates that this sample has a lower absolute concentration across elements, that other effects apply, or that it is a resolution issue in the gamma ray log is uncertain.

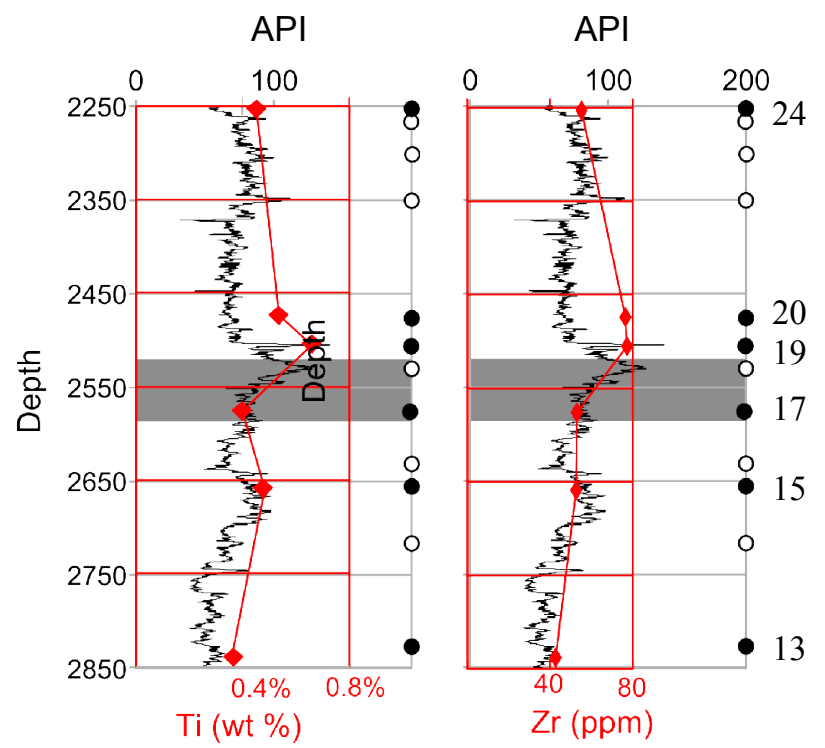

Figure 5.2.1: A comparison between two mainly terrestrially-sourced elements, $\mathrm{Ti}$ and $\mathrm{Zr}$, and the gamma ray log in Pakaha-1. The gamma ray log has a resolution of several metres while the SWC samples represent only a few $\mathrm{cm}$. 

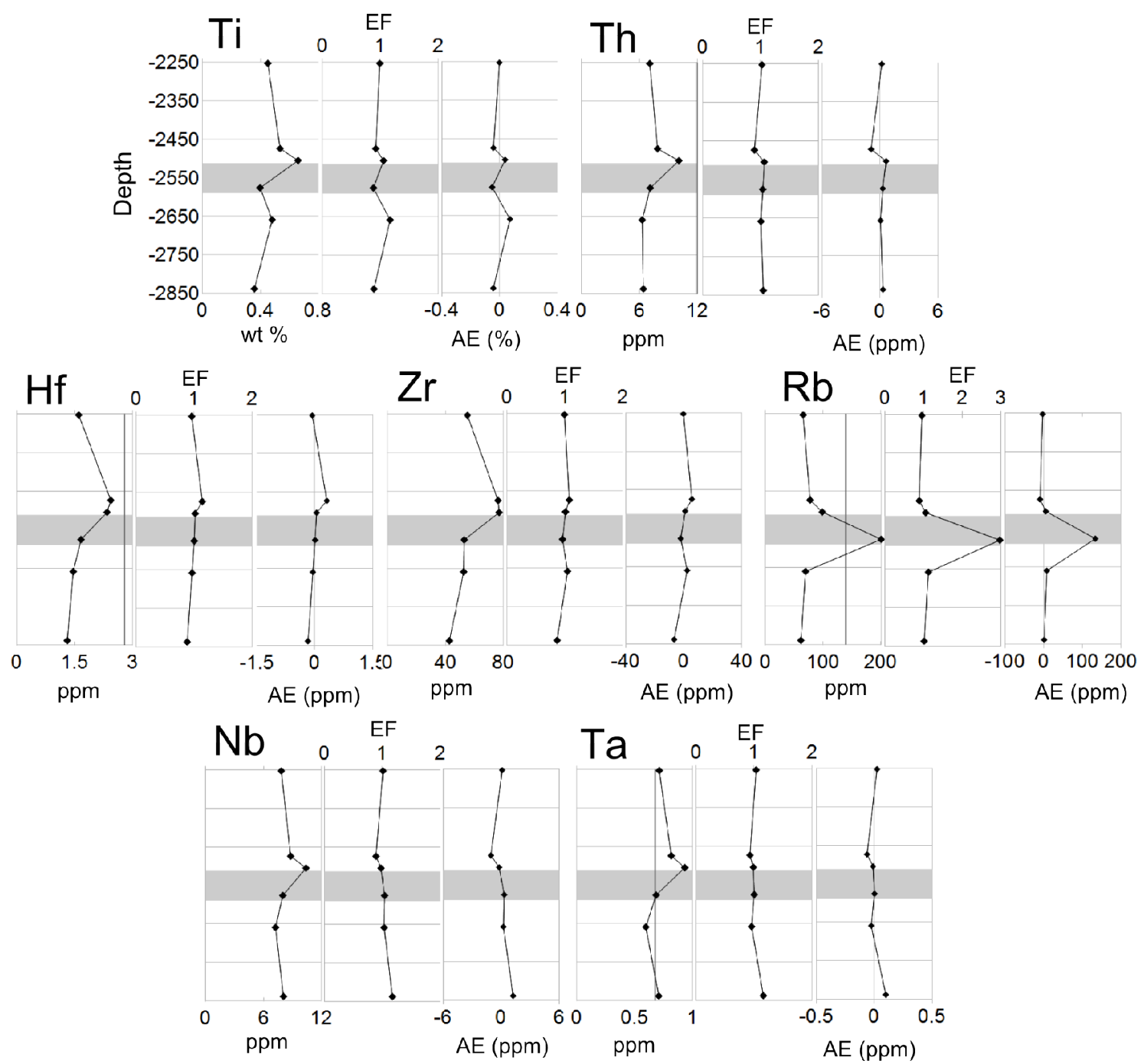

Figure 5.2.2: Terrestrial indicators in the Pakaha-1 well. A large spike in the Rb concentration is visible in the Tartan Formation. See text for discussion.

Most of the terrestrial indicators show less variation in absolute concentration through the well than at Kawau-1A. However, the SWC at $2580 \mathrm{~m}$ (figure 5.2.2) contains significantly higher $\mathrm{Rb}$ than the other samples, with an EF of 3 or an AE of 133 $\mathrm{ppm}$. This may indicate the presence of a mineral particularly rich in $\mathrm{Rb}$. Any other elements which would be included in such a mineral could also be significantly enriched. At $2570 \mathrm{~m}$ is also the only Tartan Formation SWC from Pakaha-1 for which sample remains and whether the increased $\mathrm{Rb}$ is related to the lithology, oceanic conditions, or whether it indicates a different composition of terrestrial background is uncertain. 


\section{Indicators of anoxia (included in sedimentary pyrite)}

Molybdenum shows peak abundance in the sample directly above the Tartan Formation (figure 5.2.3. $2510 \mathrm{~m}$ ). The other samples are all considerably lower in Mo. Mo concentration in this sample is similar to the concentration in Kawau-1A. The sample at $2510 \mathrm{~m}$ was taken at a gamma ray spike directly above the Tartan Formation (figure 5.2.1).

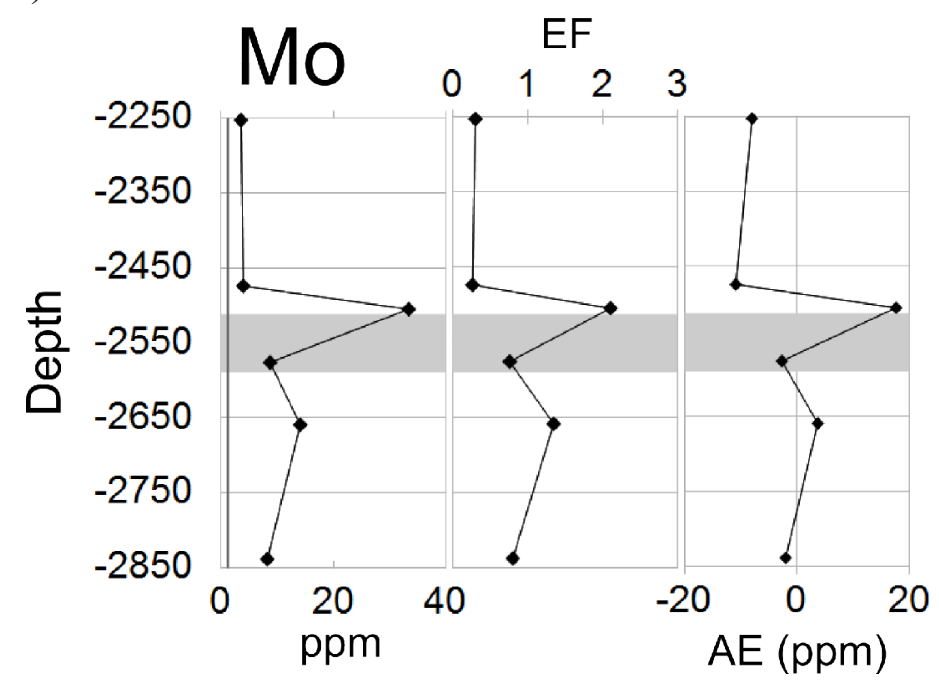

Figure 5.2.3: Mo in the Pakaha-1 well. The sample with the highest abundance is SWC 19, and was taken at a point with high gamma ray values.

\section{Indicators of anoxia (included in sedimentary pyrite); anthropogenic in recent sediments}

SWC sample Pakaha-1 24 (2250 m) appears to be enriched in $\mathrm{Pb}$ (figure 5.2.4), as is the sample from within the Tartan Formation. Bi peaks in the sample above the Tartan Formation, which also shows a high GR value (figure 5.2.1) and is enriched in Mo

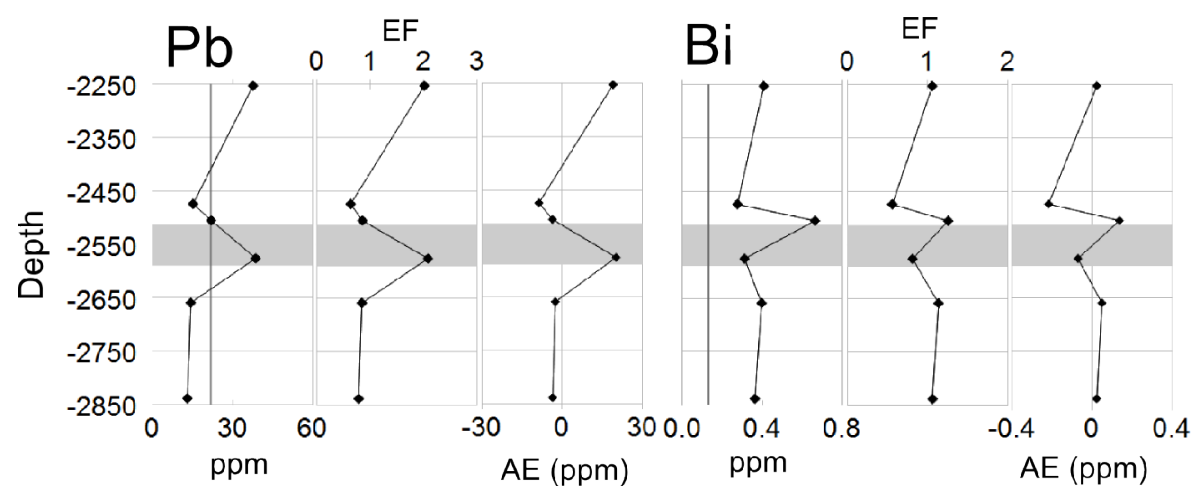

Figure 5.2.4: $\mathrm{Pb}$ and $\mathrm{Bi}$ values through Pakaha-1. See text for discussion. 
(figure 5.2.3).

\section{Biological component or involved in biocycling}

$\mathrm{Sr}$ reaches values of up to $886 \mathrm{ppm}$ in the uppermost sample from Pakaha-1 (figure 5.2.5), which far exceeds the $\mathrm{Sr}$ concentration in any other samples from any of the field locations. Both the AE and EF strongly reflect the absolute concentration graph as the variations far exceed the variations in terrestrial input. Sr contains a second smaller peak in the Tartan Formation. Sr showed peaks in the same samples as with $\mathrm{Pb}$; however, a plot of the two produces a $\mathrm{R}^{2}$ of 0.66 , suggesting no direct relationship.

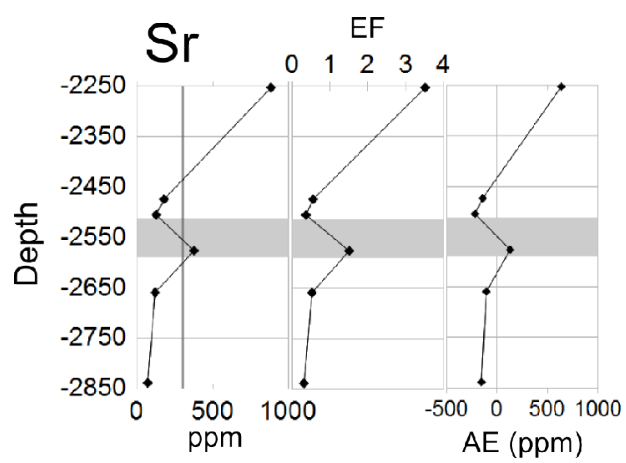

Figure 5.2.5: $\mathrm{Sr}$ values in the Pakaha-1 well. The peak is several times higher than the $\mathrm{Sr}$ concentration recorded in any other location in this study.

\section{Biological component or involved in biocycling; indicators of anoxia (included in sedimentary pyrite)}

$\mathrm{Tl}$ (figure 5.2.6) shows a peak in abundance within the Tartan Formation, and its absolute concentration strongly resembles that of $\mathrm{Rb}$. A plot of $\mathrm{Rb}$ against $\mathrm{Tl}$ gives an $\mathrm{R}^{2}$ of 0.99 and, if the large peak at $2576 \mathrm{~m}$ is excluded, of 0.88 (figure 5.2.7).

$\mathrm{Cd}$ and $\mathrm{Ni}$ both peak in abundance in the sample directly above the Tartan Formation, the same sample as the highest concentrations of Mo and Bi. A direct correlation between these elements was not identified. 

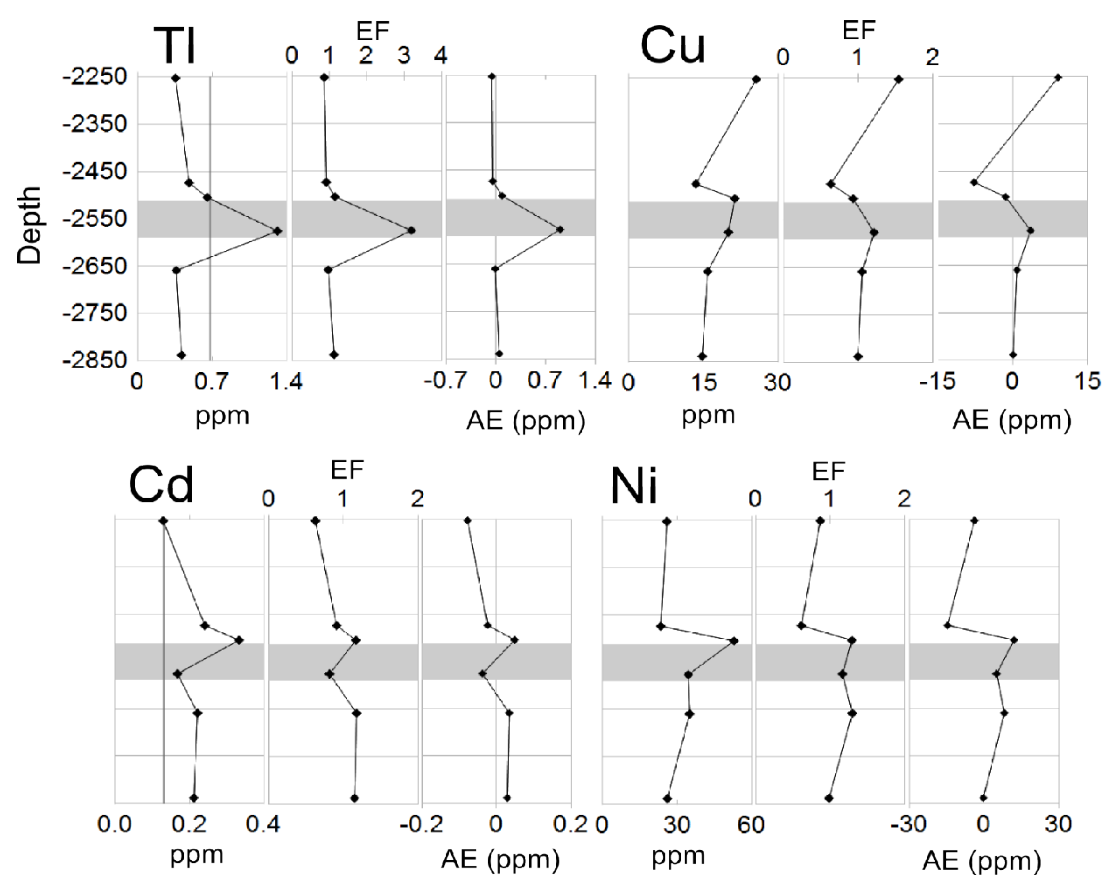

Figure 5.2.6: Elements which are affected by both sedimentary pyrite and biocycling plotted in depth sections for the Pakaha-1 well. See text for discussion

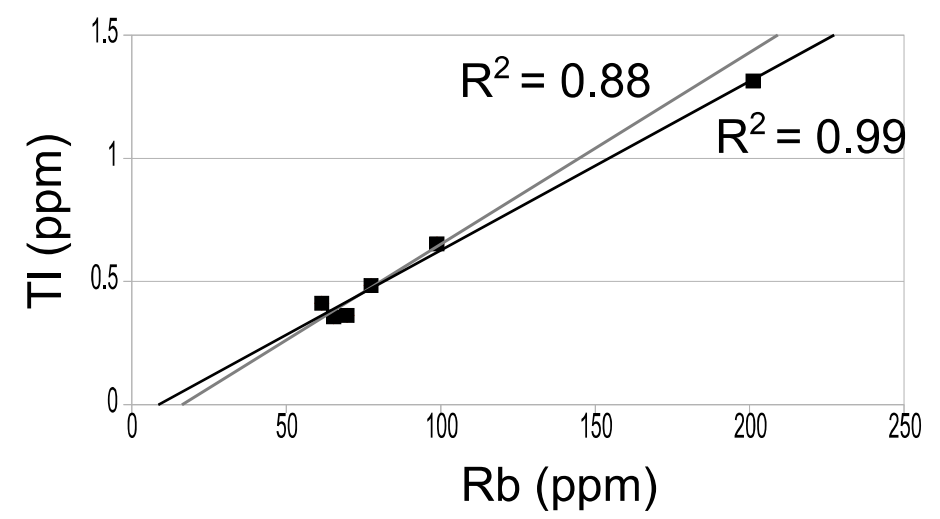

Figure 5.2.7: Graph showing the relationship between $\mathrm{Rb}$ and $\mathrm{TI}$. The $\mathrm{R}^{2}$ of 0.99 includes SWC sample 17, whereas the other value excludes this sample.

\section{Depleted under oxygen-depleted conditions; indicators of anoxia (included in sedimentary pyrite)}

Above the Tartan Formation Mn appears to increase in concentration in the uppermost two samples (figure 5.2.8). However, the highest concentrations are still below the average shale value of $850 \mathrm{ppm}$. Co shows considerable variation through the entire section, with its peak directly above the Tartan Formation, the same sample as 
Mo.

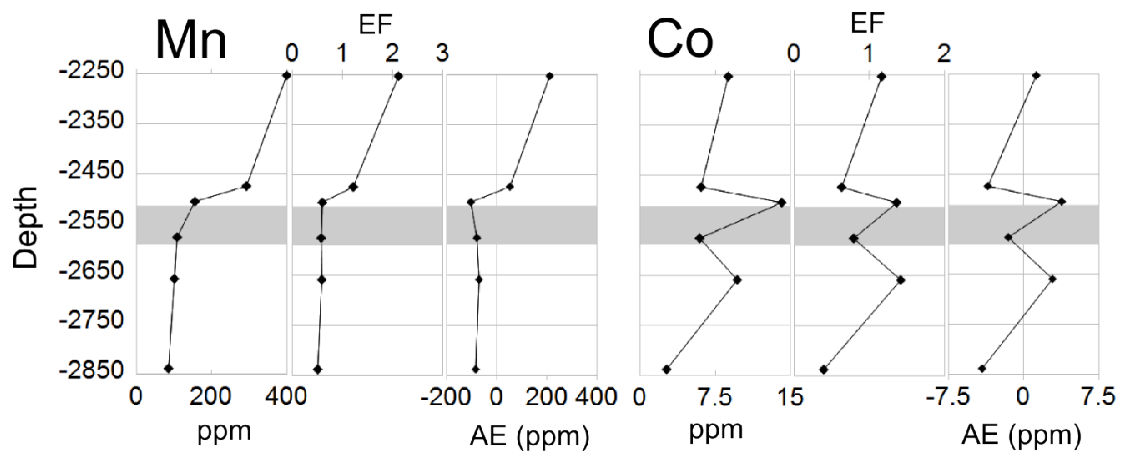

Figure 5.2.8: Depth sections of Mn and Co in Pakaha-1.

\section{Enriched under reducing conditions}

Arsenic, $\mathrm{U}$ and $\mathrm{V}$ all have peak abundances in the sample directly above the Tartan Formation at $2500 \mathrm{~m}$ (figure 5.2.9). Arsenic and U show slight depletion in the other samples in the Laing Formation. Cr shows a strong depletion in the Laing Formation relative to the Tartan and Wickliffe formations.

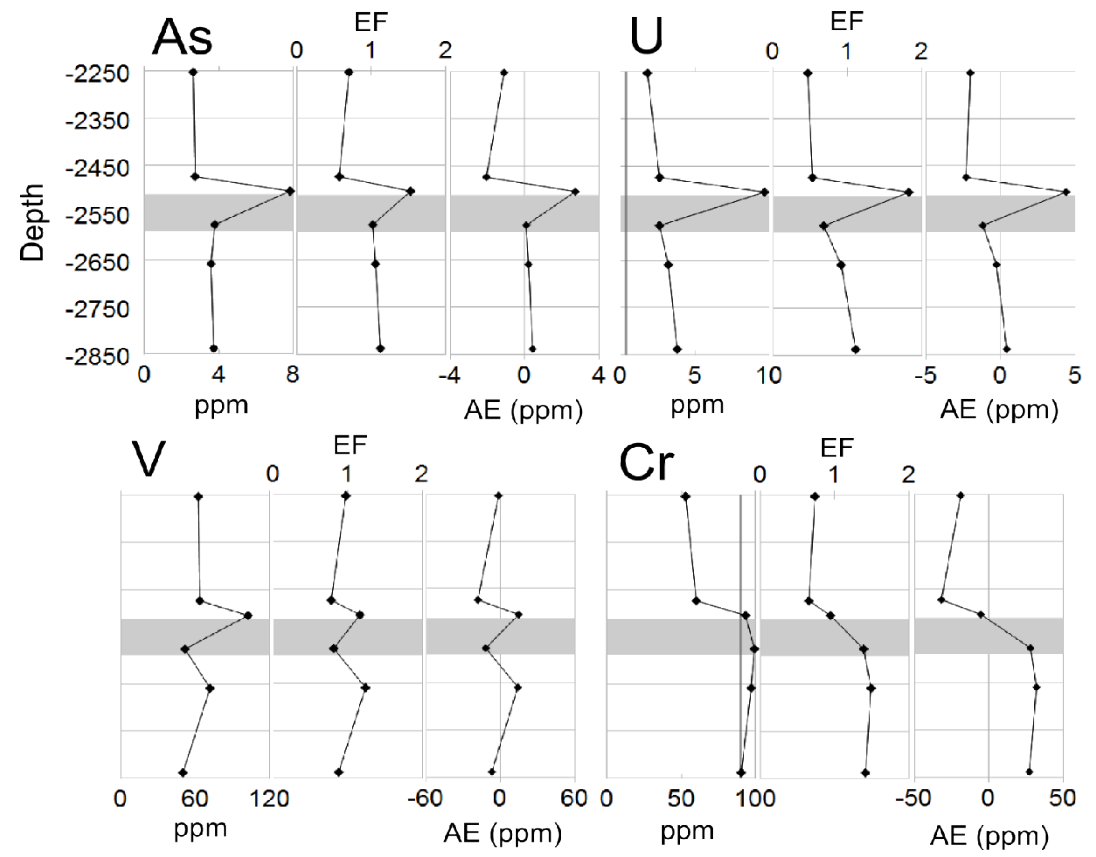

Figure 5.2.9: Elements generally enriched under oxygen-depleted conditions plotted against depth in the Pakaha-1 well. U, As and V all have a spike in the sample directly above the Tartan Formation, whereas $\mathrm{Cr}$ shows a depletion in concentration through the section. 


\section{Enriched under reducing conditions, rarely studied}

$\mathrm{Sb}$ and Se both show peak abundance in the sample directly above the Tartan Formation (figure 5.2.10). Sb otherwise remains constant throughout the rest of the section, but in contrast Se is depleted in the Laing Formation compared to the Wickliffe Formation.
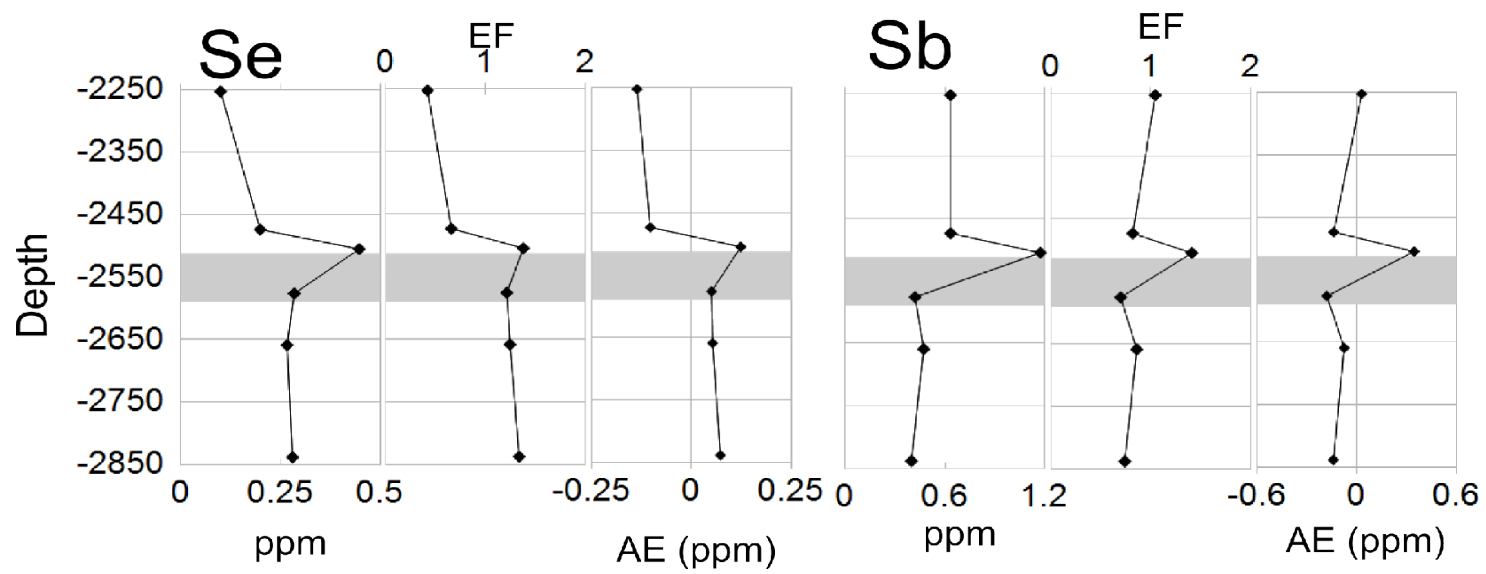

Figure 5.2.10: Elements generally enriched under oxygen depletion, but rarely measured.

$\mathrm{Se}$ and $\mathrm{Sb}$ both contain the spike above the Tartan Formation, Se otherwise shows depletion through the Above the Tartan Formation.

\section{Rarely studied in sediments}

Sn shows peak abundance above the background variation within the Tartan Formation (figure 5.2.11). This may be particularly significant as in both Angora Quarry and Kawau-1A the Tartan or Waipawa Formation samples were depleted in Sn after

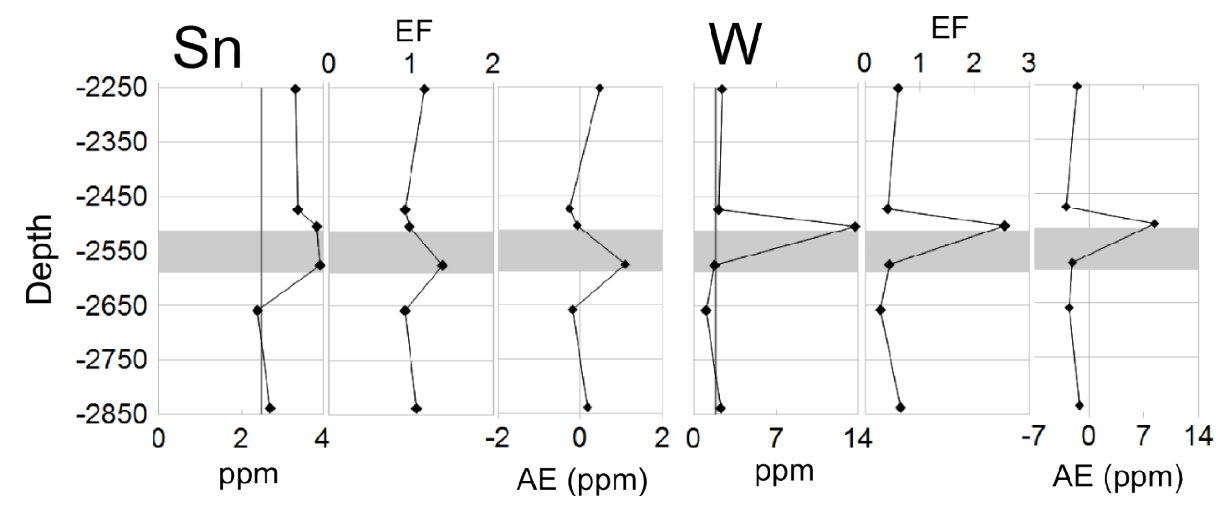

Figure 5.2.11: Rarely measured elements in Pakaha-1. $\mathrm{Sn}$ is enriched in the Tartan Formation, whereas W is enriched in the SWC sample above the Tartan Formation. 
terrestrial input had been taken into account. $\mathrm{W}$ is enriched in the sample directly above the Tartan Formation.

\section{Rare Earth Elements (REE)}

REE were again not measured for Pakaha-1, however Y which behaves like REE

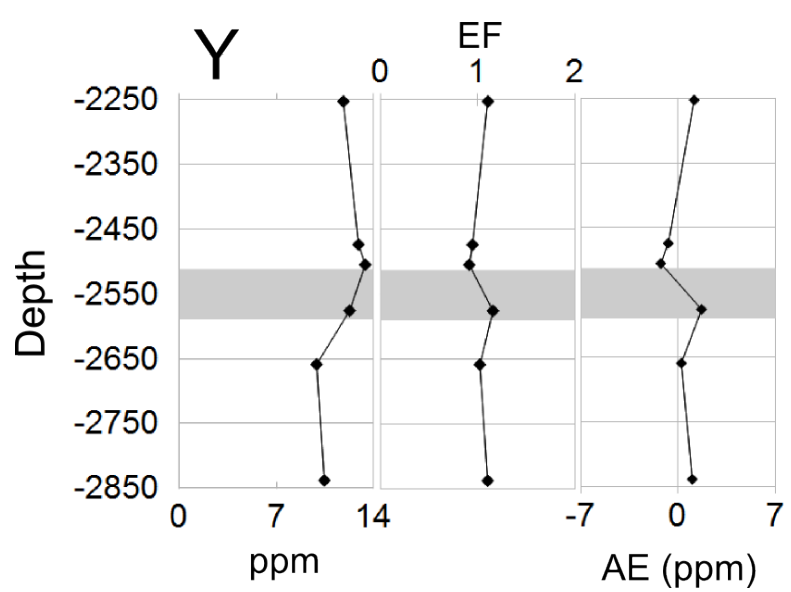

Figure 5.2.12: $Y$ vs depth in the Pakaha-1 well $Y$ shows little variation through the section.

was. Y show little variation through the section (figure 5.2.12). The sample within the Tartan Formation may show some minor enrichment. 


\section{Chapter 6}

\section{Discussion}

\subsection{Angora Quarry}

\section{Overview}

In order to aid interpretation of the data, TOC measurements from Leckie et al., (1992) are presented in figure 6.0.1. These measurements are only indicative when related to the samples used in this study, as the values for the TOC as different samples from those of the present study were used. Leckie et al. (1992) also used a different starting point for the base of their section.

Although the TOC has not been measured directly in the present study, the samples were sorted by colour to provide an approximate guide to the amount of organic carbon present. While this value is not absolute, and thus precludes quantitative comparison, it does allow elements to be plotted in a specific order to show if any enrichments might covary with organic carbon content.

The Ternary diagram (figure 5.0.2) shows a distinct separation between the

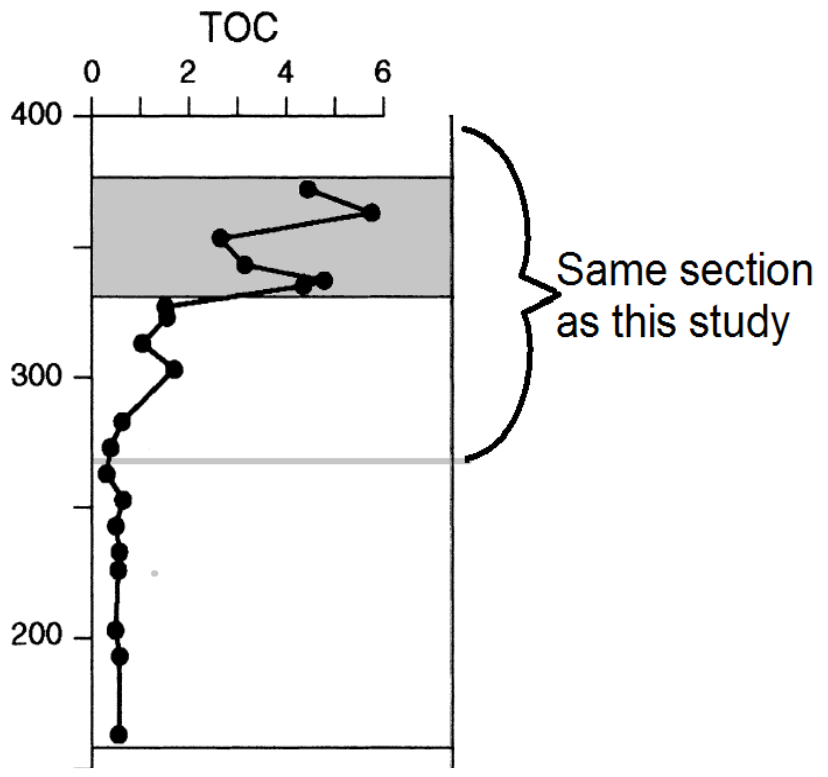

Figure 6.0.1: TOC values for the same interval at Angora Quarry section from Leckie et al. (1992). As Leckie et al. (1992) did not present data in tabulated form, this image was extracted from Killops et al. (2000) because of the higher resolution of the figure. 
Waipawa Formation and the other formations with respect to $\mathrm{Ca}, \mathrm{Si}$ and $\mathrm{Al}$. The relatively higher aluminium content comes at the expense of most of the calcite content and some of the silica.

Figure 6.0.2 shows aluminium content plotted against colour. A clear trend is visible for the darker samples with presumably higher TOC. A-C-1 and A-C-2 are plotted separately as they are not from the same section. Sample A-A-8 is the only outlier; this sample also contained several $3 \mathrm{~mm}$ to $1 \mathrm{~cm}$ thick glauconitic beds which are not in the photo and significantly lighter in colour, taking these into account would move the sample to the left.

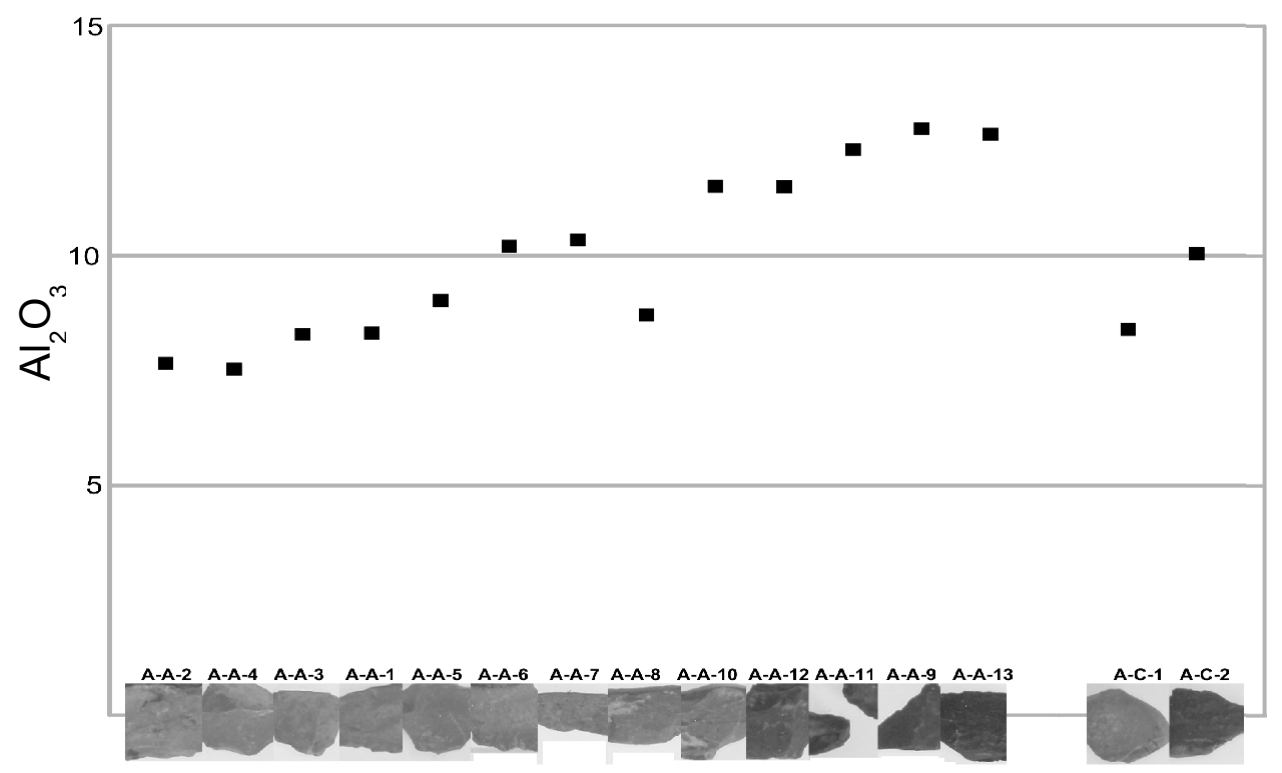

Figure 6.0.2: $\mathrm{Al}_{2} \mathrm{O}_{3}$ from Angora Quarry plotted against increasing darkness of the samples. Except for sample AA8, a darkening appears to indicate an increase in Al. A-C-1 and A-C-2 are plotted separately to the right as they are from further upstream, across a fault with unknown displacement. See text for discussion.

The $5 \mathrm{wt} \%$ increase in $\mathrm{Al}_{2} \mathrm{O}_{3}$ must come at the expense of one or more other elements. Both $\mathrm{CaO} / \mathrm{Al}_{2} \mathrm{O}_{3}$ and $\mathrm{SiO}_{2} / \mathrm{Al}_{2} \mathrm{O}_{3}$ are plotted similarly in figure 6.03 and 6.0.4 respectively, although without the colour photos. Calcium is mainly included in sediments through biologically produced $\mathrm{CaCO}_{3}$. Figure 6.0.3 shows the relationship between $\mathrm{CaO} / \mathrm{Al}_{2} \mathrm{O}_{3}$, and sample colour. While the $\mathrm{Ca}$ does partially dilute the $\mathrm{Al}$ content it also dilutes other elements, and hence the maximum value of $6.8 \mathrm{wt} \% \mathrm{CaO}$ should only make $0.93 \mathrm{wt} \%$ difference in the $\mathrm{Al}_{2} \mathrm{O}_{3}$ content while affecting elements 
such as $\mathrm{SiO}_{2}$ to a greater extent due to the high amount of $\mathrm{Si}$ present. The irregular

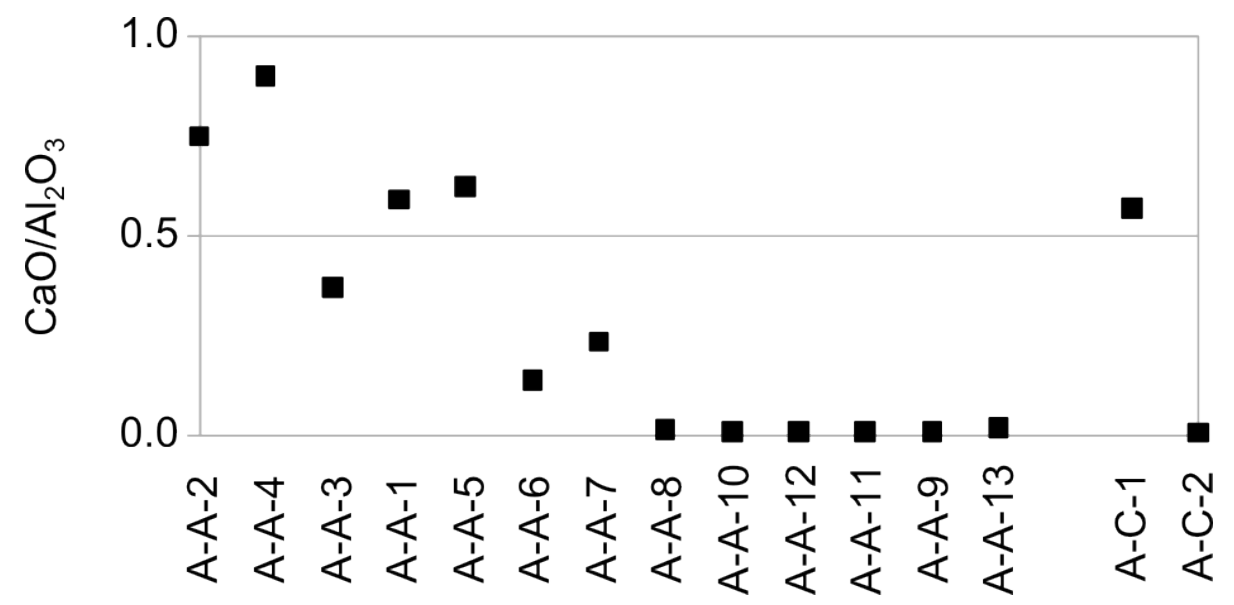

Figure 6.0.3: $\mathrm{CaO} / \mathrm{Al}_{2} \mathrm{O}_{3}$ ratio plotted against increasing darkness as in Fig. 6.0.2. . While Ca does have some affect towards diluting the Al content of the sediments, the jagged nature and lack of similarity to figure 6.0.2 suggests it is not the main factor.

nature of the plot, suggests that dilution of $\mathrm{Al}_{2} \mathrm{O}_{3}$ by $\mathrm{CaO}$ is neither the only nor the dominant process.

The $\mathrm{SiO}_{2}$ relationship to $\mathrm{Al}_{2} \mathrm{O}_{3}$ (figure 6.0.4) is the expected relationship if the main element being diluted is $\mathrm{SiO}_{2}$. Using $\mathrm{SiO}_{2} / \mathrm{Al}_{2} \mathrm{O} 3$, and $\mathrm{CaO} / \mathrm{Al}_{2} \mathrm{O}_{3}$ instead of the pure element concentrations removes the dilution effects of other elements and volatiles like LOI.

Overall the colour, likely caused by the organic-matter content at Angora Quarry

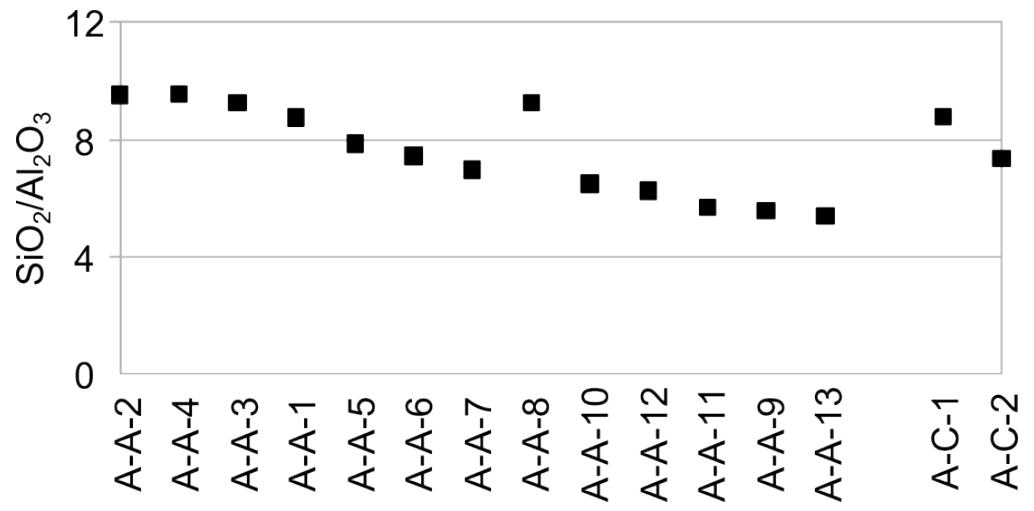

Figure 6.0.4: $\mathrm{SiO}_{2} / \mathrm{Al}_{2} \mathrm{O}_{3}$ ratio plotted against increasing darkness of samples as for Fig. 6.0.2. The ratio between $\mathrm{SiO}_{2}$ and $\mathrm{Al} 2 \mathrm{O}_{3}$ is what would be expected to explain the colour trend seen in $\mathrm{Al}_{2} \mathrm{O}_{3}$ concentration and indicates that the bulk of the increased $\mathrm{Al}$ comes at the expense of $\mathrm{Si}$. 
covaries with $\mathrm{Al}$ content, and increases in $\mathrm{Al}$ content is closely related to a decrease in Si content and somewhat related to a decrease in biological Ca content.

\section{Terrestrial indicators}

Table 6.0.1 shows the correlation between all the elements which are assumed to be indicators of terrestrial background. Excluding Ga, the worst correlation is an $\mathrm{R}^{2}$ coefficient of 0.766 between $\mathrm{Al}$ and $\mathrm{Zr}$.

Gallium varies independently of the terrestrial source in this study, suggesting that it is not a suitable terrestrial indicator. A positive relation between $\mathrm{Ga}$ and $\mathrm{Ba}$ was noticed and is discussed below with the biological components.

\begin{tabular}{|c|c|c|c|c|c|c|c|c|c|}
\hline & $\mathbf{A l}$ & $\mathbf{N b}$ & $\mathbf{T i}$ & $\mathbf{R b}$ & $\mathbf{T h}$ & $\mathbf{K}$ & $\mathbf{H f}$ & $\mathbf{Z r}$ & $\mathbf{G a}$ \\
\hline $\mathbf{A l}$ & $\mathrm{N} / \mathrm{A}$ & 0.970 & 0.970 & 0.950 & 0.949 & 0.937 & 0.799 & 0.766 & 0.011 \\
\hline $\mathbf{N b}$ & 0.970 & $\mathrm{~N} / \mathrm{A}$ & 0.962 & 0.913 & 0.958 & 0.879 & 0.800 & 0.776 & 0.028 \\
\hline $\mathbf{T i}$ & 0.970 & 0.962 & $\mathrm{~N} / \mathrm{A}$ & 0.941 & 0.974 & 0.924 & 0.853 & 0.834 & 0.030 \\
\hline $\mathbf{R b}$ & 0.950 & 0.913 & 0.941 & $\mathrm{~N} / \mathrm{A}$ & 0.922 & 0.960 & 0.830 & 0.786 & 0.002 \\
\hline $\mathbf{T h}$ & 0.949 & 0.958 & 0.974 & 0.922 & $\mathrm{~N} / \mathrm{A}$ & 0.877 & 0.872 & 0.848 & 0.012 \\
\hline $\mathbf{K}$ & 0.937 & 0.879 & 0.924 & 0.960 & 0.877 & $\mathrm{~N} / \mathrm{A}$ & 0.836 & 0.779 & 0.000 \\
\hline $\mathbf{H f}$ & 0.799 & 0.800 & 0.853 & 0.830 & 0.872 & 0.836 & $\mathrm{~N} / \mathrm{A}$ & 0.979 & 0.002 \\
\hline $\mathbf{Z r}$ & 0.766 & 0.776 & 0.834 & 0.786 & 0.848 & 0.779 & 0.979 & $\mathrm{~N} / \mathrm{A}$ & 0.001 \\
\hline $\mathbf{G a}$ & 0.011 & 0.028 & 0.030 & 0.002 & 0.012 & 0.000 & 0.002 & 0.001 & $\mathrm{~N} / \mathrm{A}$ \\
\hline
\end{tabular}

Table 6.0.1: $\mathrm{R}^{2}$ correlation coefficients for elements thought to be detrital indicators; for each element on the vertical axis only the highest $R^{2}$ is coloured. The best matches between elements are shaded liaht arev. the highest value for $\mathrm{Ga}$ is dark grey, and the low result
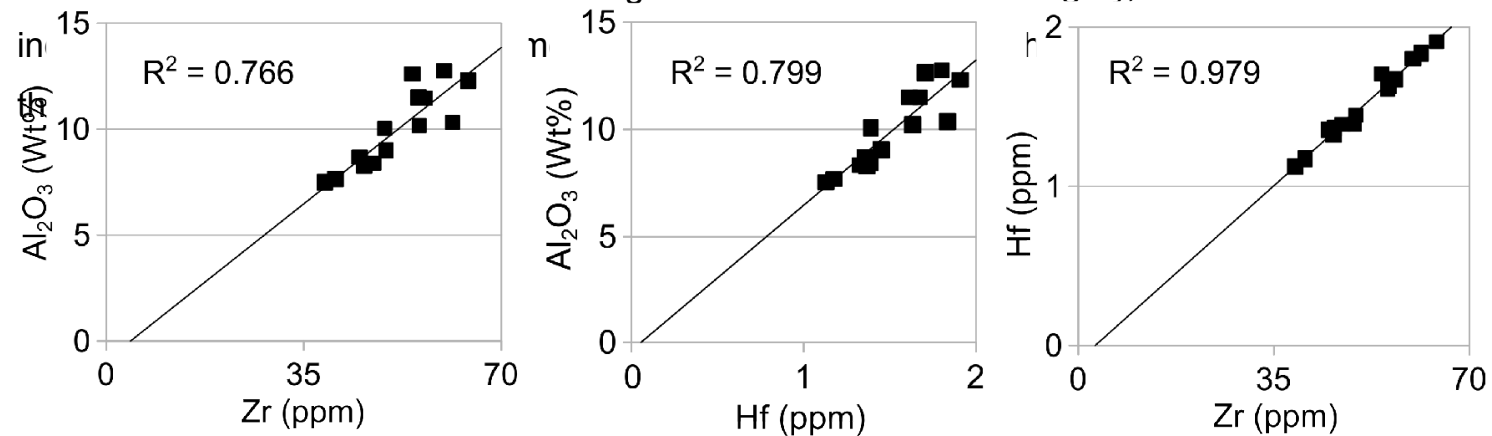

Figure 6.0.5: Graphs showing the correlation between $\mathrm{Al}, \mathrm{Zr}$ and $\mathrm{Hf}$. While $\mathrm{Zr}$ and $\mathrm{Hf}$ show a strong correlation to each other, Al shows some variation independently of these elements.

Although $\mathrm{Al}$ is taken to represent the bulk detrital composition, there is some evidence of variation in the mineralogical detrital composition. $\mathrm{Zr}$ and $\mathrm{Hf}$ are closely related with an $\mathrm{R}^{2}$ value of 0.979 (figure 6.0.5) when plotted against one another; however, this ratio is less than 0.8 when plotted against Al.

Having $\mathrm{R}^{2}$ ratios close to one and plotting through the origin indicates the detrital 
sediment source remained constant with any variaition due to dilution from other sources.

\section{Anoxic indicators (sedimentary pyrite)}

None of the samples from the three formations at Angora Quarry show any indication of sedimentary pyrite, suggesting that some oxygen was present during deposition. The sediments contain 2-4 wt\% Fe, sufficient (figure 5.0.6) to form pyrite, suggesting that the lack of sedimentary pyrite is due to a lack of anoxic conditions.

\section{Oxygen depletion}

Manganese and Co are often depleted under reducing conditions. Of these, Mn may show some depletion in the Waipawa Formation (figure 5.0.15) but the measurement errors are too large for the observed variations to be considered significant. Co appears to be enriched through the Waipawa Formation.

From the elements which are normally enriched under oxygen-depleted conditions (figures 5.0.16, 5.0.17), only sample A-C-2 shows enrichment in all these (As, U, V, Cr and $\mathrm{Sb}$ ), although not always by significant amounts. This sample was from the Waipawa Formation approximately $1 \mathrm{~km}$ upstream from the other samples.

The enrichment of these elements alone is not enough to confirm whether or not the formation was deposited under oxygen-depleted conditions at this location as the enrichment is not significantly higher than for other elements. REE, however, allow comparison between elements which otherwise chemically behave in a very similar way. Caesium is generally depleted under reducing conditions depleted (e.g. de Baar et al., 1988; German and Elderfield, 1989; Sholkovitz et al., 1992), and europium may be enriched (Sverjensky, 1984; more details given in section 2.2).

As $\mathrm{Ce}$ and $\mathrm{Eu}$ are enriched under opposite redox conditions, but related as REE, depth graphs of $\mathrm{Ce} / \mathrm{La}$, and $\mathrm{Gd} / \mathrm{Eu}$ should show significantly lower values for reduced conditions. Figure 6.0.6 shows plots for $\mathrm{Ce} / \mathrm{La}$ and $\mathrm{Gd} / \mathrm{Eu}$, the standard used (vertical line) is the North American Shale Composite (NASC), the same standard used in the results section. A-C-2 (circled in red) shows the lowest values in both $\mathrm{Ce} / \mathrm{La}$ and $\mathrm{Gd} / \mathrm{Eu}$, indicating that sample A-C-2 was deposited under more oxygen depleted during deposition. While the distance between the field sites is only $1 \mathrm{~km}$, a fault with 


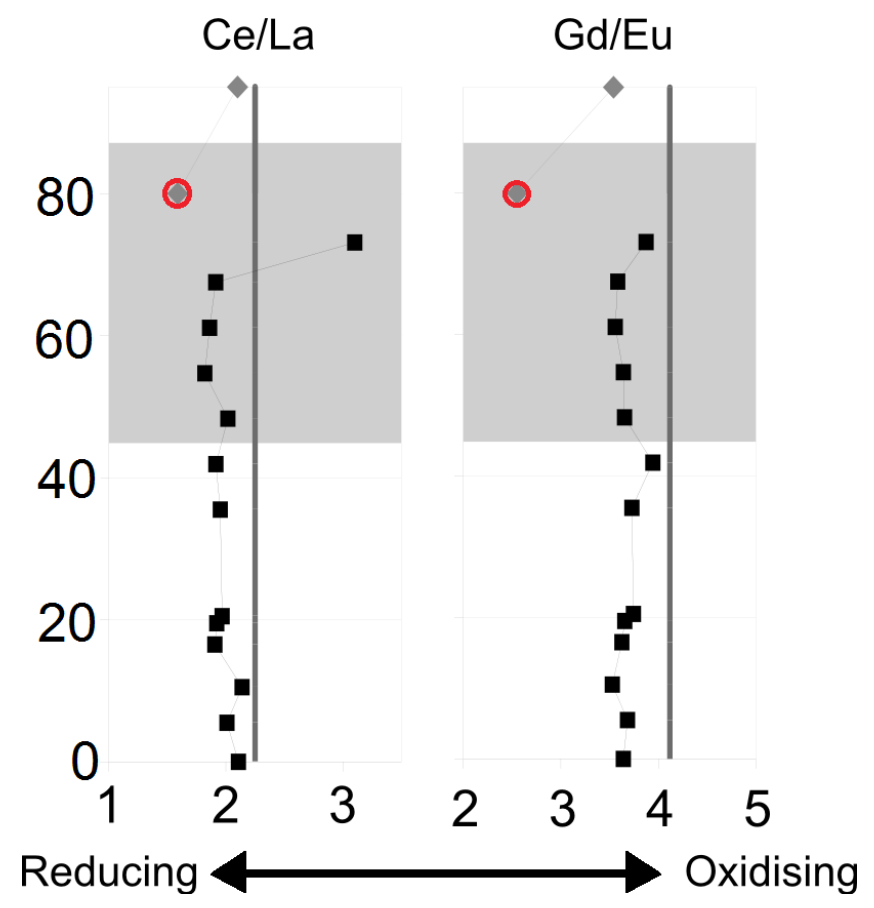

Figure 6.0.6: A depth graph of redox-sensitive REEs normalised against La and Gd. Sample A-C-2 is highlighted in red for reasons discussed in text.

unknown displacement separates them and hence the paleogeographic distance as well as exact stratigraphic position is uncertain (see section 4.1).

\section{Biological components and biocycling.}

The relationship noticed on a ternary diagram of $\mathrm{Ba}, \mathrm{Ga}$ and $\mathrm{Al}$ concentrations (figure 5.0.10) may prove to be significant to interpreting Ba results. Few studies have measured $\mathrm{Ga}, \mathrm{Al}$ and $\mathrm{Ba}$ together in sediments. However, a comparison of one set of results from Devonian-Mississippian shales from the Western Canadian Sedimentary Basin, (Ross and Bustin, 2009) and those from Angora Quarry (this study) is given in figure 6.0.7.

The data from Ross and Bustin (2009) have a larger concentration of Al relative to both $\mathrm{Ba}$ and $\mathrm{Ga}$, with $\mathrm{Ba}$ appearing to vary largely independently of $\mathrm{Ga}$ and $\mathrm{Al}$. Ga and $\mathrm{Ba}$ do not appear to be related in the Western Canadian Sedimentary Basin. Whether the relationship at Angora Quarry is just a local process is uncertain. There may be background variation in both $\mathrm{Ba}$ and $\mathrm{Ga}$ in the Western Canadian Sedimentary Basin. Plots between different terrestrial indicators show large amounts of variation, $\mathrm{K}_{2} \mathrm{O}$ vs $\mathrm{Al}_{2} \mathrm{O}_{3}$ for the Ross and Bustin (2009) data shows an $\mathrm{R}^{2}$ correlation of 0.52 , considerably 


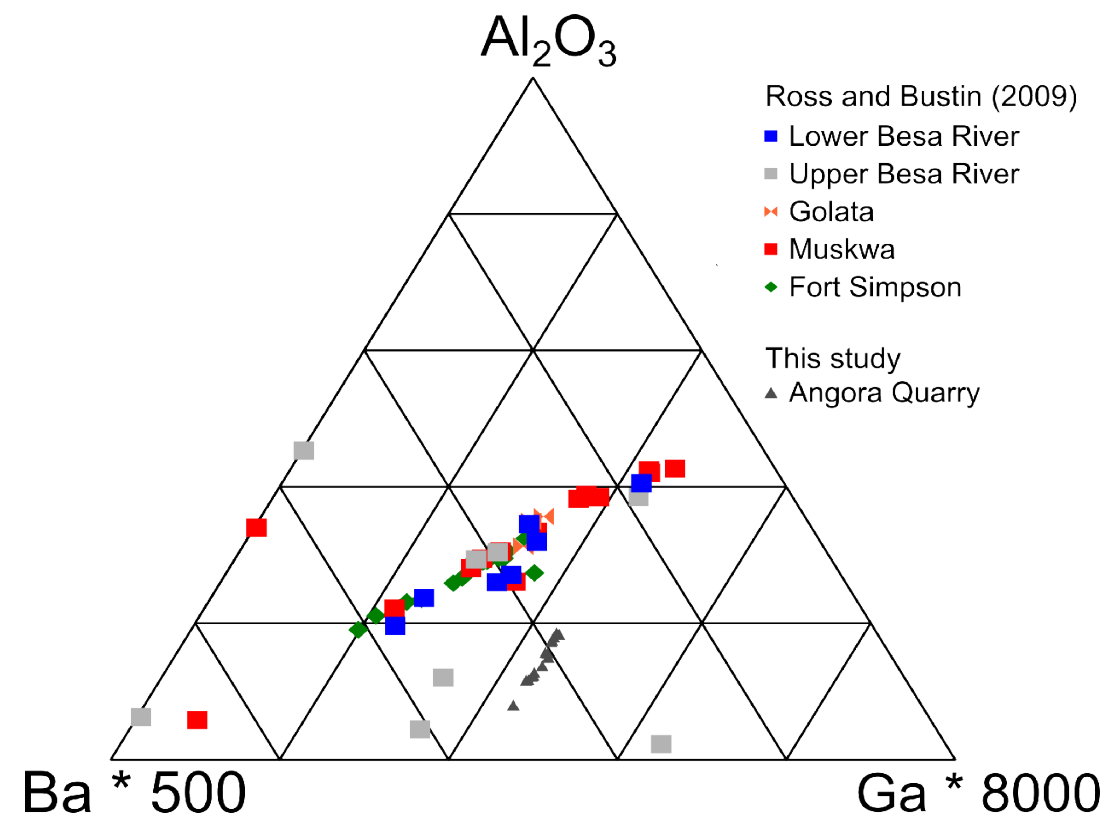

Figure 6.0.7: $\mathrm{Ba}, \mathrm{Ga}$ and $\mathrm{Al}_{2} \mathrm{O}_{3}$ from the Western Canadian Sedimentary Basin (Ross and Bustin, 2009) and Angora Quarry (this study).

lower than the 0.96 from this study and indicating multiple detrital sources.

$\mathrm{Ca}$ is largely of biological origin, and hence the $\mathrm{EF}$ and $\mathrm{AE}$ corrections using $\mathrm{Al}_{2} \mathrm{O}_{3}$ are not a particularly useful way of displaying the data. The depletion in $\mathrm{Ca}$ through the Waipawa Formation may either indicate a lack of calcareous shells being deposited or the dissolution of calcium minerals after deposition.

At Angora Quarry, the similarity between the $\mathrm{SO}_{3}$ content and $\mathrm{CaO}$ (figure 5.0.13) is probably indicative of a decrease in the amount of marine productivity relative to the sedimentation rate. The $\mathrm{S}$ in the Whangai and Wanstead formations would hence be sourced from marine organic matter. Leventhal (1983) suggested that approximately 1 $\mathrm{wt} \% \mathrm{~S}$ for every $3 \mathrm{wt} \%$ TOC was approximately the ratio for organic matter deposited under normal marine conditions, a value that is consistent with the TOC (figure 6.0.1) from Angora Quarry.

In the Whangai and Wanstead formation samples, Sr correlates with $\mathrm{Ca}$ and $\mathrm{Al}$ on a ternary diagram (figure 5.0.11) although many Waipawa Formation samples are depleted after a correction for both $\mathrm{Al}$ and $\mathrm{Ca}$ has been made. The cause of this depletion is unknown, and indeterminable from this study. The technique of calculating the $\mathrm{AE}$ of $\mathrm{Sr}$ using both $\mathrm{Al}$ and $\mathrm{Ca}$ values can aid in gaining a better understanding why Sr varies in organic-rich sediments and perhaps in sediments in general.

The variation of $\mathrm{Mg}$ with $\mathrm{Al}$ and $\mathrm{Ca}$ (5.0.12) may indicate an increase in kaolinite 
or dolomite content as these are what $\mathrm{Mg}$ is mainly linked to in North American black shales (Ross and Bustin, 2008; 2009). Whether these minerals are causing the increased $\mathrm{Mg}$ or whether some other process is responsible is not shown by the data.

Germanium shows no correlation to $\mathrm{Si}$, suggesting either that a significant proportion of the variation in either $\mathrm{SiO}_{2}$ or $\mathrm{Ge}$ is not of biological origin, or that there is a second process involved.

TOC values from Leckie (1992) and S from this study can be combined to show where Angora Quarry samples would plot on an S vs TOC graph (figure 6.0.8). As Leckie (1992) did not measure TOC in the Wanstead Formation at Angora Stream, that sample has been omitted from the figure, previous values at other locations for the Wanstead Formation where included. The data are plotted alongside data from Elgar (1997) and Rogers (1995), the two previous studies which have measured S in East Coast Basin samples.

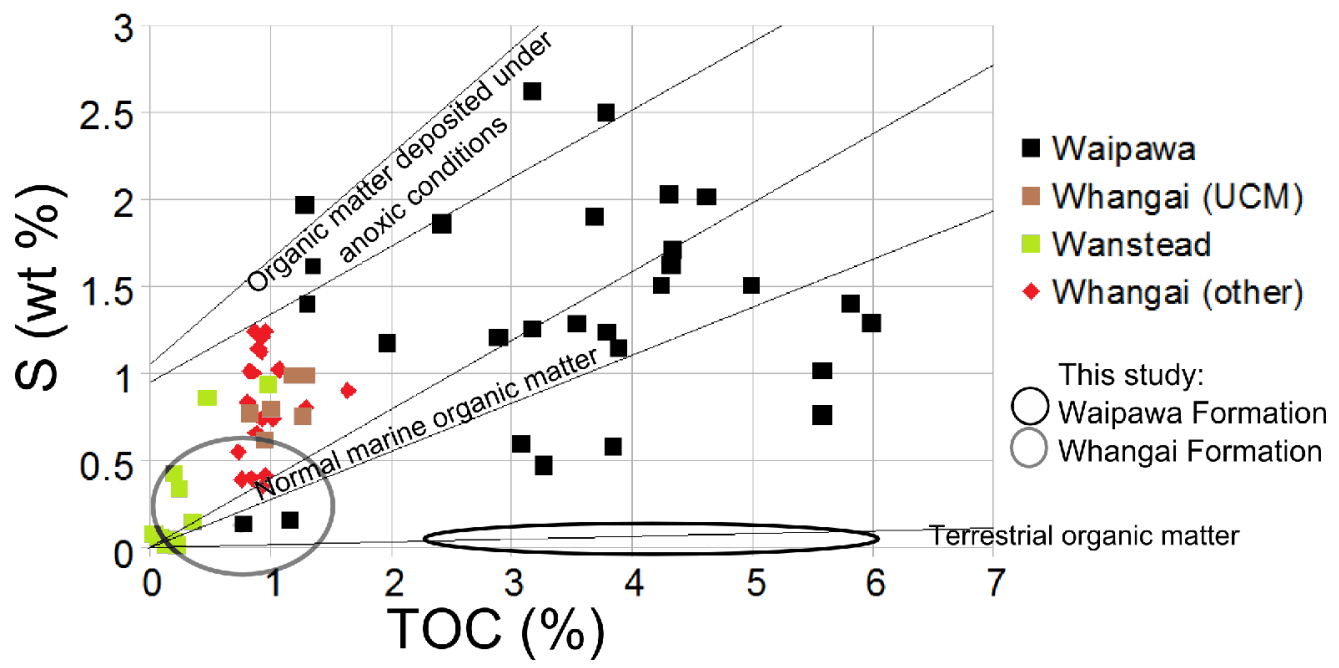

Figure 6.0.8: $\mathrm{S}$ plotted against TOC to differentiate types of organic matter and deposition. $\mathrm{S}$ and TOC data for data points are from Rogers (1995), and Elgar (1997). The circles show $S$ from this study plotted against TOC values from Leckie (1992). As separate samples were used by Leckie (1992) and this study, the figure shows only approximate locations with circles. Graph style after Leventhal (1993).

Overall, the Waipawa and Whangai formations vary across this plot. The anoxic and oxic fields on the plot are based on the assumption that the bulk of organic matter in the anoxic section is of marine origin (Leventhal, 1993), and thus high terrestrial 
organic content may move the lower constraining line for anoxic conditions to include more samples. Without analysing the origin of the $\mathrm{S}$, this plot may only be able to differentiate non-marine influence and some definitely anoxic samples.

\section{Rare earth elements}

Overall, most of the REE are not very different from the NASC (North American Shale Composite) (figure 5.0.21) standard. However, the bell-shaped curve in A-A-13 (figure 5.1.21) showing enrichment in the middle REE is noteworthy. A similar curve was observed in apatites formed from fish and shark teeth (Lécuyer et al., 2004); however, even the most REE-rich apatites in this study had at the most $0.5 \% \mathrm{Ce}$, at this concentration 50 times more $\mathrm{P}$ would be required to achieve the observed $\mathrm{Ce}$ at angora Quarry in apatite form.

Another source for the high REE concentration in A-A-13 could be contamination of the sample by an REE rich mineral, or a detrital REE-rich mineral being fortuitously introduced during deposition.

\section{Summary of Angora Quarry data}

Terrestrial organic matter washed offshore was deposited in dysoxic to oxic conditions. The increased influx of terrestrial organic matter coupled with terrestrial clays caused a dilution of $\mathrm{CaO}, \mathrm{SiO}_{2}$ and marine organic matter (as indicated by the low $\mathrm{SO}_{3}$ ). How much of the $\mathrm{SiO}_{2}$ is of biogenic origin, and how much is of terrestrial origin cannot be determined from the data, sedimentary sorting could have led to a change in detrital quartz content.

The low $\mathrm{SO}_{3}$ and lack of similarity between other anoxic indicators, along with an abundance of $\mathrm{Fe}_{2} \mathrm{O}_{3}$, leads to the conclusion that anoxic conditions were not present due to the lack of pyrite. Other indicators of oxygen depletion suggest that at the outcrop 1 $\mathrm{km}$ upstream from Angora Quarry, there was increased oxygen depletion in the water column or upper sediments during deposition; however, the level of depletion cannot be quantified. Minor oxygen depletion during the deposition of the Waipawa Formation at the Angora Quarry section cannot be ruled out, however, but is also not indicated by the inorganic geochemistry and likely would have had no effect on overall conditions of deposition of the Waipawa Formation. 


\subsection{Kawau-1A}

\section{Overview}

TOC measurements were made for the Kawau-1A well by Meadows (2008) for the same SWC samples as studies here and his measurements are presented in figure 6.1.1.

The relationship between the gamma ray log and the detrital input appears to indicate that the gamma ray measurements can be used to approximate the terrestrial clay content (figure 5.1.1). The lower terrestrial clay content is likely to indicate that the terrestrial clays are being diluted, either by calcareous material, silicates or both.

The large influx of terrestrial clays during the deposition of the organic-rich layer agrees with the interpretation of Schiøler et al. (2010), who showed the organic matter was largely of terrestrial origin.

\section{Terrestrial indicators}

Overall, the terrestrial indicators all show a similar trend, with the greatest amount of terrestrial clays deposited during the deposition of the Tartan Formation. The lowest values are in the Laing Formation, which is more calcareous than the underlying Wickliffe and Tartan Formations (Beggs, 1993; Cook et al., 1999).

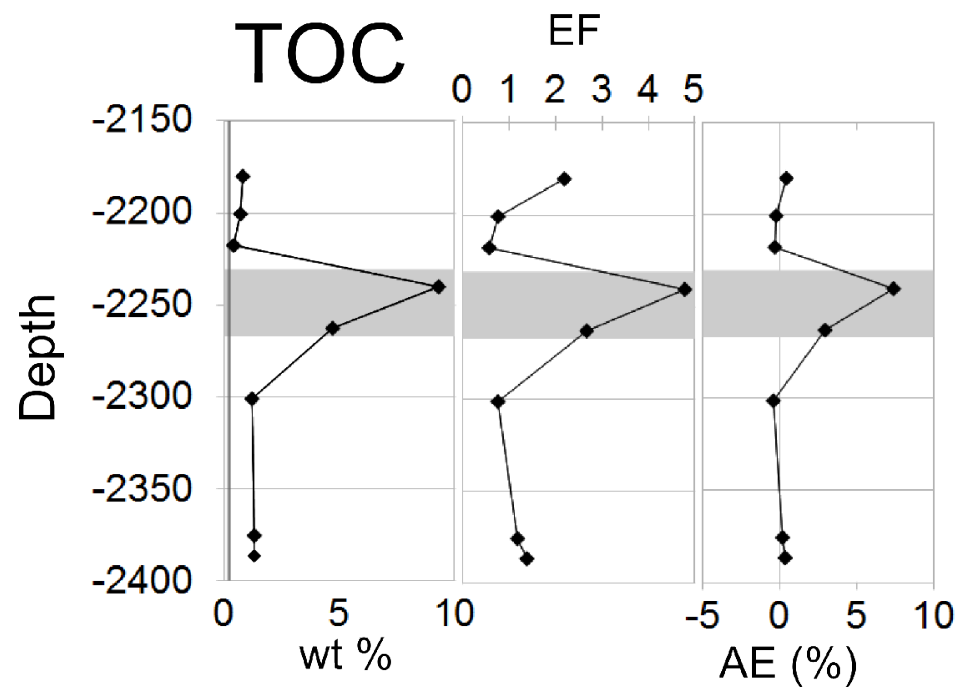

Figure 6.1.1: TOC, EF and AE plotted against depth for Kawau-1A. Absolute concentrations of TOC from Meadows (2008). 
Correlation between the terrestrial indicators is shown in table 6.1.1. The $\mathrm{R}^{2}$ correlation between terrestrial indicators is above 0.9 except for $\mathrm{Th} / \mathrm{Ta}$ and $\mathrm{Hf} / \mathrm{Ta}$. Most of the elements correlate best to either $\mathrm{Zr}$ or $\mathrm{Ti}$, with $\mathrm{Rb}$ the only exception and this correlates best with Th. Zr and Hf do not vary relative to one another, and produced the strongest correlation at 0.997 . This indicating that the Kawau-1A results do not appear to have large errors when treated as fractions; as EF calculations use only fractions the EF are likely to have smaller errors than the other graphs in section 5.1.

The larger variation in $\mathrm{Ta}$ is mainly due to its lower concentration, with measurements between 0.19 and $0.99 \mathrm{ppm}$. Ta should correlate most closely with $\mathrm{Nb}$ as they behave the same way under natural processes (e.g. Ross and Bustin, 2009).

The large increase in terrestrial clay content (figure 5.1.2) indicates limited dilution from biological sources and likely very rapid deposition.

\begin{tabular}{|c|c|c|c|c|c|c|c|}
\hline & $\mathrm{Hf}$ & $\mathrm{Zr}$ & $\mathrm{Ti}$ & $\mathrm{Nb}$ & $\mathrm{Rb}$ & $\mathrm{Ta}$ & $\mathrm{Th}$ \\
\hline $\mathrm{Hf}$ & $\mathrm{N} / \mathrm{A}$ & 0.997 & 0.979 & 0.939 & 0.939 & 0.886 & 0.941 \\
\hline $\mathrm{Zr}$ & 0.997 & $\mathrm{~N} / \mathrm{A}$ & 0.989 & 0.952 & 0.947 & 0.914 & 0.942 \\
\hline $\mathrm{Ti}$ & 0.979 & 0.989 & $\mathrm{~N} / \mathrm{A}$ & 0.970 & 0.967 & 0.950 & 0.950 \\
\hline $\mathrm{Nb}$ & 0.939 & 0.952 & 0.970 & $\mathrm{~N} / \mathrm{A}$ & 0.965 & 0.935 & 0.937 \\
\hline $\mathrm{Rb}$ & 0.939 & 0.947 & 0.967 & 0.965 & $\mathrm{~N} / \mathrm{A}$ & 0.939 & 0.958 \\
\hline $\mathrm{Ta}$ & 0.886 & 0.914 & 0.950 & 0.935 & 0.939 & $\mathrm{~N} / \mathrm{A}$ & 0.862 \\
\hline $\mathrm{Th}$ & 0.941 & 0.942 & 0.950 & 0.937 & 0.958 & 0.862 & $\mathrm{~N} / \mathrm{A}$ \\
\hline
\end{tabular}

Table 6.1.1: $R^{2}$ correlation of terrestrial indicators in Kawau-1A. Grey shading indicates the best correlation for the element. See text for discussion.

\section{Anoxic indicators (sedimentary pyrite)}

Some of the elements included as traces within sedimentary pyrite (Mo, Ni and, in one sample, $\mathrm{Cu}$ ) are enriched in the Tartan Formation to varying degrees, but the remaining elements which should also be enriched in pyrite do not show significant enrichment (figures 5.1.3, 5.1.4, 5.1.6 and 5.1.7). Many elements, however, are affected by multiple processes and it may be possible that very rapid deposition diluted the effect of anoxic conditions on the inorganic geochemistry of the Tartan Formation. Unfortunately, insufficient sample remained to allow measurement of sulphur concentrations by XRF. 
It cannot be conclusively said from the limited trace element data available whether or not the water was anoxic during deposition of the Tartan Formation in Kawau-1A, although it is unlikely.

\section{Oxygen depletion}

Mn and Co (figure 5.1.7) show no significant signs of depletion through the Tartan Formation; however, As, U, V, Cr, and Se are all enriched through the Tartan Formation. As and U, may also be enriched in the uppermost sample (figure 5.1.8, 5.1.9). $\mathrm{Sb}$ is the only indicator which is normally enriched under conditions of oxygen depletion which here does not show enrichment, and in this case Sb behaves in a similar way to Bi.

Overall the bulk of the elements measured suggest that oxygen-depleted conditions existed during the deposition of the Tartan Formation. While no depletion can be shown in $\mathrm{Mn}$ and Co, the amounts of these elements present are already very low, compared to average shale which has $850 \mathrm{ppm} \mathrm{Mn}$ and $19 \mathrm{ppm} \mathrm{Co}$. It may be the case that the conditions were already suboxic prior to Tartan Formation time and that Mn depletion was already occurring in the Laing and Wickliffe formations.

\section{Biological components and biocycling}

$\mathrm{Ni}$ is the only element of this group which is enriched in both samples of the Tartan Formation (figure 5.1.6) while $\mathrm{Cu}$ is enriched in the upper Tartan Formation sample. Cadmium, $\mathrm{Tl}$ and $\mathrm{Ni}$ are show increases in $\mathrm{AE}$ and $\mathrm{EF}$ in the uppermost sample of the Laing Formation. Without being able to link $\mathrm{Ca}$ to $\mathrm{Sr}$ it is not possible to say anything definite about the $\mathrm{Sr}$ concentration.

Increases in $\mathrm{Cu}$ and $\mathrm{Ni}$ were also noticed in some of the samples in Angora Quarry and are on a similar scale to those observed in Kawau-1A, while the lack of variation in $\mathrm{Cd}$ apparent in Kawau-1A may be due to the limited numbers of samples. While Kawau-1A and Angora Quarry do not show the same variations in trace elements, the resolution is different and it cannot be determined whether or not the biological conditions were similar from trace metals alone. 


\section{Rarely studied elements}

Tungsten behaves in a similar way to Bi at Kawau-1A (figure 5.1.12), which may suggest that $\mathrm{Bi}$ and $\mathrm{W}$ are affected by similar processes. The processes involved with $\mathrm{Bi}$ variations in sedimentary environments are uncertain, however, and $\mathrm{W}$ has been excluded in all such previous studies. The variation of $\mathrm{Sn}$ is different to all other elements in Kawau-1A, but the processes which affect it are unknown.

\section{Rare Earth Elements}

While REE were not measured, $\mathrm{Y}$ is affected the same chemically (e.g. Haskin and Gehl, 1962). Y was enriched through the Tartan Formation (figure 5.1.13). In the other samples, Y behaves like a terrestrial indicator. Without having any REE measured in this site, nothing can be said about the source of the REE apart from the suggestion that they are probably affected by more than just detrital input.

\section{Summary of Kawau-1A}

Samples from Kawau-1A were deposited in the more distal setting of the two Great South Basin wells studied here. The Tartan Formation in the well is characterised by high gamma ray levels, and the concentration of terrestrial indicators follows a similar trend to the GR log.

Fully anoxic conditions during deposition of the Tartan Formation appear unlikely, with no agreement across the data, such conditions cannot be completely ruled out. An increase in concentrations of the trace metals As, U, Cr and Se through the Tartan Formation does indicate that the Tartan Formation was deposited under oxygen depleted conditions in Kawau-1A.

It should be noted that the SWC samples of the Tartan Formation were taken during drilling operations from horizons identified by gamma ray spikes within the formation. Sedimentary and geochemical conditions between these samples, where the GR log is on average 20-30 api units lower, are unknown as no sidewall samples exist from these levels. 


\subsection{Pakaha-1}

\section{Overview}

TOC measurements were made for the Pakaha-1 well by Meadows (2008) and are presented here in figure 6.2.1. These measurements are from the same SWC samples as those analyzed in the present study.

The GR log again matches the terrestrial background (figure 5.2.1), and there is far less variation in both the gamma ray signal and terrestrial background observed in this well. This has previously been interpreted as indicating a more rapid rate of deposition and higher terrestrial influx due to the more proximal location of the Pakaha1 well during the Late Paleocene (e.g. Schiøler et al., 2010).

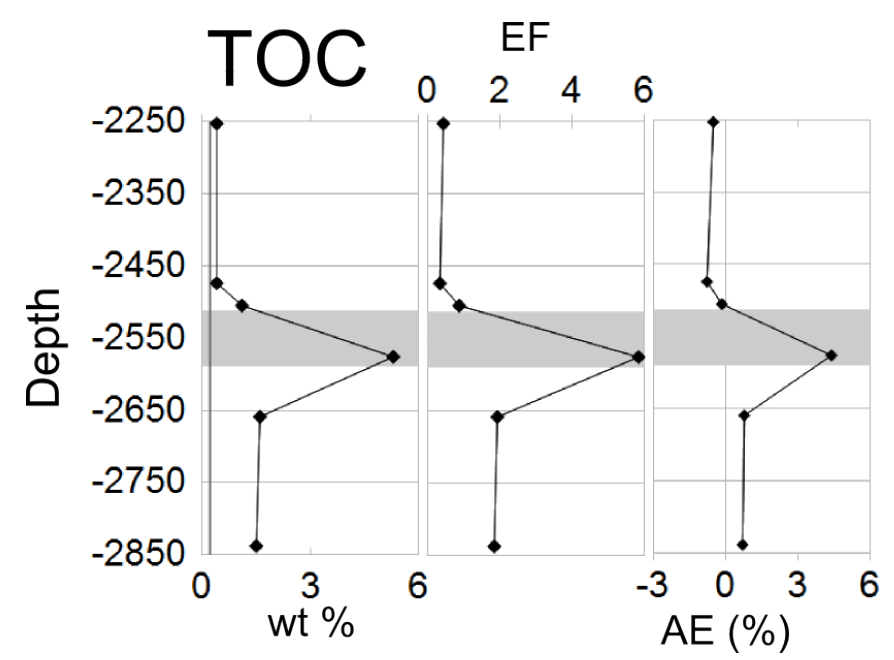

Figure 6.2.1: TOC, EF and AE plotted against depth for Pakaha-1. Absolute concentration of TOC is from Meadows (2008)

\section{Terrestrial indicators}

Significantly less variation is seen within each of the terrestrial indicators than in Kawau-1A, and this lower range also corresponds to significantly lower $\mathrm{R}^{2}$ values (table 6.2.1). While most of the terrestrial indicators show only slight variation, $\mathrm{Rb}$ behaves completely independently to the other terrestrial indicators in Pakaha-1, and hence shows no correlation.

Zirconium and $\mathrm{Hf}$ again show the strongest correlation. The spike in $\mathrm{Rb}$ is unexpected (figure 5.2.2), and it is not easily explained. Only $\mathrm{Tl}$ has a similar variation 
(figure 5.2.7). While $\mathrm{Rb}$ changes bear some resemblance to those of the TOC, they do not directly correlate with it. The cause of the spike in $\mathrm{Rb}$ hence remains unknown.

\begin{tabular}{|c|c|c|c|c|c|c|c|}
\hline & $\mathrm{Hf}$ & $\mathrm{Zr}$ & $\mathrm{Nb}$ & $\mathrm{Ta}$ & $\mathrm{Th}$ & $\mathrm{Ti}$ & $\mathrm{Rb}$ \\
\hline $\mathrm{Hf}$ & $\mathrm{N} / \mathrm{A}$ & 0.967 & 0.819 & 0.693 & 0.677 & 0.679 & 0.003 \\
\hline $\mathrm{Zr}$ & 0.967 & $\mathrm{~N} / \mathrm{A}$ & 0.616 & 0.636 & 0.712 & 0.819 & 0.001 \\
\hline $\mathrm{Nb}$ & 0.819 & 0.616 & $\mathrm{~N} / \mathrm{A}$ & 0.958 & 0.937 & 0.629 & 0.002 \\
\hline $\mathrm{Ta}$ & 0.693 & 0.636 & 0.958 & $\mathrm{~N} / \mathrm{A}$ & 0.882 & 0.582 & 0.001 \\
\hline $\mathrm{Th}$ & 0.677 & 0.712 & 0.937 & 0.882 & $\mathrm{~N} / \mathrm{A}$ & 0.770 & 0.013 \\
\hline $\mathrm{Ti}$ & 0.679 & 0.819 & 0.629 & 0.582 & 0.770 & $\mathrm{~N} / \mathrm{A}$ & 0.021 \\
\hline $\mathrm{Rb}$ & 0.003 & 0.001 & 0.002 & 0.001 & 0.013 & 0.021 & $\mathrm{~N} / \mathrm{A}$ \\
\hline
\end{tabular}

Table 6.2.1: $\mathrm{R}^{2}$ correlation for the terrestrial indicators in Pakaha-1. Grey shading indicates the best correlation for the element. See text for discussion.

\section{Anoxic indicators (sedimentary pyrite)}

There is no indication of sedimentary pyrite in the Tartan Formation sample, although the sample immediately above the formation has a spike in $\mathrm{Mo}, \mathrm{Bi}, \mathrm{Cu}, \mathrm{Cd}, \mathrm{Ni}$ and $\mathrm{Co}$ which are incorporated in sedimentary pyrite (figures 5.2.3, 5.2.4, 5.2.6, 5.2.8). This sample was taken at a narrow but pronounced gamma ray spike (figure 5.2.1). Mn, $\mathrm{Tl}$, and $\mathrm{Pb}$ can be included into sedimentary pyrite but are not enriched in this sample. As all the other elements which indicate sedimentary pyrite are enriched, indicating that sedimentary pyrite was in fact deposited in this sample.

Schiøler et al., (2010) suggested that the deposition of the Tartan Formation began earlier in relation to eustatic sea level at Pakaha-1 than elsewhere. If so, it is thus possible that at Pakaha-1 the Tartan Formation was deposited during prior to deposition of the Tartan elsewhere in the basin, sediments later largely bypassed Pakaha-1 while the Tartan Formation was being deposited elsewhere. Increased productivity due to the influx of micro nutrients would be needed to lead to anoxic conditions for the sample above the Tartan Formation.

An earlier pulse is not inconsistent with the literature, several previous authors suggested that the Waipawa and Tartan formations consist of two pulses of organic matter-rich sediment, sometimes separated by a more calcareous unit. The best example of a section where the Waipawa Formation is certainly divided into two parts is Mead Stream (Hollis et al., 2005a), or two pulses in TOC content such as at Angora Quarry. 


\section{Oxygen depletion}

No elements indicate oxygen depletion during the deposition of the Tartan Formation in Pakaha-1, although enrichments in As, U, V, Sb, Se, and Mn indicate oxygen depletion in the sample above the Tartan Formation (figures 5.2.8, 5.2.9, 5.2.10). This agrees with the anoxic indicators which suggest no oxygen and the precipitation of sedimentary pyrite during deposition of this sample.

\section{Biological components and biocycling}

Interpreting $\mathrm{Sr}$ values without $\mathrm{Ca}$ is difficult. In Pakaha-1 $\mathrm{Sr}$ values significantly higher than were recorded at any other site were encountered in the uppermost sample. If the Sr was mainly of biological origin, and was at the same ratio of $\mathrm{Sr}$ to $\mathrm{Ca}$ as at Angora Quarry, the uppermost sample would have to contain $48 \%$ calcite. This amount is unlikely given that neither the GR log nor the concentrations of terrestrial indicators indicate any dilution of the terrestrially-sourced component. This sample also has an unusually high concentration of $\mathrm{Mn}$, at $400 \mathrm{ppm}$.

There is a spike in the $\mathrm{Tl}$ concentration in samples from the Tartan Formation which can be correlated to $\mathrm{Rb}$ with an $\mathrm{R}^{2}$ of 0.88 (figure 5.2 .7 ); however, there are few data points and there is little spread, thus whether or not $\mathrm{Tl}$ and $\mathrm{Rb}$ are controlled by the same process in Pakaha-1 cannot be confirmed.

\section{Rarely studied elements}

Tungsten is significantly enriched in the sample directly above the Tartan Formation but shows very little variation in all the other samples. This suggests that $\mathrm{W}$ is affected by some process. $\mathrm{W}$ is a chalcophile element, hence the process is probably sedimentary pyrite precipitation. Sn is enriched in the Tartan Formation in Pakaha-1, although there is no clear reason as to why this happened and variations in $\mathrm{Sn}$ have been little studied. The concentration is relatively constant in the other samples once the terrestrial input was corrected for.

\section{Rare earth elements}

Yttrium behaves like REEs; it shows little variation through the section, 
suggesting that it is sourced largely from detrital input. Measurement of more rare earth elements is needed.

\section{Summary of Pakaha-1}

There is no indication of oxygen depletion during the deposition of the Tartan Formation at Pakaha-1; however, the sample above the Tartan Formation which corresponds with a sharp gamma ray spike appears to indicate anoxic conditions during deposition. The anoxic sample in the Pakaha-1 well also corresponds with the highest terrestrial input, although it contains only a low TOC content.

\subsection{Regional depositional environment}

This section will draw on data from this and previous studies to suggest a depositional environment for Waipawa and Tartan formations on both a local and regional scale.

\section{East Coast Basin trace element work from Elgar (1997)}

A plot of Rb against Th from Elgar (1997) and Moore (1980) (figure 6.3.1) was used to identify whether the regional East Coast Basin trace metal data could be used together. As both $\mathrm{Th}$ and $\mathrm{Rb}$ are of detrital origin at Angora Quarry $\left(\mathrm{R}^{2}\right.$ of 0.922$)$, if the mineralogy remains constant across the basin they should plot in a straight line.

The variation in $\mathrm{Rb} / \mathrm{Th}$ suggests that there are at least two separate detrital sediment sources with different $\mathrm{Rb} / \mathrm{Th}$ ratios. Elgar (1997) sampled a wide range of different formations, including the Waipawa Formaiton throughout the East Coast Basin. Without a larger range of terrestrial indicators identifying which variations in other elements are due to the terrestrial component and which are due to oceanic conditions it is not possible to extract new data from his study.

While a vague linear trend may exist in the non-Waipawa samples, this is uncertain, and does not appear to pass through zero, more measurements would need to be done to investigate this. 


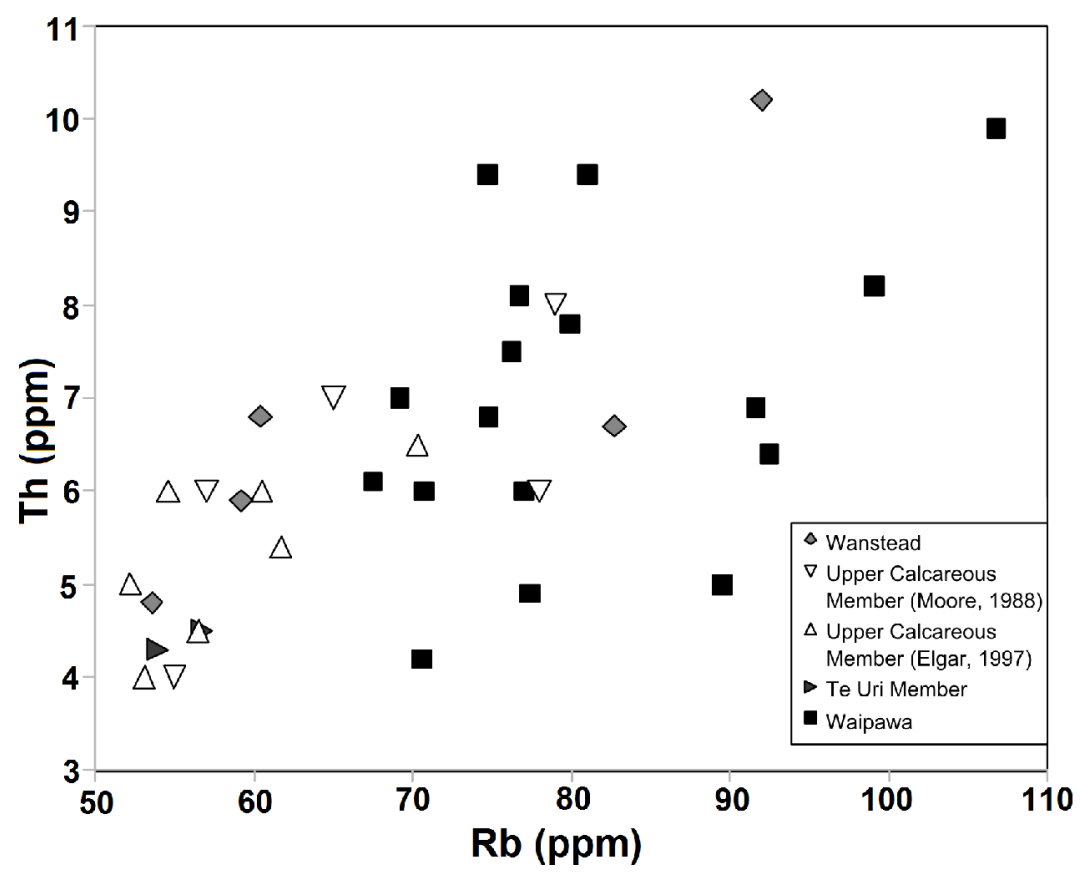

Figure 6.3.1: A plot of $\mathrm{Rb}$ against Th using data from Elgar (1997) and Moore (1988). The wide spread of values indicates that there is variation in the composition of the local background through the East Coast Basin.

\section{Summary of results}

Terrestrial indicators indicate an increase in the abundance of terrestrial clays during deposition of the Tartan and Waipawa formations. This was previously suggested as one of several potential causes of the gamma ray spike by Schiøler et al., (2010), and was confirmed in this study. Other proposed causes of the gamma ray spike were discussed in section 1.1.

Low $\mathrm{Ca}$ abundance through the Waipawa Formation was found at the Angora Quarry section, and is in line with XRF measurements have been made previously on two Waipawa Formation samples by Moore (1988), suggesting this is a more regional phenomena.

Variation in the redox equilibria under which the formation was deposited depended on locality, as first suggested in a S vs. TOC plot by Elgar, (1993) for the East Coast Basin. This was later supported by Schiøler et al., (2010) based on AOMphytoclast-polynomorph kerogen plots for the Great South Basin. The present study confirmed that redox conditions change with locality for the deposition of the Waipawa 
and Tartan formations.

Water depth at the time of deposition is unknown. It has been suggested that the Tartan Formation was deposited in 0-20 m water depth (Raine et al., 1993; Cook et al., 1999; Schiøler et al., 2010). Shallow hypersaline conditions were suggested due to the presence of a low-diversity foraminiferal fauna including Cyclammina elegans and abundant terrestrial organic matter (Schiøler et al., 2010). However, the oxygen depletion seen in Kawau-1A within the Tartan Formation and the anoxic indicators directly above the Tartan Formation in Pakaha-1 would have required deposition below the mixing caused by waves (e.g. Demaison and Moore, 1980), suggesting waters significantly deeper than $50 \mathrm{~m}$.

The Waipawa Formation was likely deposited at a very rapid rate at Angora Quarry, leading to similarities between $\mathrm{CaO}$ and $\mathrm{SO}_{3}$ abundances due to dilution with terrestrial clays and terrestrial organic matter, and burying the organic matter before it could be biologically degraded. Without anoxic conditions, only rapid burial can preserve organic matter (Gavrilov et al. 1997). It is likely that the formation was also deposited rapidly in the Great South Basin as the gamma ray peaks correspond to intervals of maximum terrestrial sediment supply.

Supporting a rapid depositional rate is the low amount of enrichment in oxygen depleted samples in comparison to Brumsack (2006). Redox depletion can enrich elements by several orders of magnitude, however, even in the Pakaha-1 sample which contained anoxic indicators Mo shows only an enrichment factor of 2 , in comparison to 2-3 orders of magnitude in Brumsack (2006). The difference in results to present day depositional environments makes present day analogues to the depositional environment impossible.

\section{Possible depositional environments}

1) Schiøler et al., (2010) suggested the Waipawa and Tartan formations are regressive units due to the increasing non-marine proxies, with the top of the Tartan Formation representing a Maximum Regressive Surface. They suggested that a fall in sea level caused a base level drop and erosion provided the terrestrial material.

Beggs (2010a, b) suggested that the Waipounamu Erosion Surface which followed the cessation of sea-floor spreading indicated a "broad domain up-warping," in which 
large parts of the New Zealand continent were uplifted and eroded. This may have provided the mechanism to uplift and erode swamps, giving the high terrestrial input, and causing the maximum regression suggested by Schiøler et al., (2010).

2) An alternative explanation is suggested by this study. A marine transgression might have flooded coastal swamps and re-deposited the organic matter offshore. This model is suggested by the present study due to the indication of oxygen depletion during deposition of the Tartan Formation in the Great South Basin wells, which in turn indicates undisturbed and deeper waters.

Increased influx of detrital sediments during transgression is known to occur in New Zealand sediments elsewhere during the Tertiary; for example, increased aluminosilicates producing marl beds during the deposition of the Amuri Limestone have been linked to marine transgressions in the Early Eocene (e.g. Nicolo et al., 2007).

An organic matter-rich shale up to several $\mathrm{m}$ thick and extensive over $2500 \mathrm{~km}$ was deposited during the IETM (Initial Eocene Thermal Maximum) in the southern territory of the former Soviet Union (Gavrliov et al., 1997; 2000; 2003). This sapropelitic unit contained large amounts of terrestrial organic matter and decreases in carbonate content, and other similarities in trace metal content, making it the closest analogy found for the inorganic geochemistry of the Waipawa Formation. This organic matter-rich shale has been interpreted as a transgression unit which was preceded by a regression. With peat swamps and bogs present along the shoreline, eustatic sea level transgression caused flooding and rapid erosion, depositing a thin layer of organic mater across the basin and causing anoxic conditions.

Due to the widespread but unique nature of the Tartan and Waipawa formations in the Late Paleocene to Early Eocene sediments, the relative sea level change must have been a unique event whether the transgression suggested herein or regression suggested by Schioler et al., (2010) occurred. Regional tectonic events as suggested by Beggs (2010a, b) may have played a roll in the sediment deposition but other evidence has yet to be presented proving specific tectonic events were synchronous with the deposition. 


\section{Comparison of depositional environments}

Either a transgression or a regression may have caused the influx of terrestrial organic matter into the Waipawa and Tartan formations. Both models invoke erosion of terrestrial organic matter, and both models can cause increased marine productivity due to increased nutrients and the increased influx of terrestrial clays. A transgression also allows for increased productivity close to shore with the resulting organic matter being washed offshore along with the terrestrial organic matter.

The microfossil assemblages which indicate 0-20 m water depth (Raine et al., 1993) are explainable by a transgression regression if water depths are this shallow; however, a transgression may have reworked shallow sediments such as peats and swamps were eroded, depositing reworked shallow water sediments and terrestrial matter at greater water depths.

For ocean floor environments to be oxygen depleted, vertical mixing must be restricted by stratification (Tyson and Pearson, 1991). At shallow depths oxygen depletion only occurs seasonally, and only where there is restricted wave action. Without the re-oxygenation and reversal of many trace metal processes having occurred, sections of the Tartan and Waipawa formations which were deposited under oxygendepleted conditions were likely deposited at water depths greater than 50 metres. Kawau-1A shows some indications for oxygen depletion, whereas Pakaha-1 shows anoxic conditions in the sample directly above the Tartan Formation. Schiøler et al. (2010) suggested in Toroa-1 that the Tartan Formation was deposited under dysoxic to anoxic conditions. The deposition of Te Uri member greensand as time equivalents to the Waipawa Formation was interpreted by Rogers et al. (2001) as representing oxic bottom waters, in comparison to the Waipawa Formation representing anoxic conditions resulting from a regional upwelling as suggested by Killops et al. (2000).

Under a transgressive model, the greensands which are equivalent in time to the Waipawa Formation may represent a sediment bypass, and / or regions where near-shore swamps did not exist. At some locations such as Te Hoe River, both the Te Uri greensand unit is present as well as the Waipawa Formation (Leckie et al., 1992 appendix II). This may be related to the double pulse of the Waipawa Formation observed elsewhere. Under modern conditions glaconite is generally formed in lowenergy conditions at mid-shelf to deeper-water environments (e.g. Dias and Nittrouer, 1984), hence glauconite equivalents to the Tartan and Waipawa formations fit better 
with a marine transgression.

Difficulty in constraining the dates under which the Waipawa and Tartan formations were deposited as well as sea level changes has left much debate about whether the formation is transgressive or regressive. Figure 6.3.2 shows two different sea level curves along with different age constraints for the age of the Waipawa Formation. The Waipawa Formation may have been deposited very rapidly due to the low $\mathrm{CaO}$ and $\mathrm{SO}_{3}$ concentrations, at Angora Quarry the Waipawa Formation contains 27 times less $\mathrm{CaO}$ than the surrounding formation, and at least 10 times less $\mathrm{SO}_{3}$ (assuming the maximum of $0.01 \mathrm{wt} \%$ when below the $0.01 \mathrm{wt} \%$ minimum detection level).

The rate of deposition of the Waipawa Formation at Angora Quarry cannot be quantified and can only be inferred as very rapid; it is probably well below the resolution of the sea level curves from figure 6.3.2. Without direct indicators of sea level change, neither the Schiøler et al., (2010), nor the transgressive model proposed by this study can be ruled out.

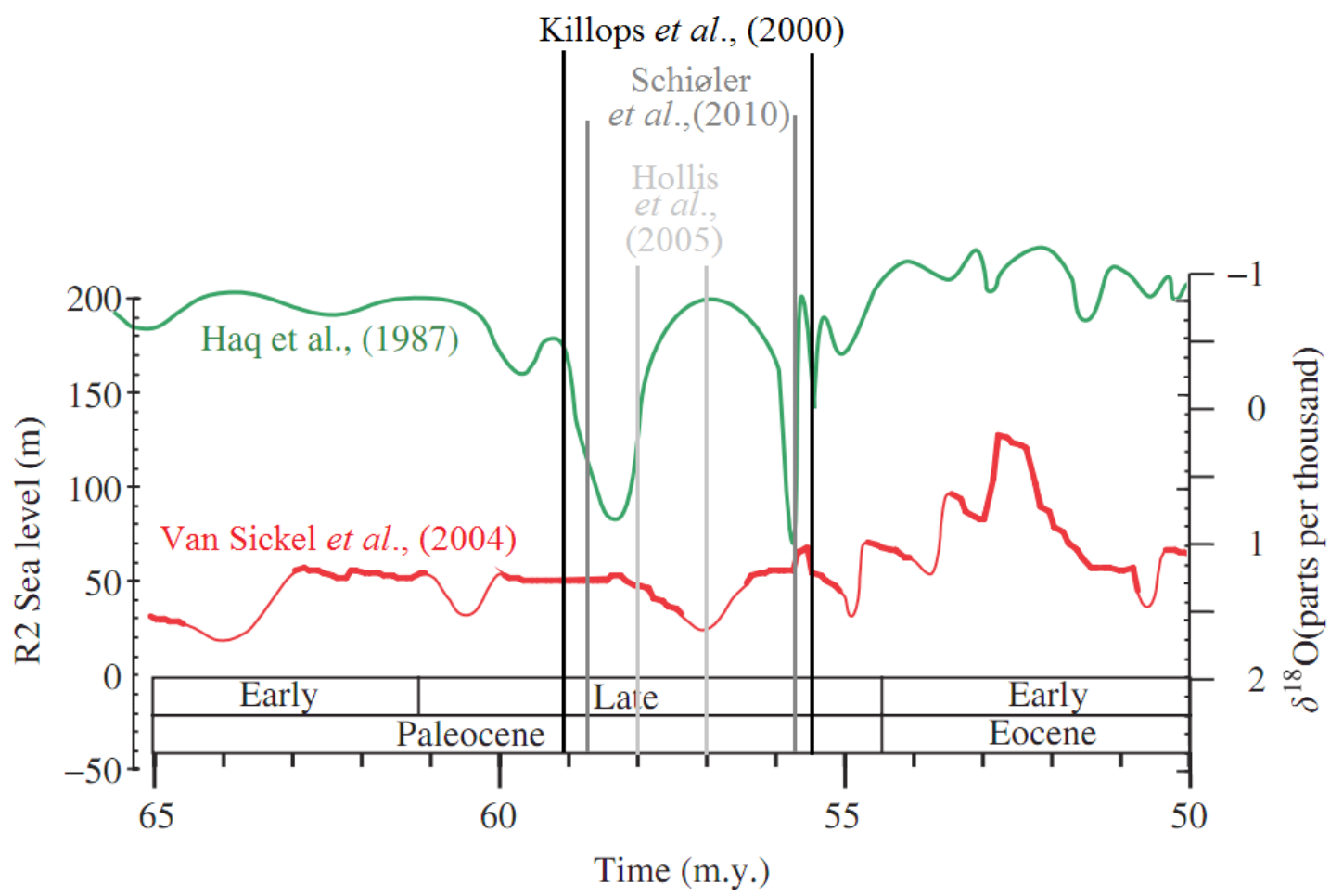

Figure 6.3.2: Two sea level curves in green and red, and the estimated age ranges for the Waipawa Formation in different shades of grey, see text for discussion. Sea level data from Van Sickel et al., (2004). 


\section{Summary}

Reduced oxygen content in the water column can be ruled out as the forcing factor behind the deposition of the Tartan and Waipawa formations, as can extremely shallow water depths which preclude oxygen depletion.

Both transgressive and regressive sea level change are able to explain the deposition of the Tartan and Waipawa Formation; however, the increased terrestrial content of the sediment indicates transgression with increased erosion. On a regional scale, transgression better explains the glauconite content and localised reducing conditions.

The anoxic conditions in Pakaha-1 also correspond to an increased terrestrial component. Such anoxic conditions suggest that depths were likely significantly deeper than 50 metres, and possibly several hundred metres deep.

A regressive model cannot be ruled out, but overall a transgressive model appears to fit better with the geochemical properties of the Waipawa Formation, with increased terrestrial input coming from erosion of nearshore swamps.

\subsection{Discussion of trace metals}

\section{Effects of thermal maturation on trace metals}

The Waipawa Formation has been the source of oil in several New Zealand Basins, including that in the Kora structure in the Taranaki Basin (Killops et al., 1994) and the Waitangi oil seeps in the East Coast Basin (Rogers et al., 1999). Frankenberger (1994) measured trace elements in oils from both Kora and the Waitangi oil seep, and a comparison between the TM content of the oil and of the Waipawa Formation at Angora Quarry is shown in figure 6.4.1.

Overall none of the elements which were measured both in this study and by Frankenberger (1994) were present in high concentrations in the oils. Having lower concentrations in the oil than in the rocks suggests that the overall mass lost though oil expulsion has the net affect of increasing trace element concentration in the mature source rock; however, this effect is very small. 


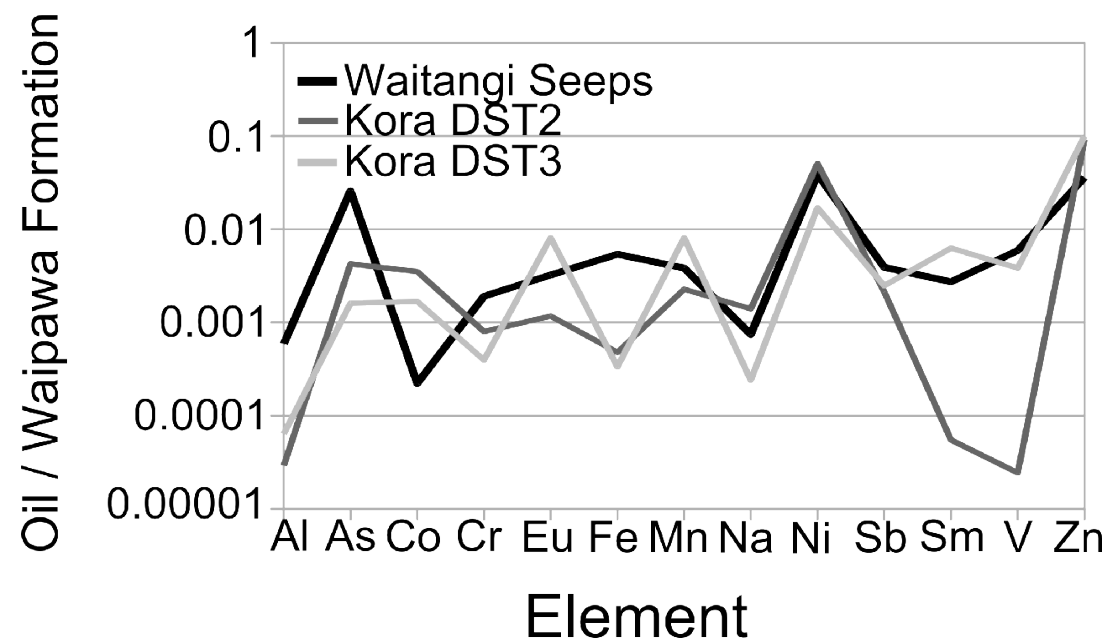

Figure 6.4.1: Trace metal composition of oils divided by the comparison to the Waipawa Formation at Angora Quarry. Oil concentrations are from Frankenberger (1994).

This is a simplification as the oil has migrated, there is potential for the composition of the oils to have changed during migration, and the concentration of elements within the Waipawa Formation may vary from place to place. 


\section{Chapter 7 \\ Conclusions}

\subsection{Angora Quarry section.}

- There was no significant change in redox conditions during the deposition of the Angora Quarry section of the Waipawa Formation. This rules out anoxic conditions caused by upwelling, as suggested in the model of Killops et al., (2000) for deposition of the Waipawa Formation.

- The section $1 \mathrm{~km}$ upstream from Angora Quarry was somewhat oxygendepleted in comparison to samples in the quarry. This assessment is based on the enrichment in $\mathrm{As}, \mathrm{V}, \mathrm{U}, \mathrm{Cr}, \mathrm{Ag}, \mathrm{Sb}$ and $\mathrm{Se}$ in both $\mathrm{AE}$ and $\mathrm{EF}$ graphs, as well as the significantly lower $\mathrm{Ce} / \mathrm{La}$ and $\mathrm{Gd} / \mathrm{Eu}$ ratios than in all other samples. The paleogeographic distance, and exact stratigraphic relationship is unknown, however, as the two sets of samples are separated by a fault.

- Low $\mathrm{CaO}$ and $\mathrm{SO}_{3}$ concentrations through the Waipawa Formation at Angora Quarry indicate very rapid deposition with little biological calcite and with little marine organic matter indicated by the low sulphur. Terrestrial clays increase through the section, as indicated by the $\mathrm{Al}_{2} \mathrm{O}_{3}$.

- $\mathrm{SO}_{3}$ from this study together with TOC values from Leckie (1992) indicate that the organic matter from the Waipawa Formation is largely of terrestrial origin. This agrees with data presented by Elgar (1997), who found 90\% structured organic matter in his sample from Angora Quarry in a visual kerogen analysis. $\mathrm{Al}_{2} \mathrm{O}_{3}$ values sorted by colour of the sample as an indicator of TOC content shows that the terrestrial clay content covaries with colour and by extension likely with TOC.

- There is no evidence for a change in terrestrially sourced minerals; the ratios of the detrital elements remain largely constant. However there is larger amounts of terrestrially sourced elements during the deposition of the Waipawa Formation. 


\subsection{Kawau-1A.}

- The gamma ray spike characteristic of the Tartan Formation can be correlated in the Great South Basin well Kawau-1A with purely detritally-sourced elements, suggesting that it is indicative of increased terrestrial input.

- Kawau-1A was deposited under oxygen-depleted conditions; however it is unlikely the conditions were completely anoxic due to the absence of sedimentary pyrite.

- Similarities in the scale of variations between $\mathrm{Ni}$ and $\mathrm{Cu}$ in the Tartan Formation at Kawau-1A and the Waipawa Formation at Angora Quarry where observed. With only two samples at Kawau-1A confirming whether this correlates is impossible.

- Similarly to Angora Quarry, no change in sediment source was noticed, however there is a variation of a factor of 5 in the amount of terrestrial indicators in individual samples.

\subsection{Pakaha-1.}

- The gamma ray log correlated with the detritally-sourced elements, confirming the correlation noticed in Kawau-1A.

- Only material from one sample in the Tartan Formation remained in Pakaha-1 to be analysed, in this sample there was no indication of oxygen depletion.

- The sample above the Tartan Formation in Pakaha-1 contained indicators for both oxygen depletion (enhanced $\mathrm{As}, \mathrm{U}, \mathrm{V}, \mathrm{Sb}$ and $\mathrm{Se}$ ) and anoxic conditions (enhanced $\mathrm{Mo}, \mathrm{Bi}, \mathrm{Cu}, \mathrm{Cd}, \mathrm{Ni}$ and $\mathrm{Co}$ ), indicating it was likely deposited under anoxic conditions.

- A spike in $\mathrm{Rb}$ was noticed in the Tartan Formation sample, the cause of this is uncertain, it may indicate a different terrestrial mineralogy or may indicate the presence of a single mineral which due to the small sample size caused a large spike. The $\mathrm{Rb}$ measurement may be related to $\mathrm{Tl}$ with an $\mathrm{R}^{2}$ correlation of 0.88 . 


\subsection{Depositional environment.}

- Oxic conditions during deposition of the Waipawa and Tartan formations at Angora Quarry and at Pakaha-1 do not fit with the upwelling model proposed by Killiops et al., (2000).

- Time-equivalent glauconitic sandstones to the Waipawa and Tartan formations, and the dysoxic conditions in the shallow suggested depositional environment in the Great South Basin are difficult to reconcile with the regressive model of deposition proposed by Schiøler et al., (2010).

- The present study supports a transgressive model where rising sea level flooded low-lying swamps and peats. Rapid erosion and redeposition diluted the biological $\mathrm{CaO}$ and $\mathrm{SiO}_{2}$ contents at Angora Quarry. In the Great South Basin, the foraminifera Cyclammina elegans is interpreted as indicating $0-20 \mathrm{~m}$ water depth by Raine et al., (1993). However, oxygen depletion must be significantly below wave base, a depth significantly deeper than $50 \mathrm{~m}$ is suggested for oxygen depletion by Demaison and Moore (1980). The erosion of peat swamps during transgression may have limited deposition of sediments in the shallow water with shallow water indicators washed into deeper waters.

Increased terrestrial clays are often indicators of marine transgressions, as is also observed later in the Early Eocene as marl layers in the Amuri Limestone (e.g. Nicolo et al., 2007).

- The overall low enrichment factors in samples which were deposited under oxygen-depleted conditions are orders of magnitude lower than those presented by Brumsack (2006), and may indicate very rapid deposition with no present day analogue. The closest analogue found was an Early Eocene unit (Gravilov et al. 1997) on which the transgressive model proposed in this thesis is based.

\subsection{Trace metals in sediments.}

- Defining the local background is rarely done in the literature; however, local background can vary significantly from "average shale" and other standards. Without 
defining local backgrounds, comparisons across regions cannot be done without introducing biases into the data.

- The large variation in detrital element concentration at Kawau-1A shows the difference between the enrichment factor (EF) and the absolute enrichment (AE) formula, especially in regards to the uppermost sample. While EF data has been the conventional way of displaying data, in regions where background content varies the use of AE is more appropriate.

- Ternary diagrams provide a useful way to calculate absolute enrichments of elements affected by multiple processes. Intersection points on the ternary diagram allow the effects of some processes to be quantified, (e.g. biological $\mathrm{Ca} / \mathrm{Sr}$ ratio), and the identification of other processes which form straight lines on a ternary diagrams may aid in working out which processes occurred in ancient sediments during deposition

- $\mathrm{Ga}$ and $\mathrm{Ba}$ behave in a similar way, and at Angora Quarry they appear to be affected by the same two processes, detrital input and biological enrichment. On a ternary diagram $\mathrm{Ga}, \mathrm{Ba}$ and $\mathrm{Al}_{2} \mathrm{O}_{3}$ plotted in a straight line, with an $\mathrm{R}^{2}$ coefficient of 0.97. The relationship between $\mathrm{Ba}$ and $\mathrm{Ga}$ could not be confirmed in other localities however, and variation in detrital background composition is a problem.

- Previous studies have not included W among the trace elements measured. In the present study, Kawau-1A showed a direct correlation between $\mathrm{W}$ and $\mathrm{Bi}$ with an $\mathrm{R}^{2}$ coefficient of 0.93 . In contrast, Pakaha-1 showed no such correlation, although a peak in W occurred in the sample above the Tartan Formation, the same sample with enrichment in $\mathrm{Bi}$ and other anoxic indicators. W thus appears to behave in a similar way to $\mathrm{Bi}$, and to show enrichment in sedimentary pyrite. As $\mathrm{W}$ is a chalcophile element, enrichment in pyrite is expected.

- Comparison of the trace metal concentrations of three oils sourced from the Waipawa Formation with the average concentration of the same elements in the Waipawa Formation at Angora Quarry indicates that oils have between one and five orders of magnitude lower concentrations. Assuming concentrations did not vary much during migration, oil expulsion would have only a minor effect on source rock trace metal concentrations through a minor loss of mass. 


\subsection{Future work.}

This study raises several questions which require future work on both the Waipawa Formation and on trace metals in general.

- Other evidence for sea level change around New Zealand during the deposition of the Waipawa Formation should be examined, to confirm either the transgressive or regressive model.

- More inorganic geochemistry studies on the Waipawa Formation are needed to better understand the lateral variations in the lithology. Studies would have to be conducted on sequences through the Waipawa Formation, including samples where possible from both the adjacent Whangai and Wanstead formations.

- Investigation should be made into whether the REE anomaly in the A-A-13 sample at Angora Quarry is just a local phenomenon or whether it occurs elsewhere.

- $\mathrm{Ga}$ and $\mathrm{Al}$ measurements should be included in studies of $\mathrm{Ba}$ to determine whether the relationship noted on ternary diagrams here can be used to better correct data for detrital Ba content.

- Further investigation of the impact on trace metal concentrations in source rocks to the trace metals in oils needs to be made to investigate the impacts on thermal maturity on trace metal content. Bitumen extracted directly from a known source rock may prove useful for this.

- $\mathrm{Re}, \mathrm{Ag}$, and $\mathrm{Au}$ are indicators of oxygen depletion but were below significance level when measured. They showed similar trends to related elements and future work could look at measuring these more accurately in the Waipawa and Tartan Formations. 


\section{$\underline{\text { References }}$}

Abanda P.A., Hannigan R.E. 2006. Effect of diagenesis on trace element partitioning in shales. Chemical Geology, 230, 42-59.

Aller R.C. 1982. Carbonate dissolution in nearshore terrigenous muds: The role of physical and biological reworking. The Journal of Geology, 90/1, 79-95.

Aller R.C., Rude P.D. 1988. Complete oxidation of solid phase sulfides by manganese and bacteria in anoxic marine sediments. Geochimica et Cosmochimica Acta, 52, 751-765.

Alveirinho Dias J.M., Nittrouer C.D. 1984. Continental shelf sediments of northern Portugal. Continental shelf research, 3/2, 147-165.

Bacon M.P. Anderson R.F. 1982. Distribution of Thorium Isotopes Dissolved and Particulate Forms in The Deep Sea. Journal of Geophysical Research, 87/C3, 2045-2056.

Ballance P.F. 1993. The New Zealand Neogene forearc basins. Balance P.F. (Ed). Sedimentary Basins of the World $2^{\text {nd }}$ editon, South Pacific Sedimentary Basins, 177-193.

Beanland S., Melhuish A., Nicol A., Ravens J. 1998. Structure and deformational history of the inner forearc region, Hikurangi subduction margin, New Zealand. New Zealand Journal of Geology and Geophysics, 41, 325-342.

Berner R.A. 1981. A new geochemical classification of sedimentary environments. Journal of Sedimentary Petrology. 51/2, 359-365.

Bertine K.K., Koide M., Goldberg E.D. 1996. Comparative marine chemistries of some trivalent metals - bismuth, rhodium and rare earth elements. Marine Chemistry, 53, 89-100.

Beggs J.M. 1993. Depositional and tectonic history of the Great South Basin. Balance P.F. (Ed). Sedimentary Basins of the World $2^{\text {nd }}$ editon, South Pacific Sedimentary Basins, 365-373. 
Beggs J.M. 2010a. Tectonic-forced punctuation of the "passive margin" phase of New Zealand's sedimentary basins. (paper) New Zealand Petroleum Conference Proceedings, Ministry of Economic Development, Wellington.

Beggs J.M. 2010b. Tectonic-forced punctuation of the "passive margin" phase of New Zealand's sedimentary basins. (presentation) New Zealand Petroleum Conference Proceedings, Ministry of Economic Development, Wellington.

Beu A.G., Maxwell P.A. 1990. Cenozoic Mollusca of New Zealand. New Zealand Geological Survey Paleontological Bulletin, 58.

Bloch J., Hutcheon I.E.. 1992. Shale diagenesis: a case study from the Albian Harmon Member, (Peace River Formation), Western Canada. Clays and clay minerals, 40/6, 682-699.

Böning P., Brumsack H-J., Böttcher M.E., Schnetger B., Kriete C., Kallmeyer J., Borchers S.L. 2004. Geochemistry of Peruvian near-surface sediments. Geochimica et Cosmochimica Acta, 68/21, 4429-4451.

Böning P., Brumsack H-J., Schnetger B., Grunwald M. 2009. Trace element signatures of Chilean upwelling sediments at $\sim 36^{\circ} \mathrm{S}$. Marine Geology, 259, 112 121 .

Böning P., Cuypers S., Grunwald M., Schnetger B., Brumsack H-J. 2005. Geochemical characteristics of Chilean upwelling sediments at $\sim 36^{\circ} \mathrm{S}$. Marine Geology, 220, 1-21.

Brown J., Colling A., Park D., Phillips J., Rothery D., Wright J. 1989. Ocean Chemistry and Deep-Sea Sediments. Bearman G. (Ed), Ocean Chemistry and Deep-Sea Sediments.

Brumsack H.J. 1989. Geochemistry of recent TOC-rich sediments from the Gulf of California and the Black Sea. Geologische Rundschau, 78/3, 851-882.

Brumsack H.J. 2006. Trace metal content of recent organic carbon-rich sediments: Implications for Cretaceous black shale formation. Palaeogeography, $\mathrm{Pa}$ laeoclimatology, Palaeoecology, 232, 344-361. 
Brumsack H.J., Gieskes J.M. 1983. Interstitial water trace-metal chemistry of laminated sediments from the Gulf of California, Mexico. Marine Chemistry, 14, 89-106.

Brüchert V., Jørgensen B.B., Neumann K., Riechmann D., Schlösser M., Schulz H. 2003. Regulation of bacterial sulfate reduction and hydrogen sulfide fluxes in the central Namibian coastal upwelling zone. Geochimica et Cosmochimica Acta, 67/23, 4505-4518.

Byrne R.H., Kim K-H. 1993. Rare earth precipitation and coprecipitation behaviour: The limiting role of $\mathrm{PO}_{4}{ }^{3-}$ on disolved rare earth concentrations in seawater. Geochimica et Cosmochimica Acta, 57, 519-526.

Calvert S.E. Pedersen T.F. 1993. Geochemistry of Recent oxic and anoxic marine sediments: Implications for the geological record. Marine Geology, 113, 6788.

Canfield D.E., Raiswell R., Bottrell S. 1992. The reactivity of sedimentary iron minerals towards sulfide. American Journal of Science, 292 659-683.

Chan L.H., Kasnter M. 2000. Lithium isotopic composition of pore fluids and sediments in the Costa Rica subduction zone: implications for fluid processes and sediment contribution to arc volcanoes. Earth and Planetary Science Letters, 183, 275-290.

Chapman P., Shannon L.V. 1985. The Benguela ecosystem: Part II. Chemistry and related processes. Oceanography and Marine Biology Annual Review, 23, 183251.

Church T.M., Wolgemuth K. 1972. Marine barite saturation. Earth and Planetary Science Letters, 15, 35-44.

Conoco Northland Ltd. 1999. Waka Nui-1 Well Completion Report. Petroleum Report 2436, Ministry of Economic Development, Wellington.

Cook R.A., Sutherland R., Zhu H., and others. 1999. Cretaceous - Cenozoic geology and petroleum systems of the Great South Basin, New Zealand. Institute of Geological and Nuclear Sciences Monograph 20, Institute of Geological and Nuclear Sciences, Lower Hutt. 
Crown Minerals. 2010. New Zealand Petroleum Basins. Available from www.crownminerals.govt.nz.

Crusius J., Calvert S., Pederson T., Sage D. 1996. Rhenium and molybdenum enrichments in sediments as indicators of oxic, suboxic and sulfidic conditions of deposition. Earth and Planetary Science Letters, 144, 65-78.

Crusius J., Thompson J. 2003. Mobility of authigenic rhenium, silver and selenium during postdepositional oxidation in marine sediments. Geochimica et Cosmochimica Acta, 67, 265-273.

Cutter G.A. 1989. The estuarine behaviour of selenium in San Francisco bay. Estuarine, Coastal and Shelf Science, 28, 13-34.

de Baar H.W.J., Brewer P.G., Bacon M.P. 1985. Anomalies in rare earth distributions in seawater: Gd and Tb. Geochimica et Cosmochimica Acta, 49, 1961-1969.

de Baar H.W.J., German C.R., Elderfield H., van Gaans P. 1988. Rare earth element distributions in anoxic waters of the Cariaco Trentch. Geochimica et Cosmochimica Acta, 52, 1203-1219.

Demaison G.J., Moore G.T. 1980. Anoxic Environments and Oil Source Bed Genesis. American Association of Petroleum Geologists Bulletin, 64/8, 1179-1209.

Dean W.E., Gardner J.V., Piper D.Z. 1997. Inorganic geochemical indicators of glacial-interglacial changes in productivity and anoxic on the California continental margin. Geochimica et Cosmochimica Acta, 61/21, 4507-4518.

Dellwig O., Hinrichs J., Hild A., Brumsack H.J. 2000. Changing sedimentation in tidal flat sediments of the southern North Sea from the Holocene to the present: a geochemical approach. Journal of Sea Research, 44, 195-208.

Disnar J.R., Sireau J.F. 1990. Organic mater in ore genesis: progress and perspectives. Advances in Organic Geochemistry, 16, 577-599.

Dodd J.R. 1967. Magnesium and strontium in calcareous skeletons: a review. Journal of Paleontology, 41/6, 1313-1329.

Dymond J., Suess E., Lyle M. 1992. Barium in Deep-Sea Sediment: A Geochemical Proxy for Paleoproductivity. Paleoceanography, 7/2, 163-181. 
Elbaz-Poulichet F., Seidel J.L., Jézéquel D., Metzger E., Prévot F., Simonucci C., Sarazin G., Viollier E., Etcheber H., Jouanneau J-M., Weber O., Radakovitch O. 2005. Sedimentary record of redox-sensitive elements (U, Mn, Mo) in a transitory anoxic basin (the Thau lagoon, France). Marine Chemistry, 95, 271-281.

Elderfield H., 1970. Chromium speciation in sea water. Earth and Planetary Science Letters, 9, 10-16.

Elgar N. 1997. Petroleum geology and geochemistry of oils and possible source rocks of the Southern East Coast New Zealand. PhD thesis, Geology, Victoria University, Wellington.

Erickson B.E., Helz G.R. 2000. Molybdenum (VI) speciation in sulfidic waters: stability and liability of thiomolybdates. Geochimica et Cosmochimica Acta, 64, 1149-1158.

ExxonMobil Exploration Company. 2010a. Great South Basin 2D/3D seismic interpretation report, PEP 50117. Petroleum Report 4233, Ministry of Economic Development, Wellington.

ExxonMobil Exploration Company. 2010b. Great South Basin open acreage 2D seismic interpretation report, PEP 50117. Petroleum Report 4234, Ministry of Economic Development, Wellington.

Field B.D., Brown G.H. 1989. Cretaceous and Cenozoic sedimentary basins and geological evolution of the Canterbury region, South Island, New Zealand. New Zealand Geological Survey Basin Studies 2, New Zealand Geological Survey, Lower Hutt.

Field B.D., Higgs K.E., Chanier F., Nicol A., Darby D. 2004. Play concepts for a complex margin: East Coast North Island, New Zealand. New Zealand Petroleum Conference Proceedings, Ministry of Economic Development, Wellington.

Field B.D., Uruski C.I., and others. 1997. Cretaceous - Cenozoic Geology and Petroleum Systems of the East Coast Region, New Zealand. Institute of Geological and Nuclear Sciences Monograph 19, Institute of Geological and Nuclear Sciences, Lower Hutt. 
Filella M., Belzile N., Chen Y-W. 2002. Antimony in the environment: a review focused on natural waters I. Occurrence. Earth-Science Reviews, 57, 125-176.

Finlay H.J. 1940. New Zealand Foraminifera: Key Species in Stratigraphy, No. 4. Transactions of the Royal Society of New Zealand, 69, 448-472

Frankenberger A. 1994. Trace Elements in New Zealand Oils their significance for analytical chemistry, geochemistry and oil classification. PhD Thesis, Massey University, New Zealand.

Froelich P.N., Andreae M.O. 1981. The Marine Geochemistry of Germanium: Ekasilicon. Science, 213/4504, 205-207.

Gravilov Y.O., Shcherbinina E.A., Muzylöv N.G. 2000. A Paleogene sequence in central North Caucasus: A response to paleoenvironmental changes. $G G F$, 122/1, 51-53.

Gavrilov Y.O., Shcherbinina E.A., Oberhänsli H. 2003. Paleocene-Eocene boundary events in the northeastern Peri-Tethys. Geological Society of America Special Paper, 369, 147-168.

Gavrilov Y.O., Kodina L.A., Lubchenko I.Y., Muzylev N.G. 1997. The Late Paleocene Anoxic event in Epicontinetal Seas of Peri-Tethys and Formation of the Sopropelite Uint: Sedimentology and Geochemistry. Lithology and mineral resources, 32/5, 427-450.

German C.R., Elderfield H. 1989. Rare earth element in the Saanich Inlet, British Columbia, a seasonally anoxic basin. Geochimica et Cosmochimica Acta, 53, 2561-2571.

Goldschmidt V. M. 1954. Geochemistry. Muir, A. (Ed), The International Series of Monographs on Physic, Clarendon Press, Oxford.

Hammond D.E., McManus J., Berelson W.M., Meredith C., Klinkhammer G.P., Coale K.H. 2000. Diagenetic fractionation of Ge and Si in reducing sediments: The missing Ge sink and a possible mechanism to cause glacial/interglacial variations in oceanic Ge/Si. Geochimica et Cosmochimica Acta, 64/14, 2453-2465. 
Haskin L., Gehl M.A. 1962. The Rare-Earth Distribution in Sediments. Journal of Geophysical Research, 64/6, 2537-2541.

Heinrichs H., Hermann A.G. 1990, Praktikum der analytischen Geochemie. Springer Verlag, Berlin.

Heinrichs H., Schultz-Dobrick B., Wedepohl K.H. 1980. Terrestrial Geochemistry of Cd, Bi, Tl, Pb, Zn, Rb. Geochimica et Cosmochimica Acta, 44 1519-1533.

Henrichs S.M., Reeburgh W.S. 1987. Anerobic mineralisation of marine sediment organic matter: Rates and roll of anerobic processes in the oceanic carbon economy. Geomicrobiol Journal, 5, 191-237

Herut B., Gavrieli I., and Halicz L. 1997. Sources and distribution of trace and minor elements in the western Dead Sea surface sediments. Applied Geochemistry, 12, 497-505.

HIPCO, 1977a. Pakaha-1 well completion report. Petroleum Report 703, Ministry of Economic Development, Wellington.

HIPCO, 1977b. Toroa-1 well completion report. Petroleum Report 691, Ministry of Economic Development, Wellington.

Hirner A.V., Robinson B.A. 1989. Stable isotope geochemistry of crude oils and possible source rocks from New Zealand-2: sulfur. Applied Geochemistry, 4, 121-130.

Hollis C.J., Dickens G.R., Field B.D., Jones C.M., Strong P.C. 2005a. The PaleoceneEocene transition at Mead Stream, New Zealand: a southern Pacific record of early Cenozoic global change. Palaeogeography, Palaeoclimatology, $\mathrm{Pa}$ laeoecology, 215, 313-323.

Hollis C.J., Manzano-Kareah K., Crampton J., Field B., Funnell R., Morgans H., Rogers K. 2005b. Source rock potential of the East Coast Basin (central and northern regions). Petroleum Report 3179, Ministry of Economic Development, Wellington.

Hollis C.J., Field B.D., Crouch E.M., Sykes R. 2006. How good a source rock is the Waipawa (Black Shale) Formation beyond the East Coast Basin? An outcrop- 
based case study from Northland. New Zealand Petroleum Conference Proceedings, Ministry of Economic Development, Wellington.

Hornibrook N. de B. 1959. Waipawa Black Shale (Siltstone). Flemming, C.A. (Ed). Lexique Stratigraphique Ineternational, 6/4, 443-444.

Hornibrook N. de B., Harrington H.J. 1957. The status of the Wangaloan Stage. The New Zealand Journal of Science and Technology, B 38/7, 655-670.

Howard J.J. 1981. Lithium and potassium saturation of illite/smectite clays from interlaminated shales and sandstones. Clays and Clay Minerals, 29/2, 136-142.

Huerta-Diaz M.A., Morse J.W. 1992. Pyritization of trace metals in anoxic marine sediments. Geochimica et Cosmochimica Acta, 56, 2681-2702.

Hunt International. 1977. Final report Kawau-1A. Petroleum Report 716, Ministry of Economic Development, Wellington.

Hunt International. 1978. Hoiho-1C well completion report. Petroleum Report 730, Ministry of Economic Development, Wellington.

Ingall E., Jahnke R. 1996. Influence of water-column anoxia on the elemental fractionation of carbon and phosphorus during sediment diagenesis. Marine Geology, 139, 219-229.

Isaac M.J., Herzer R.H., Brook F.J., Hayward B.W. 1994. Cretaceous and Cenozoic Sedimentary Basins of Northland. New Zealand. Institute of Geological and Nuclear Sciences Monograph 8, Institute of Geological and Nuclear Sciences, Lower Hutt.

Jean G.E., Bancroft M. 1985. An XPS and SEM study of gold deposition at low temperatures on sulphide mineral surfaces: Concentration of gold by absorption/reduction. Geochimica et Cosmochimica Acta, 49, 979-987.

Kaiho K. 1994. Benthic foraminiferal dissolved-oxygen index and dissolved oxygen levels in the modern ocean. Geology, 22, 719-722.

Katz H.R. 1968. Potential oil formation in New Zealand, and their stratigraphic position as related to basin evolution. New Zealand Journal of Geology and Geophysics, 11/5, 1077-1133. 
Killops S.D., Cook R.A., Sykes R., Boudou J.P. 1997. Petroleum potential and oilsource correlation in the Great South and Canterbury Basins. New Zealand Journal of Geology and Geophysics, 40, 405-423.

Killops S.D., Hollis C.J., Morgans H.E.G., Sutherland R., Field B.D., Leckie D.A. 2000. Paleoceanographic significance of Late Paleocene dyserobia at the shelf/slope break around New Zealand. Palaeogeography, Palaeoclimatology, Palaeoecology, 156, 51-70.

Killops S.D., Morgans H.E.G., Leckie D.A. 1996. The Waipawa Black Shale - a ubiquitous super source rock? New Zealand Petroleum Conference Proceedings, Ministry of Economic Development, Wellington.

Killops S.D., Woolhouse A.D., Weston R.J., Cook R.A. 1994. A geochemical appraisal of oil generation in the Taranaki Basin, New Zealand. American Association of Petroleum Geologists Bulletin, 74/10, 1560-1585.

King P.R. 2000. New Zealand's changing configuration in the last 100 million years: plate tectonics, basin development and depositional setting. New Zealand Petroleum Conference Proceedings, Ministry of Economic Development, Wellington.

King P.R., Thrasher G.P. 1996. Cretaceous sedimentary geology of the Taranaki Basin, New Zealand. Institute of Geological and Nuclear Sciences Monograph 13, Institute of Geological and Nuclear Sciences, Lower Hutt.

Klump J., Hebbeln D., Wefer G. 2000. The impact of sediment provenance on barium-based productivity estimates. Marine Geology, 169, 259-271.

Kremling K. 1983. The behaviour of $\mathrm{Zn}, \mathrm{Cd}, \mathrm{Cu}, \mathrm{Ni}, \mathrm{Co}, \mathrm{Fe}$, and $\mathrm{Mn}$ in anoxic Baltic waters. Marine Chemistry, 13, 87-108.

Kurtz A.C., Kump L.R., Arthur M.A., Zachos J.C., Paytan A. 2003. Early Cenozoic decoupling of the global carbon and sulfur cycles. Paleoceanography, 18/4, 1090-1103.

Lavergren U., Åström1 M.E., Bergbäck B., Holmström H. 2009. Mobility of trace elements in black shale assessed by leashing tests and sequential chemical extraction. Geochemistry: Exploration, Environment Analysis, 9, 71-79. 
Leckie D.A., Morgans H.E.G., Wilson G.J., Uruski C.I. 1992. Stratigraphic framework and source-rock potential of Maastrichtian to Paleocene marine shale, East Coast, North Island, New Zealand: hydrocarbon prospects. Institute of Geological and Nuclear Science report, 92/5.

Lécuyer C., Reynard B., Grandjean P. 2004. Rare earth evolution of Phanerozoic seawater recorded in biogenic apatites. Chemical Geology, 204, 63-102.

Lee C. 1992. Controls on organic carbon preservation: The use of stratified water bodies to compare intrinsic rates of decomposition in oxic and anoxic environments. Geochimica et Cosmochimica Acta, 56, 3323-3335.

LeMasurier W.E., Landis C.A. 1996. Mantle-plume activity recorded by low-relief erosion surfaces in West Antarctica and New Zealand. Geological Society of America Bulletin, 108/11, 1450-1466.

Leventhal J.S. 1983. An interpretation of carbon and sulfur relationships in Black Sea sediments as indicators of environments of deposition. Geochimica et Cosmochimica Acta, 47, 133-137.

Leventhal J.S. 1993. Metals in black shales. Engel M.H., Macko S.A. (Eds) Organic Geochemistry, Principles and Applications.

Lewis K.B., Pettinga J.R. 1993. The emerging, imbricate frontal wedge of the Hikurangi Margin. Balance P.F. (Ed). Sedimentary Basins of the World $2^{\text {nd }}$ editon, South Pacific Sedimentary Basins, 225-250.

Lipski P.S. 2004. Evidence for an oil play fairway on the inner shelf of the Great South Basin, New Zealand. New Zealand Petroleum Conference Proceedings, Ministry of Economic Development, Wellington.

McKelvey V.E. Nelson J.M. 1950. Characteristics of marine uranium-bearing sedimentary rocks. Economic Geology, 45, 35-53.

McManus J., Berelson W.M., Klinkhammer G.P., Johnson K.S., Coale K.H., Anderson R.F., Kumar N., Burdige D.J., Hammond D.E., Brumsack H-J., McCorkle D.C., Rushdi A. 1998. Geochemistry of barium in marine sediments: Implications for its use as a paleoproxy. Geochimica et Cosmochimica Acta, 62, 3453-3473. 
McMillan S.G., Wilson G.J. 1997. Allostratigraphy of coastal south east Otago: a stratigraphic framework for interpretation of the Great South Basin, New Zealand. New Zealand Journal of Geology and Geophysics, 40, 91-107.

Meadows D.J. 2008. Geochemistry of the Paleocene Tartan Formation in the Great South Basin, New Zealand. Unpublished Graduate Diploma of Science. Victoria University of Wellington, New Zealand.

Meadows D.J. 2009. Stable isotope geochemistry of Paleocene to Early Eocene strata around southern New Zealand. Masters of Science thesis. Victoria University of Wellington.

Morse J.W. 1994. Interactions of trace metals with authigenic sulfide minerals: implications for bioavailability. Marine Chemistry, 46, 1-6.

Morse J.W., Luther G.W. 1999. Chemical influences on trace metal-sulfide interactions in anoxic sediments. Geochimica et Cosmochimica Acta, 63, 33733378 .

Moore P.R. 1987. Terebellina - sponge or foraminiferid? A comparison with Makiyama and Bathysiphon. New Zealand Geological Survey Record, 20, 43-50.

Moore P.R. 1988. Stratigraphy, composition and environment of deposition of the Whangai and associate Late Creataceous-Paleocene rocks, eastern North Island, New Zealand. New Zealand Geological Survay Bulletin, 100.

Moore P.R. 1986. A revised Cretaceous - Early Tertiary Stratigraphic nomenclature for eastern North Island, New Zealand. New Zealand Geological Survey Report, G104.

Moore P.R., Morgans H.E.G. 1987. Two new reference sections for the Wanstead Formation (Paleocene-Eocene) in the southern Hawkes Bay. New Zealand Geological Survey Record, 20, 81-87.

Nathan S. 1977. Cretaceous and lower Tertiary stratigraphy of the coastal strip between Buttress Point and Ship Creek, South Westland, New Zealand. New Zealand Journal of Geology and Geophysics, 20/4, 615-654. 
Nathan Y., Soudry D., Levy Y., Shitrit D., Dorfman E. 1997. Geochemistry of cadmium in the Negev phosphorites. Chemical Geology, 142, 87-107.

Nicolo M.J., Dickens G.R., Hollis C.J., Zachos J.C. 2007. Multiple early Eocene hyperthermals: Their sedimentary expression on the New Zealand continental margin and in the deep sea. Geology, 35/8, 699-702.

Orians K.J., Bruland K.W. 1986. The bigeochemistry of aluminium in the Pacific Ocean. Earth and Planetary Science Letters, 78, 397-410.

Otsuki A., Hanyta T. 1972a. Production of dissolved organic matter from dead green algal cells. I. Aerobic microbial decomposition. Limnology and Oceanography, 17, 248-256.

Otsuki A., Hanyta T. 1972b. Produciton of dissolved organic matter from dead green algal cells. II. Anaerobic microbial decomposition. Limnology and Oceanography, 17, 258-264.

Pedersen T.F., Calvert S.E. 1990. Anoxia vs. Productivity: What controls the formation of organic-carbon-rich sediments and sedimentary rocks? American Association of Petroleum Geologists Bulletin, 74/4, 454-466.

Peterson M.N.A. 1966. Calcite: Rates of dissolution in a vertical profile in the Central Pacific. Science, 154/3756, 1542-1544.

Plank T., Langmuir C.H. 1998. The chemical composition of subducting sediments and its consequences for the crust and mantle. Chemical Geology, 145, 325394.

Prakash Babu C., Brumsack H.J., Schnetger B., Böttcher M.E. 2002. Barium as a productivity proxy in continental margin sediments: a study from the eastern Arabian Sea. Marine Geology, 184, 189-206.

Raine J.L., Strong C.P., Wilson G.J. 1993. Biostratigraphic revision of petroleum exploration wells, Great South Basin, New Zealand. Institute of Geological and Nuclear Sciences Report, 93/32, Institute of Geological and Nuclear Sciences, Lower Hutt.

Raiswell R., Berner R. 1985. Pyrite formation in euxinic and semi-euxinic sediments. American Journal of Science, 285/8, 710-724. 
Rhoads D.C., Morse J.W. 1971. Evolutionary and ecologic significance of oxygen-deficent marine basins. Lethaia, 4, 413-428.

Rogers K.M. 1995. Oil seeps and potential source rocks of the northern East Coast Basin, New Zealand: a geochemical study. PhD thesis, Geology, Victoria University, Wellington.

Rogers K.M., Collen J.D., Johnston J.H., Elgar N.E. 1999. A geochemical appraisal of oil seeps from the East Coast Basin, New Zealand. Organic Geochemistry, 30, 593-605.

Rogers K.M., Morgans H.E.G., Wilson G.S. 2001. Identification of a Waipawa Formation equivalent in the upper Te Uri Member of the Whangai Formation implications for depositional history and age. New Zealand Journal of Geology and Geophysics, 44, 347-454.

Ross D.J.K., Bustin M.R. 2008. Characterizing the shale gas resource potential of Devonian-Mississippian strata in the Western Canada sedimentary basin: Application of an integrated formation evaluation. American Association of Petroleum Geologists Bulletin, 92, 87-125.

Ross D.J.K., Bustin M.R. 2009. Investigating the use of sedimentary geochemical proxies for paleoenvironment interpretation of thermally mature organic-rich strata: Examples from the Devonian-Mississippian shales, Western Canadian Sedimentary Basin. Chemical Geology, 260, 1-19.

Roy S. 1992. Environments and processes of Manganese Deposition. Economic Geo$\log , 87,1218-1236$.

Schaule B.K., Patterson C.C. 1981. Lead concentrations in the northeast Pacific: evidence for global anthropogenic perturbations. Earth and Planetary Science Letters, 54, 97-116.

Schiøler P., Roncaglia L. 2008. Age and depositional environment of the Tartan Formation, a potential source rock in the Great South Basin. New Zealand Petroleum Conference Proceedings, Ministry of Economic Development, Wellington.

Schiøler P., Rogers K., Sykes R., Hollis C.J., Ilg B., Meadows D., Roncaglia L., Uruski C. 2010. Palynofacies, organic geochemistry and depositional environ- 
ment of the Tartan Formation (Late Paleocene), a potential source rock in the Great South Basin, New Zealand. Marine Geology, 27, 351-369.

Schmitz B. 1987. Barium, equatorial high productivity, and the northward wandering of the Indian continent. Paleoceanography, 2/1, 63-77.

Schnetger B. 1997. Trace element analysis of sediments by HR-ICP-MS using low and medium resolution and different acid digestions. Fresnius' journal of analytical chemistry, 359/4-5, 468-472.

Schröder S., Grotzinger J.P. 2007. Evidence for anoxia at the Ediacaran-Cambrian boundary: the record of redox-sensitive trace elements and rare earth elements in Oman. Journal of the Geological Society, London, 164, 175-187.

Shackleton N.J. 1987. The carbon isotope record of the Cenozoic: history of organic carbon burial and oxygen in the ocean and atmosphere. Geological Society of London, Special Publications, 23, 423-434.

Shaw T.J., Gieskes J.M., Jahnke R.A. 1990. Early diagenesis in differing depositional environments: the response of transitions metals in pore water Geochimica et Cosmochimica Acta, 54, 1233-1246.

Shell BP Todd Oil Serviced Ltd. 1984. Completion Report. Ariki-1 Well. PPL 38048. Petroleum Report 1038, Ministry of Economic Development, Wellington.

Sholkovitz E.R., Shaw T.J., Schneider D.L. 1992. The geochemistry of rare earth elements in the seasonally anoxic water column and porewaters of Chesapeake Bay. Geochimica et Cosmochimica Acta, 56, 3389-3402.

Speijer R.P., Schmitz B., van der Zwaan G.J. 1997. Benthic foraminiferal extinction and repopulation in response to latest Paleocene Tethyan anoxia. Geology, 25/8, 683-686.

Stagpoole V.M., Reid E., Browne G.H., Bland K. Ilg B., Griffin A., Herzer R.H., Uruski C. 2009. Petroleum Prospectivity of the Reinga Basin, New Zealand. Petroleum Report 4037, Ministry of Economic Development, Wellington.

Staubwasser M., Sirocko F. 2001. On the formation of laminated sediments on the continental margin off Pakistan: the effects of sediment provenance and sediment redistribution. Marine Geology, 172, 43-56. 
Sutherland R., Spasojevic S., Gurnis M. 2001. Mantle upwelling after Gondwana sebduction death explains anomalous topography and subsidence histories of eastern New Zealand and West Antartica. Geology, 38/2, 155-158.

Sverjensky D.A. 1984. Europium redox equilibria in aqueous solution. Earth and Planetary Science Letters, 67, 70-78.

Takayanagi K., Cossa D. 1997. Vertical distributions of $\mathrm{Sb}(\mathrm{III})$ and $\mathrm{Sb}(\mathrm{V})$ in Pavin Lake, France. Water Research, 31/3 671-674.

Taylor S.R., McLennan S.M. 1985. The Continental crust: Its composition and evolution. $1^{\text {st }}$ edition, $311 p$.

Tribovillard N., Lyons T.W., Riboulleau A., Bout-roumazeilles B. 2008. A possible capture of molybdenum during early diagenesis of dysoxic sediments. Bulletin de la societe geologique de France, 179/1, 3-12.

Turgeon S., Brumsack H-J. 2006. Anoxic vs dysoxic events reflected in sediment geochemistry during the Cenomanian-Turonian Boundary Event (Cretaceous) in the Umbia-Marche Basin of central Italy. Chemical Geology, 234, 321-339.

Turner D.R., Whitfield M., Dickson A.G. 1981. The equilibrium speciation of dissolved components in freshwater and seawater at $25^{\circ} \mathrm{C}$ and $1 \mathrm{~atm}$ pressure. Geochimica et Cosmochimica Acta, 45, 855-881.

Tyson R.V., Pearson T.H. 1991. Modern and ancient continental shelf anoxia: an overview. Geological Society of London, Special Publication, 58, 1-24.

Uruski C., Kennedy C., Harrison T., Maslen G., Cook R.A., Sutherland R., Zhu H. 2007. Petroleum Potential of the Great South Basin, New Zealand-new seismic data improves imaging. Australian Petroleum Production and Exploration Association conference, 47, 143-160.

Van der Weijden C.H. 2002. Pitfalls of normalization of marine geochemical data using a common divisor. Marine Geology, 184, 167-187.

Van Sickel W.A., Kominz M.A., Miller K.G., Brownling J.V. 2004. Late Cretaceous and Cenozoic sea-level estimates: Backstripping analysis of borehole data, onshore, New Jersey. Basin Research, 16, 451-465. 
Vernadsky,V.I., McMenamin M.A.S., Langmuir D.B. 1998. The Biosphere. Copernicus, New York, NY. 192p.

Vine J.D., Tourtelot E.B. 1970. Geochemistry of Black Shale Deposits-A Summary Report. Economic Geology, 65, 253-273.

Von Breymann M., Emeis K.C., Suess E. 1992. Water depth and diagenetic constraints on the use of barium as a palaeoproductivity indicator. Prell C.P., Emeis K.C. (Eds), Uppwelling systems: Evolution since the Early Miocene. Geological Society of London, Special Publications 64, 273-284.

Vorlicek T.P., Kahn M.D., Kasuya Y., Helz G.R. 2004. Capture of molybdenum in pyrite-forming sediments: role of ligand-induced reduction by polysulfides. Geochimica et Cosmochimica Acta, 68 547-566.

Wanty R.B., Goldharber M.B. 1992. Thermodynamics and kinetics of reactions involving vanadium in natural systems: accumulations of vanadium in sedimentary rocks. Geochimica et Cosmochimica Acta, 56, 1471-1483.

Wedepohl K.H. 1971. Environmental influences on the chemical composition of shales and clays. Ahrens, L.H., Press, F., Runcorn, S.K., Urey, H.C. (Eds.), Physics and Chemistry of the Earth, 8, 305-333.

Weeks S.J., Currie B., Bakun A., Peard K.R. 2004. Hydrogen sulphide eruptions in the Atlantic Ocean off southern Africa: implications of a new view based SeaWiFS satellite imagery. Deep Sea reasearch Part 1, 51/2, 153-172.

Wehausen R., Brumsack H-J. 2002. Astronomical forcing of the East Asian monsoon mirrored by the composition of Pliocene South China Sea sediments. Earth and Planetary Science Letters, 201, 621-636.

Westrich J.T. Berner R.A. 1984. The role of sedimentary organic matter in bacterial sulfate reduction: The G model tested. Limnoogy and Oceanography 29, 236-249.

Wilding A., Sweetman L.A.D. 1971. Endeavour-1 well completion report. Petroleum Report 303, Ministry of Economic Development, Wellington.

Yarincik K.M., Murray R.W., Peterson L.C. 2000. Climatically sensitive eolian and hemipelagic deposition in the Cariaco Basin, Venezuela, over the past 
578,000 years: results from Al/Ti, and K/Al. Paleoceanography, 15/2, 210228. 


\title{
Previous S and TOC data
}

\begin{tabular}{|c|c|c|c|}
\hline Sample & Formation & S\% & TOC \\
\hline KR1 & Waipawa & 1.71 & 4.34 \\
\hline KR128 & Waipawa & 0.59 & 3.08 \\
\hline KR13 & Waipawa & 2.03 & 4.31 \\
\hline KR14 & Waipawa & 1.62 & 4.32 \\
\hline KR15 & Waipawa & 2.50 & 3.78 \\
\hline KR16 & Waipawa & 2.62 & 3.17 \\
\hline KR17 & Waipawa & 1.97 & 1.28 \\
\hline KR20 & Waipawa & 1.40 & 5.81 \\
\hline KR44 & Waipawa & 1.29 & 5.99 \\
\hline KR46 & Waipawa & 1.28 & 3.54 \\
\hline KR54 & Waipawa & 1.20 & 2.89 \\
\hline KR7 & Waipawa & 2.01 & 4.62 \\
\hline KR93 & Waipawa & 1.17 & 1.97 \\
\hline KR12 & Wanstead & 0.42 & 0.2 \\
\hline KR18 & Wanstead & 0.93 & 0.98 \\
\hline KR26 & Wanstead & 0.06 & 0.08 \\
\hline KR33 & Wanstead & 0.01 & 0.12 \\
\hline KR42 & Wanstead & 0.05 & 0.06 \\
\hline KR5 & Wanstead & 0.14 & 0.35 \\
\hline KR8 & Wanstead & 0.85 & 0.47 \\
\hline KR134 & Whangai (POR) & 0.13 & 0.75 \\
\hline KR113 & Whangai (RAK) & 0.83 & 0.81 \\
\hline KR121 & Whangai (RAK) & 1.24 & 0.87 \\
\hline KR28 & Whangai (RAK) & 1.14 & 0.9 \\
\hline KR29 & Whangai (RAK) & 1.01 & 0.83 \\
\hline KR30 & Whangai (RAK) & 1.11 & 0.92 \\
\hline KR31 & Whangai (RAK) & 1.02 & 1.07 \\
\hline KR32 & Whangai (RAK) & 1.20 & 0.93 \\
\hline KR55 & Whangai (RAK) & 0.34 & 0.93 \\
\hline KR6 & Whangai (RAK) & 1.00 & 0.85 \\
\hline KR9 & Whangai (RAK) & 1.24 & 0.96 \\
\hline KR100 & Whangai (UCM) & 0.77 & 0.83 \\
\hline KR49 & Whangai (UCM) & 0.98 & 1.18 \\
\hline KR57 & Whangai (UCM) & 0.75 & 1.26 \\
\hline R0gers & (995) \\
\hline
\end{tabular}

\begin{tabular}{|c|c|c|c|}
\hline Sample & Formation & S\% & TOC \\
\hline NE131 & Waipawa & 0.58 & 3.84 \\
\hline NE23 & Waipawa & 1.50 & 4.99 \\
\hline NE26 & Waipawa & 0.15 & 1.16 \\
\hline NE31 & Waipawa & 1.90 & 3.69 \\
\hline NE33 & Waipawa & 1.39 & 1.3 \\
\hline NE37 & Waipawa & 1.86 & 2.42 \\
\hline NE4 & Waipawa & 1.61 & 1.35 \\
\hline NE40 & Waipawa & 1.14 & 3.89 \\
\hline NE43 & Waipawa & 1.01 & 5.58 \\
\hline NE44 & Waipawa & 1.25 & 3.17 \\
\hline NE45 & Waipawa & 1.50 & 4.24 \\
\hline NE48 & Waipawa & 0.47 & 3.27 \\
\hline NE54 & Waipawa & 0.76 & 5.58 \\
\hline NE63 & Waipawa & 1.23 & 3.79 \\
\hline NE1 & Waipawa?? & 0.13 & 0.77 \\
\hline NE141 & Wanstead & 0.01 & 0.19 \\
\hline NE18 & Wanstead & 0.04 & 0.15 \\
\hline NE22 & Wanstead? & 0.33 & 0.24 \\
\hline NE55 & Wanstead & 0.03 & 0.2 \\
\hline NE58 & Wanstead & 0.07 & 0.03 \\
\hline NE62 & Wanstead & 0.01 & 0.22 \\
\hline NE49 & Whangai & 0.41 & 0.96 \\
\hline NE50 & Whangai & 0.39 & 0.84 \\
\hline NE53 & Whangai & 0.65 & 0.88 \\
\hline NE56 & Whangai & 0.74 & 0.93 \\
\hline NE32 & Whangai (other) & 0.55 & 0.73 \\
\hline NE121 & Whangai (RAK) & 0.80 & 1.29 \\
\hline NE136 & Whangai (RAK) & 0.74 & 1.02 \\
\hline NE144 & Whangai (RAK) & 0.90 & 1.64 \\
\hline NE24 & Whangai (UCM) & 0.98 & 1.3 \\
\hline NE46 & Whangai (UCM) & 0.61 & 0.95 \\
\hline NE113 & Whangai (UCM) & 0.79 & 1 \\
\hline NE111 & Whangai? & 0.39 & 0.76 \\
\hline
\end{tabular}

Rogers (1995)

\author{
Elgar (1997)
}



Appendix B

\title{
Preliminary study on Kawau-1A
}

\section{Trace metal variations through the Tartan Formation, Kawau-1A, Great South Basin, New Zealand: Implications for the depositional environment.}

\begin{abstract}
The Tartan Formation is a Late Paleocene organic-rich mudstone found in the Great South and Canterbury basins. It is often considered to be the lateral equivalent of the Waipawa Formation which occurs in many sedimentary basins New Zealand-wide and is an important hydrocarbon source rock. The depositional environment of the Tartan and Waipawa formations has been of much debate; however, it has been generally accepted that anoxia is the most likely explanation for the high organic matter preservation. In the Great South Basin limited availability of samples from hydrocarbon exploration wells and the lack of outcrops hinder detailed analyses of the Tartan Formation.
\end{abstract}

The cause of the anoxia is unclear and studies have reached different conclusions. Recent research has identified much of the organic matter as terrestrial, and suggested a possible change in sediment source causing the organic mater enrichment. This differs from earlier studies which have generally considered the organic mater to be of predominantly marine origin. Whether an influx of organic matter caused the anoxia or Whether the anoxia was caused by something else and then allowed better organic mater preservation is currently uncertain.

This study used inductively coupled plasma mass spectrometry (ICP-MS), to examine trace metal variations in eight side wall cores from the Kawau-1A exploration well in order to examine the depositional environment of the Tartan Formation. The results show significant enrichments in 26 of the 32 trace metals measured throughout the Tartan Formation, but when normalised to the background detrital concentrations, both enrichments and depletions are noticed.

The highly accurate ICP-MS equipment allowed measurement of twelve of the trace 
metals which are not routinely measured in sediments (Bi, Nb, Hf, Rb, Sb, Sn, Sr, Ta, Tl, W, Y and Zr). Many of these have no removal mechanism suggested are poorly understood, or very rarely fractionated in nature. The concentration of those elements which are rarely fractionated in nature can be used to normalise the other trace metal concentrations. As Al was too highly concentrated to be measured by ICP-MS, enrichment factors in this study were calculated using $\mathrm{Hf}, \mathrm{Zr}$ and $\mathrm{Ti}$. As this is a new technique this approach will be examined in more detail during the thesis research.

Of particular interest is the enrichment of both $\mathrm{Zr}$ and $\mathrm{Hf}$ by more than a factor of two. As these elements generally do not fractionate in nature, anoxia is probably not responsible for the enrichments. Thus a change in sediment source or a change in sediment sorting would be more likely models to explain their enrichments.

The enrichment factors are generally on a smaller scale than those reported from studies on other black shales. This may indicate rapid deposition allowing less time for redox, biological and early diagenetic enrichment processes to affect the sediments, and/or a different depositional environment from the standard models for black shale enrichments.

\subsection{Introduction}

The Tartan Formation is an organic-rich mudstone found in the Great South and Canterbury basins. It is laterally equivalent to the Waipawa Formation which is considered to have been deposited on the outer shelf to upper slope environment around Late Paleocene New Zealand (Killops et al., 2000).

The depositional environment of the Tartan Formation is of particular interest due to previous studies not having reached a consensus on the paleoceanographic facies that the Tartan and Waipawa formations represent. Aspects of the depositional environment such as relative sea level are uncertain, and it is unknown whether the Tartan Formation represents high stand, regressive, or transgressive sea level change. Schiøler and Roncaglia (2008) suggested that all these interpretations of relative sea level were plausible.

A recent study by Schiøler et al. (2010) suggested that deposition of the Tartan 
Formation occurred during peak regression in the Thanetian. This conclusion was reached through study of a broad range of aspects of the Tartan Formation including type of organic matter.

Aspects such as the oxygen availability during deposition are of particular interest due to high total organic carbon (TOC) values (e.g. Meadows. 2008). Most authors have suggested an anoxic environment possibly linked to a regional upwelling, but except for the high TOC values, direct evidence of anoxia has not so far been found in the Tartan Formation.

Trace metal variations are complex and governed by redox sensitivity, biological cycling, diagenetic processes, and the precipitation of other minerals (e.g. sulphates and phosphates) at the sediment water interface (e.g. Brumsack, 2006; Ross and Bustin, 2009; Turgeon and Brumsack, 2006).

This project is a preliminary study of trace metal variations in the Tartan Formation, focusing on samples from the Kawau-1A hydrocarbon exploration well in the Great South Basin. This well is one of five wells in the Great South Basin which encountered the Tartan Formation. The present study examined a comprehensive suite of trace elements in order to assess the feasibility of examining enrichments in trace metals through the Tartan Formation.

\subsection{Kawau-1A: summary}

Kawau-1A was drilled in 1977 by Hunt International Petroleum Co NZ. The well was located $250 \mathrm{~km}$ south-south-east of Stewart Island, in $\sim 680 \mathrm{~m}$ water depth. The well was drilled to 3826 mrkb (meters below rotary kelly bushing), encountering the Tartan Formation between 2220 and 2264 mrkb (Cook et al., 1999).

Kawau-1A has more available side wall core material from the Tartan and adjacent formations than other exploration wells in the Great South Basin, and thus was chosen for this preliminary study. The wells were all drilled more than 30 years ago, and many other studies have used up the bulk of the side wall core material. 


\begin{tabular}{|c|c|c|c|}
\hline SWC & depth feet(rkb) & depth mrkb & description (as in original well report) \\
\hline $15 / 4$ & 7984 & 2433.5 & $\begin{array}{l}\text { Shale, light grey-tan, firm, blocky, slightly calcareous, trace mica, } \\
\text { pyrite, glauconite. Few carbonaceous partings }\end{array}$ \\
\hline $16 / 4$ & 7830 & 2386.6 & shale, light grey-tan as above, light increase in carbonaceous partings \\
\hline $17 / 4$ & 7794 & 2375.6 & Shale light grey-tan as above \\
\hline $18 / 4$ & 7550 & 2301.2 & $\begin{array}{l}\text { shale, light-medium grey as above. Non calcareous, no carbonaceous } \\
\text { partings. }\end{array}$ \\
\hline $19 / 4$ & 7424 & 2262.8 & $\begin{array}{l}\text { Shale, chocolate brown, firm, sub fissie-blocky, non calcareous, } \\
\text { carbonaceous, micaceous, rare trace glauconite. Slight gas odour. }\end{array}$ \\
\hline $20 / 4$ & 7350 & 2240.3 & $\begin{array}{l}\text { Shale, chocolate brown as above, some laminations of dark grey- } \\
\text { brown very micaeous shale. Slight gas odour. }\end{array}$ \\
\hline $21 / 4$ & 7276 & 2217.7 & $\begin{array}{l}\text { shale, very light grey, firm, soft, semi-waxy, think laminations, sub } \\
\text { fissile. Rare carbonaceous inclusion. Trace pyrite. Non calcareous. }\end{array}$ \\
\hline $22 / 4$ & 7220 & 2200.7 & Shale, very light grey, as above \\
\hline $23 / 4$ & 7195 & 2193.0 & $\begin{array}{l}\text { Shale light grey-tan as above, becoming predominantly soft. Very } \\
\text { thin laminations }\end{array}$ \\
\hline $24 / 4$ & 7176 & 2187.2 & $\begin{array}{l}\text { sub-fissle, very slight trace carbonaceous inclusions. Trace mica, } \\
\text { pyrite }\end{array}$ \\
\hline $25 / 4$ & 7153 & 2180.2 & $\begin{array}{l}\text { shale very light grey, very soft, thin laminations as above, black } \\
\text { carbonaceous partings. }\end{array}$ \\
\hline $26 / 4$ & 6912 & 2106.8 & $\begin{array}{l}\text { shale, very light grey, firm to soft as above. Black carbonaceous } \\
\text { partings, micaceous, pyritic. }\end{array}$ \\
\hline
\end{tabular}

Table 1) Side wall core samples depths and information on them from Hunt (1977). Samples in grey were analysed here, with the darker grey being the Tartan Formation.

Four side wall cores (SWC) runs were made at different times during the drilling; the samples in and around the Tartan Formation are from the fourth run only (Table 1). Samples 23/4 and 24/4 were not analysed as all the side wall core material had been previously used up.

Samples from Kawau-1A have been used in many studies, including that of Meadows (2008) who measured $\% \mathrm{C}, \% \mathrm{~N}, \delta^{13} \mathrm{C}$, and TOC. No comprehensive trace or major element work has yet been carried out on these side wall core samples.

An accurate age is not known for samples of either the Tartan or laterally equivalent Waipawa Formation. The best estimate is that the deposition represents a shorter period of time between two nano fossil horizons at 58.7 and 55.8Ma (Schiøler et al., 2010). These dates agree with ones in the East Coast Basin (Hollis et al., 2005). The base of the Tartan Formation in Pakaha-1 well in the Great South Basin is older than the other wells (Schiøler et al., 2010). There have been fewer comprehensive studies on the Tartan Formation in the Great South Basin than on the Waipawa Formation in the East Coast Basin, as the only samples of the Tartan Formation come from five hydrocarbon exploration wells, Pakaha-1, Kawau-1A, Hoiho-1C, Toroa-1 and Pukaki-1. Pukaki-1 had no side wall cores shot in the Tartan but cutting samples are available.

\subsection{Background to trace metal enrichment in sedimentary rocks}


Trace metal enrichments have been studied in anoxic sediments for over 50 years (e.g. Goldschmit, 1954). Many different reasons for variations in trace metal concentration have been noticed over the years, but there are four major processes which enrich or deplete trace metals. These are enrichment from organic mater, diagenetic processes, redox sensitivity in the water column and upper sediments, and inclusion into precipitating minerals.

Most trace metals are enriched by several different processes, but by studying a suite of different trace metals it is possible to separate some of the processes and make inferences about the depositional environment. The following section provides a summary of why trace metals vary in anoxic sediments. Some trace metals have undergone much study (e.g. Cd, and Mo) while others (e.g, W) have not been measured before in any anoxic sediments.

The sediments in silicate rocks are generally dominated by terrestrial input with relatively minor input from biological tests. This detrital clastic debris is thus usually silicate and aluminium-rich. An assumption is generally made that Al is derived completely from detrital aluminosilicate sources. Although this assumption may not always be accurate, Al makes up a large weight percentage of the sediments, and thus any added by another method is generally insignificant. Plotting aluminium against other elements which are also purely detrital should give a straight line through the origin (e.g. Dean et al., 1997). This of course relies on the assumption that the sediment source and sorting remain constant, as any change in these change the background detrital minerals and thus affects the background element composition.

Variations in trace element composition due to shifts in the redox equilibrium of the sea water are seen mainly in anoxic settings. There are two different anoxic settings which can produce different trace metal signatures (e.g. Brumsack, 2006). Theses are an open system which has a continuous supply of water which gets oxygen depleted but moves through the system (e.g. the Peruvian upwelling, Böning et al., 2004), and an anoxic basin where evaporation is the main process which removes the water (e.g. the Black Sea, Brumsack, 1989). Figure 1 shows both the classic anoxic basin and the open ocean upwelling.

In an anoxic basin environment (Figure 2), most trace elements entering into the 


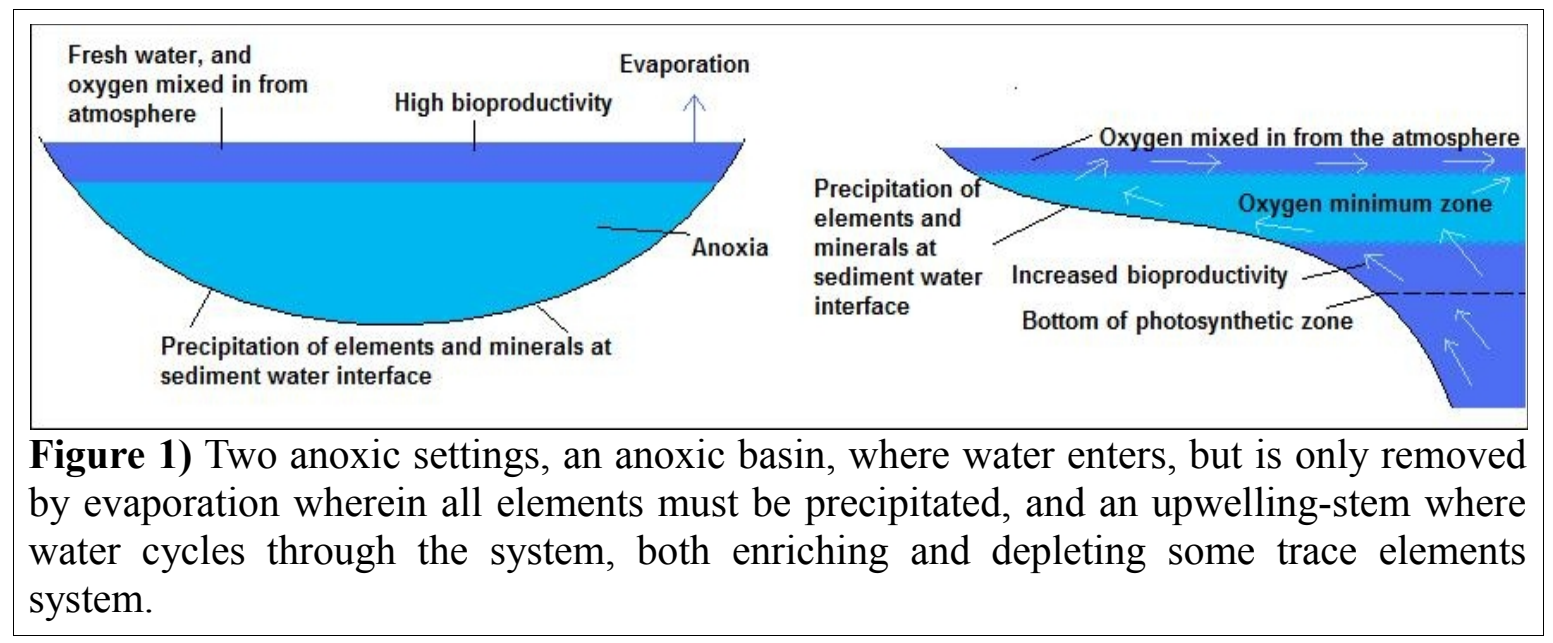

system must be included into the sediments in one way or another. Water enters the system and is usually evaporated. In some anoxic basins there is an outflow, which may cause some depletion of those elements (e.g. Mn) which are more stable in oxic conditions and are reduced out of the sediments in anoxic conditions. When evaporation is the only way for water to leave the system (e.g. in the Dead Sea; Herut et al., 1997), even elements such as $\mathrm{Mn}$ are not depleted in the sediments. The enrichment factors (how much the trace metals are enriched) are dependent in anoxic basins on the rate of deposition, the rate of evaporation, and the concentration of elements in the water (Brumsack, 2006).

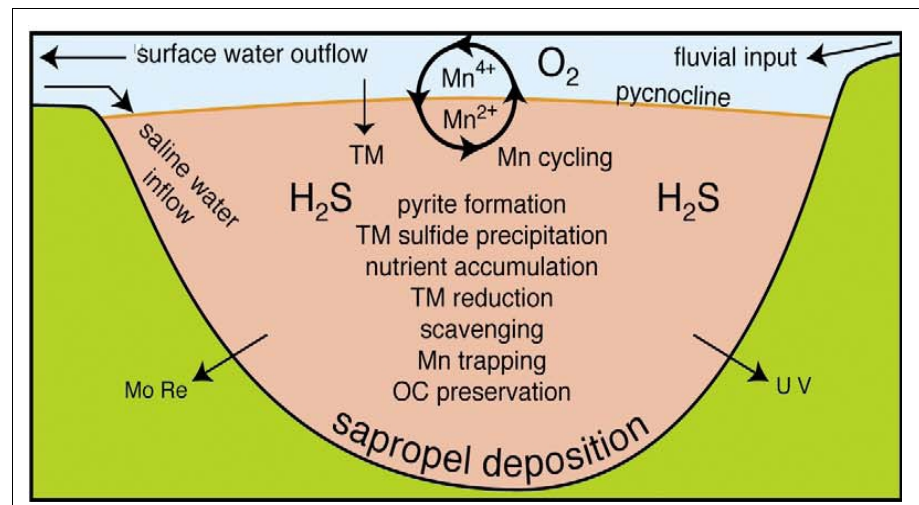

Figure 2) a schematic showing the basic redox processes governing trace metal in anoxic basins.

Figure from Brumsack 2006

Anoxic basins often have high $\mathrm{H}_{2} \mathrm{~S}$ in the water as well as in the sediments, and this can cause a more intense precipitation of sulphates (e.g. Brumsack, 2006). The precipitation of sulphates is a very effective removal mechanism for many trace metals. 
Upwellings (Figure 1) have the potential to cause anoxia by introducing oxygen-poor nutrient-rich water from the deep ocean into the photosynthetic zone, enhancing biological productivity which consumes the oxygen (Demaison and Moore, 1980). The result is an oxygen minimum layer, above which oxygen again becomes available through interaction between the water and the atmosphere. The still, nutrient-rich water boosts productivity. High productivity can also influence trace metal deposition and is generally referred to as biocycling (Brumsack, 2006).

Two major types of upwellings which cause different trace metal enrichments, were identified by Brumsack (2006), and are depicted in Figure 3. They are basic upwelling (Figure 3A) and upwelling over an extended shelf (Figure 3B). The extended shelf environment often allows more intense enrichment as $\mathrm{H}_{2} \mathrm{~S}$ can survive at the sediment water interface and thus allows the precipitation of sulphates. Aside from $\mathrm{H}_{2} \mathrm{~S}$ there are very few differences between the enrichment processes active on an extended shelf

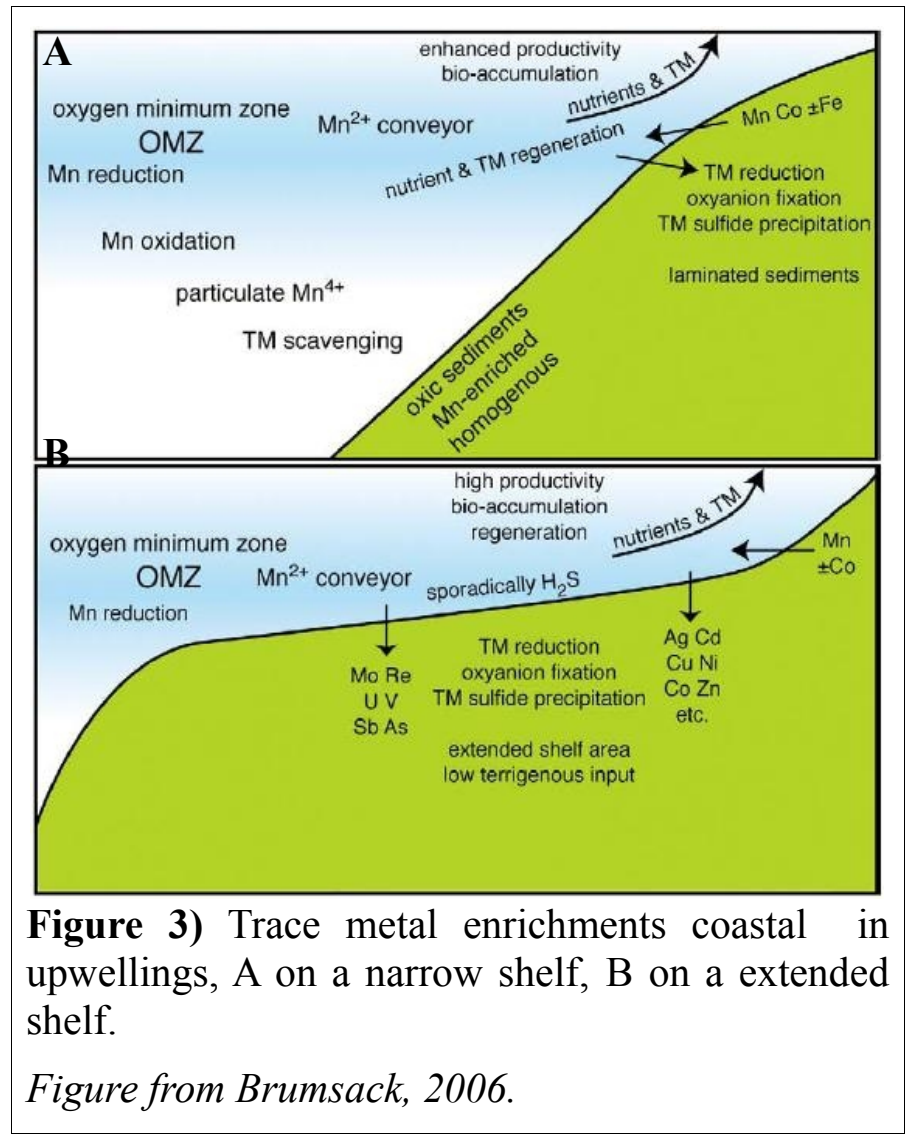

compared to a narrow shelf

While anoxic basins generally cause enrichments in a wider range of elements than in 
upwelling conditions, some elements can be considerably more enriched in upwellings than in anoxic basins. Anoxic basins are limited by the amount of trace metals carried into the system by water and sediments, with little or no water cycling through the system; in upwellings water gets cycled through the system providing a continuous supply of trace metals which can be reduced into the sediments (Brumsack 2006).

The overall enrichment and depletion processes that govern trace metal concentrations occur at different levels throughout the sediments. The depths that these occur at are generally dependent on porosity, sedimentation rate, and depth of the oxic/anoxic boundary (Böning et al., 2005).

In average marine oxic conditions oxygen is abundant in the top tens of $\mathrm{cm}$ of sediments, allowing areobic life to flourish. Below the oxygen layer less efficient sulphate-reducing bacteria take over, and below this the even less efficient $\mathrm{CO}_{2}$-reducing bacteria become dominant (Demaison and Moore, 1980). The tens of $\mathrm{cm}$ of sediments above the oxic/anoxic boundary limit water flow.

In anoxic conditions the sulphate-reducing bacteria are at or near the surface, precipitating out sulphates and phosphates. This process enriches many trace elements in the precipitates, especially while fresh nutrient-rich water cycles through. Restricting this flow (e.g. by putting more sediments between the oxic/anoxic boundary) limits the trace metal enrichments (e.g. Morse and Luther, 1999).

Anoxic conditions are also favourable for the preservation of organic matter in sediments (Demaison and Moore, 1980).

\subsection{Processes governing trace metal variation in sedimentary rocks.}

Silver (Ag) is generally enriched in all anoxic sediments (Brumsack, 2006); however, it is a poorly studied trace metal in organic rich sediments. Böning et al. (2004) suggested the main factor in enriching Ag off the coast of Peru was biocycling above the oxygen minimum layer caused by the local upwelling. McKay and Peterson (2002) suggesting the main control on Ag precipitation was the increase of Ag with depth in the water column. Böning et al. (2005) suggested the increase with depth may be related to the deposition of opaline silica, which also increases with depth, but that changes in 
redox conditions can also influence the concentration of silver.

Morford et al. (2008) collected sediments from a transect off the west coast of North America purely to study the Ag enrichments in both the pore water and in solid state in the top $30 \mathrm{~cm}$ of sediment. They noted a potential relationship with Ag, and discovered significantly enriched solid state Ag near the base of the upwelling, but concluded that the relationship was more complex and required more study.

Arsenic (As) is generally enriched in organic rich sediments (Brumsack, 2006). Off the coast of Peru, As was found to be enriched mainly through diffusion, and the limited enrichments was mainly due to sea water availability and not saturation of arsenic in the sediments (Böning et al., 2004). Huerta-Diaz and Morse (1992) found that very little As is in the poor fluids in anoxic conditions but that most of it is deposited with pyrite precipitation. Morse (1994) showed that the oxidation of sedimentary pyrite will release most of the As in a very short period of time. This type of oxidation occurs naturally during sediment resuspension or in seasonally anoxic regions. In outcrop As is considered relatively stable during the weathering of black shales as it has two solid states and with leaching tests showed less than $1 \%$ loss upon oxidation (Lavergren et al., 2009).

Gold $(\mathrm{Au})$ is a very poorly studied trace metal in sediments in general. Koide et al. (1986) noted a considerable enrichment of $\mathrm{Au}$ in hydrothermal sulphides and suggested an involvement of sulphides in the precipitation. Mao et al. (2002) noted a factor of 100 enrichment over standard continental crust in a sulphide layer in Lower Cambrian marine black shales from south China.

Jean and Bancroft (1985) noticed solid Au forming on the surface of sulphides on individual irregularities, forming relatively quickly and efficiently. They suggested that sulphide can act as the reducing agent. Springer (1985) suggest that there may be a relationship between organic carbon and Au precipitation when carbon flakes were seen to be coated in $\mathrm{Au}$ in a sedimentary Archean black argillite. The mechanism which is responsible for this is unknown; it is uncertain whether the carbon flakes are of organic origin or not, but hydrocarbons in the rock indicate that an organic origin is likely.

Bismuth (Bi) is generally enriched in sediments beneath upwellings (Brumsack, 2006). Bi was mentioned as being more closely related to sulphur than organic carbon 
(Heinrich et al., 1980), but very little more work has been done on it and it is rarely studied in organic-rich sediments. Hindering the understanding of $\mathrm{Bi}$ in recent sediments is the enrichment caused by anthropogenic input from mining (Böning et al., 2004, 2009).

Cadmium (Cd) is enriched in several ways under anoxic conditions. The most important is the inclusion of $\mathrm{Cd}$ into sulphides (e.g. Heinrichs et al., 1980; Kreming, 1983). Heinrichs et al. (1980) showed that Cd was more closely related to sulphur than to organic matter in black shales. It also can accumulate in phosphates (Nathan et al., 1997) which explains some of the differences which are seen in Cd enrichments relative to other trace elements that are included in sulphates (Turgeon and Brumsack, 2006). Cadmium is also involved in biocycling, and is often associated with plankton growth (Calvert and Pedersen, 1993).

Cobalt $(\mathrm{Co})$ is included into sulphides, and can thus be enriched in sulphur-rich anoxic conditions (Kreming, 1983). In sulphur-poor anoxic conditions Co behaves similarly to Mn, and in upwellings it is generally depleted (Böning et al., 2004).

Chromium $(\mathrm{Cr})$ is enriched almost purely because of redox sensitivity. It exists in two main forms in the oxic ocean, as $\mathrm{CrO}_{4}{ }^{2-}$ and to a lesser extent $\mathrm{Cr}(\mathrm{OH})_{2}^{+}\left(\mathrm{H}_{2} \mathrm{O}\right)_{4}$. However under reducing conditions, it generally forms $\mathrm{Cr}\left(\mathrm{H}_{2} \mathrm{O}\right)_{4}(\mathrm{OH})_{2}{ }^{+}$(Elderfield, 1970), and is quickly moved into the sediments (Calvert and Pederson, 1993). For Cr to be effectively scavenged into sediments, the pore waters must be completely anoxic (Morse and Luther, 1999).

Copper $(\mathrm{Cu})$ is a micronutrient (e.g. Calvert and Pederson, 1993) and is thus generally enriched in many anoxic environments. Off the coast of Peru biocycling above the oxygen minimum zone is suggested to be the main reason for its enrichment (Böning et al., 2004). Cu can also included into sulphides (e.g. Morse, 1994). Another factor which can complicate its enrichment is an increase in the concentration of $\mathrm{Cu}$ in sea water with depth (Calvert and Pederson 1993).

Hafnium (Hf) and niobium ( $\mathrm{Nb}$ ) have rarely been measured in sedimentary rocks and no enrichments have been noticed. $\mathrm{Hf}$ and $\mathrm{Nb}$ are usually immobile, and are not affected by diagenetic, redox or weathering processes (e.g. Ross and Bustin, 2009). 
Manganese $(\mathrm{Mn})$ in modern sediments is generally depleted in oxygen minimum zones (e.g. Böning et al., 2004; Brumsack, 2006; Huerta-Diaz and Morse, 1992). Mn gets dissolved from the sediments and transported along the oxygen minima layer to a more oxygen rich waters. The processes involved in $\mathrm{Mn}$ enrichment or depletion are complex. Enrichment of $\mathrm{Mn}$ in sediments usually correlates positively with Fe and Co (Roy, 1992).

$\mathrm{Mn}^{2+}$ is the reduced form of manganese and is generally soluble in sea water, but easily oxidised to $\mathrm{Mn}^{4+}$ (Huerta-Diaz and Morse, 1992), which is more stable as a solid state and often forms manganese nodules. $\mathrm{MnO}_{2}$ is the most common form of solid $\mathrm{Mn}$ in nature, but this is not stable in reducing conditions. Thus, generally in upwelling environments a Mn depletion is observed, but bacteria utilising solid state sulphate can oxidise $\mathrm{Mn}$. With the lack of oxygen in reducing conditions, $\mathrm{Mn}^{4+}$ formed by bacteria is precipitated into calcites or sulphates with only $\sim 20 \%$ remaining in the water (Aller and Rude, 1987).

Molybdenum (Mo) is a highly studied trace metal in anoxic sediments. It is found to be strongly enriched, and usually included in sulphides (e.g. Elbaz-Poulichet et al., 2005). Mo is enriched in both upwellings (e.g. Böning et al., 2004), and in anoxic basins (Elbaz-Poulichet et al., 2005).

$\mathrm{MoO}_{4}{ }^{2-}$ is diffused into the sediments forming $\mathrm{MoS}_{4}{ }^{-}$(Erickson and Helz, 2000) and then later forms Mo-Fe-S cuboïdal clusters on pyrite, from which it is reduced to Mo(VI) to stabilise the structure (Vorlicek et al., 2004). Crusius et al. (1996) found that enrichment of Mo begins at $\sim 1 \mathrm{~cm}$ below the sediment water interface in anoxic environments, and at $>10 \mathrm{~cm}$ in sub-oxic to oxic environments.

Nickel (Ni) is considered a micronutrient in the oceans and is important to plankton growth. In anoxic conditions it is also incorporated into sulphides, but requires a solid surface to precipitate on (Calvert and Pederson, 1993). Ni can also be correlated to oxyhydroxides in the water column, which are dissolved in the pore waters (Calvert and Pederson, 1993).

Lead $(\mathrm{Pb})$ is generally related to sulphur in anoxic sediments (Heinrich et al., 1980) and has a short residence time in the ocean (Schaule and Patterson, 1981). The residence time is likely to be due to lead being rapidly scavenged by biogenic particles 
(Brumsack, 1989; Böning et al., 2004). In modern sediments any enrichment due do anoxia is comparably less than the enrichments due to anthropogenic input (Böning et al., 2004).

Rubidium $(\mathrm{Rb})$ is relatively poorly studied in anoxic sediments, but was shown to be related to K (Plank and Langmuir, 1998), and is also generally behaves like Zr, Hf, and $\mathrm{Nb}$. Although $\mathrm{Rb}$ is often measured, mechanisms of enrichment are uncertain and more study is required.

Rhenium $(\mathrm{Re})$ is enriched in anoxic sediments, begins at $1 \mathrm{~cm}$ below the sediment water interface in sub-oxic and anoxic environments, and at $>10 \mathrm{~cm}$ in oxic environments (Crusius et al., 1996). Böning et al. (2004) suggested that the enrichment of $\operatorname{Re}$ is mainly a factor of sea water availability. A highly useful aspect of $\mathrm{Re}$ enrichment is that it starts in suboxic environments. Thus Re can be used with Mo (which requires completely anoxic conditions to be enriched) to distinguish environments which are sub-oxic at the surface from those that are anoxic (Crusius et al., 1996). $\left[\mathrm{Re}_{\mathrm{TOT}}\right] /\left[\mathrm{Mo}_{\mathrm{TOT}}\right]$ should be significantly higher than the same ratio in sea water if the sediment-water interface is sub-oxic, while the ratio should be similar to sea water, or sometimes lower if the sediment-water interface is anoxic (Crusaius et al., 1996). The use of the $\left[\mathrm{Re}_{\mathrm{TO}}\right] /\left[\mathrm{Mo}_{\mathrm{TO}}\right]$ ratio is limited as pyrite concretions (polyframboids) form in sub-oxic environments and enrichments of Mo within these have also been noticed (Tribovillard et al., 2008). Before this ratio is used to form any major conclusions on trace elements, the type of pyrite in the sediments needs to be assessed to gauge which processes caused the Mo enrichment.

Antimony ( $\mathrm{Sb}$ ) is a poorly understood trace element in respect its behaviour in anoxic conditions (e.g. Filella et al., 2002). Takayanagi and Cossa (1997) suggested that Sb may be included into manganese and iron oxide particles or sulphides. $\mathrm{Sb}$ is generally enriched in anoxic environments (e.g. Böning et al., 2004), but the exact process causing the enrichment is unknown.

Selenium (Se) is often enriched in upwellings, yet the reason for enrichment is not clear. Se is involved in biocycling (Cutter, 1989) but is also enriched at the bottom of the ocean in the form of $\mathrm{Se}^{6+}$, and thus upwelling intensity may be important (Crusius and Thompson, 2003). Solid Se is normally related to Ag; in sub-oxic conditions 
biological influences can produce $\mathrm{AgSe}$ or $\mathrm{Ag}_{2} \mathrm{Se}$ (Crusius and Thompson, 2003).

Tin (Sn) is a very poorly studied metal in anoxia and has been omitted from most trace element studies on sediments.

Strontium ( $\mathrm{Sr}$ ) is often dependent on carbonate as it is significantly enriched through biological precipitation of carbonate tests, which is a temperature dependent process (Plank and Langmair, 1998). Redox relationships have not been addressed for the effect of marine anoxia on strontium.

Tantalum (Ta) is generally unaffected by redox condtions and is generally paired with $\mathrm{Nb}$ as they are difficult to separate (Ross and Bustin, 2009). Ta is also very rarely included into marine trace element studies.

Thorium (Th) is mainly detrital in sediments but may be enriched in the hydrogenous Fe-Mn component of sediments (Plank and Langmair, 1998). Generally Th is not very strongly enriched and is often related to $\mathrm{Hf}, \mathrm{Nb}, \mathrm{Zr}$, and $\mathrm{Ta}$.

Titanium (Ti) is generally related to Al in anoxic sediments, but can be enriched in sediments by mechanical processes. Ti is often contained in heavy minerals such as rutile, and thus increases in Ti often indicate increase in energy (Dellwig et al., 2000). Ti is also involved in biocycling, and its exact removal pathway is poorly understood (Brumsack, 2006).

Thallium (Tl) is a relatively poorly studied trace element which is not included in many of the older studies. Heinrich et al. (1980) showed that $\mathrm{Tl}$ was more closely related to sulphur than to organic carbon. Thallium may also be involved in biocycling as suggested by Böning et al. (2004) with respect to the Peruvian upwelling, but more work is required to confirm this.

Uranium (U) is enriched in anoxic sediments in several ways. $U$ enrichments in black shales were noticed very early (e.g. McKelvey and Nelson, 1950), and thus U is one of the better studied elements in anoxic conditions. $U$ has been noted to diffuse directly into the sediments (e.g. Shaw et al., 1990), and to precipitate uranium salts (Disnar and Sureau, 1990). Phosphates contain the best link to $U$ enrichments in most marine sediments, with phosphate-rich black shales considered generally the most enriched (e.g. McKelvey and Nelson, 1950). In anoxic conditions the limiting factor on U 
enrichment is generally its availability in sea water.

Vanadium (V) is always enriched in anoxic marine settings. Vanadium has three soluble oxidation states which occur naturally, $\mathrm{HVO}_{4}{ }^{2-} \mathrm{H}_{2} \mathrm{VO}_{4}^{-}$and $\mathrm{VO}(\mathrm{OH})_{3}^{-}$(e.g. Turner et al., 1981). However, when reduced $\mathrm{V}$ is precipitated as $\mathrm{V}_{2} \mathrm{O}_{3}$ or $\mathrm{V}(\mathrm{OH})_{3}$ (Wanty and Goldhaber, 1992). V has a strong relationship with organic matter yet its concentration is chiefly governed by redox sensitivity (e.g. Shaw et al., 1990). A main limiting factor is often sea water availability, as has been suggested for the Peruvian upwelling (Böning et al., 2004).

Tungsten (W) has not been studied with respect to its abundance in anoxic sediments.

Yttrium (Y) is occasionally measured in trace metal studies on anoxic sediments (e.g. Ross and Bustin, 2009), yet an explanation for variations of $\mathrm{Y}$ in anoxic sediments is still required.

Zirconium $(\mathrm{Zr})$ has been measured in only a few studies and enrichments have not generally been noted. Ross and Bustin (2009) have suggested that Zirconium is not normally enriched due to anoxic conditions, but that it should have a direct relationship with Hf and with other elements which are insoluble in both oxic and anoxic environments.

\subsection{Methods}

This study examined eight side wall core samples from the Kawau-1A well (table 1). The samples were digested in the clean laboratory facilities at Victoria University of Wellington, then trace metals were measured using inductively coupled plasma mass spectrometry (ICP-MS).

$50 \mathrm{mg}$ of each of the side wall core samples were taken, weighed and digested in hydrofluoric (HF) and nitric $\left(\mathrm{HNO}_{3}\right)$ acids. The USGS BHVO-1 and BHVO-2 standards where also digested, and a blank was also run to check for contamination. BHVO-1 was used to calculate whole rock values, and BHVO-2 to calculate errors.

A minor issue was encountered with the digestion process as the organic matter was very sticky and would often adhere to the lids of the digestion containers. Traces of the 
samples may have been lost in the digestion process and as this is not measurable this provides a potential error for the absolute concentrations of trace metals. However, as this affects all elements in a sample simultaneously, it is not a problem for the enrichment factors (EF) calculated later. The following 32 elements were measured using ICP-MS in an attempt to understand the depositional environment of the Tartan Formation: Ag, As, Au, Bi, Ca, Cd, Co, Cr, Cu, Hf, Hg, Mn, Mo, Nb, Ni, Pb, Rb, Re, $\mathrm{Sb}, \mathrm{Se}, \mathrm{Sn}, \mathrm{Sr}, \mathrm{Ta}, \mathrm{Th}, \mathrm{Ti}, \mathrm{Tl}, \mathrm{U}, \mathrm{V}, \mathrm{W}, \mathrm{Y}, \mathrm{Zn}$ and Zr.

\subsection{Results}

29 of the 32 measured elements gave potentially meaningful results, $\mathrm{Zn}$ and $\mathrm{Ca}$ encountered major interferences in the cleaning liquids, and $\mathrm{Hg}$ was not distinguishable from the background. All three of these elements thus occasionally gave negative concentrations and hence were excluded from the results.

Table 2 shows the absolute errors for the trace metal measurements in percent. Most seem realistic, but many of the errors are too large due to poor constraints on the USGS BHVO-2 concentrations (taken from USGS website). The numbers below Au on the list are larger than what the graphs (Figure 4, 5, 6, and 7) indicate. The graphs of elements plotted against one another (Figure 5,6) do not support such large errors especially with $r^{2}$ values of up to 0.994 (Figure 5) for a direct linear relationship. The red values indicate elements where problems were encountered or which had undetectable amounts of that element as explained in the above paragraph.

\begin{tabular}{|c|r|}
\hline Element & Error $\pm \%$ \\
\hline $\mathrm{Cr}$ & 3.58 \\
\hline $\mathrm{V}$ & 4.32 \\
\hline $\mathrm{Ni}$ & 4.48 \\
\hline $\mathrm{Co}$ & 4.57 \\
\hline $\mathrm{Tr}$ & 5.28 \\
\hline $\mathrm{As}$ & 5.79 \\
\hline $\mathrm{Ta}$ & 6.09 \\
\hline $\mathrm{Y}$ & 6.34 \\
\hline $\mathrm{Sr}$ & 6.36 \\
\hline $\mathrm{Mn}$ & 7.13 \\
\hline $\mathrm{Zr} 90$ & 7.67 \\
\hline
\end{tabular}

\begin{tabular}{|c|r|}
\hline Element & Error $\pm \%$ \\
\hline $\mathrm{Zr} 91$ & 7.81 \\
\hline $\mathrm{Nb}$ & 7.87 \\
\hline $\mathrm{Rb}$ & 8.31 \\
\hline $\mathrm{Th}$ & 8.78 \\
\hline $\mathrm{Ca}$ & 9.13 \\
\hline $\mathrm{Hf}$ & 9.43 \\
\hline $\mathrm{Cd}$ & 9.99 \\
\hline $\mathrm{U}$ & 10.24 \\
\hline $\mathrm{Cu}$ & 10.49 \\
\hline $\mathrm{Ag}$ & 10.5 \\
\hline $\mathrm{Se}$ & 10.64 \\
\hline
\end{tabular}

\begin{tabular}{|c|r|}
\hline Element & Error $\pm \%$ \\
\hline $\mathrm{Au}$ & 15 \\
\hline $\mathrm{W}$ & 21.1 \\
\hline $\mathrm{Sn}$ & 28.18 \\
\hline $\mathrm{Pb}$ & 34.74 \\
\hline $\mathrm{Bi}$ & 43.31 \\
\hline $\mathrm{Sb}$ & 43.76 \\
\hline $\mathrm{T}$ & 50.81 \\
\hline $\mathrm{Hg}$ & 123.92 \\
\hline $\mathrm{Zn}$ & 178.24 \\
\hline $\mathrm{Re}$ & 178.65 \\
\hline $\mathrm{Mo}$ & 270.27 \\
\hline
\end{tabular}


Table 2) calculated errors for trace metal variations in the Tartan Formation as calculated
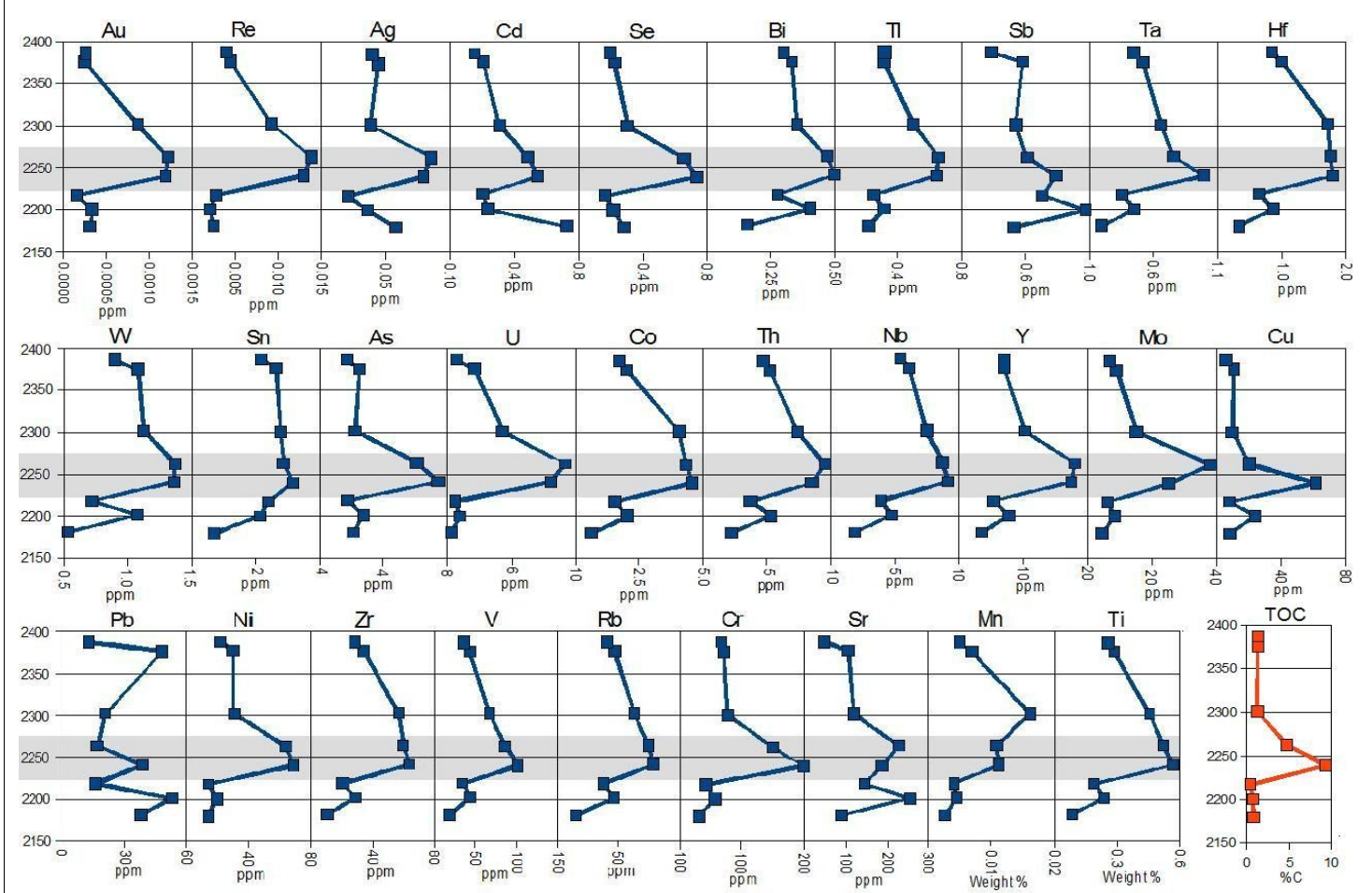

Figure 4) Depth profiles of trace metal variations in Kawau-1. The TOC measurements are from Meadows (2008). All data are plotted against depth (meters below rotary kelly bushing). Depths are taken from Hunt (1977).

Most of the data is presented in ppm (parts per million) apart from $\mathrm{Mn}, \mathrm{Ti}$, and TOC which are in weight percent.

The grey band represents the Tartan Formation.

Re was in very low concentrations in the BHVO-1 and BHVO-2 standards; thus the errors show up as far larger than is realistic. In addition for many of the elements (e.g. Mo) the concentration was assumed to be the same in BHVO-1 and BHVO-2 as the concentration has not been measured and published on the USGS website for BHVO-2.

A table showing the trace metal variations measured in the Kawau-1A samples is included as Appendix 1. Figure 4 shows the different trace metal variations in the eight samples measured.

As Al was not measured, normalising to elements was difficult. This study attempted to get around this by finding another element which should have a similar relationship as aluminium. Al is normally used as it is thought to be unaffected by enrichment processes because it makes up a structural component of the silicate grains. Many authors have commented that Ti has a direct relationship to Al (e.g. Böning et al., 2004).

Several elements which should be stable in relation to one another and to $\mathrm{Ti}$ are $\mathrm{Zr}$, 


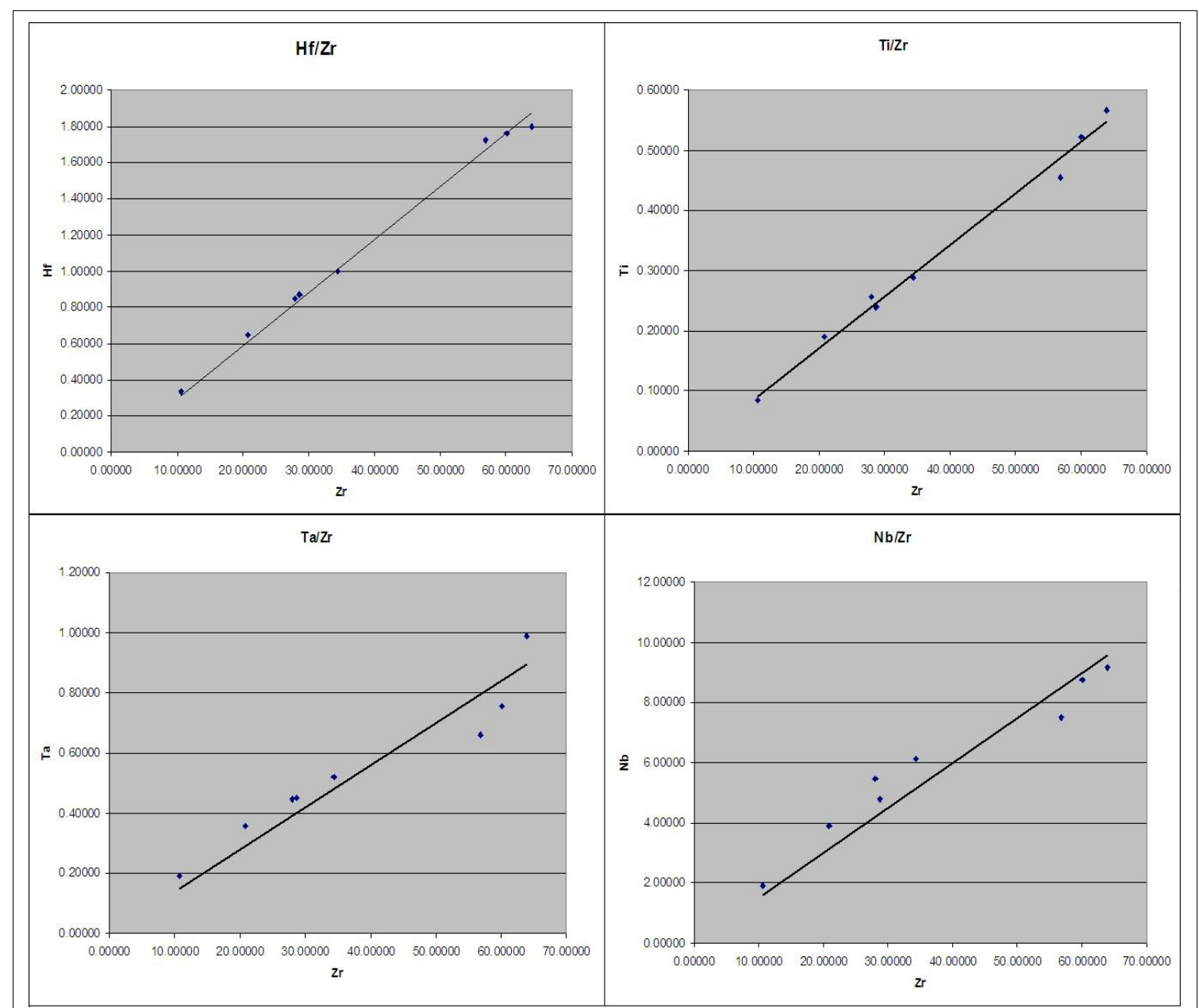

Figure 5) The relationship of $\mathrm{Zr}$ to $\mathrm{Hf}, \mathrm{Ti}, \mathrm{Ta}$, and $\mathrm{Nb}$ is approximately linear. Error bars have not been plotted on these graphs.

The $\mathrm{r}^{2}$ values are as follow $\mathrm{Hf} / \mathrm{Zr}$ 0.9943, Ti/Zr 0.9904, Ta/Zr 0.8891, and $\mathrm{Nb} / \mathrm{Zr}$ 0.8878 .

$\mathrm{Nb}$, Hf, and Ta (as long as the source of sediments does not change). Figure 5 shows plots of these elements against $\mathrm{Zr}$. Zr has a very strong relationship to both $\mathrm{Ti}$ and $\mathrm{Hf}$, and a slightly weaker relationship to $\mathrm{Ta}$ and $\mathrm{Nb}$.

Whether $\mathrm{Zr}, \mathrm{Nb}$, Ta or $\mathrm{Hf}$ are viable alternatives to measuring $\mathrm{Al}$ in sediments still needs to be confirmed in a separate study which measures both. A relationship in the Tartan Formation between these elements to the detrital contributions of sediments may prove to be more complicated. The spike in $\mathrm{Zr}, \mathrm{Hf}, \mathrm{Nb}$ and $\mathrm{Ta}$ (Figure 4) within the Tartan Formation is large and indicative of a change in sediment type, not an increase in the concentration of detrital sediments as can occur when there is a decrease in carbonate or TOC. High TOC values make up a considerable portion of the Tartan Formation; thus if sediment source and sorting remains constant, a decrease in elements 
such as $\mathrm{Zr}$, Hf, $\mathrm{Nb}$, and Ta should be expected.

The relationship between $\mathrm{Zr}, \mathrm{Hf}, \mathrm{Ti}$, Ta, and $\mathrm{Nb}$ is linear (Figure 5), and thus they can be assumed to be related to the detrital material in some way. Plotting these against the other elements will provide interesting information that at the very least should show which of them vary with these other elements and which vary independently or due to other processes.

Figure 6 shows several other sets of elements which appear to follow close to a linear tread when plotted against $\mathrm{Zr}$. The two red points on each graph are the Tartan Formation, with the rest of the points being from adjacent units. Using the background work discussed in section $3.1 \mathrm{~V}, \mathrm{Y}$, and $\mathrm{Tl}$ should in theory be enriched in anoxic conditions, and plot above the line in Figure 6, while if in the open ocean Mn should be depleted and plots below the line. While these elements do follow this trend, the enrichment is not as great as is seen in other anoxic sediments (e.g. Brumsack, 2006). The line is an average through all the samples, and includes the Tartan Formation samples; if these are excluded, the difference becomes more obvious.

As these results indicate anoxic conditions when plotted against $\mathrm{Zr}$, an enrichment factor (EF) for these samples can be calculated using a variation of the enrichment

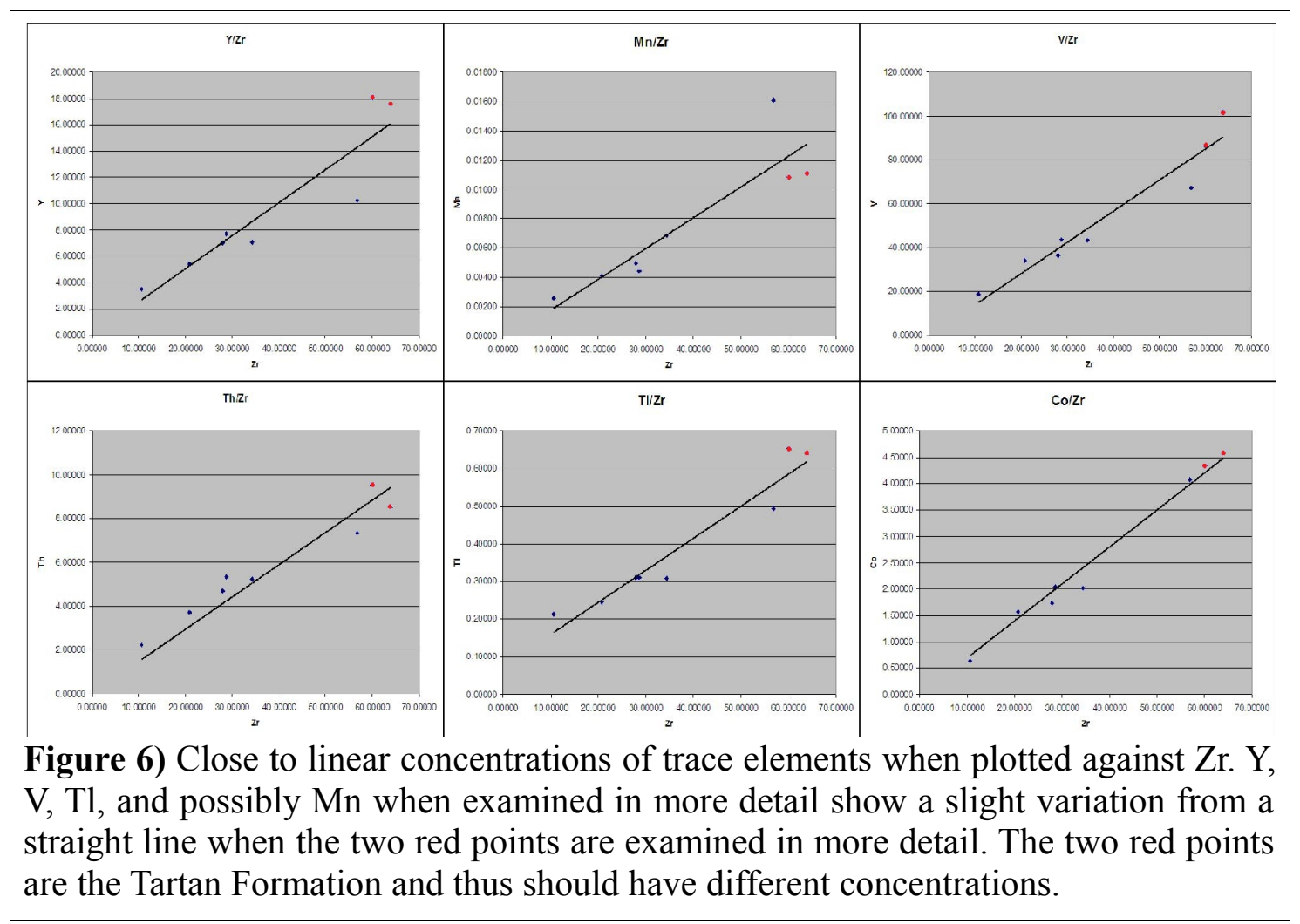


factor formula generally used for trace metal enrichments. Enrichment factor is used as it is the only way to attempt to remove the background variation introduced from variations from the detrital sediment source.

The general formula for calculating an enrichment factor $(E F)$ is: $E F=$ (element/Al $)_{\text {sample }} /(\text { element/Al })_{\text {average shale }}($ e.g. Brumsack, 2006). Although average shale is generally used as the background, when looking at ancient deposits it is often more useful to look at the variations relative to the local background as average shale composition is likely to vary with time. Concentrations of trace metals in sea water are not constant through time and thus a local background from the overlying and underlying units may give more meaningful results (e.g. Brumsack, 2006). Further, when plotting against local shales, the processes driving the local variations in trace metals may become more noticeable.

The formula used here is: $\mathrm{EF}=\left(\right.$ element $/(\mathrm{Zr}, \mathrm{Hf} \text {, or Ti) })_{\text {Tartan }} /($ element $/(\mathrm{Zr}, \mathrm{Hf}$ or

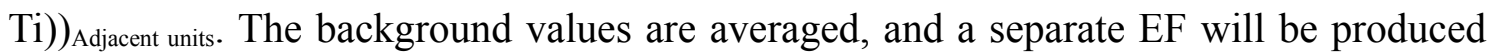
for each of the Tartan Formation samples. This formula will give identical results as the original when the aluminium concentration is directly related to $\mathrm{Zr}$, $\mathrm{Hf}$ or Ti. If $\mathrm{Al}$ is not related then this formula will give a different $\mathrm{EF}$.

\begin{tabular}{|c|c|c|c|c|c|c|c|c|c|}
\hline & & & & $\mathrm{Ti}$ & $\mathrm{Ti}$ & $\mathrm{Zr}$ & $\mathrm{Zr}$ & $\mathrm{Hf}$ & $\mathrm{Hf}$ \\
\hline & background & Tartan 20/4 & Tartan 19/4 & Tartan 20/4 & Tartan 19/4 & Tartan 20/4 & Tartan 19/4 & Tartan 20/4 & Tartan 19/4 \\
\hline $\mathrm{Ti}$ & 0.25 & 0.57 & 0.52 & - & - & 1.05 & 1.03 & 1.13 & 1.06 \\
\hline$Z r$ & 29.89 & 63.91 & 60.11 & 0.95 & 0.97 & - & - & 1.08 & 1.03 \\
\hline $\mathrm{Hf}$ & 0.904 & 1.797 & 1.761 & 0.89 & 0.94 & 0.93 & 0.97 & - & - \\
\hline $\mathrm{Au}$ & 0.0004 & 0.0012 & 0.0012 & 1.44 & 1.59 & 1.51 & 1.64 & 1.62 & 1.69 \\
\hline $\operatorname{Re}$ & 0.0042 & 0.0130 & 0.0138 & 1.39 & 1.6 & 1.46 & 1.64 & 1.57 & 1.7 \\
\hline $\mathrm{Ag}$ & 0.04 & 0.08 & 0.08 & 0.9 & 1.05 & 0.95 & 1.08 & 1.02 & 1.11 \\
\hline $\mathrm{Cd}$ & 0.301 & 0.543 & 0.486 & 0.8 & 0.78 & 0.84 & 0.8 & 0.91 & 0.83 \\
\hline $\mathrm{Se}$ & 0.23 & 0.73 & 0.66 & 1.45 & 1.4 & 1.52 & 1.44 & 1.63 & 1.49 \\
\hline $\mathrm{Bi}$ & 0.303 & 0.496 & 0.467 & 0.73 & 0.75 & 0.77 & 0.77 & 0.82 & 0.79 \\
\hline$\pi$ & 0.31 & 0.64 & 0.65 & 0.91 & 1.01 & 0.95 & 1.04 & 1.03 & 1.07 \\
\hline $\mathrm{Sb}$ & 0.62 & 0.79 & 0.61 & 0.57 & 0.47 & 0.6 & 0.49 & 0.64 & 0.5 \\
\hline $\mathrm{Ta}$ & 0.44 & 0.99 & 0.76 & 1.01 & 0.84 & 1.06 & 0.86 & 1.13 & 0.89 \\
\hline W & 0.902 & 1.360 & 1.371 & 0.67 & 0.74 & 0.71 & 0.76 & 0.76 & 0.78 \\
\hline Sn & 2.13 & 3.13 & 2.86 & 0.66 & 0.65 & 0.69 & 0.67 & 0.74 & 0.69 \\
\hline As & 2.17 & 7.49 & 6.14 & 1.54 & 1.37 & 1.61 & 1.41 & 1.73 & 1.45 \\
\hline $\mathrm{U}$ & 3.19 & 8.47 & 9.36 & 1.18 & 1.42 & 1.24 & 1.46 & 1.34 & 1.51 \\
\hline Co & 2.01 & 4.58 & 4.34 & 1.01 & 1.04 & 1.06 & 1.07 & 1.14 & 1.11 \\
\hline Th & 4.75 & 8.51 & 9.54 & 0.8 & 0.97 & 0.84 & 1 & 0.9 & 1.03 \\
\hline $\mathrm{Nb}$ & 4.94 & 9.16 & 8.74 & 0.83 & 0.86 & 0.87 & 0.88 & 0.93 & 0.91 \\
\hline $\mathrm{Y}$ & 6.83 & 17.54 & 18.07 & 1.14 & 1.28 & 1.2 & 1.32 & 1.29 & 1.36 \\
\hline Mo & 8.08 & 24.99 & 38.18 & 1.38 & 2.28 & 1.45 & 2.35 & 1.56 & 2.42 \\
\hline $\mathrm{Cu}$ & 10.92 & 61.78 & 20.14 & 2.52 & 0.89 & 2.65 & 0.92 & 2.85 & 0.95 \\
\hline $\mathrm{Pb}$ & 31.63 & 38.84 & 17.11 & 0.55 & 0.26 & 0.57 & 0.27 & 0.62 & 0.28 \\
\hline $\mathrm{Ni}$ & 21.59 & 69.22 & 63.82 & 1.43 & 1.43 & 1.5 & 1.47 & 1.61 & 1.52 \\
\hline V & 40.65 & 101.87 & 86.2 & 1.12 & 1.03 & 1.17 & 1.05 & 1.26 & 1.09 \\
\hline $\mathrm{Rb}$ & 41.6 & 78.13 & 74.34 & 0.84 & 0.86 & 0.88 & 0.89 & 0.94 & 0.92 \\
\hline $\mathrm{Cr}$ & 58.21 & 200.31 & 150.24 & 1.53 & 1.25 & 1.61 & 1.28 & 1.73 & 1.32 \\
\hline $\mathrm{Sr}$ & 126.39 & 186.51 & 226.47 & 0.66 & 0.87 & 0.69 & 0.89 & 0.74 & 0.92 \\
\hline $\mathrm{Mn}$ & 0.0065 & 0.0111 & 0.0109 & 0.76 & 0.81 & 0.8 & 0.83 & 0.86 & 0.85 \\
\hline
\end{tabular}

Table 3) Estimates of enrichment factors in the Tartan Formation relative to the average background using the formula discussed in text. 
Table 3 shows the calculated enrichment factors using the different background elements. The enrichment factors for many of the elements are less than 1, which is not normal for anoxic conditions (Brumsack 2006). Average enrichment factors are plotted in Figure 7.

The depth profiles (Figure 4) are a useful comparison when explaining these enrichment factors. Three of the four most depleted elements according to the enrichment factors $(\mathrm{Sr}, \mathrm{Pb}$, and $\mathrm{Sb}$ ) show no distinctive signal throughout the depth profiles. Although from the absolute concentrations it appears as though 26 out of the 29 elements are enriched. Much of this enrichment is background from the detrital material, and only about half the trace metals are enriched (Figure 7).

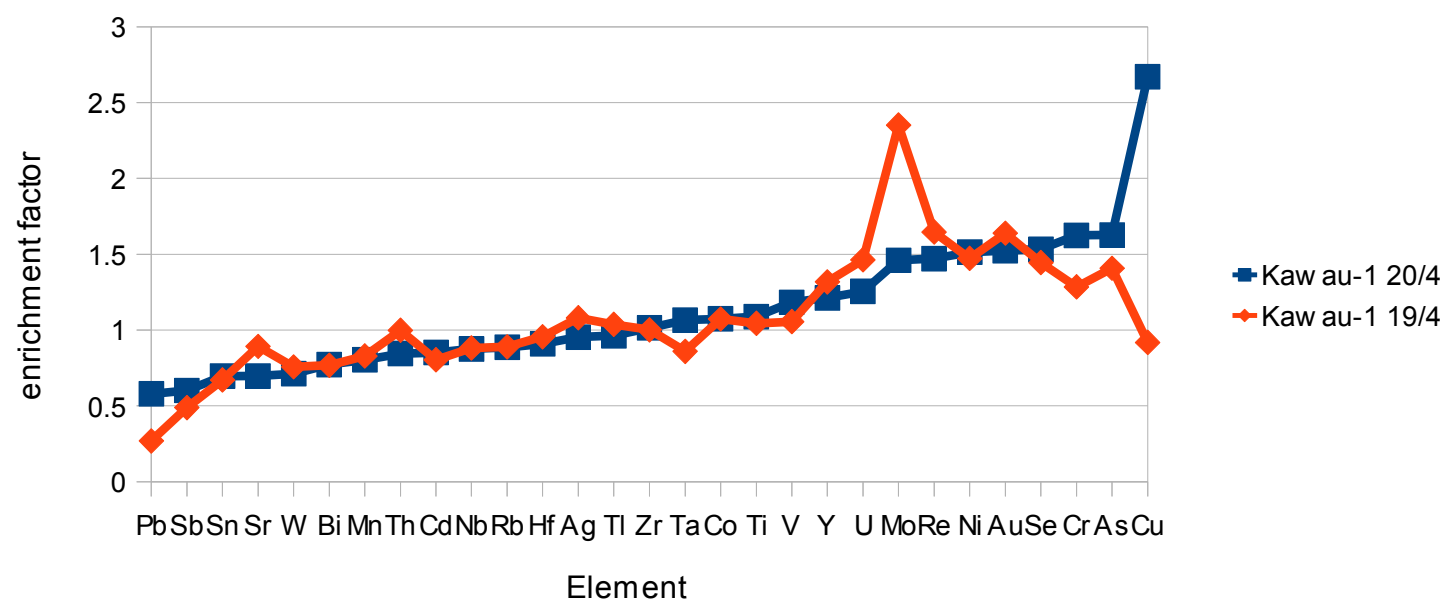

Figure 7) Average enrichment factor for each of the Tartan Formation samples. The enrichment factors are calculated using the formula provided in the text.

\subsection{Discussion}

Trace elements from sediments are generally normalised to Al to take into account the input of the detrital sediments. In this study this was not possible as Al was not measured, and $\mathrm{Ti}, \mathrm{Zr}$, and $\mathrm{Hf}$ were used instead. This technique has not been used before, but Ti has been shown by many authors (e.g. Brumsack, 2006) to be positively correlated to Al. Hf and Zr correlated extremely well to one another, with an $\mathrm{r}^{2}$ of 0.994 when plotted against a straight line through the origin. Ti/Zr correlated similarly with an $r^{2}$ of $0.990 . \mathrm{Zr}$ is very hard to differentiate from $\mathrm{Hf}$, and processes which do differentiate them do not generally occur in nature. Neither are soluble in water, and thus changes in 
redox equilibriums will have little effect their abundance (Ross and Bustin, 2009).

These elements are not generally used in this way as they are rarely measured in sediments, yet the use of several different elements allows an extra control on the calculated enrichment factor.

The increase in $\mathrm{Ti}, \mathrm{Hf}$, and $\mathrm{Zr}$ is likely due to a change in sediment source. Schiøler et al. (2010) found that most of the organic contents of the Tartan Formation was derived from terrestrial material likely relating to a maximum regression, and also suggested a potential increase in terrestrial derived clays may be responsible for the gamma ray spike in the well logs. This study suggests a drastic increase in Ti, Hf, and Zr, which may be related to sedimentation suggested by Schiøler et al., (2010), and an increase in terrestrial clays may provide the increase noticed in background variation.

An increase in detrital sediments alone can be ruled out as all the Late Paleocene sediments in the Great South Basin are almost purely detrital, with very little calcite (Cook et al., 1999). Thus a change in sediment source or, possibly, a change in sorting is required to produce a significant enrichment in $\mathrm{Zr}$, $\mathrm{Hf}$ and $\mathrm{Ti}$.

Trace metal variations suggest an anoxic environment of deposition with depletion. A near-anoxic environment has been suggested for the units above and below the Tartan Formation (Schiøler et al., 2010), thus the small changes in EF (Figure 7) may be related to both a shift in the location of the anoxic/oxic boundary, and potentially a dramatic increase in sedimentation rate, somewhat reducing the effect of trace element variations as the sediments are buried too quickly to have much water cycle through them.

Some of the elements measured $(\mathrm{Pb}, \mathrm{Sr}$, and $\mathrm{Sb})$ showed no noticeable trace metal enrichment or depletion within the Tartan Formation, and are probably controlled by a different process.

\section{Conclusion}

Trace metal variations may confirm the environment of deposition proposed by Schiøler et al. (2010), where it has been suggested that an influx of terrestrial organic 
matter helped enhance the anoxic conditions. The trace metal variations also may point to an increased depositional rate.

Zr, Hf and Ti are closely related in the sediments of the Tartan Formation. Ti has previously been shown to be directly related to Al, thus this study showed that enrichment factors could be calculated for these three elements. The enrichment factors are likely to be similar to those shown by Al. Using more elements has the added advantage that any variation in one of the reference elements will be noticed when plotted against the others.

\section{Future work}

The analysis of numerous elements simultaneously to calculate trace metal enrichment factors is an exciting prospect and requires more study. A comparison of these elements to Al needs to be made to see how these enrichment factors would compare to the standard Al-based enrichment factor. This technique would have the advantage that a change in sediment source may more often become detectable through variations of $\mathrm{Al}$ plotted against $\mathrm{Zr}$ and $\mathrm{Hf}$, especially if sediment sources have similar background $\mathrm{Al}$ but different composition of other trace elements.

Other wells which encounter the Tartan Formation should be analysed using the same technique as for Kawau-1A to see if the stratigraphic variations are similar and whether other sites show the same enrichments. The probably synchronous Waipawa Formation should also be studied, as trace metals may indicate whether it was deposited under the same conditions.

Many of the variations noticed in this preliminary study are not explained by current knowledge of trace metal variations, and more research is required to understand them. Importantly, significant depletions in $\mathrm{W}$ relative to the normalised values were noticed but no removal mechanism has yet been suggested for this element. 


\section{References}

Aller R.C., Rude P.D. 1987. Complete oxidation of solid phase supfides by manganese and bacteria in anoxic marine sediments. Geochim. Cosmochim. Acta, 50 751-765.

Böning P., Brumsack H.J., Böttcher M.E., Schnetger B., Kriete C., Kallmeyer J., Borchers S.L. 2004. Geochemistry of Peruvian near-surface sediments. Geochim. Cosmochim. Acta, 68/21 4429-4451.

Böning P., Cuypers S., Grunwald M., Schnetger B., Brumsack H.J. 2005. Geochemical characteristics of Chilean upwelling sediments at $\sim 36^{\circ}$ S. 2005. Marine Geol. 220, 1-21.

Böning P., Brumsack H.J., Schnetger B., Grunwald M. 2009. Trace element signatures of Chilean upwelling sediments at $\sim 36^{\circ} \mathrm{S}$. Marine Geol., 259 112-121.

Brumsack H.J. 1980. Geochemistry fo Cretaceous black shales from the Atlantic Ocean (DSDP legs 11, 14, 36, and 41). Chem. Geol. 31 1-25.

Brumsack H.J. 1989. Geochemistry of recent TOC-rich sediments from the Gulf of California and the Black Sea. International Journal of Earth Sciences 78/3 851-882.

Brumsack H.J. 2006. The trace metal content of recent organic carbon-rich sediments: Implications for Cretaceous black shale formation. Palaeogeography, Palaeoclimatology, Palaeoecology, 232 344361.

Calvert S.E., Pedersen T.F. 1993. Geochemistry of Recent oxic and anoxic marine sediments: Implications for the geological record. Marine Geol., 113 67-88.

Cook R.A., Sutherland R., Shu H., et al. 1999. Cretaceous - Cenozoic geology and petroleum systems of the Great South Basin, New Zealand. Institute of Geological and Nuclear Sciences Monograph 20, Institute of Geological and Nuclear Sciences, Lower Hut, New Zealand.

Crusius J., Calvert S., Pedersen T., Sage D. 1996. Rhenium and molynemdum enrichments in sediments as indicators of oxic, suboxic and sulfidic conditions of deposition. Earth and Planetary Science Letters, 145 65-78.

Crusius J., Thompson J. 2003. Mobility of authigenic rhenium, silver and selenium during postdepositoonal oxidation in marine sediments. Geochim. Cosmochim. Acta 67/2 265-273.

Cutter G.A. 1989. The estuarine behaviour of selenium in San Francisco bay. Estuar. Coast. Shelf Sci. 28 13-34.

Cutter G.A., Cutter L.S. 1995. Behaviour of dissolved antimony, arsenic and selenium in the AtlanticOcean. Mar. Chem. 49/4 295-306.

Dean W.E., Gardner J.V., Piper D.Z. 1997. Inorganic geochemical indicators of glacial-interglacial changes in productivity and anoxic on the California continental margin. Geochim. Cosmochim. Acta, 61/21, 4507-4518.

Dellwig O., Hinrichs J., Brumsack H.J. 2000. Changing sedimentation in tidal flat sediments of the southern North Sea from the Holocene to the present: a geochemical approach. J. Sea Res. 44 195-208.

Demaison G. J., Moore G. T., 1980. Anoxic Environments and Oil Bed Genesis. Am. Assoc. Pet. Geol. Bull. 64/8, 1179-1209.

Disnar J.R., Sireau J.F., 1990. Organic mater in ore genesis: progress and perspectives. Org. Geochem. 16 577-599.

Elbaz-Poulichet F., Seidel J.L., Jézéquel D., Metzger E., Prévot F., Simmonucci C., Sarazin G., Violler E., Etcheber H., Jouanneau J.M., Weber O., Radakovitch O. 2004. Sedimentary record of redoxsensitive elements (U, Mn, Mo) in a transitory anoxic basin (the Thau lagoon, France). Marine Chemistry 95, 271-281.

Elderfield H., 1970. Chromium speciation in sea water. Earth Planet. Sci. Lett., 9 10-16.

Erickson B.E., Helz G.R. 2000. Molybdenum (VI) speciation in sulfidic waters: stability and liability of thiomolybdates. Geochim. Cosmochim. Acta, 64, 1149-1158.

Goldschmidt V. M., 1954. Geochemestry. In: Muir, A. (Ed.), The International Series of Monographs on Physic. Clarendon Press, Oxford.

Heinrichs H., Schultz-Dobrick B., Wedepohl K.H. 1980. Terrestrial Geochemistry of Cd, Bi, Tl, Pb, Zn, Rb. Geochim. Cosmochim. Acta 44 1519-1533.

Herut B., Gavrieli I., Halicz L. 1997. Sources and distribution of trace and minor elements in western Dead Sea sediments. 
Hollis C.J., Dickens, G.R., Field, B.D., Jones, C.M., Strong, C.P., 2005. The Paleocene-Eocene transition at Mead Stream, New Zealand: a southern Pacific record of early Cenozoic global change. Palaeogeography, Palaeoclimatology, Palaeoecology, 215, 313-343

Huertz-Diaz M.A., Morse J.W. 1992. Pyritization of trace metals in anoxic marine sediments. Geochim. Cosmochim. Acta, 56 2681-2702.

Hunt International Petroleum Co NZ. 1977. Final well report Kawau-1A. Petroleum report PR716, Crown Minerals, Ministry of Economic Development, New Zealand.

Jean G.E., Bancrofft M.G. 1985. An XPS and SEM study of gold deposition at low temperatures on sulphide mineral surfaces: Concentration of gold by absorption/reduction. Geochim. Cosmochim. Acta, 49 979-987.

Killops S. D., Hollis C. J. Morgans H. E. G., Sutherland R., Field B. D., Leckie D. A., 2000. Paleoceanographic significance of Late Paleocene dysaerobia at the shelf/slope break around New Zealand. Palaeogeography, Palaeoclimatology, Paleoecology 156, 51-71.

Koide M., Hodge V.F., Yang J.S., Stallard M., Goldberg E.G. 1986. Some comparative marine chemistries of rhenium. Gold, silver and molybdenum. Applied Geochemistry 1 705-714.

Kremling K. 1983. The behaviour of $\mathrm{Zn}, \mathrm{Cd}, \mathrm{Cu}, \mathrm{Ni}, \mathrm{Co}, \mathrm{Fe}$, and $\mathrm{Mn}$ in anoxic Baltic waters. Mar. Chem., 13 87-108.

Lavagren U., Åström M.E., Berbäck B., Holmström H., 2009. Mobility of trace elements in black shale assessed by leaching tests and sequential chemical extraction. Geochemistry: Exploration, Environment Analysis 9 71-79.

Mao J., Lehmann B., Du A., Zhang G., Ma D., Wang Y., Zeng M., Kerrich R. 2002. Re-Os Dating of Polymetallic Ni-Mo-PGE-Au mineralization in Lower Cambrian Black Shales of South China and Its Geologic Significance. Economic Geol. 97 1051-1061

McKay J.L., Pederson T.F., 2002. Accumulation of redox-sensitive trace metals in continental margin sediments and their paleo-applications. Ocean Sciences Meet. Suppl. Absract os32b- Eos. Trans. AGU, 83 (4).

McKelly V.D., Nelson J.M., Characteristics of marine uranium-bearing sedimentary rocks. Economic Geol., 45 35-53.

Meadows D. J., 2008. Geochemistry of the Paleocene Tartan Formation in the Great South Basin, New Zealand. Graduate Diploma in Science, SGEES, Victoria University of Wellington.

Montserrat F., Belzile N., Chen Y.W. 2002. Antimony in the environment: a review focused on natural waters I. Occurrence. Earth Science Review 57 125-176.

Morford J.L., Kalnejais L.H., Helman P., Yen G., Reinard M. 2008. Geochemical cycling of silver in marine sediments along an offshore transect. Marine Chemistry, 110 77-88.

Morse J.W. 1994. Interactions of trace metals with authigenic sulfide minerals: implications for their bioavailability. Marine Chemistry 46 1-6

Morse J.W., and Luther G.W. 1999. Chemical influences on trace metal-sulfide interactions in anoxic sediments. Geochim. Cosmochim. Acta 63 3373-3378.

Nathan Y., Soudry D., Levy Y., Shitrit D., Dorfman E. 1997. Geohemistry of cadmium in the Negev phosphorites. Chem. Geol. 142 87-107.

Plank T., Langmuir C.H. 1998. The chemical composition of subduction sediment and consequences for the crust and mantle

Ross D.J.K., Bustin R.M. 2009. Investigating the use of sedimentary geochemical proxies for paleoenvironment interpretation of thermally mature organic-rich strata: Examples from Devonian-Mississippian shales, Western Canadian Sedimentary Basins. Chemical Geol. 260 1-19.

Roy S. 1992. Environments and processes of Manganese Deposition. Economic Geol., 87 1218-1236

Schaule B.K., Patterson C.C. 1981. Lead concentrations in the Northeast Pacific - evidence for global anthropogenic perturbations. Earth Planet. Sci. Lett. 53 97-116.

Schiøler P., Roncaglia L., 2008. Age and depositional environment of the Tartan Formation, a potential source rock in the Great South Basin. NZ Petroleum Conference proceedings, Crown Minerals, Minestry of Economic Development, NZ.

Schiøler P., Rogers K., Sykes R., Hollis C.J., Ilg B., Meadows D., Roncaglia L., Uruski C. 2010. Palynofacies, organic geochemistry and depositional environment of the Tartan Formation (Late Paleocene), a potential source rock in the Great South Basin, New Zealand. Marine and Petroleum Geol., doi: 10.1016/j.marpetgeo.2009.09.006 
Shaw T.J., Gieskes J.M., Jahnke R.A. 1990. Early diagenesis in differing depositional environments: the response of transitions metals in pore water. Geochim. Cosmochim. Acta 54 1233-1246.

Springer J.S. 1985. Cabon in Archean rocks of Abitibi Belt (Ontario-Quebec) and its relation to gold distribution. Can. J. Earth Sci. 22 1945-1951.

Takayanagi K., Cossa D. 1997. Vertical distribution of Sb(III) and $\mathrm{Sb}(\mathrm{V})$ in Pavin Lake, France. Water Res. 31 671-674.

Tribovillard N., Lyons T.W., Riboulleau A., Bout-Roumazeilles V. 2008. A possible capture of molybdenum during early diagenesis of dysoxic sediments. Bull. Soc. Géol. Fr., 179/1 3-12.

Turgeon S., Brumsack H.J. 2006. Chem. Geol. 234 321-339.

Turner D.R., Whitfield M., Dickson A.G. 1981. The equilibrium speciation of dissolved components in freshwater and seawater at $25^{\circ} \mathrm{C}$ and $1 \mathrm{~atm}$ pressure. Gechim. Cosmochim. Acta, 45 855-881.

Vorlicek, T.P., Kahn M.D., Kasuya Y., Helz G.R. 2004. Capture of molybdenum in pyrite-forming sediments: role of ligand-induced reduction by polysulfides. Geochim. Cosmochim. Acta, 68/3 547-566.

Wanty R.B., and Goldharber M.B. 1992. Thermodynamics and kinetics of reactions involving vanadium in natural systems: accumulations of vanadium in sedimentary rocks. Geochim. Cosmochim. Acta, 56 1471-1483.

Warning B., Brumsack H.J. 2000. Trace metal signatures of eastern Mediterranean saporpels. Palaeogeography, Palaeoclimatology, Palaeoecology 158 293-309. 


\section{Appendix C}

\section{$\underline{\text { Results }}$}

XRF results prior to normalisation for Angora Quarry

\begin{tabular}{|c|c|c|c|c|c|c|c|c|}
\cline { 2 - 9 } \multicolumn{1}{c|}{} & Av. Shale & A-A-1 & A-A-2 & A-A-3 & A-A-4 & A-A-5 & A-A-6 & A-A-7 \\
\hline $\mathrm{Fe}_{2} \mathrm{O}_{3}$ & 2.8 & 2.58 & 2.26 & 2.41 & 1.87 & 2.36 & 3.59 & 3.51 \\
\hline $\mathrm{MnO}$ & $0.1^{*}$ & 0.02 & 0.02 & 0.02 & 0.02 & 0.02 & 0.01 & 0.03 \\
\hline $\mathrm{TiO}_{2}$ & 0.78 & 0.38 & 0.33 & 0.37 & 0.33 & 0.41 & 0.46 & 0.47 \\
\hline $\mathrm{CaO}$ & 2.2 & 4.91 & 5.75 & 3.07 & 6.78 & 5.63 & 1.42 & 2.43 \\
\hline $\mathrm{K}_{2} \mathrm{O}$ & 3.6 & 1.26 & 1.16 & 1.25 & 1.12 & 1.34 & 1.49 & 1.51 \\
\hline $\mathrm{SO}_{3}$ & $0.6^{*}$ & 0.46 & 0.72 & 0.09 & 0.65 & 0.46 & $<0.01$ & 0.16 \\
\hline $\mathrm{P}_{2} \mathrm{O}_{5}$ & 0.16 & 0.08 & 0.07 & 0.07 & 0.06 & 0.07 & 0.09 & 0.08 \\
\hline $\mathrm{SiO}_{2}$ & 58.9 & 72.70 & 72.86 & 76.56 & 71.81 & 70.89 & 75.72 & 71.79 \\
\hline $\mathrm{Al}_{2} \mathrm{O}_{3}$ & 16.7 & 8.30 & 7.65 & 8.27 & 7.51 & 9.02 & 10.19 & 10.33 \\
\hline $\mathrm{MgO}$ & 2.6 & 0.78 & 0.84 & 0.90 & 0.77 & 0.88 & 0.88 & 0.92 \\
\hline $\mathrm{Na}_{2} \mathrm{O}$ & 1.6 & 0.82 & 0.76 & 0.80 & 0.61 & 0.85 & 0.93 & 0.88 \\
\hline $\mathrm{LOI}$ & & 7.65 & 7.47 & 5.99 & 8.25 & 8.06 & 5.15 & 7.83 \\
\hline $\mathrm{SUM}$ & & 99.95 & 99.89 & 99.80 & 99.79 & 99.99 & 99.94 & 99.95 \\
\hline
\end{tabular}

\begin{tabular}{|c|c|c|c|c|c|c|c|c|}
\cline { 2 - 10 } \multicolumn{1}{c|}{} & A-A-8 & A-A-9 & A-A-10 & A-A-11 & A-A-12 & A-A-13 & A-C-2 & A-C-1 \\
\hline $\mathrm{Fe}_{2} \mathrm{O}_{3}$ & 2.47 & 3.58 & 3.02 & 3.32 & 2.77 & 3.56 & 2.34 & 2.21 \\
\hline $\mathrm{MnO}$ & 0.01 & 0.01 & 0.01 & 0.01 & 0.02 & 0.02 & 0.01 & 0.01 \\
\hline $\mathrm{TiO}_{2}$ & 0.38 & 0.53 & 0.48 & 0.54 & 0.49 & 0.54 & 0.46 & 0.38 \\
\hline $\mathrm{CaO}$ & 0.14 & 0.14 & 0.12 & 0.13 & 0.11 & 0.26 & 0.09 & 4.78 \\
\hline $\mathrm{K}_{2} \mathrm{O}$ & 1.44 & 1.72 & 1.53 & 1.73 & 1.65 & 1.73 & 1.40 & 1.27 \\
\hline $\mathrm{SO}_{3}$ & $<0.01$ & $<0.01$ & $<0.01$ & 0.04 & $<0.01$ & 0.10 & $<0.01$ & 0.28 \\
\hline $\mathrm{P}_{2} \mathrm{O}_{5}$ & 0.07 & 0.11 & 0.09 & 0.04 & 0.10 & 0.10 & 0.05 & 0.06 \\
\hline $\mathrm{SiO}_{2}$ & 80.35 & 70.78 & 74.57 & 69.87 & 71.73 & 67.85 & 73.52 & 73.53 \\
\hline $\mathrm{Al}_{2} \mathrm{O}_{3}$ & 8.70 & 12.74 & 11.48 & 12.29 & 11.49 & 12.62 & 10.02 & 8.38 \\
\hline $\mathrm{MgO}$ & 0.72 & 0.83 & 0.82 & 0.80 & 0.80 & 0.89 & 0.59 & 0.81 \\
\hline $\mathrm{Na}_{2} \mathrm{O}$ & 1.18 & 1.00 & 0.76 & 0.92 & 0.97 & 0.89 & 0.83 & 0.70 \\
\hline $\mathrm{LOI}$ & 4.45 & 8.43 & 6.89 & 9.96 & 9.64 & 11.22 & 10.45 & 7.51 \\
\hline $\mathrm{SUM}$ & 99.90 & 99.87 & 99.77 & 99.94 & 99.95 & 99.90 & 99.77 & 99.87 \\
\hline
\end{tabular}


XRF results after normalisation to $\mathbf{1 0 0 \%}$ for Angora Quarry

\begin{tabular}{|c|c|c|c|c|c|c|c|c|}
\cline { 2 - 9 } \multicolumn{1}{c|}{} & Av. Shale & A-A-1 & A-A-2 & A-A-3 & A-A-4 & A-A-5 & A-A-6 & A-A-7 \\
\hline $\mathrm{Fe}_{2} \mathrm{O}_{3}$ & 2.8 & 2.582 & 2.267 & 2.414 & 1.875 & 2.363 & 3.590 & 3.516 \\
\hline $\mathrm{MnO}$ & $0.1^{*}$ & 0.018 & 0.018 & 0.019 & 0.018 & 0.018 & 0.009 & 0.028 \\
\hline $\mathrm{TiO}_{2}$ & 0.78 & 0.378 & 0.332 & 0.366 & 0.329 & 0.414 & 0.464 & 0.469 \\
\hline $\mathrm{CaO}$ & 2.2 & 4.915 & 5.751 & 3.080 & 6.797 & 5.627 & 1.421 & 2.430 \\
\hline $\mathrm{K}_{2} \mathrm{O}$ & 3.6 & 1.256 & 1.164 & 1.257 & 1.126 & 1.336 & 1.494 & 1.515 \\
\hline $\mathrm{SO}_{3}$ & $0.6^{*}$ & 0.461 & 0.719 & 0.094 & 0.650 & 0.460 & $<0.01$ & 0.156 \\
\hline $\mathrm{P}_{2} \mathrm{O}_{5}$ & 0.16 & 0.083 & 0.074 & 0.075 & 0.064 & 0.074 & 0.095 & 0.083 \\
\hline $\mathrm{SiO}_{2}$ & 58.9 & 72.74 & 72.94 & 76.71 & 71.96 & 70.89 & 75.76 & 71.83 \\
\hline $\mathrm{Al}_{2} \mathrm{O}_{3}$ & 16.7 & 8.308 & 7.659 & 8.283 & 7.529 & 9.020 & 10.20 & 10.34 \\
\hline $\mathrm{MgO}$ & 2.6 & 0.784 & 0.839 & 0.902 & 0.768 & 0.883 & 0.881 & 0.920 \\
\hline $\mathrm{Na}_{2} \mathrm{O}$ & 1.6 & 0.822 & 0.757 & 0.799 & 0.616 & 0.853 & 0.931 & 0.880 \\
\hline $\mathrm{LOI}$ & & 7.654 & 7.478 & 6.002 & 8.267 & 8.061 & 5.153 & 7.834 \\
\hline $\mathrm{SUM}$ & & 100 & 100 & 100 & 100 & 100 & 100 & 100 \\
\hline
\end{tabular}

\begin{tabular}{|c|c|c|c|c|c|c|c|c|}
\cline { 2 - 9 } \multicolumn{1}{c|}{} & A-A-8 & A-A-9 & A-A-10 & A-A-11 & A-A-12 & A-A-13 & A-C-2 & A-C-1 \\
\hline $\mathrm{Fe}_{2} \mathrm{O}_{3}$ & 2.470 & 3.587 & 3.027 & 3.327 & 2.771 & 3.562 & 2.345 & 2.211 \\
\hline $\mathrm{MnO}$ & 0.010 & 0.009 & 0.009 & 0.009 & 0.018 & 0.018 & 0.009 & 0.009 \\
\hline $\mathrm{TiO}_{2}$ & 0.381 & 0.531 & 0.483 & 0.539 & 0.486 & 0.540 & 0.456 & 0.378 \\
\hline $\mathrm{CaO}$ & 0.143 & 0.137 & 0.121 & 0.126 & 0.108 & 0.257 & 0.089 & 4.782 \\
\hline $\mathrm{K}_{2} \mathrm{O}$ & 1.446 & 1.725 & 1.529 & 1.731 & 1.649 & 1.730 & 1.399 & 1.270 \\
\hline $\mathrm{SO}_{3}$ & $<0.01$ & $<0.01$ & $<0.01$ & 0.036 & $<0.01$ & 0.097 & $<0.01$ & 0.276 \\
\hline $\mathrm{P}_{2} \mathrm{O}_{5}$ & 0.067 & 0.110 & 0.093 & 0.045 & 0.099 & 0.097 & 0.054 & 0.065 \\
\hline $\mathrm{SiO}_{2}$ & 80.42 & 70.87 & 74.74 & 69.91 & 71.77 & 67.92 & 73.69 & 73.62 \\
\hline $\mathrm{Al}_{2} \mathrm{O}_{3}$ & 8.706 & 12.76 & 11.51 & 12.30 & 11.50 & 12.63 & 10.04 & 8.394 \\
\hline $\mathrm{MgO}$ & 0.725 & 0.833 & 0.826 & 0.800 & 0.801 & 0.886 & 0.591 & 0.811 \\
\hline $\mathrm{Na}_{2} \mathrm{O}$ & 1.178 & 1.002 & 0.758 & 0.923 & 0.972 & 0.892 & 0.837 & 0.700 \\
\hline $\mathrm{LOI}$ & 4.454 & 8.441 & 6.906 & 9.966 & 9.645 & 11.23 & 10.47 & 7.520 \\
\hline $\mathrm{SUM}$ & 100 & 100 & 100 & 100 & 100 & 100 & 100 & 100 \\
\hline
\end{tabular}


ICP-MS results for Angora Quarry Part 1'

\begin{tabular}{|c|c|c|c|c|c|c|c|c|}
\hline Sample & Av. Shale & $A-A-1$ & A-A-2 & A-A-3 & A-A-4 & A-A-5 & A-A-6 & A-A-7 \\
\hline Stratigraphic height & $N A$ & 0.0 & 5.5 & 10.5 & 16.5 & 19.5 & 20.5 & 35.5 \\
\hline $\mathrm{Li}$ & 66 & 35.7 & 32.6 & 31.6 & 34.6 & 33.8 & 37.5 & 38.7 \\
\hline $\mathrm{Ca}$ & 2.2 & 4.86 & 5.71 & 3.01 & 6.64 & 5.71 & 1.42 & 2.45 \\
\hline $\mathrm{Ti}$ & 0.78 & 0.378 & 0.331 & 0.366 & 0.329 & 0.414 & 0.464 & 0.469 \\
\hline V & 130 & 53.3 & 49.0 & 53.5 & 51.0 & 64.0 & 68.0 & 65.7 \\
\hline $\mathrm{Cr}$ & 90 & 47.7 & 43.3 & 47.3 & 39.3 & 51.5 & 57.9 & 72.6 \\
\hline Co & 19 & 14.4 & 31.6 & 14.3 & 12.4 & 19.4 & 22.4 & 34.6 \\
\hline $\mathrm{Ni}$ & 68 & 19.7 & 20.4 & 20.3 & 20.9 & 32.1 & 15.4 & 27.1 \\
\hline $\mathrm{Cu}$ & 45 & 9.37 & 10.2 & 9.49 & 10.3 & 12.7 & 14.6 & 15.1 \\
\hline $\mathrm{Zn}$ & 95 & 56.7 & 54.8 & 83.0 & 53.9 & 60.9 & 68.6 & 107 \\
\hline $\mathrm{Ga}$ & 19 & 33.3 & 34.4 & 35.4 & 35.0 & 41.9 & 35.9 & 35.9 \\
\hline $\mathrm{Ge}$ & 1.6 & 0.378 & 0.349 & 0.370 & 0.287 & 0.381 & 0.561 & 0.549 \\
\hline As & 10 & 1.45 & 1.18 & 1.63 & 1.30 & 1.55 & 4.32 & 2.37 \\
\hline $\mathrm{Rb}$ & 140 & 60.2 & 57.0 & 60.6 & 58.6 & 66.8 & 72.3 & 72.9 \\
\hline $\mathrm{Sr}$ & 300 & 138 & 151 & 108 & 171 & 166 & 78.5 & 114 \\
\hline $\bar{Y}$ & 41 & 10.4 & 10.8 & 8.26 & 8.740 & 12.3 & 12.9 & 11.8 \\
\hline Zr90 & 160 & 47.5 & 42.3 & 47.3 & 40.2 & 51.1 & 57.7 & 63.6 \\
\hline Zr91 & 160 & 45.7 & 40.7 & 45.8 & 38.9 & 49.7 & 55.5 & 61.4 \\
\hline $\mathrm{Nb}$ & 18 & 5.00 & 4.45 & 5.33 & 4.84 & 5.77 & 6.03 & 6.27 \\
\hline Mo & 2.6 & 1.63 & 3.76 & $3.94^{*}$ & $3.24^{*}$ & 4.17 & 6.57 & 2.49 \\
\hline $\mathrm{Cd}$ & 0.8 & 0.0360 & 0.0445 & 0.0697 & 0.0664 & 0.0686 & 0.0353 & 0.0857 \\
\hline Sn & 2.5 & 1.57 & 1.66 & 2.19 & 1.70 & 1.92 & 1.61 & 2.30 \\
\hline $\mathrm{Sb}$ & 1.5 & 4.90 & 5.10 & 5.25 & 5.96 & 6.98 & 7.72 & 6.67 \\
\hline $\mathrm{Ba}$ & 580 & 507 & 553 & 563 & 582 & 687 & 529 & 536 \\
\hline $\mathrm{La}$ & 40 & 12.5 & 13.4 & 10.2 & 10.6 & 15.2 & 15.3 & 13.8 \\
\hline $\mathrm{Ce}$ & 95 & 26.3 & 26.9 & 21.8 & 20.2 & 29.2 & 30.1 & 27.0 \\
\hline $\mathrm{Pr}$ & 9.7 & 3.12 & 3.10 & 2.66 & 2.43 & 3.55 & 3.95 & 3.48 \\
\hline $\mathrm{Nd}$ & 39 & 11.8 & 11.7 & 9.93 & 9.04 & 13.2 & 14.9 & 13.1 \\
\hline $\mathrm{Sm}$ & 7.3 & 2.40 & 2.32 & 1.967 & 1.755 & 2.66 & 3.01 & 2.65 \\
\hline Eu151 & 1.6 & 0.589 & 0.573 & 0.487 & 0.453 & 0.652 & 0.707 & 0.623 \\
\hline Eu153 & 1.6 & 0.624 & 0.618 & 0.552 & 0.527 & 0.731 & 0.752 & 0.695 \\
\hline $\mathrm{Gd}$ & 7 & 2.21 & 2.19 & 1.83 & 1.78 & 2.53 & 2.73 & 2.46 \\
\hline $\mathrm{Tb}$ & 1.2 & 0.305 & 0.306 & 0.258 & 0.245 & 0.358 & 0.393 & 0.350 \\
\hline Dy & 5.5 & 1.81 & 1.79 & 1.49 & 1.46 & 2.13 & 2.25 & 2.03 \\
\hline $\mathrm{Ho}$ & 1.6 & 0.357 & 0.363 & 0.292 & 0.292 & 0.417 & 0.437 & 0.410 \\
\hline $\mathrm{Er}$ & 3.9 & 1.08 & 1.06 & 0.847 & 0.867 & 1.24 & 1.29 & 1.23 \\
\hline $\mathrm{Tm}$ & 0.6 & 0.159 & 0.152 & 0.126 & 0.131 & 0.179 & 0.185 & 0.184 \\
\hline $\mathrm{Yb}$ & 3.7 & 1.05 & 0.995 & 0.878 & 0.868 & 1.21 & 1.21 & 1.21 \\
\hline Lu & 0.7 & 0.148 & 0.146 & 0.128 & 0.130 & 0.176 & 0.179 & 0.178 \\
\hline $\mathrm{Hf}$ & 2.8 & 1.33 & 1.17 & 1.37 & 1.13 & 1.45 & 1.64 & 1.84 \\
\hline $\mathrm{TI}$ & 1.4 & 0.440 & 0.423 & 0.532 & 0.515 & 0.615 & 0.462 & 0.560 \\
\hline $\mathrm{Pb}$ & 20 & 7.91 & 7.26 & 8.58 & 7.57 & 9.59 & 10.3 & 11.461 \\
\hline Th & 12 & 5.58 & 5.12 & 5.59 & 5.26 & 6.33 & 6.96 & 7.24 \\
\hline $\bar{U}$ & 0.37 & 1.54 & 1.82 & 1.73 & 1.95 & 2.53 & 2.48 & 2.00 \\
\hline
\end{tabular}


ICP-MS results for Angora Quarry Part 2

\begin{tabular}{|c|c|c|c|c|c|c|c|c|}
\hline Sample & $A-A-8$ & $A-A-9$ & A-A-10 & $\mathrm{A}-\mathrm{A}-11$ & $\mathrm{~A}-\mathrm{A}-12$ & $\mathrm{~A}-\mathrm{A}-13$ & $A-C-1$ & $A-C-2$ \\
\hline Stratigraphic height & 41.9 & 48.3 & 54.7 & 61.1 & 67.5 & 73.1 & $95.0^{*}$ & $80.0^{*}$ \\
\hline $\mathrm{Li}$ & 32.6 & 61.5 & 42.6 & 48.4 & 48.8 & 54.0 & 41.7 & 46.1 \\
\hline $\mathrm{Ca}$ & 0.139 & 0.131 & 0.110 & 0.122 & 0.0987 & 0.250 & 4.74 & 0.0766 \\
\hline $\mathrm{Ti}$ & 0.381 & 0.530 & 0.482 & 0.539 & 0.486 & 0.540 & 0.377 & 0.455 \\
\hline $\mathrm{V}$ & 56.3 & 76.0 & 68.3 & 87.6 & 87.2 & 78.4 & 54.9 & 73.7 \\
\hline $\mathrm{Cr}$ & 60.1 & 94.3 & 71.6 & 94.8 & 90.5 & 82.8 & 43.3 & 97.7 \\
\hline Co & 48.9 & 36.4 & 47.9 & 73.4 & 43.1 & 67.6 & 24.6 & 62.2 \\
\hline $\mathrm{Ni}$ & 32.6 & 98.9 & 50.1 & 38.6 & 43.1 & 66.9 & 20.7 & 42.2 \\
\hline$\overline{\mathrm{Cu}}$ & 12.8 & 17.1 & 19.8 & 32.2 & 23.7 & 19.8 & 10.2 & 36.5 \\
\hline $\mathrm{Zn}$ & 213 & 166 & 134 & $\overline{78.0}$ & 124 & 157 & 58.5 & 107 \\
\hline $\mathrm{Ga}$ & 32.1 & 38.5 & 36.2 & 36.8 & 35.7 & 36.9 & 37.2 & 68.3 \\
\hline $\mathrm{Ge}$ & 0.440 & 0.561 & 0.483 & 0.518 & 0.471 & 0.983 & 0.358 & 0.378 \\
\hline As & 2.80 & 3.78 & 2.88 & 4.65 & 3.60 & 6.62 & 1.58 & 3.76 \\
\hline $\mathrm{Rb}$ & 68.2 & 80.1 & 77.4 & 81.4 & 77.1 & 82.1 & 65.0 & 68.4 \\
\hline $\mathrm{Sr}$ & 54.7 & 56.0 & 45.0 & 49.7 & 50.8 & 68.5 & 137 & 54.8 \\
\hline $\mathrm{Y}$ & 14.0 & 11.3 & 10.1 & 10.3 & 15.2 & 84.1 & 9.48 & 7.75 \\
\hline $\mathrm{Zr}$ & 46.0 & 62.3 & 57.7 & 66.9 & 58.4 & 56.2 & 48.8 & 51.5 \\
\hline $\mathrm{Zr}$ & 44.9 & 59.9 & 55.4 & 64.2 & 56.7 & 54.4 & 47.4 & 49.4 \\
\hline $\mathrm{Nb}$ & 5.00 & 7.52 & 6.74 & 7.34 & 6.75 & 7.42 & 5.22 & 6.17 \\
\hline Mo & 5.12 & 2.21 & 6.15 & $5.99^{*}$ & $8.04^{*}$ & 1.42 & 3.17 & 4.69 \\
\hline $\mathrm{Cd}$ & 0.286 & 0.0609 & 0.447 & 0.141 & 0.129 & 0.0584 & 0.0568 & 0.118 \\
\hline Sn & 1.96 & 2.06 & 2.00 & 1.89 & 1.91 & 1.96 & 1.80 & 2.21 \\
\hline $\mathrm{Sb}$ & 7.33 & 5.85 & 6.33 & 6.35 & 7.39 & 6.09 & 4.72 & 6.97 \\
\hline $\mathrm{Ba}$ & 472 & 547 & 521 & 505 & 512 & 514 & 594 & 1210 \\
\hline $\mathrm{La}$ & 11.8 & 9.759 & 11.8 & 12.9 & 16.2 & 63.5 & 11.1 & 9.21 \\
\hline $\mathrm{Ce}$ & 22.5 & 19.7 & 21.5 & 24.0 & 31.0 & 197 & 23.3 & 14.6 \\
\hline $\mathrm{Pr}$ & 3.27 & 2.90 & 3.17 & 3.15 & 4.24 & 30.3 & 2.82 & 2.14 \\
\hline $\mathrm{Nd}$ & 12.5 & 11.5 & 12.1 & 11.6 & 16.5 & 126 & 10.7 & 8.136 \\
\hline $\mathrm{Sm}$ & 2.50 & 2.26 & 2.32 & 2.22 & 3.60 & 26.1 & 2.15 & 1.69 \\
\hline $\mathrm{Eu}$ & 0.594 & 0.562 & 0.530 & 0.527 & 0.860 & 5.95 & 0.540 & 0.475 \\
\hline $\mathrm{Eu}$ & 0.642 & 0.615 & 0.599 & 0.575 & 0.921 & 6.00 & 0.608 & 0.594 \\
\hline$\overline{G d}$ & 2.44 & 2.15 & 2.06 & 1.96 & 3.19 & 23.2 & 2.03 & 1.36 \\
\hline $\mathrm{Tb}$ & 0.347 & 0.311 & 0.285 & 0.276 & 0.456 & 3.17 & 0.284 & 0.196 \\
\hline$\overline{D y}$ & 2.07 & 1.87 & 1.69 & 1.67 & 2.68 & 17.0 & 1.69 & 1.18 \\
\hline $\mathrm{Ho}$ & 0.429 & 0.394 & 0.346 & 0.354 & 0.537 & 3.02 & 0.337 & 0.250 \\
\hline $\mathrm{Er}$ & 1.27 & 1.22 & 1.08 & 1.14 & 1.60 & 7.62 & 0.977 & 0.812 \\
\hline $\mathrm{Tm}$ & 0.177 & 0.190 & 0.167 & 0.179 & 0.241 & 0.932 & 0.146 & 0.128 \\
\hline $\mathrm{Yb}$ & 1.13 & 1.31 & 1.10 & 1.28 & 1.57 & 5.45 & 0.975 & 0.906 \\
\hline $\mathrm{Lu}$ & 0.151 & 0.192 & 0.168 & 0.191 & 0.235 & 0.706 & 0.144 & 0.142 \\
\hline $\mathrm{Hf}$ & 1.36 & 1.80 & 1.62 & 1.91 & 1.67 & 1.71 & 1.39 & 1.39 \\
\hline $\mathrm{TI}$ & 0.594 & 0.602 & 0.720 & 0.693 & 0.693 & 0.639 & 0.562 & 0.871 \\
\hline $\mathrm{Pb}$ & 9.39 & 12.5 & 14.4 & 12.7 & 10.5 & 13.0 & 8.25 & 12.1 \\
\hline Th & 5.53 & 7.98 & 7.45 & 8.33 & 7.04 & 8.15 & 5.72 & 6.57 \\
\hline $\bar{U}$ & 2.35 & 2.15 & 3.07 & 3.63 & 4.46 & 2.05 & 2.05 & 2.61 \\
\hline
\end{tabular}


ICP-MS results for Kawau-1A

\begin{tabular}{|c|c|c|c|c|c|c|c|c|}
\cline { 2 - 10 } \multicolumn{1}{c|}{} & $\begin{array}{c}\text { KAWAU- } \\
1 \mathrm{~A} 25 / 4\end{array}$ & $\begin{array}{c}\text { KAWAU- } \\
1 \mathrm{~A} 22 / 4\end{array}$ & $\begin{array}{c}\text { KAWAU- } \\
1 \mathrm{~A} 21 / 4\end{array}$ & $\begin{array}{c}\text { KAWAU- } \\
1 \mathrm{~A} 20 / 4\end{array}$ & $\begin{array}{c}\text { KAWAU- } \\
1 \mathrm{~A} 19 / 4\end{array}$ & $\begin{array}{c}\text { KAWAU- } \\
1 \mathrm{~A} 18 / 4\end{array}$ & $\begin{array}{c}\text { KAWAU- } \\
1 \mathrm{~A} 17 / 4\end{array}$ & $\begin{array}{c}\text { KAWAU- } \\
1 \mathrm{~A} 16 / 4\end{array}$ \\
\hline $\mathrm{Ti}$ & 852 & 2392 & 1897 & 5662 & 5219 & 4554 & 2883 & 2565 \\
\hline $\mathrm{V}$ & 18.9 & 43.9 & 34.3 & 102 & 86.2 & 67.3 & 43.4 & 36.2 \\
\hline $\mathrm{Cr}$ & 31.6 & 56.8 & 43.6 & 200 & 150 & 78.2 & 71.7 & 67.3 \\
\hline $\mathrm{Mn}$ & 26.0 & 44.6 & 41.0 & 111 & 109 & 161 & 68.8 & 49.7 \\
\hline $\mathrm{Co}$ & 0.640 & 2.04 & 1.57 & 4.58 & 4.34 & 4.07 & 2.01 & 1.74 \\
\hline $\mathrm{Ni}$ & 14.1 & 19.3 & 13.9 & 69.2 & 63.8 & 30.5 & 29.8 & 21.9 \\
\hline $\mathrm{Cu}$ & 7.98 & 23.63 & 7.55 & 61.8 & 20.1 & 9.7 & 10.86 & 5.79 \\
\hline $\mathrm{As}$ & 2.11 & 2.76 & 1.74 & 7.49 & 6.14 & 2.23 & 2.49 & 1.7 \\
\hline $\mathrm{Se}$ & 0.277 & 0.213 & 0.158 & 0.735 & 0.657 & 0.300 & 0.219 & 0.190 \\
\hline $\mathrm{Rb}$ & 15.5 & 46 & 37.7 & 78.1 & 74.3 & 62.8 & 46.6 & 41.0 \\
\hline $\mathrm{Sr}$ & 87.9 & 254 & 145 & 187 & 226 & 119 & 105 & 46.6 \\
\hline $\mathrm{Y}$ & 3.52 & 7.71 & 5.41 & 17.5 & 18.1 & 10.2 & 7.06 & 7.04 \\
\hline $\mathrm{Zr}$ & 10.7 & 28.4 & 20.9 & 63.2 & 59.8 & 57.7 & 34.9 & 28.1 \\
\hline $\mathrm{Zr}$ & 10.7 & 28.7 & 20.8 & 63.9 & 60.1 & 56.9 & 34.4 & 28.0 \\
\hline $\mathrm{Nb}$ & 1.90 & 4.79 & 3.89 & 9.16 & 8.74 & 7.49 & 6.11 & 5.46 \\
\hline $\mathrm{Mo}$ & 4.11 & 8.19 & 5.82 & 25.0 & 38.2 & 15.0 & 8.71 & 6.67 \\
\hline $\mathrm{Cd}$ & 0.724 & 0.228 & 0.200 & 0.543 & 0.486 & 0.302 & 0.202 & 0.150 \\
\hline $\mathrm{Sn}$ & 0.694 & 2.12 & 2.39 & 3.13 & 2.86 & 2.77 & 2.63 & 2.16 \\
\hline $\mathrm{Sb}$ & 0.527 & 0.973 & 0.702 & 0.789 & 0.607 & 0.540 & 0.581 & 0.390 \\
\hline $\mathrm{Hf}$ & 0.337 & 0.870 & 0.648 & 1.80 & 1.76 & 1.72 & 1.00 & 0.847 \\
\hline $\mathrm{Ta}$ & 0.192 & 0.451 & 0.358 & 0.989 & 0.757 & 0.660 & 0.520 & 0.448 \\
\hline $\mathrm{W}$ & 0.52 & 1.07 & 0.713 & 1.36 & 1.37 & 1.13 & 1.08 & 0.90 \\
\hline $\mathrm{TI}$ & 0.213 & 0.311 & 0.245 & 0.640 & 0.654 & 0.494 & 0.309 & 0.311 \\
\hline $\mathrm{Pb}$ & 38.3 & 53.4 & 16.0 & 38.8 & 17.1 & 20.9 & 48.6 & 12.7 \\
\hline $\mathrm{Bi}$ & 0.158 & 0.402 & 0.276 & 0.496 & 0.467 & 0.350 & 0.332 & 0.300 \\
\hline $\mathrm{Th}$ & 2.22 & 5.33 & 3.70 & 8.51 & 9.54 & 7.34 & 5.24 & 4.69 \\
\hline $\mathrm{U}$ & 2.24 & 2.79 & 2.46 & 8.47 & 9.36 & 5.42 & 3.66 & 2.55 \\
\hline
\end{tabular}




\section{ICP-MS results for Pakaha-1}

\begin{tabular}{|c|c|c|c|c|c|c|}
\cline { 2 - 7 } \multicolumn{1}{c|}{} & PAKAHA-1 & PAKAHA-1 & PAKAHA-1 & PAKAHA-1 & PAKAHA-1 & PAKAHA-1 \\
\hline $\mathrm{Ti}$ & 4525 & 5372 & 6614 & 3989 & 4827 & 3599 \\
\hline $\mathrm{V}$ & 62.5 & 63.7 & 103 & 51.7 & 72.0 & 50.0 \\
\hline $\mathrm{Cr}$ & 52.8 & 60.0 & 93.2 & 99.2 & 97.0 & 90.3 \\
\hline $\mathrm{Mn}$ & 400 & 293 & 155 & 108 & 100 & 84.9 \\
\hline $\mathrm{Co}$ & 8.8 & 6.09 & 14.1 & 5.95 & 9.70 & 2.64 \\
\hline $\mathrm{Ni}$ & 25.9 & 23.4 & 52.9 & 34.5 & 35.1 & 26.1 \\
\hline $\mathrm{Cu}$ & 25.6 & 13.4 & 21.3 & 20.0 & 15.8 & 14.7 \\
\hline $\mathrm{As}$ & 2.61 & 2.72 & 7.84 & 3.78 & 3.58 & 3.72 \\
\hline $\mathrm{Se}$ & 0.0995 & 0.199 & 0.447 & 0.285 & 0.267 & 0.280 \\
\hline $\mathrm{Rb}$ & 65.4 & 77.4 & 98.8 & 201 & 69.7 & 61.5 \\
\hline $\mathrm{Sr}$ & 886 & 178 & 126 & 377 & 120 & 69.84 \\
\hline $\mathrm{Y}$ & 11.8 & 12.9 & 13.4 & 12.3 & 9.90 & 10.5 \\
\hline $\mathrm{Zr}$ & 55.2 & 76.4 & 77.1 & 53.0 & 52.6 & 42.7 \\
\hline $\mathrm{Zr}$ & 54.7 & 75.6 & 76.8 & 52.0 & 52.5 & 42.4 \\
\hline $\mathrm{Nb}$ & 7.85 & 8.82 & 10.4 & 8.00 & 7.25 & 8.08 \\
\hline $\mathrm{Mo}$ & 3.53 & 3.94 & 33.4 & 8.74 & 14.1 & 8.25 \\
\hline $\mathrm{Cd}$ & 0.129 & 0.241 & 0.333 & 0.167 & 0.221 & 0.212 \\
\hline $\mathrm{Sn}$ & 3.33 & 3.39 & 3.85 & 3.93 & 2.40 & 2.71 \\
\hline $\mathrm{Sb}$ & 0.634 & 0.635 & 1.18 & 0.421 & 0.472 & 0.399 \\
\hline $\mathrm{Hf}$ & 1.61 & 2.44 & 2.34 & 1.66 & 1.46 & 1.31 \\
\hline $\mathrm{Ta}$ & 0.712 & 0.816 & 0.934 & 0.685 & 0.597 & 0.708 \\
\hline $\mathrm{W}$ & 2.38 & 2.07 & 13.7 & 1.73 & 1.01 & 2.26 \\
\hline $\mathrm{TI}$ & 0.356 & 0.483 & 0.653 & 1.31 & 0.363 & 0.412 \\
\hline $\mathrm{Pb}$ & 37.7 & 15.2 & 22.0 & 38.8 & 14.4 & 13.1 \\
\hline $\mathrm{Bi}$ & 0.407 & 0.275 & 0.663 & 0.310 & 0.396 & 0.362 \\
\hline $\mathrm{Th}$ & 7.09 & 7.90 & 10.1 & 7.14 & 6.31 & 6.43 \\
\hline $\mathrm{U}$ & 1.81 & 2.62 & 9.70 & 2.62 & 3.21 & 3.81 \\
\hline & & & & & & \\
\hline
\end{tabular}


Appendix D

\section{Table summarising trace metal variations}

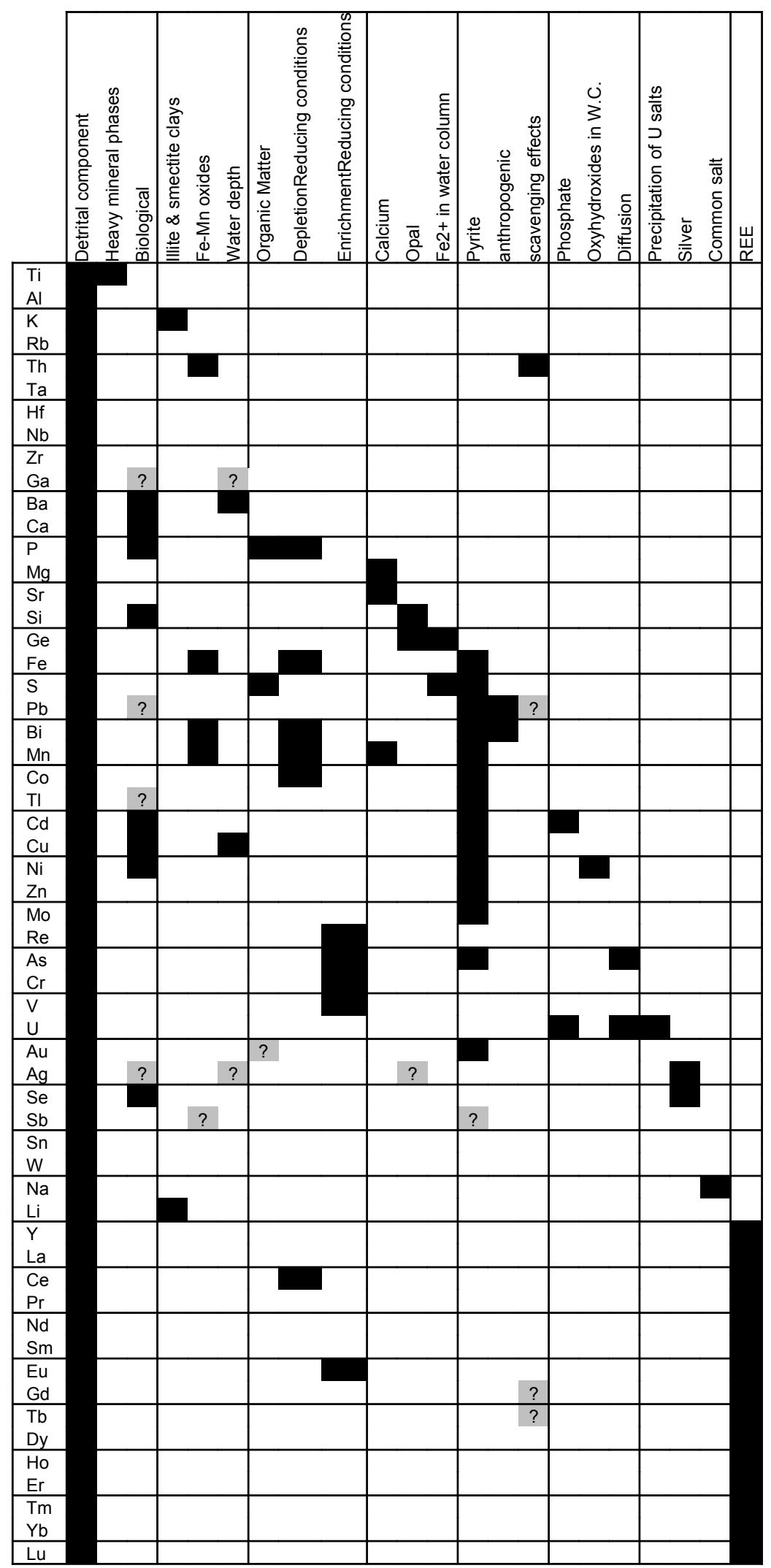

Appendix D 


